Avaliação automática de acessibilidade em RIA

\author{
Willian Massami Watanabe
}



SERVIÇO DE PÓS-GRADUAÇÃO DO ICMC-USP

Data de Depósito:

Assinatura:

\title{
Avaliação automática de acessibilidade em RIA
}

\author{
Willian Massami Watanabe
}

Orientadora: Profa. Dra. Renata Pontin de Mattos Fortes

Tese apresentada ao Instituto de Ciências Matemáticas e de Computação - ICMC-USP, como parte dos requisitos para obtenção do título de Doutor em Ciências - Ciências de Computação e Matemática Computacional. VERSÃO REVISADA 
Ficha catalográfica elaborada pela Biblioteca Prof. Achille Bassi e Seção Técnica de Informática, ICMC/USP, com os dados fornecidos pelo(a) autor(a)

Watanabe, Willian Massami

W324a Avaliação automática de acessibilidade em RIA / Willian Massami Watanabe; orientadora Renata Pontin de Mattos Fortes. -- São Carlos, 2014.

$151 \mathrm{p}$.

Tese (Doutorado - Programa de Pós-Graduação em Ciências de Computação e Matemática Computacional) Instituto de Ciências Matemáticas e de Computação, Universidade de São Paulo, 2014.

1. Acessibilidade na Web. 2. Engenharia Web. 3. RIA. 4. ARIA. 5. Web 2.0. I. Fortes, Renata Pontin de Mattos, orient. II. Título. 


\section{Agradecimentos}

À professora Dra. Renata Pontin de Mattos Fortes, por todo seu apoio durante todo o projeto; aos colegas e amigos, por suas valiosas contribuições e enriquecimento da tese; aos pais, pela compreensão e apoio presentes em todos os momentos; a Rejane Kiyomi Furuya, pelo amor; e a Deus que iluminou meu caminho durante esta caminhada. 
Often it appears that there is no better way to solve a problem than to try all possible solutions. This approach, called exhaustive search, is almost always slow, but sometimes it is better than nothing.

Ian Parberry 

$\mathrm{C}$

om a popularização da Web 2.0 e RIA - Rich Internet Applications, as aplicações web cada vez mais utilizam-se da linguagem JavaScript, para implementar recursos de interação sofisticados e complexos na plataforma da Web, visando atrair os usuários com experiências que agradem e atendam suas expectativas. Uma vez que esses recursos de RIA, muitas vezes, fornecem feedback visual de mudanças realizadas na interface, usuários que interagem com a Web por meio de Tecnologias Assistivas, como leitores de tela, não são capazes de identificar e interagir corretamente com os componentes de interface. Assim, a WAI - Web Accessibility Initiative propôs a especificação ARIA - Accessible Rich Internet Applications que determina um conjunto de propriedades que atribuem semântica aos elementos de um componente de interface (Widget), permitindo que as Tecnologias Assistivas identifiquem previamente o comportamento dos componentes de interface e informem o usuário sobre as alterações que possam ser realizadas na estrutura da página web. Nesse contexto, esta tese teve como objetivo elaborar estratégias de avaliação automática dos requisitos de acessibilidade da especificação ARIA. Foram elaboradas três diferentes abordagens para analisar os requisitos da especificação ARIA, utilizando a metodologia de pesquisa-ação com a condução de três ciclos das atividades de planejar, agir, descrever e avaliar. As abordagens foram desenvolvidas com base em Testes de Aceitação e verificações de características tecnológicas das aplicações web, considerando especificamente o modelo de interação de usuários deficientes visuais que utilizam leitores de tela. Cada uma das abordagens foi validada separadamente e os resultados apresentam tendências de que as estratégias são capazes de avaliar corretamente o comportamento esperado de uma aplicação rica de Internet acessível, segundo as recomendações ARIA para usu $\tilde{A}_{j}$ rios deficientes visuais. As abordagens também apresentaram como contribuições: a inclusão do modelo de interação do usuário no processo de avaliação e levantamentos sobre os níveis de conformidade de aplicações web e bibliotecas JavaScript com a especificação ARIA. Os resultados obtidos a partir das abordagens propostas nesta tese contribuem para o processo de Engenharia Web de aplicações ricas de Internet acessíveis.

Palavras-chave: Acessibilidade na Web, Engenharia Web, ARIA, RIA e Web 2.0. 


ith the increased popularity of the Web 2.0 and RIA - Rich Internet Applications, web applications rely more and more in JavaScript to implement richer and more complex interaction mechanisms in the Web platform. Since these mechanisms, frequently, generate dynamic updates to the DOM - Document Object Model structure of a webpage and require visual perception of users to notify them about these changes in the interface, users that interact with the Web through usage of Assistive Technologies such as a screen reader are not capable of correctly identifying and interacting with the interface components built with these technologies - the widgets. In this context, the WAI - Web Accessibility Initiative created the ARIA - Accessible Rich Internet Applications specification which describes the use of properties that add semantics to elements that compose a widget, allowing Assistive Technology to priorly identify the behavior of a widget and inform the user about changes that might be made to the DOM structure of the webpage. This thesis' goal was to elaborate automatic evaluation strategies for accessibility requirements of the ARIA specification. Three evaluation strategies were elaborated following the research-action methodology with the conduction of three cycles of the activities of planning, acting, describing and evaluating. The strategies were implemented based in Acceptance Tests and verifications on specific details of the technology that compose web applications, considering specifically blind users interaction patterns through the use of screen readers. Each strategy was separately validated and the results show tendencies that the strategies were capable of correctly evaluating the behavior of web applications, considering their conformance with ARIA recommendations for blind users. The development and validation of the evaluation strategies also presented contributions by: including user interaction models in the automatic evaluation approaches and presenting a survey on web applications and JavaScript toolkits conformance rates with the ARIA specification. Thus contributing to the Web Engineering process of ARIA.

Keywords: Web Accessibility, Web Engineering, ARIA, RIA and Web 2.0. trocar widget componente de interface 

$\begin{array}{lll}\text { Resumo } & \mathbf{v}\end{array}$

$\begin{array}{lll}\text { Abstract } & \text { vii }\end{array}$

1 Introdução $\quad 1$

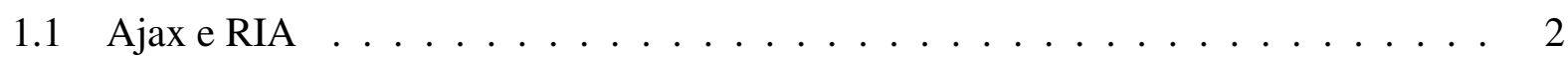

1.2 Acessibilidade na Web e RIA . . . . . . . . . . . . . . . . . . 4

1.3 A tese .......................... 7

1.4 Metodologia de pesquisa . . . . . . . . . . . . . . . 7

1.5 Principais Contribuições . . . . . . . . . . . . . . . . . . . 9

1.6 Estrutura da Tese . . . . . . . . . . . . . . . . . . 9

2 Acessibilidade na Web $\quad 11$

2.1 Considerações Iniciais $\ldots \ldots \ldots \ldots \ldots$. . . . . . . . . . . . . . . 12

2.2 Tecnologias Assistivas . . . . . . . . . . . . . . . . 13

2.3 Abordagem da WAI . . . . . . . . . . . . . . . . . . . 15

2.3 .1 WCAG $1.0 \ldots \ldots \ldots \ldots \ldots \ldots$

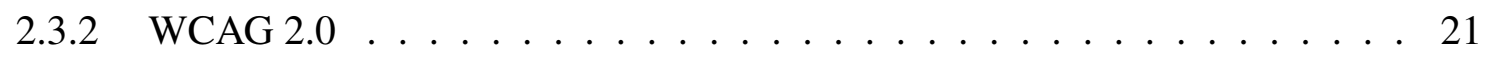

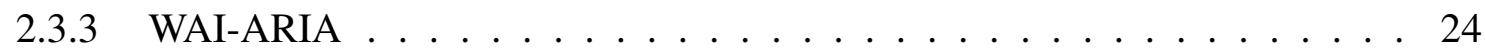

2.4 Considerações finais $\ldots \ldots \ldots$. . . . . . . . . . . . . . . . . . 29

3 Avaliação de Acessibilidade $\quad 31$

3.1 Engenharia Web . . . . . . . . . . . . . . . . . . . 31

3.1.1 Impactos da Web 2.0 na Engenharia Web . . . . . . . . . . . . . . 33

3.1.2 Práticas de Programação Extrema na Engenharia Web . . . . . . . . . . 36

3.2 Abordagens de avaliação de acessibilidade . . . . . . . . . . . . . . . . . 41

3.3 Métricas de Acessibilidade . . . . . . . . . . . . . . . . . . . 46

3.4 Avaliação automática de ARIA . . . . . . . . . . . . . . . . . . . . . 48

3.5 Considerações finais . . . . . . . . . . . . . . . . . . . 54 
4 A-Pyccuracy: utilizando BDD para avaliar ARIA $\quad 57$

4.1 Testes de Aceitação (AT) . . . . . . . . . . . . . . . . . . . . . . . 58

4.2 Ferramenta A-Pyccuracy . . . . . . . . . . . . . . . . . 60

4.3 Estudo de Caso . . . . . . . . . . . . . . . . . . . . . 67

4.3 .1 Metodologia . . . . . . . . . . . . . . . 68

4.3 .2 Resultados ......................... 73

4.4 Discussão . . . . . . . . . . . . . . . . . . . . . . 75

4.5 Considerações finais . . . . . . . . . . . . . . . . 77

5 ARIA-CHECK - Avaliando requisitos ARIA em widgets $\quad 79$

5.1 Considerações Iniciais $\ldots \ldots \ldots \ldots$. . . . . . . . . . . . . 80

5.2 AT para widget tabpanel . . . . . . . . . . . . . . . . 81

5.2.1 Modelo de Interação Acessível para a widget tabpanel . . . . . . . . . . 85

5.2 .2 Verificações Iniciais . . . . . . . . . . . . . . . . . . . . . . . . . . . . . . 87

5.2 .3 AT para a widget TabPanel . . . . . . . . . . . . . . . 88

5.2 .4 Estudo de caso . . . . . . . . . . . . . . . . . . . . . 92

5.3 Discussão . . . . . . . . . . . . . . . . . . . . . . . . . 100

5.4 Considerações Finais . . . . . . . . . . . . . . . . . . . . 101

6 Fona - Métrica do requisito ARIA de Navegação por Foco 103

6.1 Considerações Iniciais . . . . . . . . . . . . . . . . . . . . . 104

6.2 Definição da Métrica . . . . . . . . . . . . . . . . . . . . . . 106

6.3 Ferramenta de cálculo da métrica . . . . . . . . . . . . . . . . . . 109

6.4 Avaliação . . . . . . . . . . . . . . . . . . . . 110

6.4.1 Grupos do experimento . . . . . . . . . . . . . . . 111

6.4 Metodologia . . . . . . . . . . . . . . . . 114

6.4 .3 Resultados ......................... 115

6.5 Discussão . . . . . . . . . . . . . . . . . . . . . 123

6.6 Considerações Finais . . . . . . . . . . . . . . . . . . 126

7 Conclusões $\quad 127$

7.1 Principais Contribuições . . . . . . . . . . . . . . . . . 131

7.2 Artigos Resultantes da Tese . . . . . . . . . . . . . . . . 133

7.3 Limitações dos estudos realizados . . . . . . . . . . . . . . . . . . 134

7.4 Trabalhos Futuros . . . . . . . . . . . . . . . . . . 135

7.5 Considerações Finais . . . . . . . . . . . . . . . . . 136

$\begin{array}{ll}\text { Referências } & 139\end{array}$ 
1.1 Representação do ciclo em quatro fases do processo de pesquisa-ação. . . . . . . . 8

2.1 Relação entre as guidelines da WAI . . . . . . . . . . . . . . . . . . . . 17

2.2 Responsáveis pela acessibilidade no modelo da WAI. . . . . . . . . . . . . . 18

2.3 Atualização da estrutura DOM de uma widget de caixa de diálogo, durante a interação com o usuário. . . . . . . . . . . . . . . . . . 26

2.4 Exemplo de interação com uma caixa de diálogo, por um usuário utilizando um leitor de tela em uma aplicação desktop. . . . . . . . . . . . . . . . 27

3.1 Ciclo de desenvolvimento de uma aplicação Web 2.0, considerando o padrão de projeto de aplicações "beta perpétuas". . . . . . . . . . . . . . . 35

3.2 Processo de desenvolvimento utilizando práticas de Integração Contínua. . . . . . . 41

3.3 Diagrama de estados que representa os estados de uma widget . . . . . . . . . . . 49

3.4 Representação da etapa de corte dinâmico em um trecho de código JavaScript que implementa uma widget checkbox. Figura extraída do artigo (Tateishi et al., 2007). 50

3.5 Diferenças entre os ambientes de avaliação de linha de comando e avaliação no navegador. . . . . . . . . . . . . . . . 52

3.6 Múltiplos estados da estrutura DOM gerados a partir da interação do usuário com um website. . . . . . . . . . . . . . . . . . 53

3.7 Framework conceitual para avaliar a acessibilidade de RIA. Figura extraída do artigo (Doush et al., 2013). . . . . . . . . . . . . . . 55

4.1 Esquema de avaliação de acessibilidade utilizando AT. . . . . . . . . . . . . . . 60

4.2 Esquema do funcionamento da ferramenta A-Pyccuracy, em que a aplicação Pyccuracy é estendida para avaliar a acessibilidade em RIA. . . . . . . . . . . . 62

4.3 Esquema de navegação utilizando a tecla TAB no componente de interface Flyout menu, conforme avaliado no caso do AT escrito na ferramenta Pyccuracy. . . . . . 66

4.4 Exemplo de implementação da widget Fly-out utilizado no estudo de caso. . . . . . 69

4.5 Exemplo de implementação da widget Accordion utilizado no estudo de caso. . . . 69

4.6 Exemplo de implementação da widget Overlay menu utilizado no estudo de caso. . 69

4.7 Exemplo de implementação da widget Tabbed menu utilizado no estudo de caso. . 70 
4.8 Número de asserções corretas e erradas para cada ferramenta de avaliação automática de acessibilidade utilizada no estudo de caso. . . . . . . . . . . . . . . . . . 74

4.9 Esquema geral de avaliação de acessibilidade utilizando AT, em contraste ao método de avaliação de HTML estático . . . . . . . . . . . . . . . . . . 75

5.1 Geração dos casos de AT genéricos a partir de uma implementação de referência. Figura extraída do artigo submetido à UAIS - Universal Access in Information Society. . . . . . . . . . . . . . . . . . . 8

5.2 Geração dos casos de teste genéricos a partir dos casos de teste específicos de domínio. Figura extraída do artigo submetido à UAIS - Universal Access in Information Society. . . . . . . . . . . . . . . . . . . . . 8

5.3 Esquema de funcionamento da ferramenta aria-check para avaliar a conformidade de tabpanel widgets com a especificação ARIA. . . . . . . . . . . . . . . . . . 84

5.4 Tela da ferramenta aria-check que apresenta os resultados dos casos de teste para uma widget que implementa todas os requisitos da especificação ARIA. . . . . . . . 8

5.5 Tela da ferramenta aria-check que apresenta os resultados dos casos de teste para uma widget que não implementa todas os requisitos da especificação ARIA. . . . . . 85

5.6 Processo de avaliação da ferramenta aria-check. Figura extraída do artigo submetido à UAIS - Universal Access in Information Society. . . . . . . . . . . . . . . . 93

5.7 Número de casos de teste que falharam em cada implementação de widget, identificados de acordo com as verificações iniciais (Roles, Estrutura dos Elementos, Estados Inicial da Interação and Alternativas Textuais) and Casos de AT. Figura extraída do artigo submetido à UAIS - Universal Access in Information Society. 97

5.8 Número de problemas de implementação dos casos de uso de navegação por teclado pela avaliação manual e pela ferramenta aria-check. Figura extraída do artigo submetido à UAIS - Universal Access in Information Society. . . . . . . . . . . . . 99

6.1 Esquema de funcionamento da ferramenta que calcula a métrica Fona em RIA. . . 110

6.2 Números de páginas web por sub-grupo. Figura extraída do artigo submetido à revista ACM Transactions on the Web. . . . . . . . . . . . . . . . . . . . . . . . 114

6.3 Número de funções JavaScript que respondem a interação por mouse no Grupo Alvo. Figura extraída do artigo submetido à revista ACM Transactions on the Web . 116

6.4 Representação em Boxplot que apresenta o número de funções JavaScript do Grupo Alvo. Figura extraída do artigo submetido à revista ACM Transactions on the Web. 118

6.5 Representação em Boxplot que apresenta o número de funções JavaScript do Grupo Alvo em comparação com o Grupo Controle. Figura extraída do artigo submetido à revista ACM Transactions on the Web. . . . . . . . . . . . . . . . . . . . . . . 118

6.6 Número de elementos HTML que foram marcados com um atributo role não nulo no Grupo Alvo. Figura extraída do artigo submetido à revista ACM Transactions on the Web. . . . . . . . . . . . . . . . . . . . . . . . . . . . . . 119

6.7 Representação em Boxplot que apresenta o número de elementos HTML com atributo role não nulo nos grupos e sub-grupos da investigação. Figura extraída do artigo submetido à revista ACM Transactions on the Web. . . . . . . . . . . . . . 120 
6.8 Representação em Boxplot que apresenta o número elementos HTML com atributo role do Grupo Alvo em comparação com o Grupo Controle. Figura extraída do artigo submetido à revista ACM Transactions on the Web . . . . . . . . . . . . . . 120

6.9 Representação em Boxplot que apresenta o valor da métrica Fona nos grupos e sub-grupos da investigação. Figura extraída do artigo submetido à revista $A C M$ Transactions on the Web. . . . . . . . . . . . . . . . . . . . . . 122

6.10 Representação em Boxplot que apresenta a distribuição do valor da métrica Fona do Grupo Alvo em comparação com o Grupo Controle. Figura extraída do artigo submetido à revista ACM Transactions on the Web . . . . . . . . . . . . . . . . . . 122

7.1 Representação das atividades conduzidas nesta tese, considerando os três ciclos do procedimento de pesquisa-ação. . . . . . . . . . . . . . . . 128 


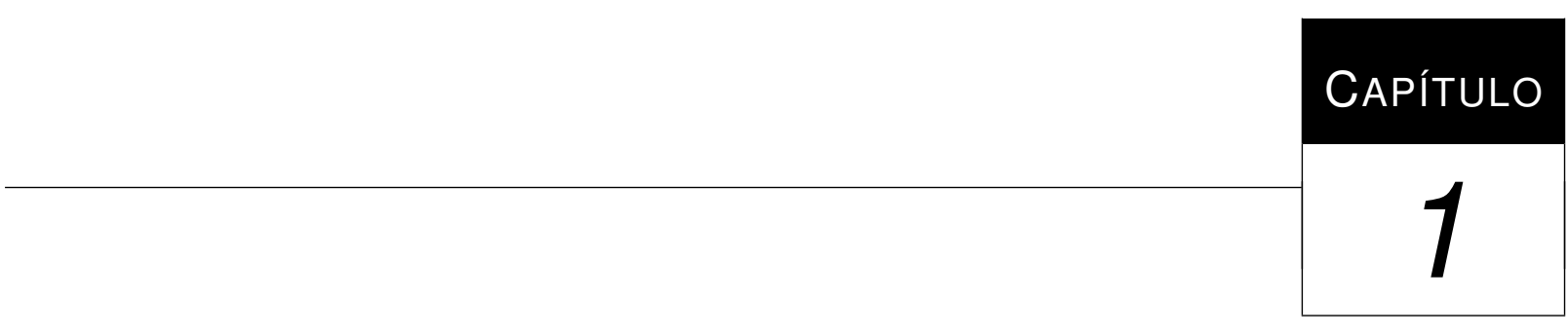

Introdução

Web e suas tecnologias se atualizam constantemente para proporcionar universaliza-
ção de acesso à informação disponibilizada. Em geral, notícias, propagandas e serviços
podem ser facilmente obtidos por meio da utilização de um navegador $\left(\right.$ browser $\left.^{1}\right)$, computador e Internet, localizados em qualquer parte do mundo.

Mais recentemente, pode ser observada a popularização da nova geração de aplicações que caracterizam a chamada Web 2.0. Essas novas aplicações possibilitam ao usuário uma forma mais ativa de participação desse meio de comunicação, ampliando o alcance da Web com mais evidências. Anteriormente, os usuários apenas realizavam buscas e consultas nos conteúdos disponibilizados, enquanto que agora, lhes é possível participar, inclusive, da autoria e disponibilização dos conteúdos (van Wamelen e de Kool, 2008). Dadas essas características, na atualidade, se formam verdadeiras comunidades virtuais sobre essas aplicações, como são verificadas em sistemas como Orkut $^{2}$, Facebook ${ }^{3}$ e Youtube ${ }^{4}$.

O termo "Web 2.0" é utilizado quando se tem a implementação de características específicas para as aplicações web, utilizando padrões tecnológicos avançados no desenvolvimento (Gehtland et al., 2006). Dentre essas características que devem ser incorporadas na aplicação web são destacadas (Cooper, 2007):

- Usuário participando do processo de autoria de conteúdo da aplicação;

- Maior interatividade dos websites;

\footnotetext{
${ }^{1}$ programa que habilita a obtenção e apresentação de páginas web

${ }^{2}$ http://www.orkut.com

${ }^{3}$ http://www.facebook.com/

${ }^{4}$ http://www.youtube.com/
} 
- Experiência semelhante à observada em aplicações desktop.

As características de maior interatividade e experiência semelhante à observada em aplicações desktop são resultado do emprego de um novo conjunto de tecnologias (DHTML, CSS, XMLHTTPRequest, DOM Events, entre outros) que permite o desenvolvimento de interações complexas na arquitetura web, nas chamadas RIA - Rich Internet Applications. Essas aplicações introduzem o conceito de separação de processamento (Fraternali et al., 2010), implementando as funcionalidades de interações no lado cliente da arquitetura web, por meio de componentes de interface, e comunicação assíncrona com o servidor por meio do objeto XMLHTTPRequest (Munson e Pimentel, 2008). O desenvolvimento dessas funcionalidades nas aplicações web caracteriza o "movimento Ajax" (Garrett, 2005), que destaca o emprego de tecnologias abertas com base em padrões arquiteturais da Internet e da Web (Fraternali et al., 2010).

Nesse contexto, esta tese considera RIA como um conceito relacionado à melhoria da experiência do usuário, incluindo a utilização de recursos sofisticados de interação na interface de uma aplicação web; enquanto Ajax é identificado como um conceito relacionado ao uso de tecnologias abertas de Internet que viabilizam a implementação de RIA.

A seguir são apresentadas as mudanças alavancadas pelo uso da arquitetura Ajax, na Seção 1.1; na Seção 1.2, é apresentado o conceito de acessibilidade na web associado à implementação de RIA; a tese, com os objetivos, motivações e definição de escopo são apresentados na Seção 1.3; a metodologia de pesquisa utilizada neste trabalho é descrita na Seção 1.4; as principais contribuições 1.5; e a estrutura da tese é apresentada na Seção 1.6.

\section{$1.1 \quad$ Ajax e RIA}

O acrônimo AJAX representa JavaScript e XML Assíncronos (Asynchronous Javascript and $X M L)$. No entanto, atualmente, o significado de Ajax é estendido para muitas outras tecnologias além de Javascript e XML. Portanto, Ajax é definido como um estilo arquitetural composto por diferentes tecnologias e idéias relacionadas ao desenvolvimento web (Mahemoff, 2006). Esse estilo arquitetural define um novo modelo de interação de websites que pode ser observado em aplicações da chamada "Web 2.0".

Com Ajax, o novo modelo de interação é aquele no qual a interface das aplicações web tornase semelhante à observada em aplicações desktop, com a disponibilização de componentes de interface altamente reativos. As aplicações Ajax habilitam interações ricas por meio de construções lógicas para adaptação do documento utilizando linguagens estáticas de script como o Javascript (Schmidt et al., 2008).

No modelo de interação da "Web 1.0", os websites contavam apenas com elementos de tipo link e input para implementar interatividade. Cada vez que o usuário manipulasse um componente da página web, ele deveria esperar pelo completo reload da página para perceber o resultado de suas ações. Com o Ajax, o desenvolvedor tem maior controle sobre os componentes e pode definir 
diferentes procedimentos para tratar diferentes formas de interação do usuário com a aplicação web. O Ajax também implementa uma interface de controle sobre requisições remotas ao servidor (W3C, 2012b), o que possibilita a atualização de partes de uma página web, sem a necessidade de realizar o reload completo da página web. Esses recursos associados ao uso de linguagens de script para desenvolvimento de interações no lado cliente de uma aplicação web permitem a implementação de lógica de apresentação de informações a respeito do andamento de requisições de dados ao servidor, disponibilização de menus interativos sem a necessidade de processamento do servidor, componentes de interface com a funcionalidade de drag-and-drop, animações, entre outras características.

No lado cliente da aplicação, são utilizadas tecnologias de apresentação de informação, linguagens de script para controle da interação, enquanto o servidor é utilizado para receber dados referentes a interação e para transmitir atualizações de dados ao cliente (Munson e Pimentel, 2008).

As características geradas pelo uso de Ajax permitem uma experiência na Web semelhante à observada em aplicações desktop, e as aplicações que implementam esse novo modelo de interatividade são denominadas RIA - Rich Internet Applications (Velasco et al., 2008). Nesse contexto, RIAs disponibilizam componentes de interface com o usuário sofisticados e mecanismos de interação que causam impacto na usabilidade e personalização das aplicações web. Dentre os benefícios e características implementadas pela arquitetura RIA, podem ser observadas associações diretas com princípios de usabilidade (Kluge et al., 2007; Linaje et al., 2009).

A natureza ambivalente de RIA (separação de tarefas entre o lado servidor e cliente da aplicação web) é provavelmente uma das principais razões para o seu sucesso. É possível em RIA, utilizar a Web como servidor para a aplicação assegurando todas as vantagens de um ambiente de baixo custo, multi-plataforma e arquitetura sem a necessidade de instalação de aplicações. Ao mesmo tempo, o processamento computacional alocado no cliente permite o desenvolvimento de interações ricas semelhantes às observadas em aplicações desktop modernas (Munson e Pimentel, 2008; Fraternali et al., 2010).

Assim, introduz-se o conceito de widget, como uma aplicação de lado cliente completa, implementada com base em padrões da Web (HTML - HyperText Markup Language, CSS - Cascading Style Sheets e JavaScript) e pode ser disponibilizada na plataforma Web (W3C, 2012a). Widgets abrangem desde componentes de interface disponíveis em bibliotecas Ajax, como Caixas de Diá$\log o^{5}$, menus drop-down ${ }^{6}$, caixas seletoras de data ${ }^{7}$; até aplicativos que disponibilizam informações e atualizam seus dados utilizando a Web como plataforma de comunicação, como aplicativos de apresentação da previsão do tempo, jogos casuais e notícias. Dessa forma, esta tese considera widgets como componentes de interface reutilizáveis que implementam interações ricas e podem ser orquestrados no desenvolvimento de uma RIA.

\footnotetext{
${ }^{5} \mathrm{http} / / /$ jqueryui.com/dialog/

${ }^{6} \mathrm{http}: / /$ jqueryui.com/menu/

${ }^{7}$ http://jqueryui.com/datepicker/
} 
Linaje et al. destacam que RIAs apresentam diferenças que afetam a interação do usuário (com componentes de interface de usuário e novo paradigma de interação na Web) e aspectos arquiteturais da aplicação (com a separação de processamento entre os lados cliente/servidor e distribuição de lógica de dados e negócios) (Linaje et al., 2009). Essas diferenças dificultam o desenvolvimento de RIA, uma vez que muitas das boas práticas e metodologias de desenvolvimento web devem ser adaptadas para considerar os novos aspectos de interação do usuário e a separação de processamento entre o servidor e o cliente. As ferramentas disponíveis no mercado ainda focam a complexidade de implementação, auxiliando o desenvolvedor, essencialmente na fase de implementação de um projeto de aplicação web, apresentando sugestões de comandos HTML e JavaScript que podem ser utilizados. O foco na fase de implementação das ferramentas de desenvolvimento de RIA do mercado trata-se de um resultado típico do desenvolvimento de ferramentas que seguem um paradigma arquitetural em evolução e imaturo (Fraternali et al., 2010).

Nesse contexto, para projetar aplicações Ajax, no contexto da Web 2.0, torna-se necessário adaptar o fluxo de desenvolvimento tradicional de aplicações web para considerar as novas capacidades do cliente, diferentes meios de comunicação entre cliente e servidor, e novas características de apresentação que afetam a interação do usuário (Linaje et al., 2009).

Atualmente, existem extensões das tecnologias utilizadas na Web 2.0 sendo desenvolvidas na nova especificação da W3C entitulada HTML5. Essas extensões estão relacionadas: a inclusão de novos elementos e atributos de marcação no HTML que ajudam na descrição semântica de uma aplicação web, elementos que permitem a inserção de conteúdo de vídeo/audio, recursos associados ao desenvolvimento de APIs de geolocalização, web workers, armazenamento de dados localmente e banco de dados no navegador, entre outras funcionalidades (Thiessen, 2011; W3C, 2013b). Esses novos recursos apresentados pelo HTML5 representam melhorias nos mecanismos de interação no lado cliente (navegador web) de uma aplicação web. Nesta tese, é abordada uma especificação diretamente associada a descrição semântica de elementos do HTML5 que tem como objetivo promover a acessibilidade em RIA.

\subsection{Acessibilidade na Web e RIA}

A Web foi elaborada com o objetivo de oferecer um repositório multi-plataforma e interoperável de dados e informações. Para permitir que o conteúdo pudesse ser acessado por quaisquer conjuntos de software e hardware que os usuários estivessem operando, foram especificados o HTML - HyperText Markup Language e o HTTP - HyperText Transport Protocol, como mecanismos para transmitir arquivos textuais entre diferentes plataformas e sistemas operacionais conectados em uma rede (Berners-Lee, 1990).

O uso da Web foi estendido não apenas às pessoas técnicas da área de computação, mas para toda a população. Esses novos usuários incentivaram o surgimento do conceito de Web 2.0, que estabelece que o seu conteúdo não é mais proprietário e disponibilizado por pequenos grupos de 
pessoas. Esse conteúdo deve ser decidido por toda a população presente na Web como usuários (van Wamelen e de Kool, 2008). Essas comunidades exigiram novos requisitos para a Web, como o desenvolvimento de RIA, Redes Sociais, e-business, entre outros serviços, os quais têm o potencial de amenizar as maiores tragédias do mundo como a pobreza, fome, doenças, violência, corrupção, analfabetismo; por meio da disponibilização de um repositório universal de dados, informações e conhecimento (Bratt, 2010).

No entanto, essas oportunidades não são estendidas a todos. Atualmente, a Web apresenta outras questões tecnológicas que vão além da proposta idealizada inicialmente, de disponibilizar um repositório multi-plataforma e interoperável permitidos pelo HTML e HTTP. Essas questões se colocam, muitas vezes, como barreiras de acessibilidade por não considerarem as habilidades, cultura, linguagem, entre outras características relacionadas aos usuários como seres humanos, em contraste aos requisitos de hardware e software (Naftali et al., 2010). A característica humana pode ser interpretada como a última barreira aos requisitos iniciais da Web de promover um ambiente multi-plataforma e interoperável, e vai de encontro à inclusão social de pessoas com deficiência $^{8}$. Assim, Tim Berners-Lee ${ }^{9}$ já destacava que "o poder da Web está em sua universalidade. A possibilidade de ser acessada por qualquer pessoa, independentemente de suas características e habilidades, é um aspecto essencial".

De fato, esse aspecto essencial tem sido abordado como um desafio e tem motivado estudos da área de Acessibilidade na Web, que têm como objetivo apresentar soluções de design ao desenvolvedor web, que permitam que usuários com deficiência acessem e interajam na Web. Essas soluções de design consideram o desenvolvimento de características específicas no conteúdo Web (considerando sua estrutura e forma de disponibilização de informações) (W3C, 2008b; Affonso de Lara et al., 2010; dos Santos et al., 2011; Watanabe e Fortes, 2009), padronização dos meios de acesso ao conteúdo pelos navegadores web e Tecnologias Assistivas (W3C, 2002; Watanabe et al., 2010b, 2009a, 2010a) e ferramentas de auxílio à implementação de soluções acessíveis (W3C, 2000a; Bittar et al., 2009; Watanabe et al., 2010c).

Com o aumento da complexidade das interações nas aplicações da Web 2.0, as interfaces do usuário se tornaram mais ricas e interativas (Gibson, 2007) que em contrapartida, cada vez mais dos agentes de usuários (navegadores web) e Tecnologias Assistivas, para que a interação permaneça acessível a usuários com deficiência. As alterações e atualizações na estrutura de uma aplicação web geradas pelo JavaScript nem sempre são apresentadas aos usuários interagindo por meio da adoção de recursos de Tecnologias Assistivas. Tradicionalmente, as Tecnologias Assistivas (como leitores de tela) apresentam informações, considerando que a página web possui uma estrutura linearizada de conteúdo, no entanto, RIAs, muitas vezes, não possuem uma estrutura linearizada e estática, permitindo que a estrutura da página web seja modificada durante a interação.

\footnotetext{
${ }^{8}$ Pessoa com deficiência: atualmente, chegou-se ao consenso quanto à utilização da expressão pessoa com deficiência em lugar de termos como: "deficientes", "pessoa portadora de deficiência", "pessoa com necessidades especiais" e "portador de necessidades especiais"

${ }^{9}$ Inventor da Web e diretor da W3C - World Wide Web Consortium
} 
Para lidar com o aumento de complexidade das interfaces de usuário na Web introduzidas pelas RIAs, a WAI (Web Accessibility Initiative) elaborou a especificação ARIA (Accessible Rich Internet Applications (W3C, 2011)). O objetivo da especificação ARIA é incluir dados semânticos nos elementos HTML para informar aos mecanismos de Tecnologias Assistivas sobre como cada componente de interface deve ser apresentado considerando possíveis mudanças e atualizações da sua estrutura HTML (Gibson, 2007). A inclusão de dados semânticos nos elementos HTML conforme descrito na especificação ARIA também caracteriza uma das melhorias de recursos de interação no navegador web e constituem parte da especificação do HTML5 (W3C, 2013b).

Vale destacar que, embora a especificação ARIA apresente soluções de design para a acessibilidade em RIA, não há garantias que essas soluções serão incorporadas nas aplicações (Watanabe et al., 2009b). Freire et al., por exemplo, realizaram levantamentos sobre o conhecimento de acessibilidade por pessoas envolvidas no desenvolvimento Web no Brasil (Freire et al., 2008c) e sobre a implementação de soluções de design acessíveis em websites de municípios brasileiros (Freire et al., 2008b). A conclusão de ambos os trabalhos foi de que soluções de design acessível ainda são pouco aplicadas no desenvolvimento web, uma vez que os desenvolvedores não têm conhecimento sobre elas. Como os desenvolvedores nem sempre conhecem todas as soluções de acessibilidade disponíveis, torna-se necessária a elaboração de ferramentas e metodologia de avaliação que os auxiliem a integrar designs acessíveis em suas aplicações.

Essas dificuldades apresentadas no desenvolvimento de RIA são ainda mais relevantes, quando considerando ambientes de desenvolvimento que utilizam estratégias automáticas para testar os requisitos de software. As ferramentas automáticas de avaliação e manutenção de acessibilidade apresentam capacidades limitadas de análise da estrutura HTML do conteúdo (avaliando apenas o conteúdo estático das páginas) e não são capazes de analisar elementos gerados dinamicamente no $\mathrm{DOM}^{10}$, que são essenciais para o desenvolvimento de ARIA em aplicações da Web 2.0 (Velasco et al., 2008).

No estado da arte diferentes trabalhos podem ser encontrados na área de elaboração de estratégias automáticas para avaliar a acessibilidade em RIA. Esses trabalhos abordam tópicos relacionados a avaliação de acessibilidade de código estático JavaScript (Tateishi et al., 2007), avaliação de conformidade com a WCAG na estrutura DOM renderizada no navegador web (Fernandes et al., 2011, 2012) e elaboração de um framework de avaliação de ARIA em aplicações web (Doush et al., 2013).

Os trabalhos apresentados nesta tese foram conduzidos concorrentemente com esses trabalhos, com o mesmo objetivo de avaliar a acessibilidade em RIA, no entanto, são utilizadas abordagens distintas com foco na inclusão do modelo de interação de usuários que utilizam leitores de tela no processo de avaliação de acessibilidade.

\footnotetext{
${ }^{10}$ Document Object Model: modelo de acesso de elementos HTML carregado em memória utilizando uma estrutura de dados de tipo árvore para qualquer página web renderizada no navegador web. Especificação disponível em: http://www.w3.org/DOM/.
} 


\subsection{A tese}

Dadas: (i) a popularização de RIAs e as vantagens de melhoria de usabilidade associadas à implementação da arquitetura Ajax na Web; (ii) a importância de garantir o acesso universal às aplicações web, independente das necessidades especiais que possam ser apresentadas pelos usuários; (iii) a dificuldade associada à implementação de requisitos de acessibilidade em aplicações da Web 2.0; e (iv) a dificuldade de interação com componentes de interface de aplicações web apresentada por usuários deficientes visuais; a seguinte questão de pesquisa é levantada e norteou os trabalhos científicos conduzidos nesta tese:

\section{É possível projetar estratégias de avaliação automática de critérios de acessibi- lidade em RIA, para apoiar o desenvolvimento de widgets acessíveis a usuários que interajam com aplicações web utilizando leitores de tela?}

Nesse contexto, a tese sendo defendida é de que é possível automatizar técnicas e processos de avaliação que avaliam critérios de acessibilidade em RIA, considerando usuários que utilizem leitores de tela.

RIAs, diferentemente das aplicações web que não utilizam JavaScript, implementam recursos dinâmicos que alteram a estrutura hierárquica do HTML. Dessa forma, a análise da interface e conteúdo apresentado de RIA deve considerar não apenas o conteúdo HTML de uma aplicação web, mas também o seu comportamento implementado utilizando JavaScript e CSS.

\subsection{Metodologia de pesquisa}

Para conduzir e validar este trabalho, foi realizado o procedimento científico de pesquisa-ação. A pesquisa-ação é um tipo de investigação-ação, que estabelece um processo que segue um modelo de ciclos, no qual a cada volta completa em um ciclo se aprimora a prática sendo realizada pela realização sistemática de atividades relacionadas a agir no campo da prática, descrever os efeitos observados, avaliar os resultados da ação e planejar uma melhora para a prática (Tripp, 2005). A Figura 1.1 ilustra o processo de pesquisa-ação.

Neste trabalho, o procedimento de pesquisa-ação foi realizado considerando as atividades de elaboração de estratégias de avaliação automática de requisitos de acessibilidade em RIA (considerando os passos de planejar e agir da pesquisa-ação), e a realização de procedimentos de validação para analisar se as estratégias de avaliação elaboradas foram eficazes na identificação de problemas de acessibilidade associados à especificação ARIA (considerando os passos de descrever e avaliar) e, consecutivamente, estabelecer questões e requisitos que foram abordados na próxima etapa do ciclo. Dessa forma, foram realizados ciclos dessas atividades, a fim de se aprimorar os recursos desenvolvidos a cada iteração das atividades, para identificar diferentes formas de avaliar requisitos de acessibilidade em RIA. 


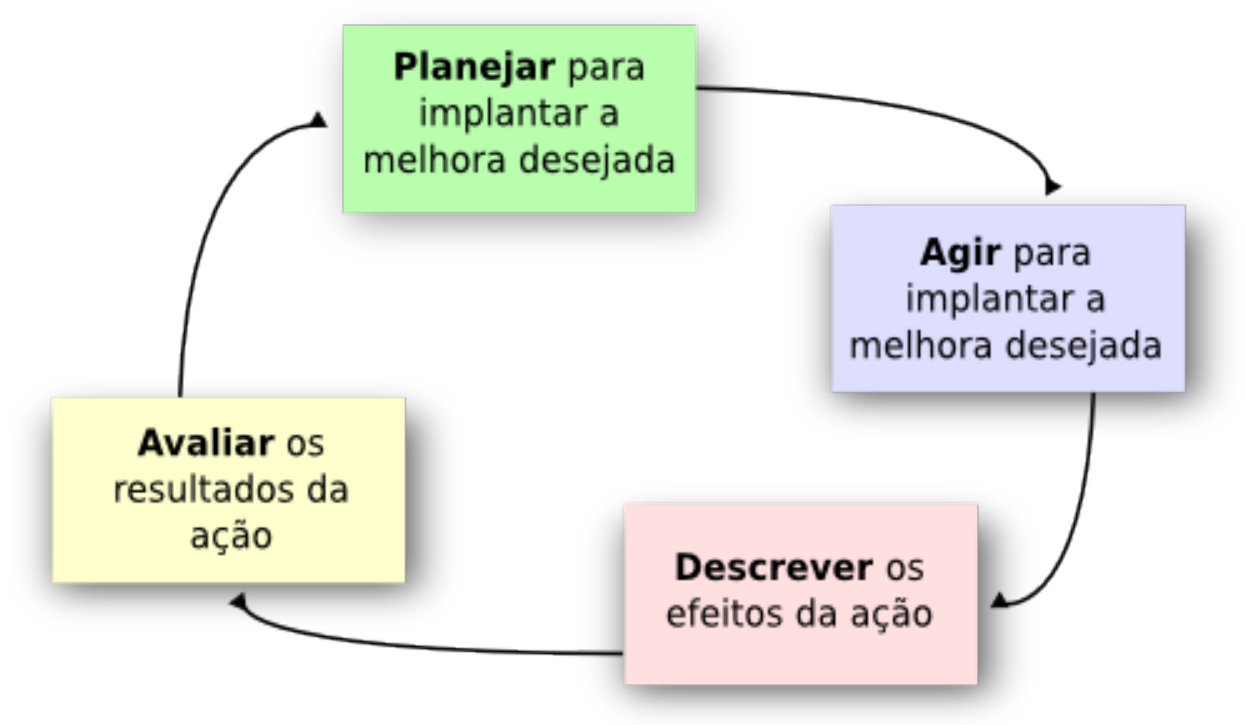

Figura 1.1: Representação do ciclo em quatro fases do processo de pesquisa-ação.

Muitas das técnicas utilizadas para avaliar requisitos de acessibilidade em aplicações da Web 1.0 não são capazes de analisar as alterações dinâmicas da estrutura DOM que são realizadas em RIA. Portanto, são incapazes de avaliar requisitos de acessibilidade associados à especificação ARIA. Este trabalho aborda metodologias específicas de avaliação e teste de uma aplicação web que possibilitam a análise e verificação de requisitos da especificação ARIA.

Dois ciclos de condução das atividades de planejar, agir, descrever e avaliar, que compõem o procedimento de pesquisa-ação foram realizados nesta tese utilizando Testes de Aceitação (AT - Acceptance Tests). No primeiro ciclo, foi desenvolvida a ferramenta A-pyccuracy que suporta a elaboração de ATs para cenários de uso acessíveis (Capítulo 4). No segundo ciclo, foi desenvolvida a ferramenta aria-check que utiliza um conjunto de casos de AT padrão para avaliar a acessibilidade em widgets (Capítulo 5).

Por fim, em um terceiro ciclo de condução de atividades do procedimento de pesquisa-ação, é apresentada a proposta de uma métrica, entitulada Fona, para avaliação de um requisito específico associado à ARIA, a navegação por foco (Capítulo 6). Essa métrica utiliza-se de coletas quantitativas calculadas a partir da estrutura DOM inicial de aplicações web, para identificar se a funcionalidade de navegação por foco é implementada ou não. Uma vez que essa métrica resulta em valores sobre um único requisito de acessibilidade que precisa ser implementado por qualquer aplicação web, foi investigada sua adequação em um conjunto de websites reais, que podem ser encontrados na Web. Os resultados da aplicação dessa métrica nesse conjunto de websites possibilitou uma análise sobre como desenvolvedores web têm implementado o requisito de navegação por foco na Web. 


\subsection{Principais Contribuições}

As principais contribuições dos trabalhos apresentados nesta tese foram:

- Elaborar diferentes estratégias para avaliar automaticamente a acessibilidade em RIA, considerando requisitos de navegação em componentes de interface dinâmicos para usuários que utilizem leitores de tela.

- Apresentar estratégias automáticas que incluem o modelo de interação de usuários que utilizam leitores de tela no processo de avaliação de acessibilidade em widgets.

- Apresentar levantamentos a respeito da implementação de requisitos da especificação ARIA em bibliotecas JavaScript e aplicações web empresariais, como resultado dos processos de validação das diferentes estratégias de avaliação de acessibilidade elaboradas nesta tese.

Na próxima seção, é apresentada a estrutura desta tese.

\subsection{Estrutura da Tese}

Esta tese está organizada da seguinte forma: no próximo capítulo (Capítulo 2), são introduzidos os conceitos relacionados a acessibilidade na web; no Capítulo 3, é apresentado o estado da arte a respeito dos métodos de avaliação de acessibilidade, incluindo os trabalhos relacionados que foram estudados e possuem alguma abordagem semelhante à proposta nesta tese; no Capítulo 4, é descrita a proposta de utilização de AT para avaliar acessibilidade de aplicações web que representa a primeira iteração de condução de atividades do procedimento de pesquisa-ação; no Capítulo 5, é apresentada uma abordagem que tem como base a utilização de AT específicos para cada widget definida na especificação ARIA, que representa a segunda iteração de condução de atividades do procedimento de pesquisa-ação; no Capítulo 6, é apresentada uma métrica que quantifica um valor proporcional a quanto os websites têm implementado o requisito de navegação por foco na Web, representando o terceiro ciclo de condução de atividades do procedimento de pesquisa-ação; por fim, no Capítulo 7, são apresentadas as conclusões e trabalhos futuros. 



\section{Acessibilidade na Web}

ste capítulo tem como objetivo apresentar os principais conceitos relacionados à acessibilidade na web. A compreensão desses conceitos foi essencial para este trabalho, por assegurar que as contribuições sejam compatíveis ao cenário científico de pesquisas na área.

A revisão bibliográfica apresentada neste capítulo foi também discutida em dois trabalhos publicados como resultados parciais desta tese, na linha de pesquisa de acessibilidade na web:

\section{Artigo publicado no SIGDOC 2010 - International Conference on Design of Communication}

: WCAG conformance approach based on model-driven development and WebML (Watanabe et al., 2010c).

\section{Artigo publicado no SIGDOC 2010 - International Conference on Design of Communication}

: Improving WCAG for elderly web accessibility (Affonso de Lara et al., 2010).

A próxima seção (Seção 2.1) introduz o tema de acessibilidade na web. Na Seção 2.2 são descritos os conceitos relativos a Tecnologias Assistivas e como elas devem ser utilizadas para auxiliar usuários com deficiência a interagir com aplicações web; a Seção 2.3 introduz o modelo de acessibilidade estabelecido pela WAI (W3C Accessibility Initiative), um dos modelos mais referenciados e utilizados no desenvolvimento de aplicações web acessíveis; por fim, a Seção 2.4 apresenta as considerações finais sobre o que foi estudado sobre o tema de acessibilidade na web. 


\subsection{Considerações Iniciais}

O tema "acessibilidade na web" corresponde a uma característica de qualidade relativa ao design da página web de forma geral, de maneira que os usuários sejam capazes de acessá-la a partir de diferentes situações (W3C, 1999). Como por exemplo, nas situações em que os usuários:

- Sejam incapazes de ver, ouvir, mover ou compreender determinadas formas de disponibilização do conteúdo,

- Possuam dificuldades de leitura e compreensão do texto,

- Sejam incapazes de utilizar o teclado ou o mouse,

- Utilizem navegadores apenas em modo texto, tela com dimensões reduzidas ou conexão com a Internet lenta,

- Estejam com os olhos, ouvidos ou mãos ocupadas em outras atividades, e

- Utilizem versões antigas ou diferentes navegadores, navegador por voz ou diferentes sistemas operacionais.

É importante observar que essas situações envolvem tanto requisitos tecnológicos necessários para a interação, quanto características do usuário.

As situações relacionadas aos requisitos tecnológicos consideram as características do hardware e software utilizados na interação com o usuário. Dessa forma, os sites devem ser implementados de forma que possam ser apresentados e visualizados, independentemente dos dispositivos, sistema operacional e navegadores sendo utilizados.

Por outro lado, nas situações relacionadas com as características do usuário é priorizada a adaptação, redundância e substituição do conteúdo de acordo com as deficiências físicas ou cognitivas que os usuários possam apresentar. As deficiências físicas geralmente identificadas são: deficiência visual, auditiva e motora. Já as deficiências cognitivas consideradas são: patologias, como alzheimer e dislexia, dificuldades de leitura e compreensão do conteúdo, entre outras.

A preocupação de acordo com as características dos usuários, mais especificamente de acordo com suas deficiências, possui também um impacto relacionado à sua inclusão social e digital, por meio do seu acesso à informação e utilização de serviços que possam ser disponibilizados na web. A importância desse impacto pode ser observada pela regulamentação que exige a disponibilização de conteúdo acessível por parte de orgãos governamentais de países como Estados Unidos (Section $508^{1}$ ), Canadá, Portugal, Japão e, inclusive, o Brasil (obrigatoriedade de acessibilidade nos portais e sítios eletrônicos da administração pública na rede mundial de computadores, determinada no Decreto Lei 5.296, promulgado em 2004).

\footnotetext{
${ }^{1} \mathrm{http}: / /$ www.section508.gov/
} 


\subsection{Tecnologias Assistivas}

No Brasil, em 2010, mais de 45 milhões de indivíduos se declararam portadores de algum tipo de deficiência, representando 23,9\% da população total (IBGE, 2010). As pessoas que possuam algum tipo de deficiência física (incapacidades de visão, audição ou locomoção) ou cognitiva (dificuldades ou limitações intelectuais) representam, portanto, quase um quarto da população brasileira.

Esses indivíduos possuem dificuldades no desempenho de determinadas atividades diárias, conforme o tipo de deficiência por eles manifestada. Como exemplos podem ser destacados: entrada nos meios de transporte coletivos por indivíduos com locomoção reduzida ou leitura de cardápios em restaurante por pessoas com deficiência visual.

Quando considerando a utilização dos sistemas de informação, inclusive da web, por esses indivíduos, essas dificuldades também podem ser observadas: leitura da tela por indivíduos com deficiência visual, utilização do mouse por pessoas com deficiências motoras nos membros superiores, entre outras.

Observa-se que a taxa de pessoas com deficiência aumenta conforme aumenta a faixa etária da população brasileira, ou seja, 4,3\% indivíduos que apresentam deficiências são crianças de até 14 anos, enquanto que 54\% são indivíduos com mais de 65 anos (IBGE, 2000). Esse fato aliado ao envelhecimento da população brasileira, observado nos últimos anos (aumento mais acelerado para segmentos da população com idade superior a 60 anos (IBGE, 2008)), denota ainda uma maior importância de estudos que estejam vinculados a acessibilidade por indivíduos que apresentem algum tipo de deficiência.

Nesse contexto se insere o conceito de Tecnologias Assistivas, como uma forma de auxílio no desempenho de atividades comuns para esses indivíduos. O termo Tecnologia Assistiva é definido como o conjunto de equipamentos, serviços, estratégias e práticas concebidas e aplicadas para atenuar os problemas encontrados por pessoas com deficiência (Cook e Hussey, 2001).

Como exemplos de mecanismos de Tecnologias Assistivas, comumente observados, podem ser citados: cadeira de rodas, lentes de correção de deficiências visuais (óculos), aparelhos auditivos entre outras.

Para o desenvolvimento de atividades que envolvam a utilização de computadores, também podem ser observados alguns produtos de Tecnologias Assistivas. Essas tecnologias agem como uma forma de interface entre os conteúdos e informações disponíveis no computador e o usuário, durante as interações.

Os conteúdos disponibilizados em formato inacessível ou de difícil compreensão pelos usuários são convertidos em uma forma alternativa de mídia que seja mais facilmente percebida e interpretada, durante interações de saída de informações do computador para o usuário.

Nas interações de entrada, o funcionamento é o mesmo, o usuário que não consiga utilizar o teclado ou o mouse para efetuar a entrada de dados no computador utiliza um meio diferente de 
inserção de dados, que seja apropriado para superar sua deficiência. Os dados são então convertidos por determinada Tecnologia Assistiva em um formato que seja processável pelo computador.

Entre os principais exemplos de produtos de Tecnologias Assistivas utilizadas em computadores, temos:

- Leitor de tela: software que realiza a leitura dos componentes apresentados na tela do computador, emitindo-os por voz a indivíduos com deficiência visual. Exemplo: JAWS ${ }^{2}$, Orca $^{3}$ e NVDA ${ }^{4}$.

- Navegador textual: navegador que apresenta apenas o conteúdo textual das páginas e aplicações web. Normalmente, utilizado junto com um software de leitor de tela para auxiliar a navegação na Web por usuários com deficiência visual. Exemplo: Lynx ${ }^{5}$.

- Reconhecedor de fala: software que traduz comandos passados por voz pelos usuários em tarefas a serem executadas pelo computador. Pode ser utilizado por indivíduos que possuam algum tipo de deficiência que limite a utilização de dispositivos de entrada como mouse ou teclado. Exemplos: Microsoft's speech technologies ${ }^{6}$ e Dragon NaturallySpeaking 10 Preferred ${ }^{7}$.

É importante destacar que a utilização de um produto de Tecnologia Assistiva apenas, na maioria das vezes, não é suficiente para o desempenho das tarefas por pessoas com deficiências. Como exemplo pode ser citado o uso de cadeira de rodas, que somente é possível em ambientes planos, sendo necessária a presença de rampas de acesso ou elevadores em edifícios que possuam mais de um andar.

Com relação à atividade de navegação na web, o leitor de tela, quando aplicado para efetuar a leitura de sites, necessita que sejam atribuídas descrições em texto para os conteúdos apresentados em formas não textuais, como imagens ou figuras, para que a informação neles contida seja narrada ao usuário. A ausência dessas descrições determina que qualquer informação representada pelas figuras é perdida, não acessada por usuários que não disponham do sentido da visão, pois o leitor de telas é capaz apenas de sintetizar em voz os conteúdos textuais das aplicações.

Requisitos de design como esses, rampas de acesso em prédios e construções, e descrição textual para os elementos não textuais nos sites também são considerados Tecnologias Assistivas e devem ser implementados por designers para garantir a acessibilidade. Esses requisitos levam a um determinado nível de padronização que garante a flexibilidade dos ambientes e produtos de acordo com as deficiências que possam ser apresentadas e as diferentes formas de Tecnologias

\footnotetext{
${ }^{2} \mathrm{http} / / /$ www.freedomscientific.com/products/fs/jaws-product-page.asp

${ }^{3}$ http://projects.gnome.org/orca/

${ }^{4}$ http://

${ }^{5}$ http://lynx.isc.org/

${ }^{6}$ http://www.microsoft.com/speech/speech2007/default.mspx

${ }^{7}$ http://www.nuance.com/naturallyspeaking/products/preferred.asp
} 
Assistivas que venham a ser utilizadas pelos usuários e são de responsabilidade de designers ou, no caso da web, disponibilizadores de conteúdo.

Essa padronização é uma das principais metas dos estudos sobre acessibilidade na web, e sua utilização em conjunto com os produtos de Tecnologias Assistivas de acesso ao computador (leitores de tela, reconhecedores de voz, mouses alternativos, entre outras) garantem o acesso a esse meio de comunicação, por um maior número de indivíduos.

Vale destacar que a busca por reduzir as barreiras de acessibilidade deve ser sempre contínua porque, de fato, no mundo real com os avanços tecnológicos e inovações de diferentes origens, constata-se que as diferenças individuais requerem uma diversidade enorme de soluções, as quais não eliminam toda e qualquer barreira de acessibilidade.

\subsection{Abordagem da WAI}

Quando considerando as questões de acessibilidade na web, uma das referências de maior importância (Kelly et al., 2005) (Freire et al., 2007) é a WCAG - Web Content Accessibility Guidelines, elaborada pela WAI (Web Accessibility Initiative).

A WAI (Web Accessibility Initiative) é uma organização criada pela W3C que tem como missão definir princípios e regras de design e desenvolvimento de sites que sejam acessíveis a pessoas com deficiência (Lucca et al., 2005). Para este fim, foi estabelecido um modelo de conformidade com três conjuntos de diretrizes agregadas nos seguintes documentos (Kelly et al., 2005) (Kelly et al., 2007):

- WCAG 1.0 - Web Content Accessibility Guidelines: explicam como tornar o conteúdo web acessível a indivíduos com deficiências e disponível a todos os usuários, quaisquer que sejam os agentes de usuário que estejam sendo utilizados (navegadores de desktop, navegadores por voz, celulares entre outros) e restrições de operações (ambientes barulhentos, com pouca iluminação, entre outros) (W3C, 1999).

- ATAG 1.0 - Authoring Tool Accessibility Guidelines: tem como propósito assistir desenvolvedores na implementação de ferramentas de autoria de conteúdo Web que seja acessível e na criação de ferramentas de autoria acessíveis (W3C, 2000a).

- UAAG 1.0 - User Agent Accessibility Guidelines: destinado ao desenvolvimento de agentes de usuário (user agents) que reduzam as barreiras a acessibilidade na Web para pessoas com deficiências (visual, auditiva, física, cognitiva e neurológica). Como agentes de usuário são incluídos os navegadores HTML e outros tipos de software que renderizam conteúdo Web (W3C, 2002).

Para cada diretriz descrita, nesses documentos, são também descritos checkpoints que definem etapas ou partes de um projeto que podem apresentar barreiras a usuários com algum tipo de 
limitação (indivíduos cegos, surdos, com problemas cognitivos, entre outros). A cada um desses checkpoints é atribuído um valor de prioridade, de acordo com o seu impacto na acessibilidade e conformidade com os respectivos documentos (W3C, 1999) (W3C, 2002) (W3C, 2000a):

- Prioridade 1: o não cumprimento desse checkpoint acarreta que um ou mais grupos de usuários vão ser impossibilitados de acessar a informação do site.

- Prioridade 2: o não cumprimento desse checkpoint acarreta que um ou mais grupos de usuários vão ter dificuldades para acessar as informações contidas no site.

- Prioridade 3:o não cumprimento desse checkpoint acarreta que um ou mais grupos de usuários vão ter um pouco de dificuldade para acessar as informações contidas no site.

Especificamente para a ATAG, existem checkpoints de prioridade relativa (Relative Priority) (W3C, 2000a). Esses checkpoints se referem a geração, autoria e verificação de conteúdo web, ou seja, estão relacionados, diretamente, a checkpoints da WCAG 1.0. Dessa forma, o nível de importância a eles atribuído depende da prioridade atribuída ao checkpoint correspondente na WCAG 1.0. Por exemplo: o checkpoint 4.1 da ATAG 1.0 indica a importância da verificação e aviso ao autor a respeito de problemas de acessibilidade. A verificação de equivalentes textuais a imagens e audio (checkpoint 1.1 de prioridade 1 da WCAG 1.0) na ferramenta de autoria também é de prioridade 1. No entanto, a verificação do agrupamento de links no mecanismo de navegação (checkpoint 13.6 de prioridade 3 da WCAG 1.0) é de prioridade 3.

De acordo com a verificação desses checkpoints na aplicação, a WAI atribui um valor de conformidade com o conjunto de diretrizes entre A e AAA:

- Conformance Level "A": todos checkpoints de prioridade 1 são satisfeitos para a WCAG 1.0 e a UAAG 1.0. Para a ATAG 1.0 também é necessária a satisfação de todos os checkpoints de prioridade relativa.

- Conformance Level "AA": todos checkpoints de prioridade 1 e 2 são satisfeitos para a WCAG 1.0 e a UAAG 1.0. Para a ATAG 1.0 também é necessária a satisfação de todos os checkpoints de prioridade relativa.

- Conformance Level "AAA": todos checkpoints de prioridade 1, 2 e 3 são satisfeitos para a WCAG 1.0 e a UAAG 1.0. Para a ATAG 1.0 também é necessária a satisfação de todos os checkpoints de prioridade relativa.

No contexto da relação entre as diretrizes WCAG, ATAG e UAAG, conforme esquematizado na Figura 2.1, o termo Tecnologia Assistiva possui definição específica. A Tecnologia Assistiva é tida como hardware ou software que age como um agente de usuário, ou em conjunto com um agente de usuário principal, para promover funcionalidades que satisfaçam requisitos de usuários com deficiências que vão além das oferecidas pelo agente de usuário principal (W3C, 2002) (W3C, 


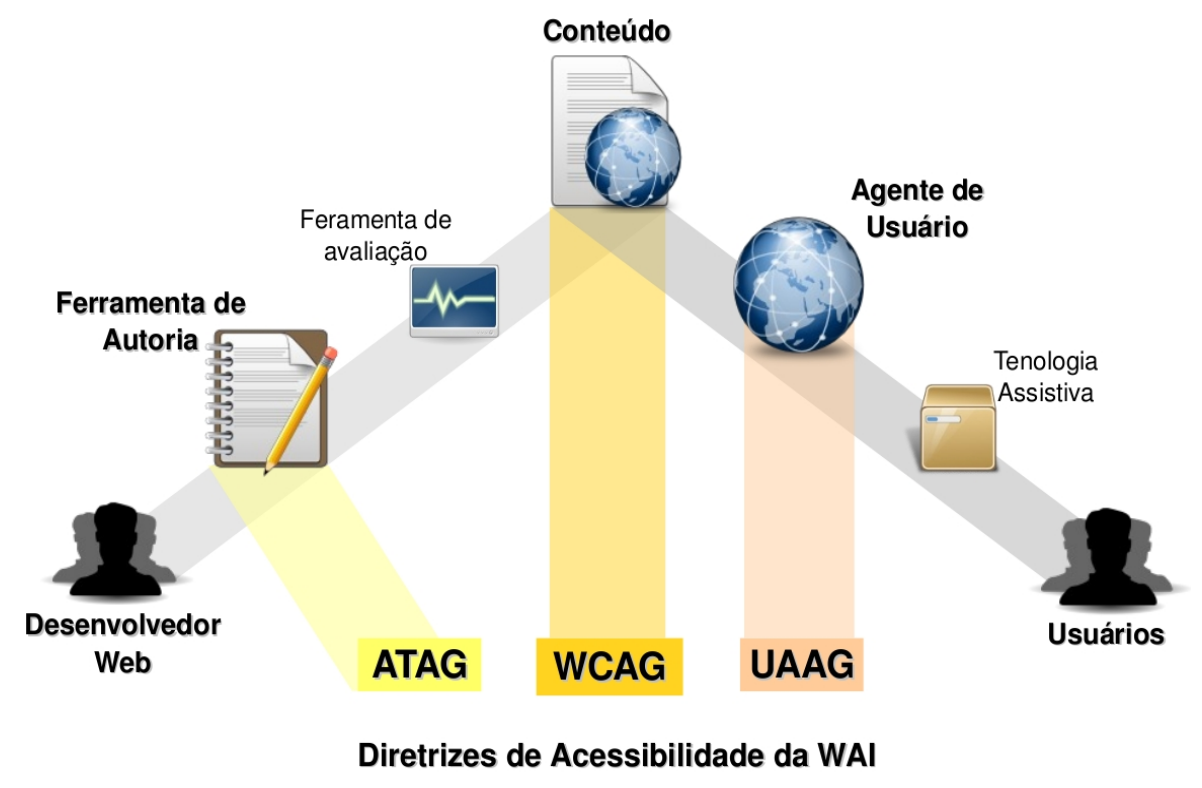

Figura 2.1: Relação entre as guidelines da WAI. Figura adaptada do site da WAI: http://www.w3.org/WAI/intro/specs.png

2008b). Com isso, a conformidade com cada um dos conjuntos de diretrizes de acessibilidade, nas interações compreendidas entre a autoria de conteúdo e disponibilização do mesmo aos usuários, junto com a utilização de uma determinada Tecnologia Assistiva, conforme o tipo de necessidade especial apresentada pelo usuário, garante o acesso a informação, de acordo com o modelo definido.

É importante destacar que cada uma dessas diretrizes de acessibilidade são destinadas a diferentes componentes e públicos-alvo na web. A WCAG diz respeito à estrutura e ao conteúdo inserido nas tecnologias de desenvolvimento web (HTML, CSS, Javascript, entre outras), sendo destinada a autores de páginas web, web designers e desenvolvedores de ferramentas de autoria (editores HTML) (W3C, 1999). ATAG refere-se às características necessárias nas ferramentas de autoria, sendo destinada aos desenvolvedores dessas aplicações (W3C, 2000a). Por fim, a UAAG é dirigida a implementação de navegadores, players multimídia, plugins (programas que executam como parte do agente de usuário, e não faz parte do conteúdo Web), entre outros (inclusive Tecnologias Assistivas) (W3C, 2002).

Dessa forma, esse modelo de conformidade com os conjuntos de diretrizes de acessibilidade pode ser classificado de acordo com três componentes (conteúdo, ferramentas de autoria e agentes de usuários) que devem ser considerados na garantia de acessibilidade na web. Seguindo a W3C, cada componente tem o seu desenvolvimento realizado por diferentes indivíduos, conforme esquematizado na Figura 2.2.

Vale observar que esse modelo é dependente do desenvolvimento de agentes de usuários (navegadores) e ferramentas de autoria de conteúdo, que sigam as diretrizes determinadas nos documentos UAAG e ATAG, respectivamente. Uma vez que os desenvolvedores web não possuem o controle sobre o desenvolvimento nessas áreas ou sobre as escolhas de utilização de navegadores e 


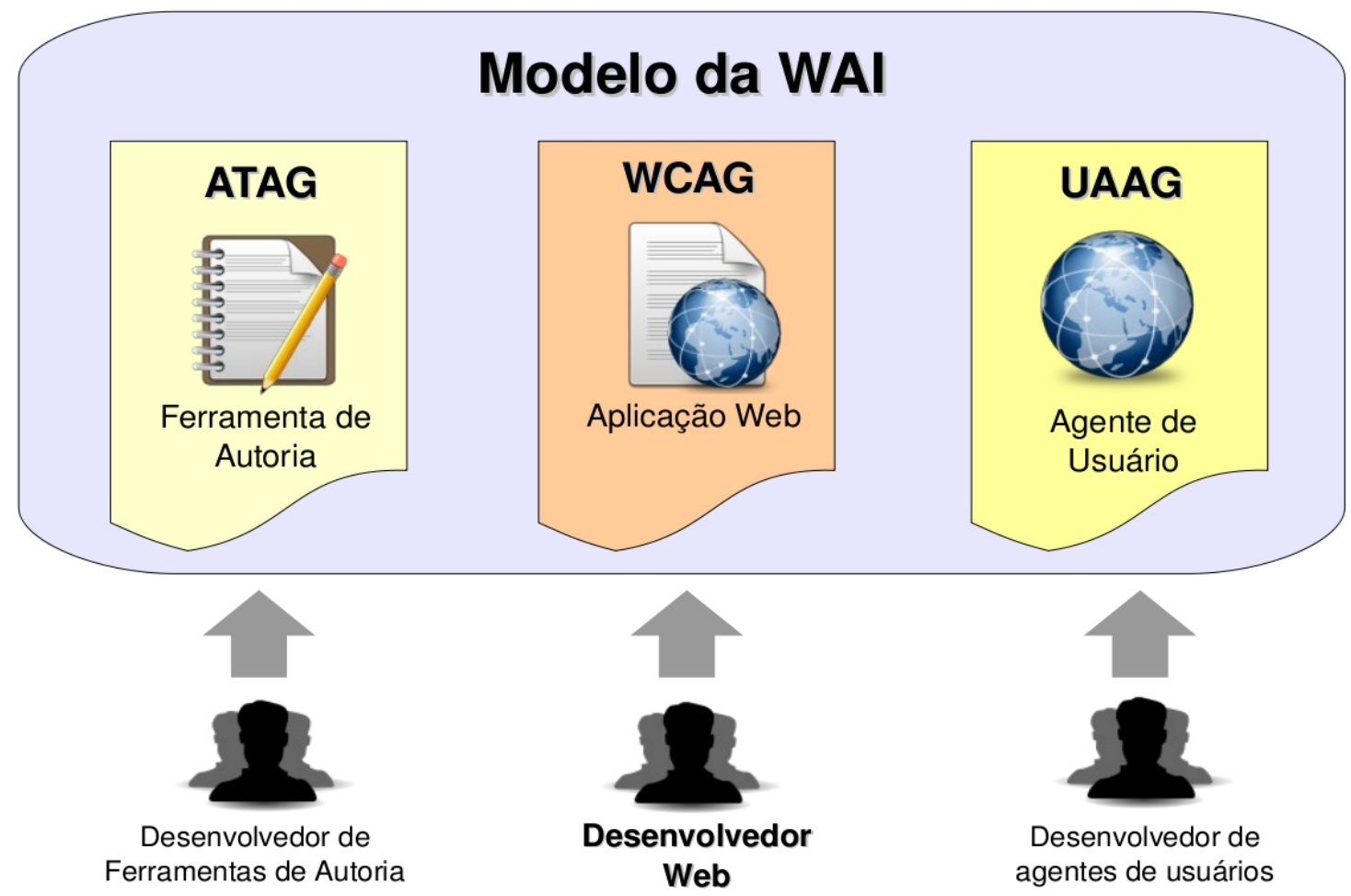

Figura 2.2: Responsáveis pela acessibilidade no modelo da WAI.

Tecnologias Assistivas utilizadas pelos usuários (Kelly et al., 2005) (Kelly et al., 2007), um maior enfoque e importância, com relação a acessibilidade na web, é atribuído a WCAG, considerando seus desenvolvedores.

As sub-seções a seguir apresentam as especificações WCAG 1.0, WCAG 2.0 e WAI-ARIA.

\subsubsection{WCAG 1.0}

A WCAG 1.0 consiste de um documento que apresenta um conjunto de diretrizes que discutem problemas de acessibilidade na utilização de tecnologias web e soluções de design acessíveis (W3C, 1999).

As diretrizes são classificadas de acordo com dois temas de design acessível:

1. Assegurar a transformação harmoniosa: a transformação harmoniosa das páginas garante que o conteúdo permanece acessível, mesmo em situações em que os usuários sejam deficientes físicos, sensoriais ou cognitivos, ou estejam operando com restrições de trabalho e barreiras tecnológicas.

Esse tema é abordado nas diretrizes 1 a 11, apresentadas a seguir.

2. Tornar o conteúdo compreensível e navegável: utilizar linguagem clara e simples nos conteúdos e promover mecanismos compreensíveis de navegação entre as páginas. A disponibilização de ferramentas de navegação e orientação de informação nas páginas maximiza 
a acessibilidade e usabilidade nas aplicações.

Esse tema é abordado nas diretrizes 12 a 14, apresentadas a seguir.

Cada diretriz apresenta:

- Um número de identificação

- Definição da guideline ou diretriz

- Motivação de uso da mesma e alguns grupos de usuários que se beneficiam por ela

- Uma lista de pontos de verificação (checkpoints), que explicam como a diretriz se aplica no cenário de desenvolvimento. Para cada checkpoint são apresentadas implementações e exemplos da solução discutida (W3C, 2000b).

As 14 diretrizes da WCAG 1.0 são (W3C, 1999):

1. Promover alternativas equivalentes a conteúdos audíveis e visuais: disponibilizar equivalentes textuais para conteúdos não textuais (imagens, audio e vídeos). Os conteúdos textuais, ao contrário de figuras e gravações de áudio por exemplo, podem ser convertidos e apresentados em diferentes modos, conforme a necessidade especial apresentada pelo usuário, por meio do uso de Tecnologias Assistivas.

2. Não recorrer apenas a cor: garantir que textos e gráficos sejam compreensíveis com e sem a visualização de cores. Quando a cor é utilizada como meio único para representação de determinadas informações, essas informações tornam-se inacessíveis a usuários que não conseguem diferenciar certas cores, ou estejam utilizando equipamentos com display sem cor ou sem visão (non-visual).

3. Utilizar corretamente a marcação e folhas de estilo: utilizar marcações de acordo com a estrutura dos elementos apresentados e controlar a apresentação com folhas de estilo, ao invés de elementos de apresentação e atributos. A estrutura de marcação do documento é um fator essencial na navegação da página por softwares especializados, por isso deve ser utilizada adequadamente, e separada das informações de apresentação.

4. Indicar claramente o idioma utilizado: utilizar marcações que facilitem a pronúncia ou interpretação de abreviaturas ou palavras estrangeiras. Quando as mudanças de linguagem natural no documento são marcadas corretamente, as Tecnologias Assistivas podem, automaticamente, se adaptar a nova língua, tornando o documento mais acessível a usuários que falem mais de uma língua.

5. Criar tabelas passíveis de transformação harmoniosa: tabelas devem ser implementadas para marcar dados tabulares. Sua utilização para fins de layout prejudica a navegação e apresentação das informações contidas nela por meio de Tecnologias Assistivas e determinados agentes de usuário. 
6. Assegurar que páginas que utilizem novas tecnologias tenham transformação harmoniosa: garantir que a utilização de novas tecnologias não afetem a acessibilidade em situações em que essas tecnologias não sejam suportadas ou estejam desligadas.

7. Assegurar o controle ao usuário sobre alterações temporais do conteúdo: assegurar que mídias com alteração de conteúdo ou apresentação durante determinados períodos de tempo possam ser interrompidas. Grupos de usuários podem apresentar dificuldades de interação e visualização de conteúdos em aplicações com movimentação de elementos.

8. Assegurar a acessibilidade direta em interfaces integradas pelo usuário: assegurar que a interface seja funcional e acessível, independentemente dos recursos, componentes (applets e script) que estejam sendo utilizados. Esses componentes, quando utilizados para disponibilização de interações ou informações essenciais a aplicação, podem representar barreiras de acessibilidade em ambientes que não os suportem.

9. Projetar a página considerando a independência de dispositivos: possibilitar a interação com a página com quaisquer dispositivos de entrada (mouse, teclado, reconhecedor de voz, entre outros).

10. Utilizar soluções provisórias: utilizar soluções tecnológicas provisórias de acessibilidade, até que os agentes de usuários sejam capazes de lidar com determinados recursos. Versões antigas de agentes de usuários e Tecnologias Assistivas apresentam o conteúdo de forma diferenciada, ou incompleta de acordo com os tipos de elementos ou recursos utilizados no site. Até que esses recursos sejam incorporados nas tecnologias web, a sua utilização deve ser limitada.

11. Utilizar tecnologias e recomendações W3C: as tecnologias W3C são recomendadas pelos seguintes motivos:

- Tecnologias W3C incluem soluções de acessibilidade integradas

- As especificações W3C passam por diversas revisões para garantir a acessibilidade

- As especificações W3C são desenvolvidas num processo aberto de consenso da indústria

12. Fornecer informações de contexto e orientação: agrupar elementos semelhantes e disponibilizar informações contextuais a respeito de relacionamentos entre elementos, para ajudar usuários a compreender páginas complexas.

13. Fornecer mecanismos claros de navegação: disponibilizar mecanismos de navegação claros e consistentes entre as páginas, como por exemplo: informações de orientação, barra de navegação, mapa do site, entre outros. 
14. Assegurar a clareza e simplicidade dos documentos: simplicidade de linguagem de escrita, layout consistente, figuras compreensíveis e didáticas nos sites beneficiam a todos os usuários, particularmente pessoas com deficiências cognitivas ou que apresentem dificuldade de leitura.

\subsubsection{WCAG 2.0}

A simplicidade do modelo de acessibilidade proposto pela WAI ajudou a aumentar a popularidade do problema de acessibilidade na web. Suas diretrizes são reconhecidas como a principal abordagem na elaboração de recursos web acessíveis (Kelly et al., 2005).

A primeira versão das diretrizes destinada ao conteúdo web, a WCAG 1.0, foi publicada no ano de 1999, quando grande parte das páginas eram implementadas utilizando HTML. Dessa forma, a WCAG 1.0 foi desenvolvida com enfoque nessa tecnologia HTML, em como torná-la acessível (Kelly et al., 2007) (Reid e Snow-Weaver, 2008).

No entanto, os sites, atualmente, utilizam uma maior diversidade de tecnologias na sua construção. A nova geração da web (Web 2.0), juntamente com a implementação de aplicações e serviços web (RIA - Rich Internet Applications, por exemplo) possuem um nível de interação mais dinâmico (Gibson, 2007) e requerem tecnologias como: ECMAScript, XMLHTTPRequest, SVG (Scalable Vector Graphics), SMIL (Synchronized Multimidia Integration Language), Flash, Java Applets, entre outras (Munson e Pimentel, 2008). Tecnologias como essas, mesmo com os esforços, por parte de seus proprietários e desenvolvedores, no seu desenvolvimento com acessibilidade, não são previstas e aceitas pelas diretrizes da WAI (Kelly et al., 2005). As diretrizes WCAG 1.0 não permitem sequer que os desenvolvedores Web utilizem soluções que promovam a acessibilidade, devido a sua natureza restritiva quanto ao uso de tecnologias que não sejam da W3C.

Um outro fator limitante na utilização da WCAG 1.0 diz respeito à subjetividade de determinados checkpoints (Centeno et al., 2005). Essa característica torna difícil uma avaliação total de conformidade com suas diretrizes (Reid e Snow-Weaver, 2008). Fator, inclusive, determinante na decisão dos Estados Unidos de não adotar a WCAG 1.0 como padrão de acessibilidade na web no país (Estados Unidos guiam seu desenvolvimento web de acordo com as diretrizes da Section $\left.508^{8}\right)$.

Nesse contexto, a WAI desenvolveu a WCAG 2.0. A WCAG 2.0 foi desenvolvida com base na WCAG 1.0 e suas diretrizes devem ser aplicáveis ao maior número de tecnologias possível agora e no futuro (tecnologicamente neutra) (Kelly et al., 2007) e ser testáveis, de maneira objetiva, com uma combinação de testes automáticos e avaliações humanas (Reid e Snow-Weaver, 2008) (W3C, 2008b).

As diretrizes WCAG 2.0 não descrevem condições tecnológicas para satisfação dos requisitos de acessibilidade, mas disponibilizam informações a respeito dos métodos conhecidos para o desenvolvimento em conformidade com as diretrizes (Reid e Snow-Weaver, 2008). Esse documento

\footnotetext{
${ }^{8}$ http://www.section508.gov/
} 
é complementado por uma seção não-normativa que descreve detalhes específicos de como as tecnologias devem ser utilizadas (Kelly et al., 2007) (W3C, 2013d). Manter as informações a respeito das técnicas, separadamente do documento da WCAG 2.0, permite alterações e atualizações sem a necessidade de alterar o padrão (sem a necessidade de passar pelo processo de recomendação da W3C) (Reid e Snow-Weaver, 2008).

A WCAG 2.0, assim como sua precursora, define maneiras de como tornar o conteúdo Web mais acessível a pessoas com deficiência (W3C, 2008b). Embora as diretrizes referenciem uma grande quantidade de cenários, elas podem não ser suficientes para garantir o acesso a informação por pessoas com todos os tipos, níveis e combinações de deficiências. Essas diretrizes também ajudam no desenvolvimento de conteúdo mais usável por indivíduos de idade avançada e com melhor usabilidade por usuários em geral.

A WCAG 2.0, diferentemente da WCAG 1.0, divide suas diretrizes em quatro princípios, que servem como características necessárias ao conteúdo Web, para que o mesmo seja apresentado ao usuário (W3C, 2013a):

- Perceptível: os usuários devem ser capazes de perceber a informação sendo apresentada (o conteúdo não pode ser invisível a todos os seus sentidos).

- Operável: os usuários devem ser capazes de operar a interface (a interface não pode exigir interações com as quais um usuário não possa realizar).

- Compreensível: os usuários devem ser capazes de entender a informação e as operações da interface (o conteúdo e as operações não podem ir além do conhecimento do usuário).

- Robusto: os usuários devem ser capazes de acessar o conteúdo conforme a tecnologia avança (mesmo com o avanço tecnológico e dos agentes de usuário, o conteúdo deve permanecer acessível).

Cada diretriz apresenta um determinado número de critérios de sucesso, que descrevem especificamente o que deve ser alcançado para satisfazer o padrão (W3C, 2013a). Todos os critérios de sucesso devem considerar:

- Problemas de acessibilidade que afetam pessoas com deficiência, diferentemente dos problemas de usabilidade que podem ser apresentados a todos os usuários.

- Aspectos testáveis na interface, ou seja, deve ser possível determinar, objetivamente, se a interface satisfaz ou não o critério de sucesso.

As prioridades, presentes na WCAG 1.0, também foram alteradas. Cada critério de sucesso é classificado em níveis de relevância entre A, AA e AAA; o nível A representa os critérios de maior importância. Essa classificação foi determinada por meio da avaliação de acordo com os seguintes fatores (Reid e Snow-Weaver, 2008) (W3C, 2013a): 
- Possibilidade da Tecnologia Assistiva tornar o conteúdo acessível

- Aplicabilidade a todos os sites e tipos de conteúdo

- Facilidade de compreensão por autores de conteúdo

- Limitações na apresentação, funcionalidade, liberdade de expressão e estética

- Existência de outros meios para contornar o problema

Também é apresentada uma grande variedade de técnicas que auxiliam no desenvolvimento em conformidade com os critérios de sucesso e são classificadas como: suficientes para satisfação do critério e complementares.

As diretrizes do conjunto WCAG 2.0 são apresentadas a seguir, agrupadas nos seus respectivos princípios (W3C, 2008b):

\section{Perceptível}

(a) Alternativas textuais: disponibilizar alternativas textuais para conteúdos não textuais.

(b) Mídias temporais: disponibilizar alternativas para mídias temporais.

(c) Adaptabilidade: criar conteúdo que possa ser disponibilizado de diferentes maneiras sem perder a informação ou estrutura.

(d) Distinguíveis: facilitar aos usuários ver e ouvir o conteúdo, apresentando foco ao conteúdo principal sendo disponibilizado.

\section{Operável}

(a) Acessível pelo teclado: tornar todas as funcionalidades acessíveis pelo teclado.

(b) Tempo suficiente: disponibilizar tempo suficiente para leitura e utilização do conteúdo.

(c) Apreensibilidade: não estruturar o site com conteúdos que possam causar apreensão nos usuários, como por exemplo: flash de frequiência superior a três vezes por segundo.

(d) Navegabilidade: disponibilizar meios que auxiliem a navegação do usuário, busca por conteúdos e localização.

\section{Compreensível}

(a) Legível e compreensível: disponibilizar o conteúdo de forma legível e compreensível aos usuários.

(b) Previsibilidade: os sites devem aparecer e operar por meios previsíveis.

(c) Assistência de entrada: auxiliar os usuários a evitar e corrigir erros. 


\section{Robusto}

(a) Compatibilidade: maximizar a compatibilidade com agentes de usuário e tecnologias disponibilizados atualmente ou no futuro.

\subsubsection{WAI-ARIA}

A Web encontra-se em um estado de constante evolução e mudança (Gibson, 2007). Esse fato destaca o padrão de desenvolvimento "beta perpétuo", que é adotado nas aplicações Web 2.0 que encontram-se em estágio beta permanentemente, com atualizações freqüentes em seus serviços e interfaces (Umbach, 2006). Juntamente com esse padrão de projeto, o estabelecimento da Web 2.0 tornou possível que as aplicações web compartilhassem e agregassem dados, e permitissem que os usuários participassem do processo de autoria de conteúdo (Cooper, 2007).

Considerando especificamente a perspectiva dos usuários, as aplicações Web 2.0 passaram a apresentar maior interatividade, permitindo que o usuário influencie a forma na qual o conteúdo lhe é apresentado. O conteúdo é atualizado e muda freqüentemente em diversos tipos de aplicações web, como por exemplo: jogos, rastreadores de voôs, lojas online, entre outros (Cooper, 2007).

Essas características das aplicações Web 2.0 são resultado da implementação de uma série de padrões arquiteturais abertos que compõem o movimento Ajax (Garrett, 2005) e RIA (Velasco et al., 2008). Esses padrões destacam o desenvolvimento de duas propriedades diferenciadas nas aplicações web (Munson e Pimentel, 2008):

- Disponibilização de recursos simplificados de processamento de dados do lado cliente de uma aplicação web, conhecidos como widgets (W3C, 2012a), utilizando linguagens de programação que sejam interpretadas pelos navegadores web, como por exemplo o JavaScript;

- E utilização do objeto XMLHTTPRequest (W3C, 2012b), que define uma API que permite que linguagens de programação do lado cliente de uma aplicação web troquem dados com o servidor de forma assíncrona.

As linguagens de scripting, como o JavaScript, em uma aplicação web permitem que sejam realizadas atualizações de layout, cálculos, adição de lógica, validação de entrada do lado cliente e atualização dinâmica dos dados, por meio do objeto XMLHTTPRequest (Gibson, 2007). Esses recursos permitem que apenas partes de uma página web sejam atualizadas, melhorando a responsividade e experiência do usuário, durante sua interação (Velasco et al., 2008).

A importância, atualmente, atribuída a essas propriedades que compõem o movimento Ajax e RIA, é destacada pela elevada proporção de aplicações web que utilizam a linguagem JavaScript para disponibilizar widgets semelhantes aos componentes de interface utilizados em aplicações desktop como menus, apresentação de estruturas de diretórios em forma de árvore (tree views), campos com formatação rica de textos e painéis com abas (Gibson e Schwerdtfeger, 2005). De 
acordo com o Relatório de Penetração de Tecnologia da agência SecuritySpace, mais de 55\% dos web sites do ano de 2006 continham códigos JavaScript, afetando a interação com o usuário ${ }^{9}$.

No entanto, o aumento de interatividade implementado por aplicações Ajax e RIA apresentam uma série de barreiras de acessibilidade para usuários que interagem com o navegador utilizando produtos de Tecnologias Assistivas (Munson e Pimentel, 2008; Thiessen e Hockema, 2010). As aplicações que compõem a Web 2.0 utilizam linguagens de script e outras tecnologias avançadas para criar aplicações com um visual sofisticado e de alta interatividade. Grande parte dessas características exigem percepção visual dos usuários e requerem interações do mouse para serem operadas (Gibson, 2007). A implementação dessas funcionalidades e componentes de interface de modo ad-hoc e sem qualquer tipo de padronização impactam negativamente a acessibilidade da aplicação (Velasco et al., 2008).

RIA e os componentes de interface Ajax alteram e atualizam dinamicamente a estrutura DOM de uma página web sem a necessidade de gerar uma atualização completa da página (Thiessen e Hockema, 2010). Tradicionalmente, as Tecnologias Assistivas consideram que as informações de uma página web possuem uma estrutura de conteúdo que pode ser linearizada. No entanto, a estrutura de conteúdo de aplicações Ajax e RIA não seguem essa premissa, de modo que novos conteúdos podem aparecer em lugares arbitrários da estrutura DOM. Como por exemplo, um componente de interface de caixa de diálogo, em que o diálogo só é apresentado ao usuário quando o cursor do mouse está posicionado sobre um outro elemento. Para implementar essa funcionalidade, torna-se necessário que, dado que o cursor do mouse seja posicionado sobre um determinado elemento, um novo elemento que representa a caixa de diálogo seja inserido ou modificado (para tornar-se visível) na estrutura DOM. Essa atualização da estrutura DOM, durante a interação com o usuário para apresentar a caixa de diálogo, é ilustrada na Figura 2.3.

Os recursos de RIA e Ajax são implementados utilizando a linguagem declarativa HTML e linguagens de programação de propósito geral, como o JavaScript. Com isso, torna-se inviável o desenvolvimento de um agente de usuário que leia todo o código fonte da aplicação web e seja capaz de descrever o seu comportamento para os usuários, antes que a interação seja realizada. Existem diversas possibilidades de implementação de widgets, e cada uma dessas widgets pode alterar rapidamente a apresentação da página web. Um navegador ou Tecnologia Assistiva que tentasse descrever todos esses eventos sobrecarregaria os usuários com informações irrelevantes (Munson e Pimentel, 2008).

Diante desse contexto, insere-se a especificação ARIA (W3C, 2011) que apresenta um framework para melhorar a acessibilidade e interoperabilidade do conteúdo e de RIA. É importante destacar que, diferentemente da especificação WCAG 2.0 (W3C, 2008b) que promove diretrizes de acessibilidade para o conteúdo web sem considerar o aspecto tecnológico envolvido no seu desenvolvimento, a ARIA apresenta recomendações e especificações de implementação para desenvolvedores de widgets customizadas e outros componentes de aplicações web.

\footnotetext{
${ }^{9} \mathrm{http}: / /$ www.securityspace.com/s_survey/data/man.200607/techpen.html
} 


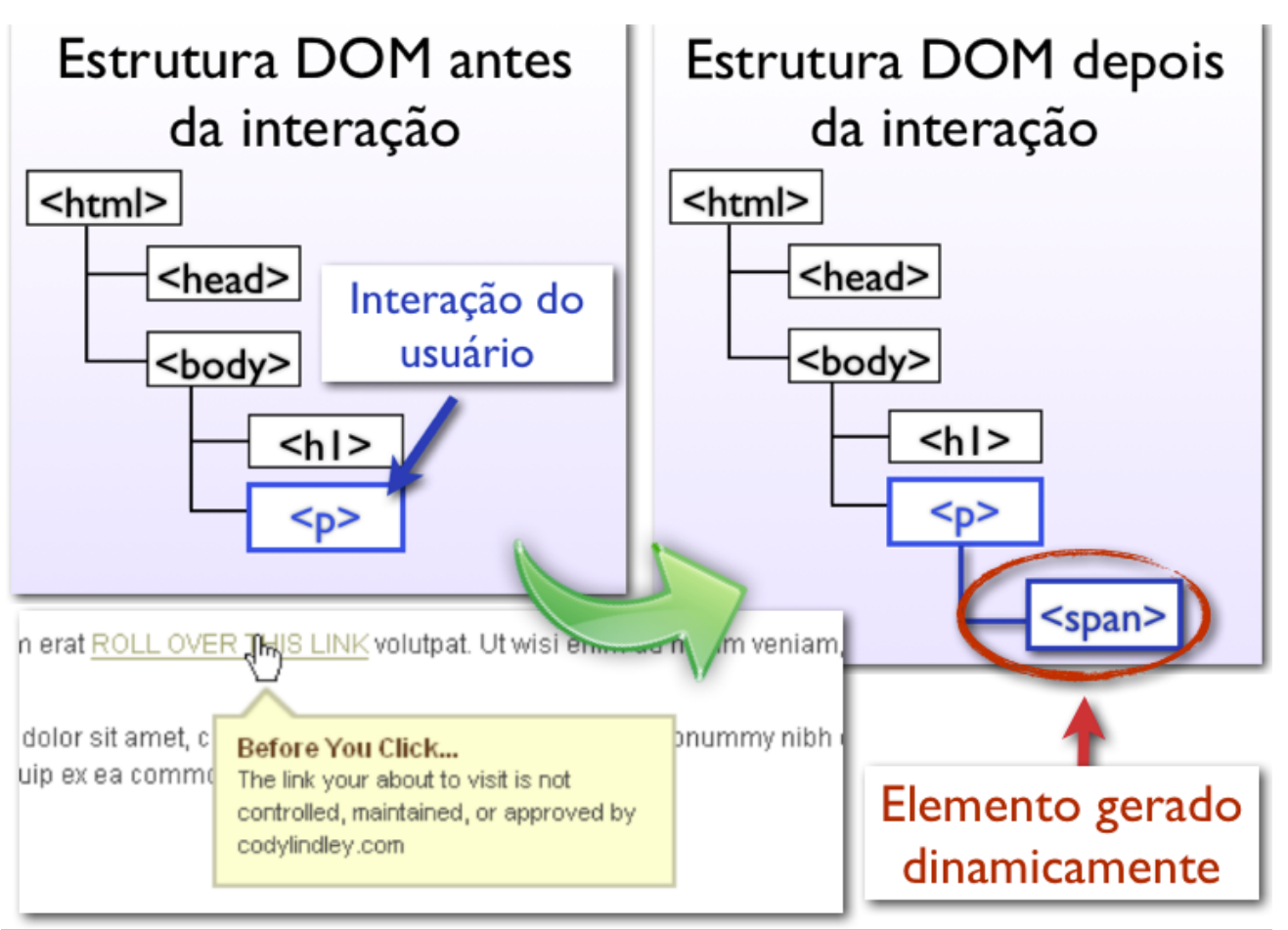

Figura 2.3: Atualização da estrutura DOM de uma widget de caixa de diálogo, durante a interação com o usuário.

Uma vez que os componentes de interface de RIA e aplicações Ajax assemelham-se aos observados em aplicações desktop, as soluções para tornar as aplicações desktop acessíveis podem também ser aplicadas no contexto da Web (Thiessen e Hockema, 2010). As aplicações desktop utilizam-se de um conjunto de componentes de interface pré-estabelecidos (como caixas de diálogo, tree views, painéis de abas) dos quais as Tecnologias Assistivas conhecem o seu comportamento e respondem à interação do usuário de maneira previsível. Assim, as Tecnologias Assistivas são capazes de informar aos usuários sobre quais eventos e modificações realizadas na interface são relevantes e devem ser apresentadas.

Um exemplo desse comportamento pode ser observado em um caso de uso da widget dialog (caixas de diálogo) em uma aplicação desktop sendo utilizada por um usuário com leitor de tela: quando o usuário ativa um determinado botão na interface, é apresentada uma caixa de diálogo sobre o conteúdo que estava sendo apresentado anteriormente. Assim que a caixa de diálogo é apresentada ao usuário, a Tecnologia Assistiva interpreta que o novo conteúdo incluído na tela trata-se de uma widget dialog, e que o foco da interação deve ser direcionado para a caixa de diálogo. Para orientar o usuário sobre a mudança de foco, a Tecnologia Assistiva lê o título do componente de interface e direciona a leitura para o conteúdo apresentado na caixa de diálogo. Na Figura 2.4, é ilustrado como a interação com uma caixa de diálogo e leitura do seu conteúdo textual são realizados por um usuário utilizando um leitor de telas em uma aplicação desktop.

Vale destacar, no entanto, que esse tipo de abordagem não pode ser diretamente utilizado em aplicações web, visto que na Web não existe um conjunto padrão de widgets e os componentes de 


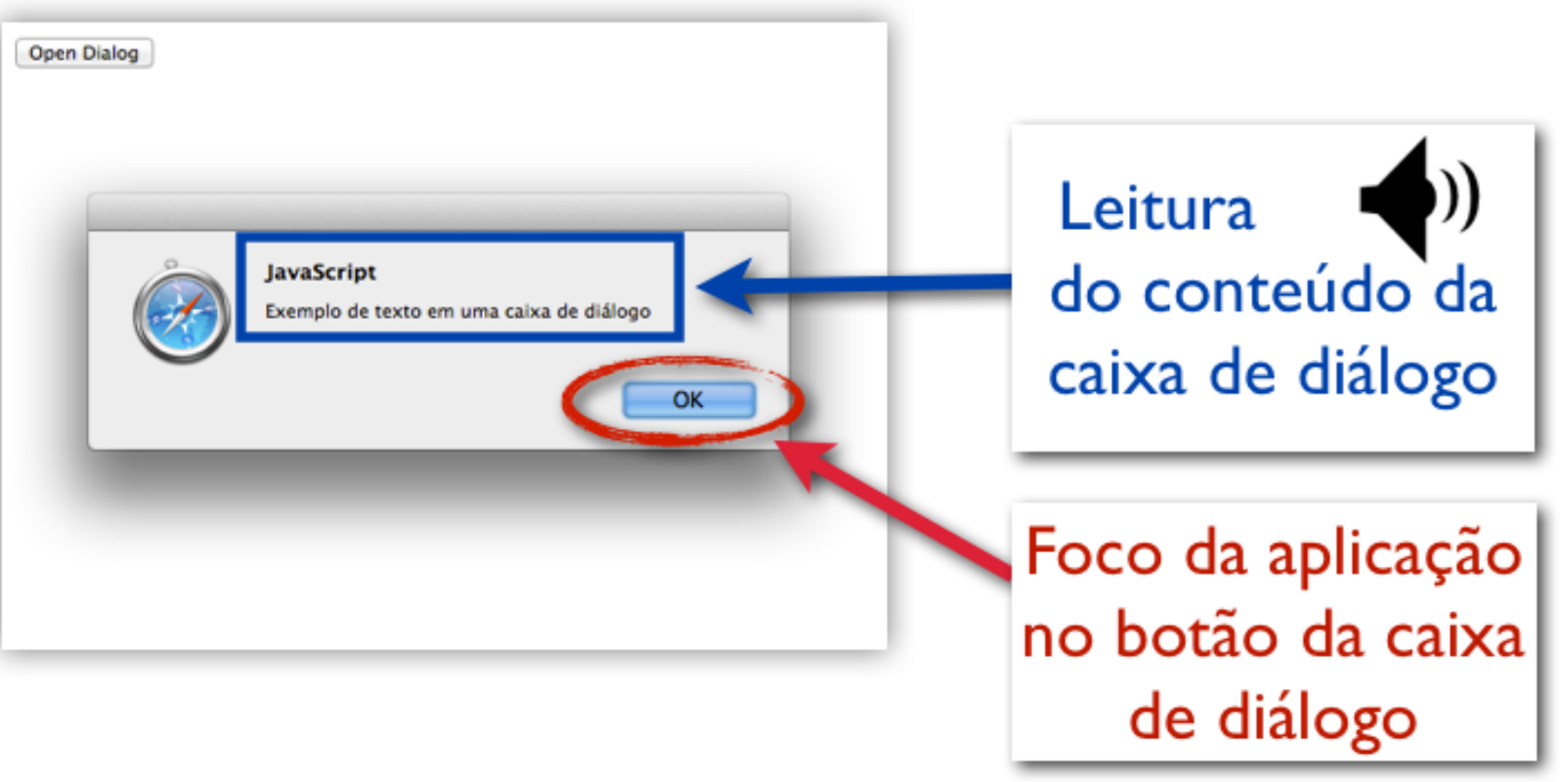

Figura 2.4: Exemplo de interação com uma caixa de diálogo, por um usuário utilizando um leitor de tela em uma aplicação desktop.

interface são muitas vezes implementados utilizando elementos HTML de uso genérico, que não comunicam aos agentes de usuário e Tecnologias Assistivas sobre qual o tipo de widget que eles implementam (Gibson, 2007; Thiessen e Hockema, 2010). Nesse contexto, a especificação ARIA define um conjunto de atributos para serem incluídos nos elementos HTML que implementam widgets. Esses atributos adicionam dados semânticos aos elementos de uso genérico utilizados pelas widgets em aplicações web e disponibilizam informações sobre o comportamento das widgets aos agentes de usuário e Tecnologias Assistivas.

O conjunto de atributos da especificação ARIA que adicionam dados semânticos às widgets sendo implementadas em aplicações web devem ser considerados pelos agentes de usuários e Tecnologias Assistivas para estabelecer um framework de aplicações Ajax e RIA acessíveis a usuários com deficiência. Esse conjunto de atributos compreende as seguintes extensões de tecnologias web que devem ser incorporadas às tecnologias utilizadas, atualmente (W3C, 2010b):

- Atributos States e Property: conjunto de modificações de atributos do (X)HTML necessários para promover a funcionalidade de foco por teclado a todos os elementos dada a atualização ou modificação dos atributos State e Property. Esses atributos devem ser mapeados a APIs de acessibilidade para assegurar interoperabilidade com as Tecnologias Assistivas. Ambos atributos possuem papéis semelhantes, no entanto eles diferem com relação a frequiência de alteração de estados que ambos podem apresentar. Enquanto o atributo State pode ter seu valor alterado freqüentemente durante uma interação com o usuário, o atributo Property apresenta menor probabilidade de ter seu valor alterado na aplicação (W3C, 2011). Como exemplos de atributos State and Property são destacados: 
- aria-expanded (State): indica se um determinado elemento ou grupo de elementos, controlados pelo elemento que contém esse atributo, encontram-se em estado expandido ou não-expandido (sendo apresentados ou não).

- aria-haspopup (Property): indica se um elemento possui uma componente de interface рорир como menu contextual ou um outro nível de menu disponível para interação.

- Atributo Role: permite que o desenvolvedor anote um determinado elemento HTML com informações semânticas sobre o seu comportamento como um componente de interface. Essas informações semânticas podem ser extraídas por agentes de usuários e Tecnologias Assistivas para permitir uma interação acessível por usuários com deficiência. Os atributos Role são divididos em quatro grupos: (1.) roles abstratas, que compõem uma estrutura hierárquica de roles e são estendidas por outras; (2.) roles de widgets que representam componentes de interface e têm seu comportamento mapeado pelos agentes de usuário e Tecnologias Assistivas; (3.) roles de estrutura de documento que organizam o conteúdo de uma página web; e (4.) Landmark roles que representam regiões recorrentes e de funcionalidade reconhecida pelos usuários em uma página web. Como exemplos de atributos role são destacados:

- dialog (widget): descreve um componente de interface que apresenta uma janela sobreposta aos outros componentes e tem como função interromper a atividade atual do usuário na aplicação para exigir a entrada de informações ou exigir uma ação do usuário.

- region (estrutura de documento): define uma seção da página web ou documento, que o desenvolver determina como sendo importante para inclusão em um sumário da aplicação web.

- Valores de Landmark: também correspondem a atributos do tipo role, no entanto descrevem elementos pertinentes à navegação do usuário na página web. Os agentes de usuário podem utilizar esses atributos para definir uma estrutura de navegação. Como exemplos desses atributos são destacados:

- banner: identifica uma região do documento que contém informações relacionadas à logos de empresas associadas ao web site e patrocinadores.

- navigation: estabelece que o elemento contém uma coleção de links de navegação do documento ou documentos relacionados.

- Taxonomia de atributos Roles: define uma estrutura hierárquica entre os atributos role juntamente com os atributos state e property que devem ser incluídos por eles.

Sobretudo, é importante observar que a especificação ARIA apresenta a funcionalidade de gerência de foco de uma aplicação web como um requisito mandatório (Gibson e Schwerdtfeger, 
2005; W3C, 2011). Para garantir que os usuários possam realizar entradas de dados e interagir com os componentes de interface independentemente de quais Tecnologias Assistivas possam estar sendo utilizadas torna-se necessário que todos os objetos interativos da página possam adquirir foco. A especificação determina que desenvolvedores devem implementar um mecanismo intuitivo, seja por meio de navegação utilizando a tecla TAB do teclado ou outras técnicas de navegação padrão, para que os usuários descubram quais elementos de uma página web são interativos (W3C, 2011) . Dada a utilização de linguagens de script para implementação das widgets, os desenvolvedores devem manipular a ordem de navegação da interface pelo teclado para garantir as funcionalidades disponibilizadas.

Desse modo, para implementar um componente Ajax ou RIA, o desenvolvedor deve definir qual o comportamento desse componente, dadas as múltiplas possibilidades de interação do usuário com o mesmo. Em seguida, o desenvolvedor deve associar esse componente de interface com um atributo role que mapeie uma funcionalidade semelhante, e atribuir os respectivos atributos state e property que são requisito desse role, utilizando a linguagem de script apropriada. Essa widget deve ter um esquema definido de navegação por teclado (por meio da gerência de foco na aplicação web) e por fim deve ser incluída na estrutura geral da página web, considerando a região onde ela será incluída e apresentada em meio às outras widgets (W3C, 2011).

Pode-se observar que esse processo de desenvolvimento de componentes (widgets) em RIA é bastante especializado e possibilita uma grande variedade de recursos a serem explorados nas várias formas de interação da Web 2.0. ARIA proporciona essas orientações gerais, mas ficam desprovidas de formas para se garantir o cumprimento de suas especificações de implementação tecnológicas. Essa foi a principal lacuna investigada nesta tese; prover estratégias automáticas de avaliação de acessibilidade em RIA, dando suporte à ARIA.

\subsection{Considerações finais}

Neste capítulo foram descritos os principais conceitos da área de acessibilidade na web. Foi descrito o modelo da WAI como uma das principais referências da área, considerando a divisão dos requisitos de acessibilidade entre o conteúdo web (WCAG), agentes de usuários (UAAG) e ferramentas de autoria (ATAG). Esse modelo especifica os requisitos de acessibilidade com um conjunto de diretrizes que apresentam soluções de design para problemas de acessibilidade que afetam usuários com deficiência.

Foi também descrita a especificação ARIA, como uma especificação tecnológica para estabelecer a acessibilidade em aplicações Web 2.0, que utilizam componentes de interface sofisticados com a finalidade de melhorar a experiência do usuário. A especificação ARIA considera a inclusão de atributos semânticos para notificar as Tecnologias Assistivas sobre o seu comportamento, e informar o usuário sobre possíveis mudanças e atualizações de conteúdo que podem ocorrer na página web. 
A partir do estudo sobre ARIA, foi observado o seu caráter prescritivo das recomendações. Ou seja, a especificação fornece apenas orientações gerais sobre as tecnologias necessárias para o desenvolvimento de interações acessíveis em RIA. No entanto, não são abordadas formas de garantir que essas recomendações sejam verificadas e efetivamente desenvolvidas. Assim, o tema de avaliação de acessibilidade precisa ser estudado. No próximo capítulo, serão apresentadas as noções principais relacionadas à avaliação de acessibilidade na web. 


\section{Avaliação de Acessibilidade} este capítulo, é apresentado o tema de avaliação de acessibilidade, a partir de estudos da bibliografia relacionada, so a perspectiva de ter uma visão sobre o estado da arte na qual a questão de pesquisa desta ese se insere. São descritos os métodos de avaliação de acessibilidade mais utilizados na literatura e trabalhos mais especializados, relativos ao tema desta tese, os métodos de avaliação automática de acessibilidade em RIA.

Este capítulo está estruturado da seguinte forma: na próxima seção (Seção 3.1), é apresentado o contexto geral da Engenharia Web, apresentando como a avaliação de acessibilidade deve ser empregada no processo de desenvolvimento; na Seção 3.2, são apresentadas as principais abordagens de avaliação de acessibilidade disponíveis na literatura; na Seção 3.3, são descritos trabalhos que utilizam uma abordagem com base em métricas para monitorar a evolução de acessibilidade em aplicações web; na Seção 3.4, são descritos métodos de avaliação automática de acessibilidade de RIA; e por fim, na Seção 3.5, são apresentadas as considerações finais deste capítulo.

\subsection{Engenharia Web}

Nesta seção, são apresentados os principais estudos realizados com o objetivo de identificar os conceitos fundamentais relacionados ao tópico de pesquisa desta tese: o contexto de Engenharia Web que é adotado no desenvolvimento de RIA. Dessa forma, esta seção apresenta um recorte do tema geral de Engenharia Web, descrevendo os impactos da Web 2.0, bem como as práticas de desenvolvimento adotadas.

O desenvolvimento de aplicações web tem aumentado exponencialmente na última década (Molina e Toval, 2009). Uma vez que o tamanho e a complexidade desses sistemas são tipica- 
mente elevados (Navarro et al., 2008; Acerbis et al., 2008), observa-se a necessidade de elaboração de processos e métodos de desenvolvimento que incorporem requisitos não-funcionais como desempenho, segurança, escalabilidade, disponibilidade, manutenibilidade, usabilidade e qualidade visual em uma arquitetura de software para esse tipo de aplicações.

Nesse contexto, a disciplina de Engenharia Web visa promover o estabelecimento e uso de metodologias científicas, princípios de engenharia e gerência de projetos, e abordagens disciplinadas e sistemáticas para o desenvolvimento, disponibilização e manutenção de sistemas web (Ginige e Murugesan, 2001).

$\mathrm{Na}$ Web, as informações gerenciadas por aplicações são alteradas muito rapidamente, armazenadas em diferentes localidades e assumem formatos estruturados e não-estruturados. Essas características demandam o uso de uma arquitetura bem definida, fundada em tecnologias bem estabelecidas para o gerenciamento dos dados. Além disso, as aplicações web devem ser projetadas para ser adaptáveis e flexíveis, considerando não apenas o seu conteúdo, mas os seus requisitos e projeto arquitetural. Dessa forma, o processo de Engenharia Web deve ser beneficiado pelas técnicas de Engenharia de Software, junto com a automatização das tarefas repetitivas, para garantir flexibilidade no sistema sendo desenvolvido (Fraternali e Paolini, 2000).

Pressman e Lowe definiram um conjunto de atividades como um framework genérico que se aplica à maioria dos projetos de aplicações web (Pressman e Lowe, 2009):

Comunicação : atividade de interação e colaboração intensa com os envolvidos do projeto, com o objetivo de realizar o levantamento de requisitos.

Planejamento : definição de um plano incremental de entrega de funcionalidades na aplicação web.

Modelagem : elaboração de modelos que auxiliam a comunicação entre o desenvolvedor e o cliente.

Construção : codificação das soluções tecnológicas da aplicação web sendo desenvolvida, juntamente com os testes.

Implantação : entrega incremental e avaliação de cada melhoria da aplicação web ao cliente.

Aplicações web apresentam características específicas que devem ser consideradas durante o processo de desenvolvimento de software. Algumas dessas características denotam vantagens para o sistema sendo desenvolvido, como por exemplo: uso de um cliente padrão (browser), atualizações centralizadas no servidor e melhor portabilidade da aplicação. No entanto, também são destacadas desvantagens que impactam no aumento do custo e complexidade do projeto, como (Gitzel et al., 2007):

- Não homogeneidade de ambientes cliente; 
- Testes de software são mais difíceis de serem aplicados;

- Dificuldade na determinação de variáveis de desempenho associadas à natureza distribuída de processamento de uma aplicação web;

- Questões de usabilidade e acessibilidade das aplicações tornam-se ainda mais relevantes, dada a ampla variabilidade dos usuários de aplicações web.

Pressman e Lowe também destacam atributos distintos de aplicações web, quando comparadas a softwares convencionais (como aplicações desktop) (Pressman e Lowe, 2009): uso intensivo de rede, acessos simultâneos, carga imprevisível, disponibilidade, orientada a dados, sensível ao conteúdo, evolução contínua, urgência, segurança e estética.

Essas vantagens e desvantagens relacionadas à plataforma tecnológica que compõe a Web, levam ao estabelecimento de práticas de desenvolvimento distintas das aplicações desktop.

\subsubsection{Impactos da Web 2.0 na Engenharia Web}

Com o estabelecimento da Web 2.0, novos padrões e características passaram a ser apresentados como requisitos para as aplicações web sendo desenvolvidas. Considerando o ponto de vista dos usuários, foram oferecidos novos meio de acesso e compartilhamento de informações, com o aumento da responsividade e melhores abordagens para lidar com a latência de rede, proporcionados pelo uso de tecnologias relacionados ao Ajax e RIA (Wang e Zahadat, 2009). No entanto, considerando o ponto de vista tecnológico, a implementação de Ajax implica no aumento da complexidade da aplicação de acordo com a sua arquitetura (Linaje et al., 2009), e dificuldades associadas ao JavaScript, como uma linguagem de programação propensa a erros pelo fato de ser dinamicamente tipada, com uma abordagem diferenciada de Orientação a Objetos, maior variedade de recursos não homogêneos entre os navegadores e falta de ferramentas que suportem o seu desenvolvimento (Gitzel et al., 2007).

Para atenuar dificuldades associadas às desvantagens do desenvolvimento de aplicações web, é proposto o uso de linguagens de projeto de aplicações web (Gitzel et al., 2007). Essas linguagens promovem o uso de modelos de alto nível de abstração para encapsular os problemas técnicos no desenvolvimento de aplicações web e facilitam a implementação efetiva do sistema.

A modelagem é uma atividade comum em diferentes áreas da engenharia e é considerada essencial para a compreensão da complexidade gerada em sistemas reais. Assim, os modelos são utilizados para: avaliar atributos de qualidade do sistema, identificar implicações de alterações no projeto do sistema, e comunicar características do sistema para as diferentes pessoas envolvidas no processo (Beydeda e Gruhn, 2005).

$\mathrm{Na}$ literatura, atualmente, são propostas diferentes instâncias do framework genérico proposto por Pressman e Lowe (Pressman e Lowe, 2009) com foco no uso de linguagens de projeto de 
aplicações web (Watanabe et al., 2010c), como: WebML (Ceri et al., 2000), OOHDM - ObjectOriented Hypermedia (Schwabe et al., 1999) e OOWS - Object-Oriented Web Solutions (Fons et al., 2003). Essas linguagens compartilham modelos semelhantes que abordam aspectos da aplicação web relacionados à estrutura do conteúdo, lógica de negócios, navegação entre outras questões do desenvolvimento. O uso dessas linguagens também é, freqüentemente, associado à aplicação de abordagens de desenvolvimento orientado a modelos (Fraternali et al., 2010).

É importante destacar que, embora o uso de abordagens de desenvolvimento orientado a modelos, com linguagens de projeto de aplicações web, seja uma prática bem estabelecido para a comunidade científica, poucas aplicações práticas podem ser obtidas na literatura (Escalona et al., 2009).

Costabile e Matera (Costabile e Matera, 2001) descrevem que os desenvolvedores não utilizam essas abordagens devido ao custo de se aprender uma nova linguagem. Gitzel et al. (Gitzel et al., 2007) relatam que os desenvolvedores podem não utilizar essas abordagens devido à falta de aderência das mesmas com padrões estabelecidos para o desenvolvimento web.

Quando considerando o desenvolvimento de aplicações RIA, métodos para modelagem de layout de apresentação e estrutura de navegação não podem ser diretamente aplicados para o desenvolvimento de interfaces ricas (Preciado et al., 2005). Portanto, torna-se necessário adaptar as abordagens de desenvolvimento web para considerar as novas capacidades do cliente, diferentes fluxos de comunicação cliente-servidor e novas características de apresentação das aplicações RIA (Linaje et al., 2009).

A Web 2.0 também introduziu características que impactam na forma como as aplicações deveriam ser implementadas e entregues (released) (Wang e Zahadat, 2009). As aplicações deixaram de ser um meio de acesso a informações e passaram a ser utilizadas como uma plataforma que agrega informações de múltiplas fontes e dispositivos, permite que indivíduos contribuam com suas idéias e conteúdo, e que disponibiliza o software na forma de um serviço atualizado continuamente. Uma conseqüência da Web ser utilizada como uma plataforma é que as aplicações e serviços permanecem em um estágio de "beta perpétuo", no qual seus recursos e características são constantemente refinados e melhorados (Umbach, 2006).

O baixo custo associado à disponibilização de novos requisitos e funcionalidades (dada a característica de atualizações serem realizadas em um servidor único, sem a necessidade de instalação nos múltiplos clientes (Munson e Pimentel, 2008)), torna possível a liberação contínua de novas e melhoradas versões de serviços aos usuários. Os usuários podem responder às alterações e oferecer sugestões, criando um ciclo de feedback e desenvolvimento (Matheson, 2006). Assim, todas as alterações realizadas no servidor são instantaneamente disponibilizadas a todos os usuários e os componentes do software podem ser revisados iterativa e continuamente.

Nesse contexto, um novo tipo de ciclo de desenvolvimento de software foi estabelecido (Wang e Zahadat, 2009) e deve ser considerado nos processos de desenvolvimento de aplicações web. A Figura 3.1 ilustra o processo de desenvolvimento de aplicações Web 2.0. Nessa figura o ciclo 
de desenvolvimento no qual os desenvolvedores atualizam e recebem os novos requisitos não é interrompido pelo uso da aplicação, e os usuários pemanecem continuamente obtendo em seus browsers as novas versões das aplicações disponibilizadas pelos desenvolvedores, e gerando novas demandas para que o processo de evolução no desenvolvimento continue, sem interrupção.

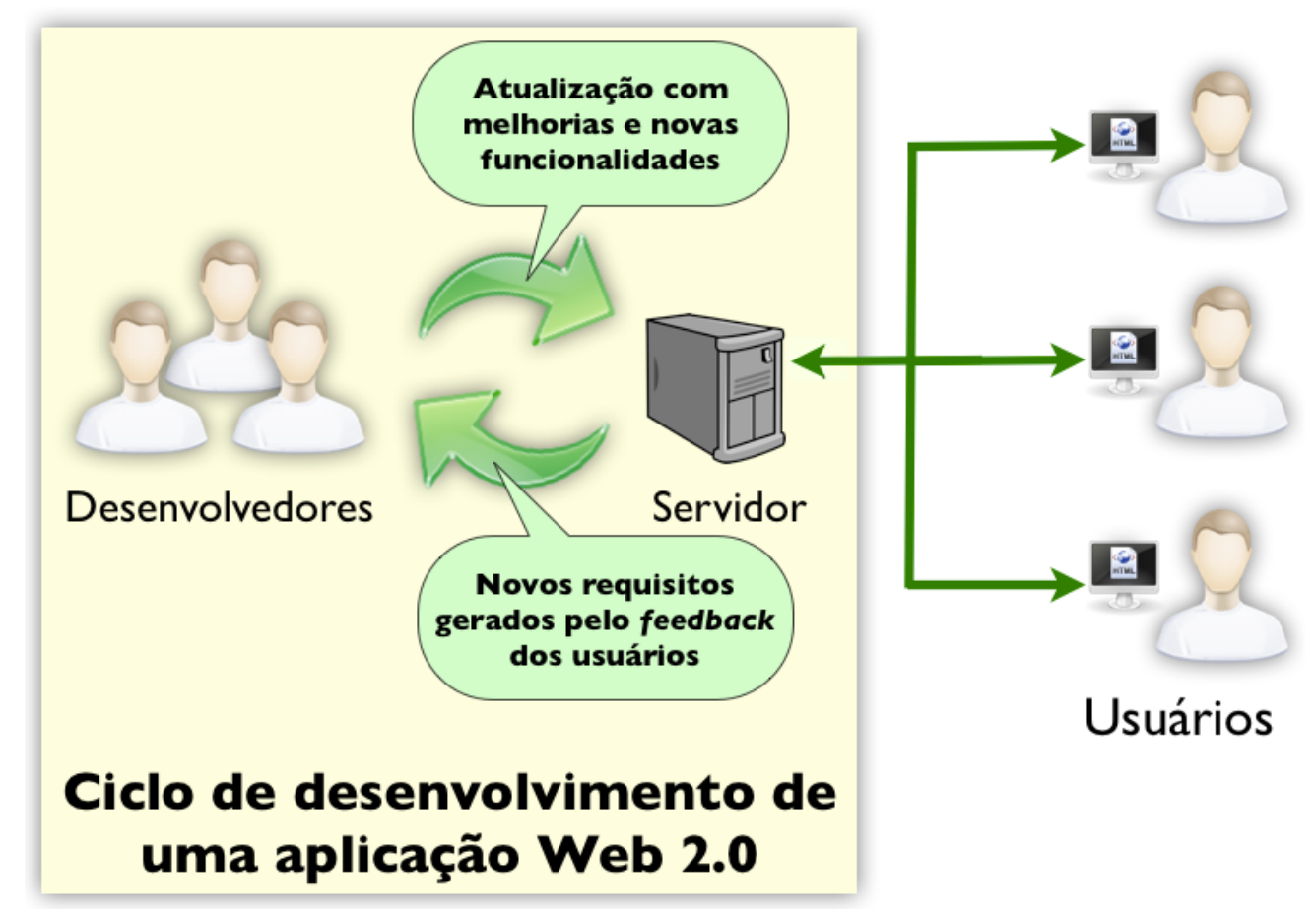

Figura 3.1: Ciclo de desenvolvimento de uma aplicação Web 2.0, considerando o padrão de projeto de aplicações "beta perpétuas".

Empresas que trabalham com esse tipo de ciclo de desenvolvimento, com entregas constantes de novas funcionalidades, reportam que uma iteração desse ciclo pode levar menos que uma hora, conforme reportado na implementação da aplicação Flickr (Matheson, 2006). Assim, torna-se necessária a utilização de um método de desenvolvimento que suporte um ciclo de desenvolvimento iterativo e de rápidas mudanças de requisitos (considerando que uma iteração de feedback dos usuários e melhoria do software pode levar menos de uma hora). Para lidar com esse tipo de cenário, é destacado o uso de métodos ágeis de desenvolvimento, que se mostraram eficientes ao trabalhar com projetos pequenos com poucos riscos, com equipes formadas por desenvolvedores experientes e com rápida resposta à mudança de requisitos (Boehm, 2006). O desenvolvimento de serviços utilizando métodos ágeis contribui para a rápida e contínua entrega e disponibilização de novas funcionalidades aos usuários (Matheson, 2006).

Especificamente, considerando as compatibilidades de características entre o processo de Engenharia Web e utilização de métodos Ágeis de desenvolvimento de software, destacam-se (McDonald, 2004):

- Ciclos curtos de desenvolvimento.

- Entrega de soluções customizadas e diferentes modelos de regras de negócio. 
- Equipes de desenvolvimento multidisciplinares.

- Equipes pequenas de desenvolvimento.

- Análise das regras de negócio e avaliação com usuários finais.

- Captura de requisitos e atividades de teste rigorosas.

- Manutenção (evolução contínua) das aplicações web.

$\mathrm{Na}$ próxima seção, serão descritas as compatibilidades entre as características do processo de Engenharia Web e a utilização do método ágil de Programação Extrema.

\subsubsection{Práticas de Programação Extrema na Engenharia Web}

O método de Programação Extrema (XP - eXtreme Programming) é provavelmente o método ágil mais conhecido na atualidade (Sommerville, 2007; McDonald, 2004; Pressman, 2010). No $\mathrm{XP}$, os requisitos do sistema são expressos como cenários (histórias do usuário) e os programadores devem trabalhar em pares e desenvolvem testes para cada atividade sendo implementada (Beck e Andres, 2004). As histórias são desenvolvidas incrementalmente em entregas freqüentes de melhorias do sistema. O XP, como um método ágil de desenvolvimento, apresenta evidente compatibilidade com o processo de Engenharia Web, considerando principalmente a característica de entregas constantes de novas funcionalidades (McDonald, 2004).

Entre o período dos anos 1980 e 2000, foi observada uma aceleração no ritmo de mudanças nas tecnologias de informação (Boehm, 2006). Essas mudanças afetam o processo de Engenharia de Software, de forma que muitas vezes torna-se praticamente impossível derivar um conjunto completo de requisitos de software estáveis, dependendo do domínio de uma aplicação. As regras de negócio que guiam uma empresa podem operar em um ambiente global sujeito a rápidas mudanças e os sistemas de informação devem acompanhar o ritmo dessas mudanças para aproveitar as novas oportunidades e responder às pressões competitivas (Sommerville, 2007).

O intenso ritmo de mudanças, observado nesse cenário de desenvolvimento, denota incompatibilidades com processos de desenvolvimento com ênfase na clara separação entre as etapas de planejamento, especificação e outras documentações adotadas nos processos de desenvolvimento tradicional, ou os que se baseiam em especificações bem definidas logo no início do processo (Sommerville, 2007; Boehm, 2006).

O domínio das aplicações web apresenta essa característica de elevado ritmo de mudanças, durante o processo de desenvolvimento, de forma que a rigidez do modelo cascata tradicional dificulta a condução de projetos nesse domínio (Altarawneh e Shiekh, 2008; Ge et al., 2006). No contexto de desenvolvimento de aplicações Web, empresas reportam que seus ciclos de desenvolvimento na média levam menos de três meses (McDonald, 2004). 
Para implementar soluções no desenvolvimento de sistemas nesses cenários de desenvolvimento, ao final da década de 1990, o Manifesto Ágil (Beck et al., 2001) propôs o uso de métodos que permitam que os desenvolvedores se concentrassem no software somente, em vez de em seu projeto e documentação (Sommerville, 2007). Esses métodos (métodos ágeis de desenvolvimento) incluem um conjunto principal de características: aceitar que os requisitos podem ser alterados durante o desenvolvimento, desenvolvimento incremental dos requisitos durante o ciclo de vida do projeto e ênfase em pessoas e suas interações em contraste à conformidade com um conjunto específico de objetivos de um processo (Ge et al., 2006).

Dentre os métodos ágeis de desenvolvimento destaca-se o XP, com a utilização de práticas relacionadas a elaboração de testes antes da codificação das funcionalidades (Test-Driven Development) e apresentação dos resultados de testes automáticos aos desenvolvedores (Integração Contínua) (Pressman, 2010). Essas práticas são utilizadas com o objetivo de garantir a qualidade de entrega do sistema apesar da alta taxa de alteração dos requisitos e do código do sistema, além de contribuir para a refatoração da aplicação web, durante a sua evolução (Sommerville, 2007).

O desenvolvimento iterativo de sistemas leva à degradação do software se mudanças são continuamente acomodadas no desenvolvimento de uma aplicação (Mahemoff e Johnston, 1999). No XP, as práticas de Test-Driven Development e Integração Contínua devem assistir a atividades de refatoração da aplicação web (para evitar a degradação do sistema), contribuindo para que as alterações de código sejam realizadas sem impactar as funcionalidades já implementadas.

Para apoiar essa atividade de refatoração do código, é necessário que os requisitos de software que precisam ser entregues aos usuários sejam automaticamente verificados, quando possível. A seguir, é descrito o desenvolvimento orientado a testes que compõe uma das práticas do XP relacionada à elaboração de testes de software para avaliar e verificar os requisitos da aplicação sendo desenvolvida.

\section{TDD - Test-Driven Development}

O aumento de utilização de métodos ágeis e práticas de Programação Extrema (eXtreme Programming) também levaram ao aumento da popularidade de práticas de Desenvolvimento Orientado a Testes (Beck, 2003) (TDD - Test-Driven Development) e Integração Contínua (Fowler e Foemmel, 2005; Cannizzo et al., 2008). Essas práticas têm sido utilizadas para implementar e disponibilizar funcionalidades desde as primeiras etapas do processo de desenvolvimento.

Beck resume o TDD como uma prática de desenvolvimento iterativo constituído pela execução dos seguintes passos (Beck, 2003):

1. Escreva um novo caso de teste.

2. Execute todos os casos de teste e verifique que o novo caso de teste inserido falhe.

3. Codifique apenas o suficiente para que o novo caso de teste passe. 
4. Execute novamente todos os casos de teste e verifique que todos passam.

5. Refatore o código para remover duplicações.

Com a crescente complexidade dos sistemas, torna-se cada vez mais difícil garantir a corretude de um sistema (Adams, 2009). Para lidar com o desafio de garantir a corretude desses sistemas, a comunidade de desenvolvimento ágil tem recorrido à utilização de práticas de TDD (Beck, 2003). As práticas associadas ao TDD guiam o desenvolvedor a elaborar primeiramente um teste automático, executar esse teste (para verificar a sua falha) e depois codificar a solução que implementa a funcionalidade verificada no teste. Uma vez que o teste é a atividade primária dessa prática, o TDD apresenta um grande potencial para melhorar a confiabilidade durante o desenvolvimento de sistemas complexos (Adams, 2009).

Como benefícios associados à utilização de práticas de TDD destacam-se (Williams et al., 2003; Erdogmus et al., 2005):

Eficiência e feedback : a baixa granularidade do ciclo de elaboração de testes e codificação de soluções possibilita a apresentação de feedback contínuo dos resultados de alterações no código fonte aos desenvolvedores.

Documentação de design em baixo nível : os testes servem como especificação das decisões de design realizadas em termos das classes, métodos e interfaces construídas.

Redução de injeção de defeitos : os testes elaborados constituem um conjunto de testes de regressão que são continuamente executados, possivelmente revelando defeitos inseridos no código durante o desenvolvimento.

Aumento do conjunto de testes : os desenvolvedores são incentivados a escrever testes que podem ser executados automaticamente e os agregam ao conjunto de testes de regressão do sistema.

É importante destacar que o TDD é considerado mais uma prática de desenvolvimento de código do que de teste de código. No TDD, os testes automáticos são utilizados com o objetivo de determinar as estratégias de design e os algoritmos que serão adotados na implementação da solução do sistema. Assim, essa estratégia de desenvolvimento considera a elaboração de testes, juntamente com a elaboração do código, fato que apresenta diferenças significativas diante de outras abordagens de elaboração de testes, depois da etapa de codificação (Canfora et al., 2006).

Uma vez que, no TDD, os testes são elaborados juntamente com o código dentro de um processo iterativo, o processo da Engenharia Web é beneficiado com as vantagens de redução de injeção de defeitos e aumento do conjunto de testes, que possibilitam a entrega contínua de novas funcionalidades nas aplicações Web 2.0.

Existem diversas extensões de TDD sendo utilizadas no desenvolvimento de software (Hammond e Umphress, 2012). Essas extensões utilizam-se dos mesmos princípios de elaboração dos 
testes antes da implementação, mas apresentam características distintas relacionadas às estratégias de teste e codificação do software. A seguir, são descritas essas extensões:

Desenvolvimento Orientado a Especificação Ágil : considera a especificação dos testes, anteriormente à codificação da solução, como forma de auxiliar o desenvolvedor na formalização de uma especificação de contrato, facilitando a documentação das pré e pós condições de execução de métodos e invariantes de uma classe (Ostroff et al., 2004). Essa abordagem combina o TDD com o DbC - Design by Contract, que utiliza uma linguagem para especificar as pré e pós condições de execução de um método de uma classe (Hammond e Umphress, 2012).

Desenvolvimento Orientado a Comportamento : o BDD - Behavior-Driven Development (Desenvolvimento Orientado a Comportamento) destaca as características do TDD como uma abordagem de projeto e construção de software, em contraste com a visão de TDD como uma abordagem de teste de software, somente (Hammond e Umphress, 2012). Essa extensão de TDD considera que os testes devem descrever o comportamento da aplicação, utilizando termos do domínio de negócios do projeto. Assim, os testes, escritos em linguagem natural tanto quanto possível, servem como documentação sobre as regras de negócio que pode ser compreendida pelos usuários, analistas e indivíduos da área de testes (North, 2006).

Desenvolvimento Orientado a AT : no TDD, freqüentemente são elaborados testes utilizando estratégias de verificação no nível dos componentes da aplicação, com testes unitários por exemplo. No entanto, essa estratégia de testes, realizada nas camadas de menor abstração, mais próximas da implementação, não reflete os requisitos do sistema (Hammond e Umphress, 2012). Nesse contexto, o ATDD - Acceptance Test-Driven Development trata-se de uma técnica que emprega o uso de AT (que atuam no nível mais alta de abstração, validando os requisitos estabelecidos pelo cliente) como estratégia de teste no TDD (Grätner e Grätner, 2012).

Growing Objects, Using Tests : Freeman e Pryce apresentam uma abordagem híbrida que considera a utilização de AT para validar os requisitos do usuário, juntamente com outras estratégias de teste no TDD (Freeman e Pryce, 2009). Essa abordagem acrescenta uma etapa no ciclo de desenvolvimento do TDD que considera a elaboração de um AT que valida um requisito funcional do sistema. Em seguida, os desenvolvedores podem utilizar outras abordagens de teste (como testes unitários e de integração), de acordo com o ciclo de codificação da solução no TDD. Ao final dos ciclos de elaboração de testes e codificação, se a solução implementada condiz com os requisitos funcionais do sistema, o AT implementado anteriormente apresentará um resultado positivo. Se a solução implementada não atender os requisitos funcionais do sistema, o AT apresentará um resultado negativo, denotando que a solução não implementa corretamente o requisito do sistema. 
Nesta tese, no Capítulo 4, foi estendida uma ferramenta de AT que tem como base o BDD, a ser utilizada no ciclo de desenvolvimento de uma aplicação web. A ferramenta foi estendida com a finalidade de acrescentar funcionalidades que permitam a elaboração de casos de AT que descrevem o comportamento do sistema (no caso, uma aplicação RIA), quando utilizado por um usuário que apresente deficiência visual. Assim, torna-se possível incluir requisitos de acessibilidade na forma de testes dentro de um processo que utilize a abordagem BDD.

\section{Integração Contínua}

As vantagens associadas a processos que utilizem práticas de Integração Contínua correspondem aos requisitos de aplicações Web 2.0, de acordo com o padrão de projeto de "beta perpétuo", em que as aplicações web devem acomodar ciclos iterativos contínuos de atualizações e re-design, permanecendo disponíveis aos usuários durante $100 \%$ do tempo.

A Integração Contínua é definida como uma prática de desenvolvimento de software em que os membros da equipe integram suas implementações freqüentemente, levando a múltiplas integrações por dia (Fowler e Foemmel, 2005). Cada integração é verificada pela execução automática de rotinas de compilação e testes que verificam erros de integração o mais rápido possível (Pereira Moreira et al., 2010).

Tipicamente, um framework de Integração Contínua utiliza-se de um sistema de detecção automática de mudanças no repositório de código fonte. Quando são identificadas mudanças no código fonte, é realizada uma cadeia de rotinas automáticas que verificam a estabilidade do sistema, dadas as modificações realizadas. Essas rotinas automáticas podem consistir de rotinas de compilação ou validação de código para linguagens interpretadas, testes de unidade, integração e aceitação. Cada rotina só é executada se não forem reportadas falhas nas rotinas anteriores (Stolberg, 2009). A execução dessa cadeia de rotinas automáticas contribui para melhorar a qualidade do software e produtividade dos desenvolvedores dada a execução proativa de atividades de compilação, validação e testes do código fonte, e rápida detecção de falhas inseridas no sistema (Kim et al., 2008).

Considerando especificamente o contexto de desenvolvimento de aplicações Web 2.0, a prática de execução de testes automáticos do software continuamente permite que sejam mantidos altos padrões de qualidade da aplicação durante a sua constante evolução e re-design, mesmo que esses ciclos iterativos sejam realizados em curtos períodos de tempo. A Figura 3.2 ilustra um exemplo de processo de desenvolvimento de uma aplicação web, utilizando práticas de Integração Contínua. Nesse processo, novos requisitos são identificados e implementados pelos desenvolvedores. A cada modificação no repositório de código fonte de um sistema web, são executados testes automáticos, para avaliar se nenhuma falha foi inserida na aplicação. Se a execução dos testes automáticos identifica alguma falha na aplicação, os desenvolvedores são notificados e instruídos a corrigir a falha inserida durante a integração dos novos requisitos. Com isso, estabelece-se um ciclo de identificação de falhas e correção até que nenhuma falha seja reportada pelos testes automáticos. 
Uma vez que nenhuma falha seja reportada, a aplicação web é classificada como estável e pode ser entregue aos usuários.

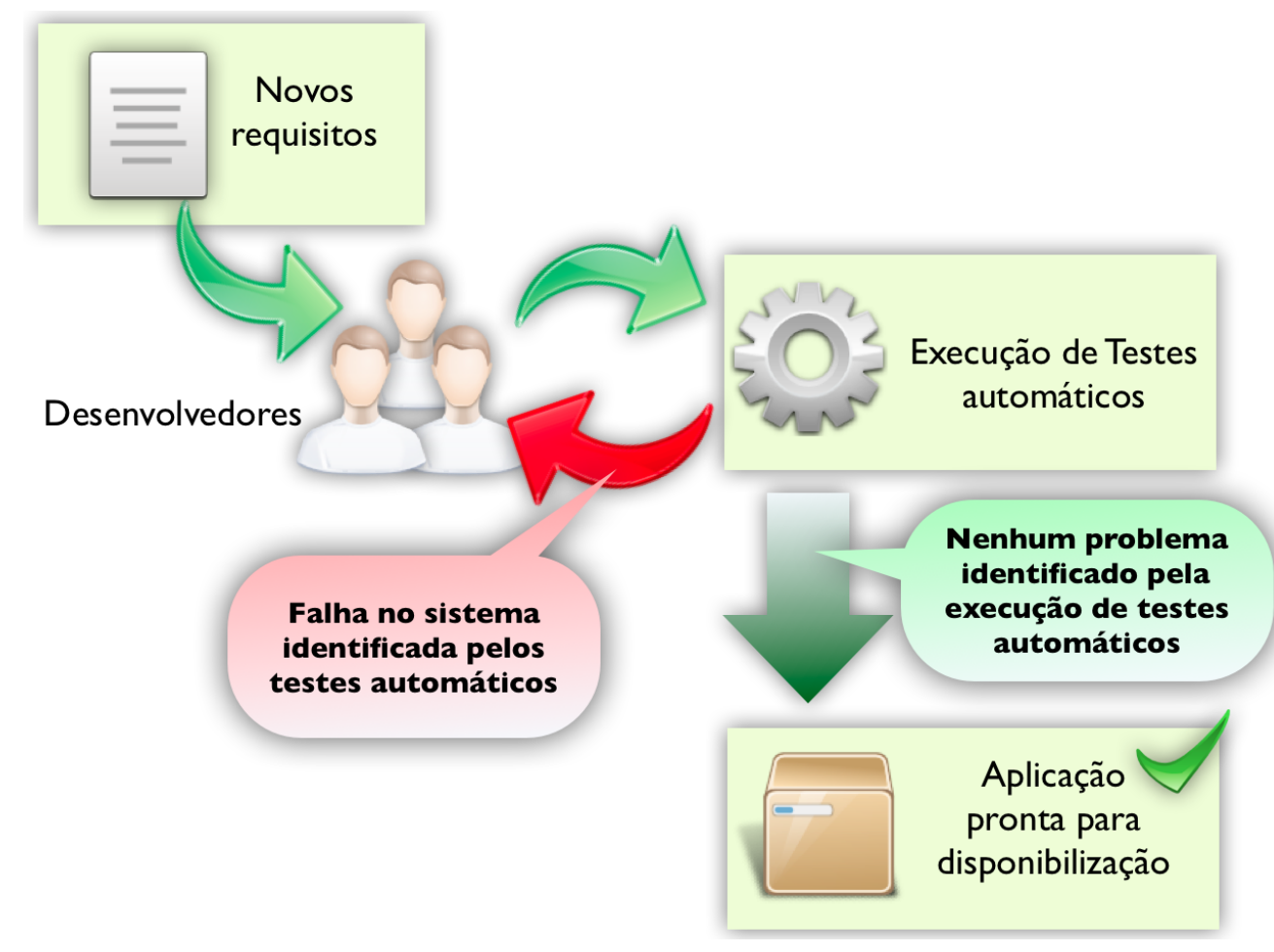

Figura 3.2: Processo de desenvolvimento utilizando práticas de Integração Contínua.

Enquanto o TDD contribui com a elaboração de casos de teste e estabilidade de uma aplicação web, a Integração Contínua favorece a identificação de problemas de integração, utilizando o conjunto de testes elaborados durante o desenvolvimento. No entanto, vale destacar que as práticas de TDD e Integração Contínua em um projeto de software, têm como requisito a utilização técnicas e abordagens de validação de código e avaliação automática de requisitos funcionais e nãofuncionais como usabilidade e acessibilidade, para garantir que a aplicação, sendo disponibilizada em cada iteração de desenvolvimento, não apresente características que afetem negativamente a sua utilização.

\subsection{Abordagens de avaliação de acessibilidade}

A avaliação de acessibilidade na Web é uma atividade que pode ser realizada durante as etapas de desenvolvimento de sites ou para determinação do nível de acessibilidade atingido por determinadas páginas. No contexto de avaliação de acessibilidade, o principal objetivo é a identificação de barreiras de acessibilidade, presentes em sites ou aplicações web, e reportar esses problemas para correção (Fortes et al., 2005).

Uma das formas mais simples de se realizar a avaliação de acessibilidade de uma aplicação web é por meio de ferramentas de avaliação automática de acessibilidade. Essas ferramentas têm 
por finalidade a avaliação de acordo com um conjunto de padrões de acessibilidade, como por exemplo as diretrizes de acessibilidade elaboradas pela WAI (WCAG), descritas no Capítulo 2.

A existência de meios de avaliação automática de conformidade com legislações, padrões e diretrizes é um fator diretamente relacionado ao sucesso de seu uso e implementação (Boldyreff, 2002).

Como ferramentas de avaliação automática de acessibilidade podem ser citadas:

- EvalAccess: avalia a conformidade com a WCAG 1.0.

Disponível em: http://sipt07.si.ehu.es/evalaccess2/index.html

- Hera: avalia a conformidade com a WCAG 1.0.

Disponível em: http://www.sidar.org/hera/index.php.en

- DaSilva: avalia a conformidade com a WCAG 1.0 e modelo de acessibilidade de governo eletrônico adotado no Brasil (E-MAG $\left.{ }^{1}\right)$.

Disponível em: http://www.dasilva.org.br/

É importante destacar que as ferramentas de avaliação automática não são capazes de avaliar total conformidade com determinados padrões e diretrizes, como a WCAG, devido à subjetividade existente em determinados checkpoints (considerando a WCAG 1.0) e critérios de sucesso (considerando a WCAG 2.0) presentes entre as diretrizes (Kelly et al., 2005).

As ferramentas automáticas avaliam a conformidade dos websites de acordo com regras simples de acessibilidade, sem verificar a semântica dos metadados de acessibilidade. Como por exemplo, as ferramentas automáticas são capazes de avaliar se uma imagem possui um conteúdo alternativo textual para sua apresentação, mas não são capazes de identificar se o conteúdo alternativo textual é de fato relevante como descrição da imagem (Borodin et al., 2010).

Sobretudo, essas ferramentas de avaliação automática analisam o código HTML de páginas web geradas dinamicamente no servidor da aplicação, utilizando linguagens como Active Server Pages (ASP), JavaServer Pages (JSP) e PHP - Hypertext Preprocessor. Dessa forma, torna-se difícil reportar a exata causa da barreira de acessibilidade encontrada. Essas ferramentas verificam, ainda, o conteúdo estático HTML de uma página, sem considerar a possibilidade de uma estrutura dinâmica DOM, como acontece em aplicações Web 2.0. Logo, essas ferramentas de avaliação automática são incapazes de analisar qualquer funcionalidade implementada no lado cliente de uma aplicação web (Gibson, 2007).

Considerando essa limitação das ferramentas de avaliação automática de acessibilidade, a WAI apresenta formas de avaliar a acessibilidade e conformidade com suas diretrizes de páginas web. Dentre elas são destacadas:

- Avaliação preliminar: revisão de páginas que combina a utilização de ferramentas automáticas de avaliação e a análise manual de determinados critérios de acessibilidade. Essa

\footnotetext{
${ }^{1}$ http://www.governoeletronico.gov.br/acoes-e-projetos/e-MAG
} 
técnica não é suficiente para determinar se uma página é acessível ou não, no entanto pode reportar barreiras de acessibilidade mais óbvias por meio de uma rápida avaliação inicial (W3C, 2013c). Os passos necessários para sua aplicação são:

1. Seleção de amostras representativas da página a ser avaliada.

2. Avaliação manual das amostras em diferentes navegadores.

3. Avaliação manual em navegadores especializados (navegadores textuais, com síntese de voz, entre outros).

4. Utilização de ferramentas de avaliação automática de acessibilidade.

5. Sumarização dos resultados encontrados.

- Avaliação de conformidade: avaliação de conformidade de uma página com as diretrizes da WAI (WCAG). Combina o uso de ferramentas de avaliação automática e testes manuais de acessibilidade (W3C, 2008a). As atividades que compõem a avaliação de conformidade são:

1. Determinar o escopo da avaliação: identificar o nível de conformidade da WCAG a ser atingido (A, AA ou AAA) e selecionar amostras representativas de páginas que serão avaliadas.

2. Utilizar ferramentas de avaliação automática:

(a) Validar a marcação utilizada (HTML ou MathML ${ }^{2}$ ).

(b) Validar a utilização de folhas de estilo.

(c) Utilizar ferramentas de avaliação automática de acessibilidade (pelo menos duas).

\section{Avaliação manual das amostras:}

(a) Analisar a conformidade das páginas de acordo com os checkpoints da WCAG determinados como escopo da avaliação.

(b) Avaliar manualmente as amostras em diferentes navegadores.

(c) Avaliar manualmente as amostras em navegadores especializados (navegadores textuais, com síntese de voz, entre outros).

(d) Verificar o nível de simplicidade e clareza do conteúdo textual apresentado.

\section{Sumarização dos resultados encontrados.}

- Avaliação com usuários: a participação de usuários nos processos de avaliação é tida como uma forma de auxílio à compreensão, por parte dos desenvolvedores, sobre como usuários com deficiência interagem com o sistema por meio de Tecnologias Assistivas (W3C, 2010a). Os problemas levantados nessa avaliação são classificados, de acordo com suas respectivas causas, em: problemas de marcação do conteúdo, sem disponibilidade de funcionalidades

\footnotetext{
${ }^{2}$ Mathematical Markup Language
} 
na Tecnologia Assistiva sendo utilizada, não familiaridade do usuário com a Tecnologia Assistiva e problemas de usabilidade comuns a todos os usuários.

Os passos que envolvem o desenvolvimento desse tipo de avaliação são:

1. Realizar uma Avaliação preliminar de acessibilidade no site.

2. Avaliar com o usuário informalmente, analisando o seu uso da aplicação web e considerações a respeito da interface apresentada; ou aplicar testes de usabilidade formais com análise de desempenho na utilização do site.

Há ainda trabalhos que destacam a importância da avaliação com o usuário, por meio de uma abordagem de design centrada no usuário (User centered design) (Romen e Svanaes, 2008; Brajnik et al., 2010; Watanabe, 2007). Nesses trabalhos é argumentado que a WAI estabelece que a conformidade com as diretrizes (WCAG para desenvolvedores de aplicações web) garante a acessibilidade. Pelo modelo da WAI, existe a necessidade de que ferramentas de autoria e navegadores sejam desenvolvidos em conformidade com as diretrizes ATAG e UAAG, respectivamente. No entanto, uma vez que a implementação de ferramentas de autoria e os navegadores não são do controle do desenvolvedor web ou web designer, a acessibilidade do site não pode ser garantida ou verificada, totalmente. A falta de garantia e verificação de acessibilidade pode ser observada pela ausência de evidências empíricas sobre a efetividade das diretrizes nos documentos da WAI (Kelly et al., 2007).

Romen e Svanaes, inclusive, apontam a insuficiência da WCAG, sozinha, em determinar a acessibilidade em um site (Romen e Svanaes, 2008). São apresentadas barreiras de acessibilidade em determinados sites identificadas por usuários com deficiências. Dessas barreiras, apenas 27\% são identificadas pelos checkpoints da WCAG 1.0. Nesse estudo, é também verificado que não há correlação entre os níveis de prioridade destacados pela WCAG e a real severidade dos problemas.

Considerando essa linha de pesquisa, ainda, determinados autores questionam a validade das diretrizes estabelecidas pela WCAG, de acordo com a clareza e objetividade do documento. Brajnik et al., por exemplo, reportam que avaliadores de acessibilidade com experiência avançada produziram $20 \%$ de falsos positivos em uma avaliação de conformidade com a WCAG e foram incapazes de identificar 32\% de problemas reais em um website (Brajnik et al., 2010). Kelly et al. também destacam que o uso de termos genéricos e vagos, utilizados na descrição de soluções de design tecnologicamente neutras na WCAG 2.0, podem dificultar o entendimento e interpretação das diretrizes (Kelly et al., 2007).

Nesse contexto, são propostas técnicas que consideram a interação com o usuário como forma de garantia de acessibilidade. São utilizados, como variáveis de avaliação contextos de uso (categorias de usuário, cenários de utilização e objetivos dos usuários) (Brajnik, 2008a, 2006) e testes com os usuários (Watanabe, 2007; Romen e Svanaes, 2008).

Dentre essas técnicas são destacadas: 
- Think aloud: essa técnica consiste de avaliações qualitativas de uma determinada interface, por meio da análise de comentários feitos em voz alta por usuários, durante interações com o sistema (Lewis, 1982; Brajnik, 2008a; Romen e Svanaes, 2008). Essa técnica consiste das seguintes etapas:

1. Determinação dos contextos em que serão efetuados os testes (características de usuários, Tecnologias Assistivas que serão utilizadas, interfaces a serem avaliadas, cenários de utilização do sistema, tarefas a serem realizadas, entre outras).

2. Realização das tarefas previamente estabelecidas na interface do site. Durante essa etapa, é estabelecido que os usuários narrem seus pensamentos (think aloud) de acordo com a aplicação sendo utilizada.

3. Avaliação de uma lista de problemas gerada a partir da análise de anotações, gravações de vídeo e áudio da sessão de testes (realização das tarefas). Também devem ser apresentados graus de severidade para cada um dos problemas encontrados.

- Barrier Walkthrough: técnica de inspeção de acessibilidade em que o contexto de utilização de um site é explicitamente considerado. Um avaliador deve identificar um determinado número de barreiras de acessibilidade, de acordo com o contexto sendo avaliado, que são interpretações e extensões de princípios de acessibilidade bem definidos (Brajnik, 2008b). Essa técnica foi desenvolvida com base no percurso cognitivo (técnica de inspeção de usabilidade) (Polson et al., 1992). Devem ser efetuadas as seguintes atividades durante a execução dessa técnica (Brajnik, 2006):

1. Levantamento de contextos de uso da aplicação (características dos usuários, cenário de utilização, atividades a serem realizadas e objetivos da interação com a aplicação).

2. Avaliação de presença de barreiras de acordo com um determinado contexto sendo avaliado. Essa etapa deve ser realizada para cada um dos contextos considerados na primeira etapa.

3. Elaboração de uma lista de problemas associados a determinados contextos, seus respectivos níveis de severidade e atributos de performance que sejam afetados (eficiência, produtividade, satisfação e segurança).

- Teste com usuários: técnica de avaliação quantitativa relativa à performance de usuários no uso de uma aplicação. Como uma forma de evidência empírica da efetividade do checkpoint 3.5, Watanabe (2007) utilizou esse método de avaliação analisando os tempos necessários para completar determinadas tarefas em sites que utilizam marcações de elementos " $h e a$ ding" adequadamente e sites que não os utilizam.

O envolvimento de usuários com deficiência torna os processos de implementação de acessibilidade mais efetivos e eficientes. No entanto, mesmo estudos de grande escala não seriam capazes 
de cobrir toda a diversidade de deficiências, estratégias de adaptação e Tecnologias Assistivas existentes. Assim, a avaliação por meio de abordagens centradas em usuário e conformidade com a WCAG é tida como uma das formas mais adequadas de se avaliar a acessibilidade de aplicações web, atualmente (W3C, 2010a).

No contexto do processo de Engenharia Web (Seção 3.1), métodos de avaliação de acessibilidade manuais são considerados entraves no processo rápido de liberação de uma aplicação web. Aplicações web freqüentemente apresentam curtos ciclos de desenvolvimento seguidos pela liberação do software. Esses ciclos de desenvolvimento demandam avaliações automatizadas ou semiautomatizadas de acessibilidade e dificultam a execução de abordagens de testes com usuários, antes da liberação do software. Nesta tese, serão abordadas formas de avaliar automaticamente a acessibilidade de acordo com a especificação ARIA (Seção 2.3.3).

\subsection{Métricas de Acessibilidade}

As diretrizes de acessibilidade como a WCAG 2.0 (W3C, 2008b) e especificações como ARIA (W3C, 2011) são de grande importância no auxílio aos desenvolvedores com o desenvolvimento de aplicações web acessíveis. Mas elas não são o suficiente para suportar todos os passos conduzidos nas práticas de Engenharia Web (Freire et al., 2007).

O desenvolvimento de aplicações web acessíveis permite uma Web mais inclusiva e acessível a todos, apesar das necessidades especiais que possam ser apresentadas pelos usuários (Freire et al., 2008b). Na literatura, exitem vários relatos e propostas sobre a elaboração de abordagens de desenvolvimento web acessível que guiam o processo de desenvolvimento durante as fases de elicitação de requisitos, design de interface, design de navegação e design da arquitetura. Apesar desses esforços, muitos estudos reportam que a acessibilidade ainda é um requisito não funcional pouco abordado em muitas páginas web (Freire et al., 2008a; Goette et al., 2006; Hanson e Richards, 2013).

Nesse contexto, estudos considerando a utilização das diretrizes da WAI, na implementação de páginas acessíveis, destacam a importância de métricas de acessibilidade no monitoramento e gerenciamento de acessibilidade no processo de Engenharia Web (Freire et al., 2008b). Quando conduzido adequadamente, o monitoramento contínuo de métricas relacionadas a atributos de qualidade, como a acessibilidade, promove importantes contribuições a atividades de melhoria desses atributos.

Destaca-se também que o modelo de avaliação proposto pela WCAG (que resulta nas classificações $0, \mathrm{~A}, \mathrm{AA}$ ou AAA) não é suficientemente preciso para monitorar a acessibilidade (Vigo et al., 2007), uma vez que uma página em conformidade com a WCAG em todos os checkpoints de prioridade 1 e quase todos de prioridade 2, teria a mesma classificação que uma página em conformidade com todos os checkpoints de prioridade 1 e nenhum de prioridade 2. 
Freire et al. descrevem uma abordagem com base em métricas para medir a acessibilidade web em páginas web de municípios brasileiros (Freire et al., 2008a). Monitorar os níveis de acessibilidade de aplicações web é uma atividade de grande importância para melhorar a acessibilidade no produto sendo desenvolvido. Dada a natureza de atualizações freqüentes que caracteriza as aplicações web, monitorar a evolução de acessibilidade requer métricas eficazes para impedir que uma aplicação web seja colocada em produção contendo barreiras de acessibilidade (Vigo et al., 2007; Freire et al., 2009).

Métricas de acessibilidade, muitas vezes, utilizam diretrizes, como a WCAG, para calcular um valor quantitativo que represente o nível de acessibilidade de uma página web (Vigo et al., 2007). Como por exemplo, Sullivan e Matson (Sullivan e Matson, 2000) propõem o cálculo da proporção entre o número de problemas de acessibilidade identificados em um determinado website (considerando como problema todas as falhas de verificação dos pontos de verificação da WCAG 1.0) e o número de barreiras de acessibilidade potenciais para calcular a métrica de acessibilidade de uma página web. Outros estudos que abordam a elaboração de métricas de acessibilidade descrevem a inclusão de pesos diferentes de acordo com pontos de verificação que possuam prioridades diferentes (Parmanto e Zeng, 2005); definição de valores de peso definidos com base em experimentos realizados com usuários com deficiência (Cluster, 2006); utilização da proporção do número de falhas de pontos de verificação semelhantes e o número total de falhas de verificação (Bühler et al., 2006); entre outras abordagens.

A tarefa de realizar o monitoramento dos níveis de acessibilidade manualmente de páginas web possui um custo elevado, principalmente quando considerando ambientes de desenvolvimento que realizam alterações e atualizações freqüentemente (Watanabe et al., 2012). Nesse contexto, Freire et al. adaptaram a ferramenta de avaliação automática $\mathrm{Hera}^{3}$ para identificar as barreiras de acessibilidade em páginas web e calcular as suas métricas de acessibilidade (Freire et al., 2008a). Apesar dos métodos de avaliação automática não considerarem muitos aspectos que devem ser avaliados manualmente, os resultados desse trabalho mostram que, na média, as páginas web apresentam um nível de acessibilidade médio a alto não desejável.

Em outro trabalho, Freire et al. utilizaram um questionário para investigar o conhecimento dos conceitos relacionados à acessibilidade na web por desenvolvedores web do Brasil (Freire et al., 2008d). Identificar como os desenvolvedores percebem a acessibilidade, quão acessíveis são as páginas web desenvolvidas por eles, e porque eles implementam páginas web que são acessíveis ou não é um fator crítico para propor novas abordagens que afetem significantemente a acessibilidade da Web. Os resultados desse questionário apontaram que poucas pessoas que atuam no desenvolvimento web no Brasil conheciam os conceitos de acessibilidade.

É importante observar que em ambos trabalhos (Freire et al., 2008a,d) são apresentados resultados de investigações sobre como a acessibilidade é considerada em projetos de desenvolvimento web e têm como foco as diretrizes da especificação WCAG 1.0 (W3C, 1999). Observa-se que esses estudos não consideraram as recomendações da especificação ARIA.

\footnotetext{
${ }^{3}$ http://www.sidar.org/hera/index.php.en
} 
No contexto da acessibilidade em aplicações ricas de Internet, RIA, muitos estudos propõem estratégias de avaliação automática de acessibilidade analisando as mudanças de estrutura que possam ser disparadas por meio do uso de JavaScript (Tateishi et al., 2007; Fernandes et al., 2011, 2012). Esses estudos descrevem estratégias automáticas de avaliação que devem auxiliar desenvolvedores durante a etapa de teste de suas aplicações, reportando se suas implementações são acessíveis ou não. No entanto, nenhum desses estudos têm como objetivo investigar como a especificação ARIA tem sido implementada por desenvolvedores web.

\subsection{Avaliação automática de ARIA}

No contexto do desenvolvimento de aplicações Web 2.0, uma vez que um website é colocado em produção, elaborar estratégias para rastrear a sua acessibilidade é essencial para manter níveis de qualidade desejáveis da aplicação sendo desenvolvida. No entanto, dada a natureza de freqüentes atualizações de funcionalidades que caracteriza as aplicações web, monitorar a evolução da acessibildiade de um website requer a utilização de métricas precisas para evitar colocar uma aplicação em ambiente de produção que apresente problemas de acessibilidade (Vigo et al., 2007).

Vale destacar que a realização de avaliações manuais têm um custo elevado de execução, principalmente em ambientes de desenvolvimento em que a aplicação é atualizada em produção com muita frequiência, como é observado em aplicações Web 2.0 que possuem ciclos de re-design e liberação para os usuários em curtos períodos de tempo (Umbach, 2006). Dessa forma, nesses ambientes de desenvolvimento, a atividade de avaliação de acessibilidade seria constituída principalmente por testes automatizados.

Embora os testes automatizados apresentem vantagens com relação à produtividade e cobertura das páginas web, eles utilizam abordagens heurísticas para determinar possíveis barreiras de acessibilidade e violação das diretrizes de acessibilidade (Brajnik, 2008a). Os testes automáticos também não são capazes de avaliar todos os requisitos estabelecidos pela especificação ARIA que são direcionados às aplicações Web 2.0, uma vez que eles possuem capacidade limitada de verificação do conteúdo HTML, analisando apenas o conteúdo estático HTML gerado nas aplicações, sem considerar as mudanças e atualizações da estrutura DOM que são gerados em RIAs (Velasco et al., 2008).

Nesse contexto, o processo de desenvolvimento de aplicações Web 2.0 deveria considerar o uso de métodos empíricos. No entanto, há um elevado custo envolvido no recrutamento de usuários reais para testar todos os aspectos de um design em evolução (Nielsen e Mack, 1994).

Para lidar com os requisitos conflitantes relacionados à garantia de acessibilidade no desenvolvimento de RIA e com a elevada freqüência de atualizações de uma aplicação Web 2.0, linhas de pesquisa na elaboração de estratégias de avaliação automática de acessibilidade em RIA têm sido 
estabelecidas. A seguir, são descritos trabalhos que abordam o desenvolvimento de estratégias de avaliação automática de acessibilidade de RIA.

\section{Tateishi et al. 2007}

Tateishi et al. propõem uma estratégia de avaliação com base na análise de código estático JavaScript (Tateishi et al., 2007). Essa estratégia tem como requisito a elaboração de um conjunto de regras que mapeiam as mudanças de valor das propriedades relacionadas à especificação ARIA em uma widget, como as propriedades aria-hidden e checked. O conjunto de regras, para uma determinada widget, representa um diagrama de estados das propriedades relacionadas à especificação ARIA, que deve ter o seu comportamento reproduzido pela implementação da mesma widget na linguagem JavaScript.

Na Figura 3.3, é ilustrado um diagrama de estados que representa os estados esperados da estrutura DOM de uma widget checkbox, juntamente com a especificação das respectivas regras. Na figura, são apresentados dois estados possíveis para a widget checkbox: o estado Checked, quando a widget encontra-se marcada pelo usuário; e o estado Unchecked, quando a widget encontra-se desmarcada. Quando a widget encontra-se no estado Checked, a estrutura DOM deve conter o atributo HTML checked com o valor true (verdadeiro) e os atributos id e class não nulos. Quando a widget encontra-se no estado Unchecked, a estrutura DOM devem conter o atributo HTML checked com o valor false (falso) e os atributos id e class não nulos, também. No diagrama de estados ilustrado na figura também é representado que a widget deve alternar entre os estados checked e unchecked quando a widget recebe um evento click.

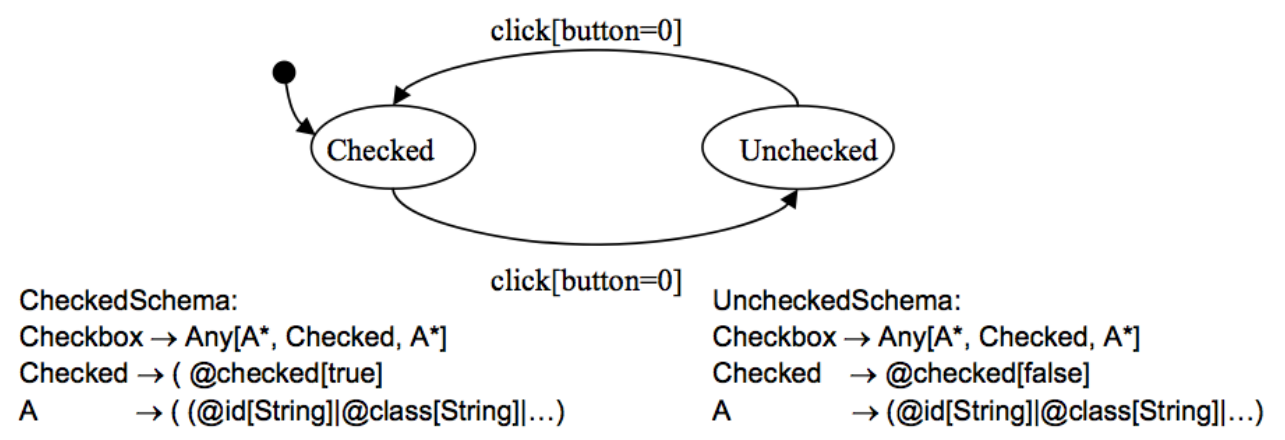

Figura 3.3: Diagrama de estados que representa os estados esperados de uma widget checkbox, juntamente com as suas respectivas regras.

Figura extraída do artigo (Tateishi et al., 2007).

Depois de estabelecido o conjunto de regras para uma determinada widget, devem ser realizadas duas etapas de análise do código JavaScript estático da widget: o corte dinâmico (dynamic slicing) e a análise da estrutura DOM (DOM analysis). O corte dinâmico compreende uma etapa que filtra os comandos JavaScript que não afetam o valor dos atributos da estrutura DOM da widget, dada a sua execução. Na Figura 3.4, é ilustrado um exemplo da execução da etapa de corte dinâmico em um trecho de código JavaScript que implementa a widget checkbox. Na figura, 
é ilustrada a remoção das linhas de código que não afetam o estado da widget, ou seja, que não alteram os valores dos seus atributos na estrutura DOM, dada um determinada entrada no código (representando a execução de um clique em uma widget checkbox no estado Checked).

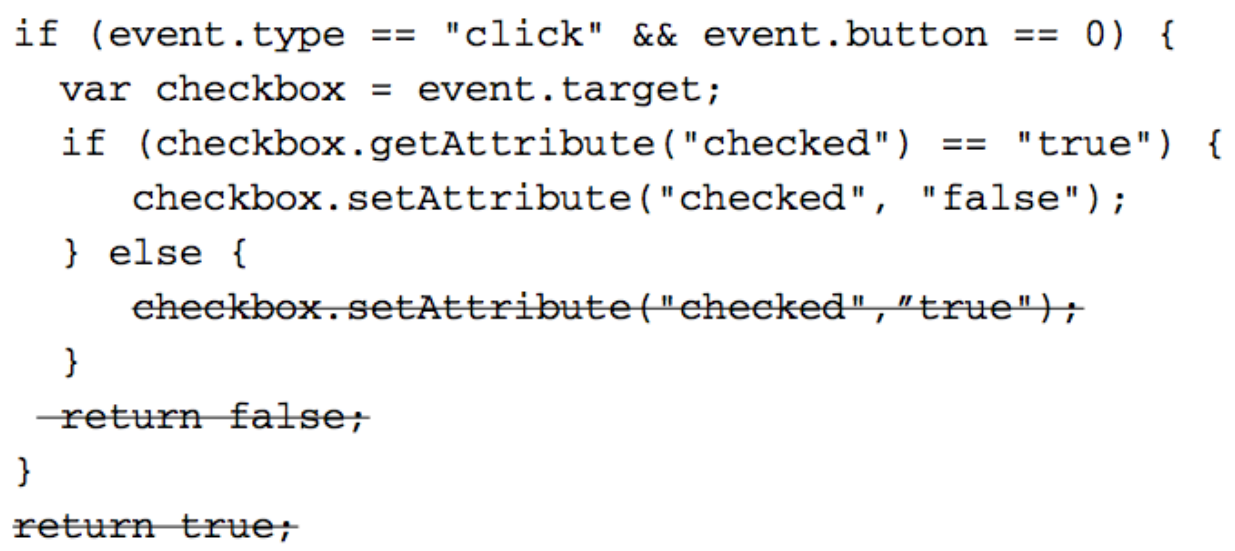

Figura 3.4: Representação da etapa de corte dinâmico em um trecho de código JavaScript que implementa uma widget checkbox.

Figura extraída do artigo (Tateishi et al., 2007).

A análise da estrutura DOM compreende uma etapa que compara o comportamento de uma instância DOM de uma widget com as regras de comportamento estabelecidas no conjunto de regras que definem o diagrama de estados de uma determinada widget, verificando se o estado da estrutura DOM da widget (de acordo com seus atributos HTML) compreende um estado definido no diagrama de estados.

As duas etapas são conduzidas de acordo com a seguinte seqüência:

1. corte dinâmico: identificar e extrair os códigos JavaScript que estejam associados a funções que respondem a eventos (verificando as funções que são associadas aos eventos utilizando os atributos onclick e onkeydown, por exemplo).

\section{2. análise da estrutura DOM conforme os seguintes critérios:}

(a) verificar se a estrutura DOM inicial da widget corresponde a um estado definido no conjunto de regras de propriedades dos elementos de uma widget.

(b) verificar se a estrutura DOM da widget corresponde a estados definidos no conjunto de regras de propriedades dos elementos de uma widget, após a execução de funções que respondem a eventos depois de terem passado pela etapa de corte dinâmico.

A abordagem proposta por Tateishi et al. não exige a execução do código fonte JavaScript de uma aplicação. Toda a análise é realizada no código fonte estático da widget. No entanto, vale destacar, que essa estratégia realiza a avaliação de acessibilidade considerando apenas funções que respondem a eventos de uma única widget. Dessa forma, outras funções que podem interferir no comportamento da widget não são consideradas, como por exemplo funções que possam alterar a visualização da widget após um clique em outro elemento. 
As abordagens descritas nos Capítulos 4 e 5, propostas nesta tese, estendem o princípio de utilização de regras definido no trabalho de Tateishi et al., uma vez que também utilizam um conjunto de regras. Nesta tese, as regras são representadas no formato de casos de AT, em contraste ao diagrama de estados adotado por Tateishi et al.

Por outro lado, as abordagens apresentadas nesta tese realizam as avaliações de acessibilidade na estrutura DOM renderizada em um navegador web, como proposto em (Fernandes et al., 2011). Com isso, as análises são realizadas em nível macro da aplicação web, verificando quaisquer possibilidades de interferência do comportamento da aplicação por trechos de código JavaScript que possam não estar diretamente associados às widgets sendo verificadas.

\section{Fernandes et al. 2011}

Fernandes et al. destacaram diferenças em avaliações de acessibilidade realizadas em aplicações web, utilizando a análise de conteúdo HTML estático e a análise da estrutura DOM renderizada em um navegador web (Fernandes et al., 2011). Com a popularização da Web 2.0, muitas aplicações web têm utilizado recursos avançados dos padrões web para aumentar a interatividade de seus componentes de interface, como o JavaScript. Esses recursos podem alterar significantemente a estrutura HTML que é apresentada aos usuários.

Nesse contexto, Fernandes et al. descrevem duas formas distintas de conduzir avaliações de acessibilidade: a avaliação realizada em ambientes de linha de comando, considerando apenas o código HTML estático que é recebido com uma requisição HTTP; e a avaliação realizada no navegador (in-browser), considerando análises realizadas na estrutura DOM renderizada, juntamente com a execução de códigos JavaScript e CSS (Fernandes et al., 2011). Na Figura 3.5, são ilustrados ambos ambientes de avaliação definidos no trabalho de Fernandes et al.

Como os testes de usabilidade e métodos de inspeção de usabilidade são conduzidos na página web que é renderizada no navegador, com a execução das funcionalidades implementadas em JavaScript, os autores apresentam a seguinte questão de pesquisa do seu trabalho:

A avaliação de acessibilidade, com base nas diretrizes da WCAG 2.0, gera resultados diferentes se executada em ambiente de linha de comando ou se executada em um navegador web, com a estrutura DOM renderizada, após a execução do código JavaScript de um website?

Nesse trabalho, foi conduzido um experimento com 82 websites da lista de websites mais populares segundo Alexa ${ }^{4}$. Os 82 websites foram avaliados segundo as recomendações de acessibilidade da WCAG 2.0 tanto por uma ferramenta de ambiente de linha de comando quanto por uma ferramenta executada no navegador web. No experimento, a avaliação em linha de comando, considerando a análise de critérios de acessibilidade da WCAG 2.0, apresentou 67\% falso negativos e $13 \%$ de falso positivos comparando os resultados gerados pela linha de comando aos resultados

\footnotetext{
${ }^{4}$ http://www.alexa.com
} 


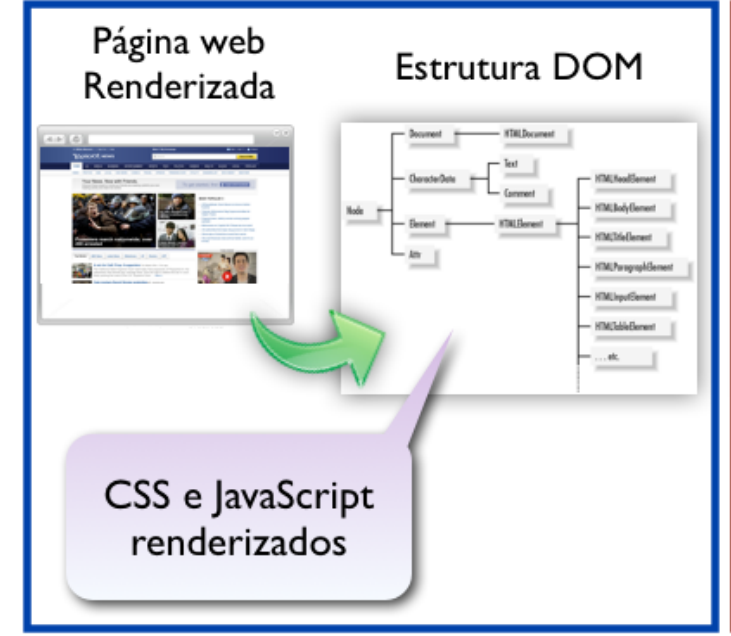

Ambiente de avaliação no navegador (in-browser)

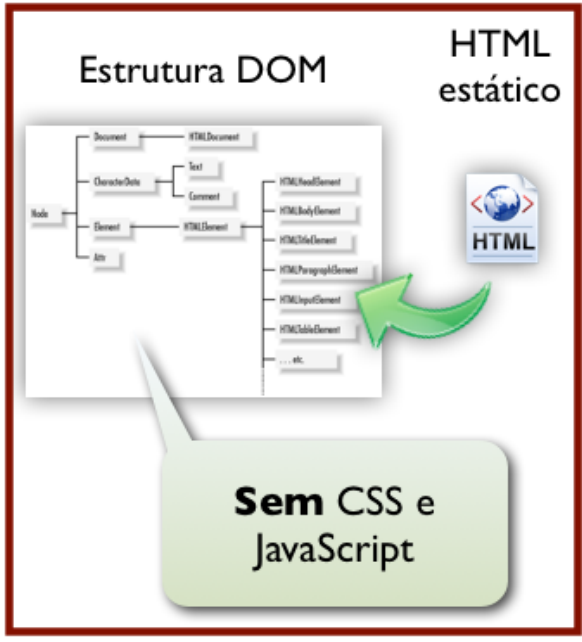

Ambiente de

avaliação em linha de comando

Figura 3.5: Diferenças entre os ambientes de avaliação de linha de comando e avaliação no navegador.

gerados pela avaliação realizada no navegador web. Nesse contexto, Fernandes et al. destacam que ferramentas de linha de comando podem confundir desenvolvedores web, uma vez que os resultados de avaliações de acessibilidade realizadas nesses ambientes não condizem com os resultados obtidos pelos usuários no navegador web. Portanto, Fernandes et al. sugerem que sejam utilizados ambientes de avaliação no navegador, visando uma maior proximidade com o ambiente de uso real.

É importante observar, que esse estudo consiste de um relatório a respeito da utilização de ambientes de avaliação em um navegador web, considerando critérios de acessibilidade da WCAG 2.0, sem considerar a avaliação dos requisitos de acessibilidade estabelecidos na especificação ARIA.

\section{Fernandes et al. 2012 e 2013}

Em outro trabalho, Fernandes et al. estendem o conceito de avaliação automática de acessibilidade realizada no navegador, para analisar também a estrutura DOM de uma página web, dadas as interações do usuário (Fernandes et al., 2012, 2013). Em RIAs, a linguagem JavaScript freqüentemente implementa funções que respondem à interação do usuário, alterando a estrutura DOM.

Em (Fernandes et al., 2011), os autores realizaram um experimento em uma página web com a estrutura DOM renderizada no navegador em seu estado inicial, depois que todas as dependências de imagens, códigos JavaScript e folhas de estilo haviam sido carregadas e executadas no navegador. 
(Fernandes et al., 2012, 2013), por outro lado, apresentaram uma abordagem de avaliação que simula interação do usuário com a página web, gerando múltiplos estados distintos da estrutura DOM, e realizando a análise de cada um desses estados para gerar um relatório geral de acessibilidade. No trabalho, foi destacado que uma vez que as funcionalidades relacionadas a RIA podem causar alteração da estrutura DOM, toda atualização e alteração na estrutura DOM deve ser analisada, para verificar se nenhuma barreira de acessibilidade foi inserida na página web. Na Figura 3.6, é ilustrado um exemplo de múltiplos estados da estrutura DOM, gerados a partir da simulação da interação do usuário com elementos de um website.

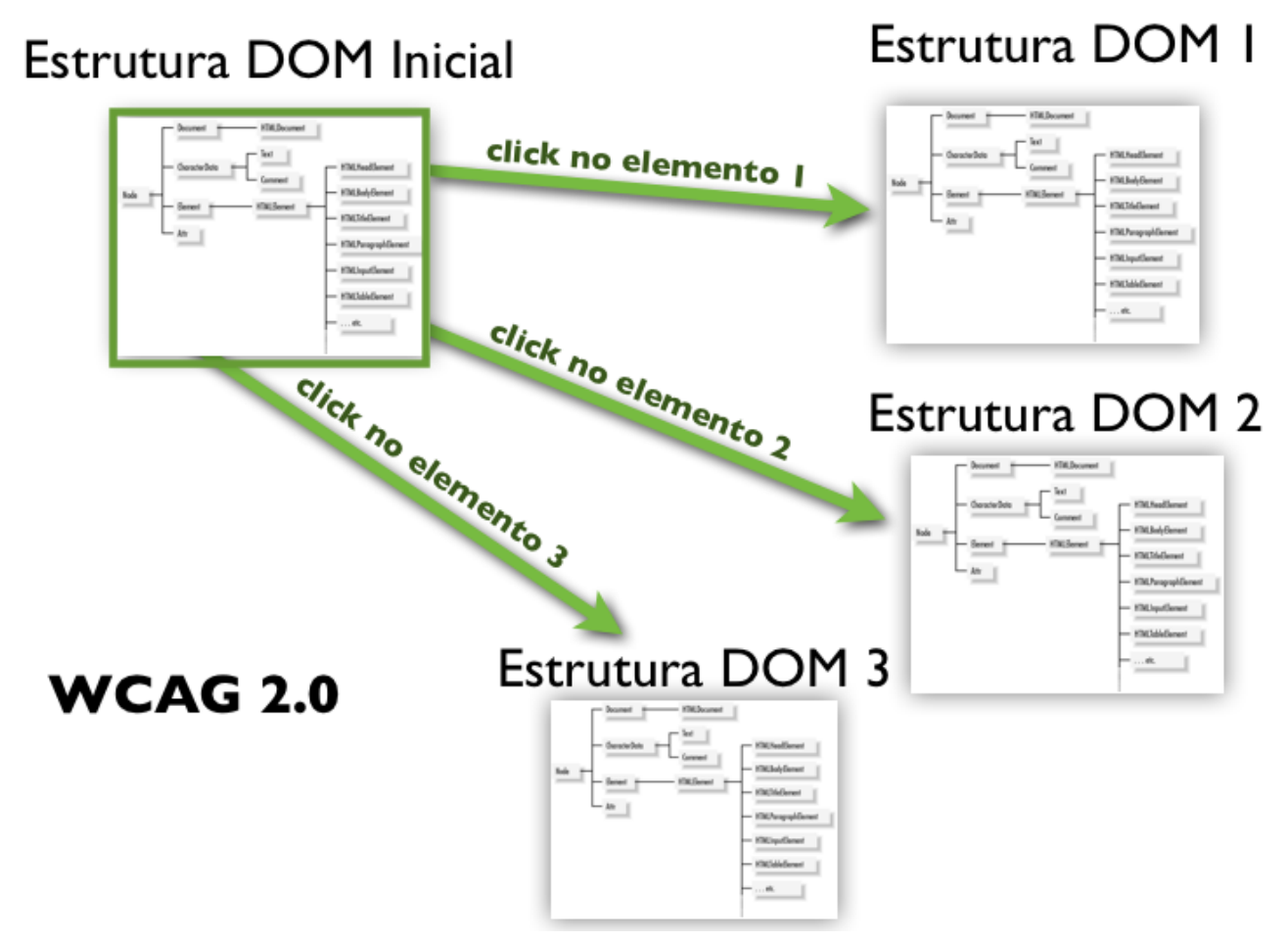

Figura 3.6: Múltiplos estados da estrutura DOM gerados a partir da interação do usuário com um website.

A abordagem descrita nesse trabalho consistiu em realizar uma avaliação automática dos critérios de acessibilidade da WCAG 2.0 para cada estado distinto da estrutura DOM, gerado a partir da simulação de um evento de click em um elemento clicável da página web.

É importante ressaltar que ambos os trabalhos ((Fernandes et al., 2011, 2012, 2013)) abordam a avaliação automática de requisitos de acessibilidade em RIA. No entanto, os trabalhos descrevem como as avaliações de critérios de sucesso especificados na WCAG 2.0 devem ser analisados em aplicações web com conteúdo dinâmico e alterações na estrutura DOM, sem considerar os requisitos da especificação ARIA.

\section{Doush et al. 2013}

Doush et al. descrevem um framework conceitual para avaliar a acessibilidade de RIA (Doush et al., 2013). Esse framework é composto por diferentes componentes com o objetivo de analisar 
a acessibilidade apesar das características de mudança dinâmica da estrutura do conteúdo que caracterizam RIAs. Os componentes desse framework são descritos a seguir:

Controlador de eventos de RIA : identifica os elementos da aplicação web que respondem a interações do usuário, com inserções e atualizações da estrutura DOM.

Robô Web : simula a interação do usuário com widgets que são disponibilizadas na RIA.

Especificação WAI-ARIA : descreve um conjunto de regras de acessibilidade da especificação ARIA que devem ser testadas para cada tipo de widget.

Avaliador : consiste de outros quatro sub-componentes:

DOM parser : permite o acesso e análise dos elementos da estrutura DOM de uma RIA.

Classificador de elementos : classifica os elementos como elementos de estrutura de navegação (utilizando roles de navegação, conteúdo principal, entre outros), live-regions que podem ter seu conteúdo atualizado, elementos que precisam implementar interações por teclado (como botões, abas, entre outros) e elementos que representam widgets complexas (elementos que agregam múltiplos elementos interativos que representam uma única widget, como um elemento com role menu que é formado por múltiplos menuitem).

Testes da especificação ARIA : verificam se todos os elementos clicáveis de uma RIA podem receber foco, de acordo com a propriedade role desses elementos.

Ontologia de roles : representação em RDF - Resource Definition Framework de todos os atributos role da especificação ARIA.

Adaptador de resultados : gera relatórios de acessibilidade em diferentes formatos.

Todos esses componentes devem ser integrados na construção de uma ferramenta de avaliação de acessibilidade em RIA, conforme ilustrado na Figura 3.7.

É importante observar que no trabalho de Doush et al. (Doush et al., 2013), foi proposto um framework de avaliação de acessibilidade em RIA, porém a validação do framework não foi experimental e serviu somente como prova de conceito no âmbito da avaliação da utilização da ontologia de roles da ARIA. Além disso, a proposta dos componentes do framework encontrase em um nível de abstração muito elevado, acarretando questionamentos sobre como viabilizar tecnologicamente, ou por meio de ferramentas automatizadas o devido suporte idealizado.

\subsection{Considerações finais}

Neste capítulo, foi apresentado o conjunto de técnicas de avaliação de acessibilidade e descritas abordagens propostas na literatura. As abordagens de avaliação automática, inspeção manual de 


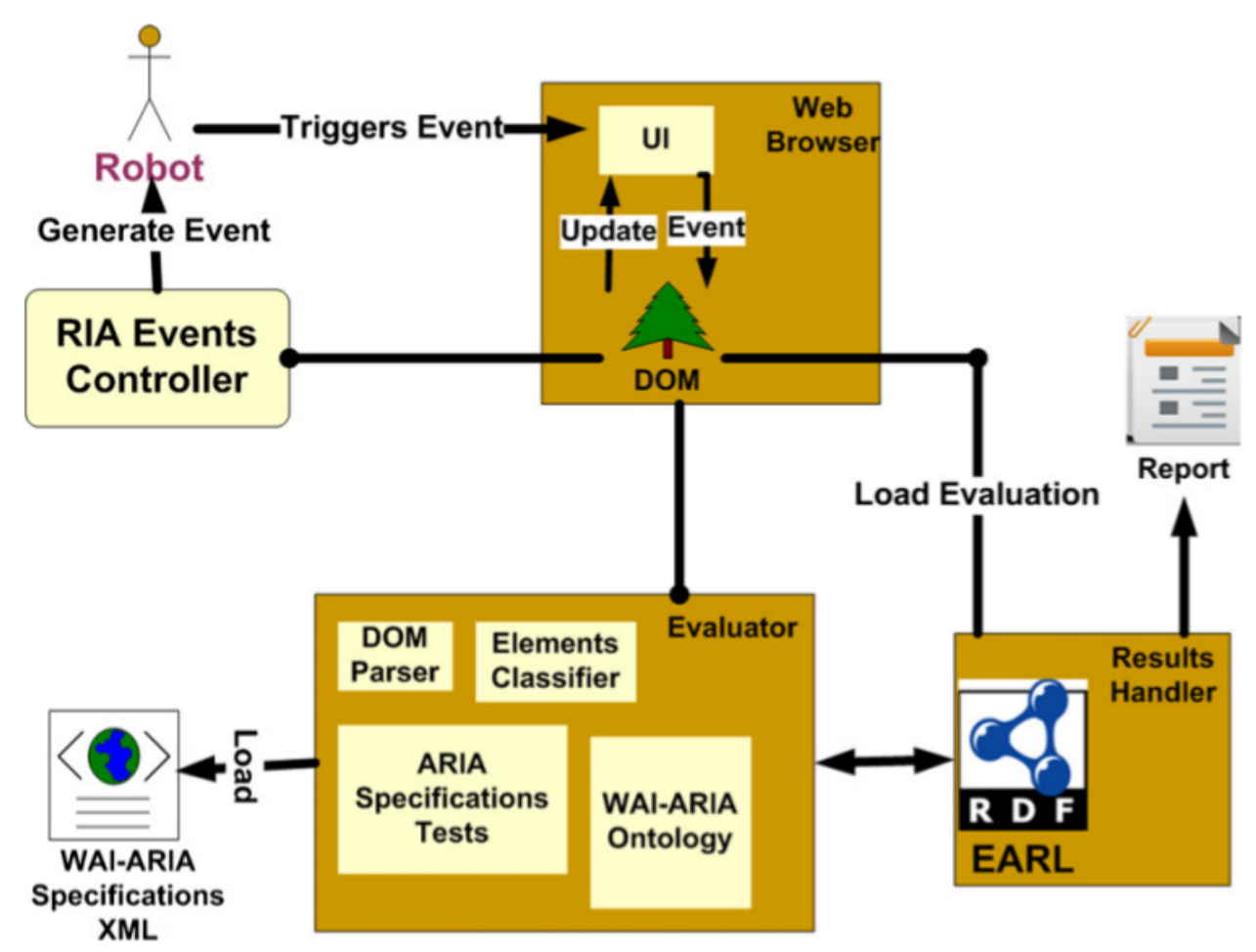

Figura 3.7: Framework conceitual para avaliar a acessibilidade de RIA. Figura extraída do artigo (Doush et al., 2013).

acordo com as diretrizes de acessibilidade e testes com usuários foram consideradas devido sua relação com o tema desta tese.

O processo de Engenharia Web tem como requisito que sejam utilizadas técnicas de avaliação automática de acessibilidade, para garantir que os requisitos de acessibilidade em RIA sejam implementados, em um processo de desenvolvimento iterativo com ciclos de entrega contínua e incremental.

Foi possível observar que os métodos de avaliação automáticas apresentados se fundamentam na análise do conteúdo dinâmico das aplicações Web 2.0, porém muitos não consideram a especificação ARIA. Dessa forma, os métodos estudados não analisam as propriedades relacionadas à utilização dos atributos role, state e properties, vistos na Seção 2.3.3, para marcar semanticamente uma widget, bem como a implementação de mecanismos de navegação acessível pré-estabelecidos para cada tipo de widget.

O único trabalho que considera a especificação ARIA nas avaliações de acessibilidade automática é o trabalho de Doush et al., no entanto, não se aprofunda quanto ao desenvolvimento de um suporte automatizável que implemente o framework de avaliação proposto (Doush et al., 2013). 



\section{A-Pyccuracy: utilizando BDD para avaliar ARIA}

ste capítulo tem como objetivo apresentar uma proposta de avaliação de acessibilidade em RIA, formulada nesta tese. Esta proposta consiste em utilizar AT e proporcionar apoio a prática de Desenvolvimento Orientado a Comportamento (BDD, uma extensão do TDD) para gerar aplicações Web 2.0 acessíveis.

O uso de AT para avaliar a acessibilidade em RIA caracterizou o desenvolvimento de uma estratégia automática de avaliação de acessibilidade em RIA inicial. Considerando a procedimento de pesquisa-ação, a estratégia de avaliação de acessibilidade por meio de AT dentro da prática de BDD (utilizando a ferramenta A-Pyccuracy) foi desenvolvida como o primeiro ciclo das atividades de planejar, agir, descrever e avaliar (Seção 1.4). O resultado do planejamento desta etapa estabeleceu como objetivo geral do ciclo o requisito de verificar se AT seriam capazes de avaliar requisitos de acessibilidade em uma interface dinâmica de RIA.

A proposta apresentada neste capítulo foi parcialmente publicada como um Artigo Completo no W4A 2012 - International Cross-Disciplinary Conference on Web Accessibility (Watanabe et al., 2012).

Este capítulo apresenta a seguinte estrutura: na próxima seção (Seção 4.1), são apresentados conceitos relacionados a utilização de AT no processo de Engenharia Web; na Seção 4.2, é descrita a abordagem de avaliação implementada por meio de um protótipo de ferramenta A-Pyccuracy de AT desenvolvida para testar o gerenciamento de foco de aplicações web; na Seção 4.3, é apresentado um estudo de caso como forma de validação do protótipo A-Pyccuracy descrito neste capítulo; 
na Seção 4.4, é apresentada uma discussão acerca dos resultados do estudo de caso descrito neste capítulo; e por fim, na Seção 4.5, são descritas as considerações finais do capítulo.

\subsection{Testes de Aceitação (AT)}

A Integração Contínua descreve um conjunto de atividades de Engenharia de Software, como uma prática de XP conforme apresentado na Seção 3.1.2, que aumentam a velocidade de entrega do software pela redução do tempo de integração do processo (Stolberg, 2009). A diminuição do tempo de integração do processo é um resultado do uso de estratégias de testes automáticos que melhoram a comunicação, permitem melhor visibilidade do estado de um projeto e reduzem os riscos de desenvolvimento (Kim et al., 2009).

Dentre as estratégias de testes automáticos que podem ser utilizadas em um processo de Integração Contínua destacam-se: os Testes Unitários, os Testes de Integração, os AT, entre outros (Araújo et al., 2007). Essas estratégias de teste são utilizadas com o objetivo de garantir a qualidade do software sendo desenvolvido. No contexto de Integração Contínua, essas estratégias de teste são utilizadas para avaliar e garantir o nível de estabilidade do software em cada etapa de integração.

Para uma aplicação Web 2.0, o resultado dos testes automáticos impacta diretamente na decisão de liberação do software em ambiente de produção (considerando o ciclo de desenvolvimento do padrão de projeto de aplicações "beta perpétuas" da Web 2.0) (Umbach, 2006). Dessa forma, a utilização de estratégias de avaliação automática torna-se essencial para verificar (identificar se o software foi construído corretamente de acordo com a sua especificação e planejamento) e validar (identificar se o software foi construído de acordo com as expectativas do cliente) todos os atributos de qualidade de uma aplicação web (Sommerville, 2007), inclusive, a acessibilidade do software sendo gerado, para garantir que as contínuas alterações e melhorias do software não constituam barreiras de acessibilidade nas funcionalidades, sejam essas funcionalidades novas ou não no sistema.

Vale destacar que a acessibilidade de uma aplicação web é um atributo de qualidade que impacta diretamente nas estratégias de uso do software pelos usuários. Uma vez que os usuários são responsáveis pela determinação final da qualidade de uma aplicação (Leung e Wong, 1997), este capítulo descreve o uso de AT para validar os requisitos de acessibilidade de uma aplicação web.

O AT constitui uma das estratégias de teste utilizadas em um processo de Integração Contínua e é definido como teste formal conduzido para determinar se um sistema satisfaz ou não os critérios de aceitação e permitir que os usuários determinem se o sistema é aceitável ou não (IEEE, 1986). Os AT operam na camada mais alta de uma aplicação: na interface do usuário (Araújo et al., 2007). Dessa forma, consideram a perspectiva do usuário para validar a qualidade da aplicação. A utilização de AT é realizada na última etapa de validação do processo de desenvolvimento de 
um software, e uma vez que os resultados do teste atingem o critério de aceitação, o software pode ser liberado para uso operacional (Leung e Wong, 1997).

Neste capítulo, é descrito o uso da estratégia comportamental, Behaviour-Driven Development - BDD (North, 2006), de elaboração de AT que examina o comportamento externo do sistema. Nessa estratégia, os casos de teste refletem os requisitos dos usuários na forma de histórias de usuários (User Stories) (Araújo et al., 2007), que irão corresponder aos termos do domínio das interações em uma aplicação web. As técnicas para encontrar erros têm como base asserções e verificações na interface externa do sistema, dentro de uma simulação que representa o contexto real de interação quando o software estiver em produção.

Asserções tratam-se de uma das técnicas automáticas, mais utilizadas, de detecção de falha e de descrição de informações sobre sua localização (da falha) no código fonte. As asserções são elementos importantes em model checking, uma abordagem alternativa utilizada na verificação de programas em que o resultado final da sua execução é comparado com uma afirmação lógica que expressa propriedades temporais do estado do programa. Essas asserções são freqüentemente utilizadas por desenvolvedores como uma forma de descrever precisamente o comportamento das interfaces de módulos para auxiliar a compreensão pelos desenvolvedores (Clarke e Rosenblum, 2006). No contexto desta tese, asserções são utilizadas em um ambiente de execução automática no qual a verificação formal das asserções é instrumentada em um programa para serem executadas juntamente com a lógica do programa.

Para realizar a avaliação de requisitos de acessibilidade por meio de AT, é necessário o levantamento de cenários de uso de aplicações web por usuários com deficiência. Esses cenários de uso devem então ser utilizados para gerar casos de teste que representem uma estratégia de uso de aplicações web por esses usuários. Esses casos de teste devem ser executados automaticamente para avaliar os requisitos de acessibilidade da aplicação. A falha em um caso de teste deve ser resultado da falta da implementação de algum recurso de design que permita que um usuário realize a tarefa que o caso de teste represente. Por outro lado, o sucesso de um caso de teste implica que a aplicação está acessível a usuários que utilizem a mesma estratégia de interação que o caso de teste represente.

Inicialmente, a partir de levantamento bibliográfico, no contexto de aplicações web, os seguintes cenários de uso por usuários com deficiência foram considerados:

- Navegação por teclado utilizando elementos que possam obter foco na tela (W3C, 2013e);

- Busca por conteúdo utilizando os elementos headings de uma página, como $<\mathrm{h} 1>,<\mathrm{h} 2>$, $<\mathrm{h} 3>$, entre outros (Watanabe, 2007);

- Busca por conteúdo utilizando os atributos landmarks estabelecidos no WAI-ARIA (W3C, 2011);

- Navegação seqüencial de conteúdo por meio do teclado, utilizando as teclas com indicação de seta para direita e para esquerda. 
Vale destacar que a abordagem de utilização de AT, para avaliar a acessibilidade, considera a utilização de cenários reais de uso da aplicação, e utiliza as mesmas interfaces e interações que o usuário deve realizar. Dessa forma, os AT são capazes de avaliar o funcionamento geral da aplicação sendo desenvolvida, considerando as mudanças e atualizações que possam ocorrer na estrutura DOM da página web, devido ao uso de JavaScript e CSS, enquanto as abordagens de avaliação do conteúdo estático HTML não são capazes de avaliar tais casos, conforme esquematizado na Figura 4.1 .

Na Figura 4.1, é ilustrado o código HTML estático que é utilizado como entrada dos validadores HTML, no entanto a interação de usuários com aplicações web é realizada na estrutura DOM de um documento HTML, renderizada no navegador web. Na Figura 4.1, também é apresentado que os AT realizam a avaliação na estrutura DOM e, a partir de cenários de uso representados como histórias do usuário, são capazes de identificar mudanças realizadas na estrutura DOM por meio do uso de JavaScript e CSS, simulando interações conduzidas pelo usuário.

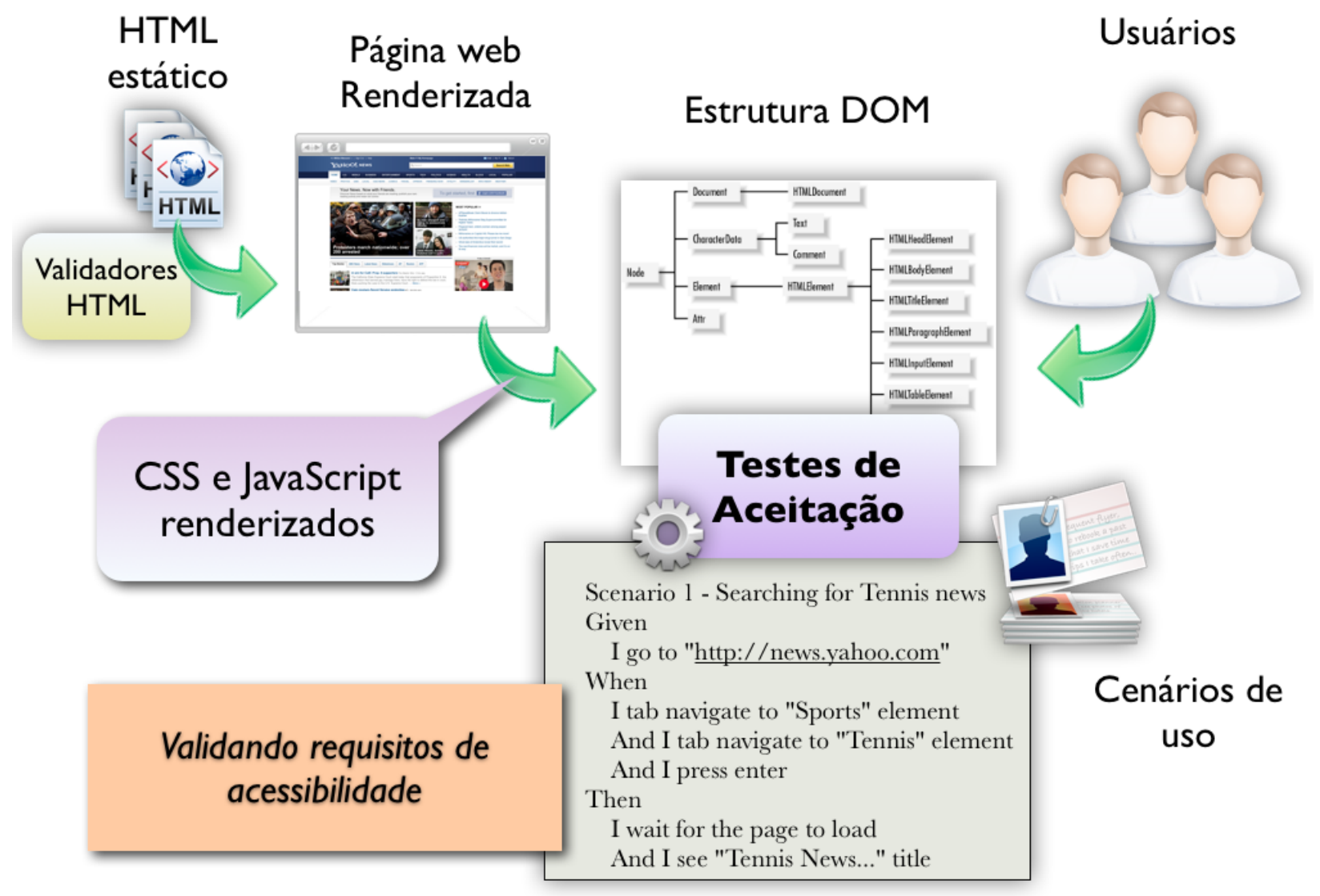

Figura 4.1: Esquema de avaliação de acessibilidade utilizando AT.

\subsection{Ferramenta A-Pyccuracy}

Inicialmente, foi implementado um protótipo de ferramenta de AT, entitulada A-Pyccuracy - Accessilibity Pyccuracy que é capaz de gerar casos de teste que representem a navegação por 
teclado utilizando os elementos que possam obter foco na tela. $\mathrm{O}$ gerenciamento de foco nas aplicações web é um requisito de acessibilidade essencial para RIA (W3C, 2011).

Usuários com pouca visão utilizam apenas o teclado como interface de entrada com o computador. Usuários com pouca visão não podem se beneficiar do feedback visual necessário para a interação de dispositivos como o mouse, e dessa forma utilizam o computador apenas com o teclado. Dessa forma, esses usuários navegam pelas páginas web utilizando o teclado para ativar links, preencher campos de texto, ou buscar por informações, e um sintetizador de voz como Tecnologia Assistiva, para ler o conteúdo textual de uma página.

O foco é um evento gerado na estrutura DOM de uma aplicação web para denotar elementos interativos na página. Caso os usuários não possam interagir com os elementos de uma página por meio do clique do mouse, deve ser realizada uma busca na página pelos elementos interativos utilizando a tecla $T A B$. Toda vez que o usuário pressiona a tecla $T A B$ no teclado, é disparado um evento de foco em um determinado elemento interativo da página web. Com isso, usuários que utilizem apenas o teclado para interagir com aplicações web, podem procurar pelos elementos interativos utilizando a tecla $T A B$ do teclado, e assim que encontrarem o elemento que desejam interagir, podem ativar esse elemento, pressionando a tecla ENTER para ativar um link por exemplo, ou preencher um campo de texto.

Considerando o contexto de uma aplicação rica (RIA), que apresenta interações complexas na página web, o gerenciamento de foco torna-se um requisito fundamental da interação, para garantir que as widgets implementadas sejam navegáveis por usuários que utilizem o computador nesses cenários. A navegação por foco é inclusive um requisito de acessibilidade definido na especificação ARIA (W3C, 2011).

Nesse contexto, um protótipo de ferramenta foi desenvolvido para dar apoio ao processo de elaboração de AT, com base em BDD, de modo a auxiliar os testadores e desenvolvedores de websites a desenvolverem casos de teste e automatizarem sua execução.

A ferramenta A-Pyccuracy trata-se de uma extensão da aplicação Pyccuracy ${ }^{1}$. O Pyccuracy trata-se de uma ferramenta de desenvolvimento orientado a comportamento (Behaviour-Driven Development - BDD (North, 2006)) que permite a elaboração de casos de AT utilizando linguagem natural.

É importante observar que os casos de teste em BDD possuem uma visibilidade maior, considerando equipes de desenvolvimento interdisciplinares, permitindo que desenvolvedores, gerentes de produto e designers possam compreender os critérios de aceitação e comunicar suas expectativas do produto para o caso de teste. A descrição dos casos de teste em linguagem natural tem como objetivo atribuir maior importância ao aspecto de design da prática de TDD, em relação a característica de validação de requisitos (Hammond e Umphress, 2012).

Na Figura 4.2, é apresentado o esquema de funcionamento da ferramenta A-Pyccuracy. Nessa figura, é ilustrado que a ferramenta consiste do desenvolvimento de um módulo da ferramenta Pyc-

\footnotetext{
${ }^{1}$ http://pyccuracy.org
} 
curacy que implementa um conjunto de Ações Acessíveis. Essas Ações Acessíveis implemetam recursos que permitem que um caso de AT simule a utilização de aplicações web por usuários com deficiência visual que utilizam a navegação por foco para interagir com os elementos de uma página web.

Com a inclusão desse módulo, dados como entradas uma RIA e um conjunto de casos de AT, que utilizam as Ações Acessíveis, o Pyccuracy gera um relatório que contém uma descrição de casos de teste que falharam (indicando os cenários que são acessíveis de acordo com o modelo de interação descrito no caso de teste) e passaram (indicando os cenários que são inacessíveis de acordo com o modelo de interação descrito no caso de teste) em sua execução.

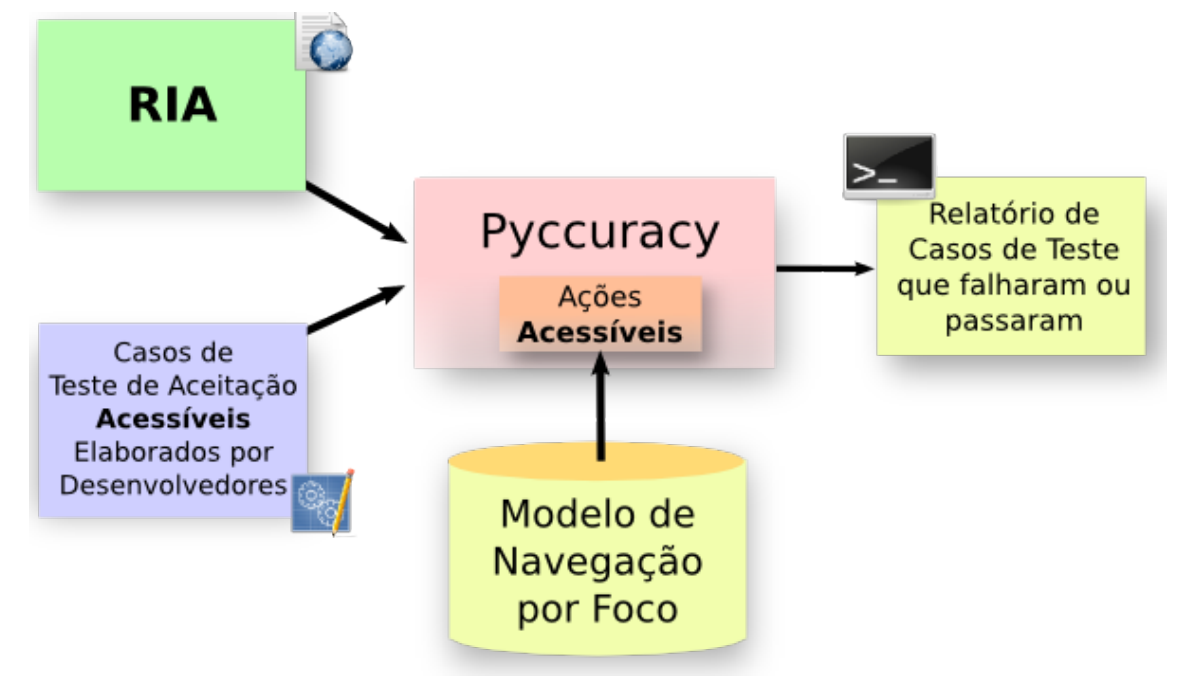

Figura 4.2: Esquema do funcionamento da ferramenta A-Pyccuracy, em que a aplicação Pyccuracy é estendida para avaliar a acessibilidade em RIA.

Um exemplo de caso de teste da ferramenta Pyccuracy é apresentado a seguir:

1. As a Flickr user

2. I want to see photos on the Web

3. So that I can share my experiences online

4 .

5. Scenario 1 - Going to the Flickr webpage

6. Given

7. I go to ' 'http://flickr.com/',

8. When

9. I wait for the page to load

10. Then

11. I see ''Seja bem-vindo(a) ao Flickr...'" title

Para o caso de teste exemplificado anteriormente, a ferramenta Pyccuracy lê as declarações escritas em linguagem natural (definidas na ferramenta como ações) e as executa em um navegador 
web, para verificar se o cenário de teste foi realizado (para o caso do teste ter obtido um resultado de sucesso) ou não (para o caso do teste ter falhado na realização da cenário).

O caso de teste do exemplo representa um cenário em que um usuário acessa a página principal do Flickr. Nesse caso de teste, o usuário deve, inicialmente, inserir o endereço da aplicação Flickr na barra de endereços do seu navegador (de acordo com a ação I go to "http://flickr.com", contida na linha 7). Em seguida, o usuário deve esperar a página web ser carregada por completo (de acordo com a ação I wait for the page to load, contida na linha 9). E, por fim, o usuário deve verificar que o título da página web contém uma mensagem de "Seja bem-vindo(a) ao Flickr..." (de acordo com a ação I see "Seja bem-vindo(a) ao Flickr...” title, contida na linha 11).

Vale destacar que esse caso de teste realiza duas asserções que podem levar a falha do cenário de uso: a segunda ação (I wait for the page to load) realiza uma asserção que verifica se a página é completamente carregada dentro de um intervalo de tempo e a terceira ação (I see "Seja bemvindo(a) ao Flickr..." title) realiza uma asserção para verificar se o título da página web que é apresentada no navegador é igual a cadeia de caracteres "Seja bem-vindo(a) ao Flickr...". Assim, exemplos de falha para esse caso de teste seriam causados pelo não carregamento da página web durante a segunda ação ou a verificação de que o título da página web durante a última ação é diferente da cadeia de caracteres "Seja bem-vindo(a) ao Flickr...".

Para permitir que a ferramenta Pyccuracy também avalie requisitos de acessibilidade, associados ao gerenciamento de foco nos elementos da aplicação web, em seus casos de teste, foram implementadas as seguintes ações simuladas e asserções, que consideram o cenário de uso de um usuário navegando em uma página web utilizando apenas o teclado:

Navegação utilizando a tecla TAB : usuários que navegam na Web utilizando apenas o teclado, como por exemplo, indivíduos com baixa acuidade visual, ou que não possam utilizar o mouse devido a falta de precisão nos movimentos da mão; freqüentemente pressionam a tecla $\mathrm{TAB}$ do teclado para procurar por elementos interativos em uma página web. Uma vez que a tecla TAB do teclado é pressionada no navegador web, o foco da página web é movido pelos elementos interativos da página. A ação de navegação utilizando a tecla TAB implementada no protótipo simula a ordenação de elementos que podem adquirir foco de uma página web, movendo o foco por esses elementos, respeitando o seu atributo TabIndex da estrutura do HTML. Essa ação procura por elementos da estrutura DOM da página web que sejam interativos e possuam um conteúdo textual em seus nós textuais, atributos de alternativa textual (atributo ALT ou TITLE) que correspondam a uma cadeia de caracteres fornecida como entrada. No exemplo a seguir, é apresentado o uso da ação implementada no protótipo de navegação utilizando a tecla TAB. O caso de teste procura por um elemento interativo que contenha o conteúdo textual "meme" utilizando a estratégia de navegação pressionando a tecla TAB do teclado. Vale destacar que essa ação ignora elementos da estrutura DOM que não sejam visíveis ao usuário, seguindo o mesmo padrão de interação de um usuário que estivesse interagindo com a página web por meio de uma Tecnologia Assistiva 
de leitor de tela como o VoiceOver ${ }^{2}$. A execução da seguinte ação deve retornar um resultado de sucesso caso a página web sendo testada possua um elemento interativo (que possa adquirir foco) com um conteúdo textual que contenha a palavra "meme", e a execução da ação falhará se não houver nenhum elemento interativo na página com esse conteúdo textual.

1. I tab navigate to ''meme' ' link

Ativação do elemento em foco : usuários que utilizam apenas o teclado para navegar pelas páginas web, uma vez que um elemento interativo tenha o foco da aplicação, podem utilizar a tecla ENTER do teclado para ativar esse elemento. A ativação do elemento é semelhante à operação de clique do mouse na interface visual (em um elemento BUTTON ou link da página web), no entanto essa operação requer que esse elemento tenha adquirido previamente o foco da aplicação. Essa ação também pode ser utilizada em elementos que representam formulários no HTML (como o elemento FORM). Formulários de uma página web, quando implementados adequadamente, possuem uma forma diferente de lidar com a ação de utilização da tecla ENTER. Uma vez que um elemento do tipo INPUT, dentro de um formulário, receber um evento de pressionamento da tecla ENTER, esse formulário será ativado e os dados serão submetidos ao servidor. Essa ação também implementa essa funcionalidade de simulação em um caso de teste. Vale destacar, que a percepção visual de um botão em um formulário possui um comportamento distinto do que efetivamente pode ocorrer, durante a interação do usuário, uma vez que o usuário não precisa clicar explicitamente no botão, para submeter o formulário. A seguir, é apresentado um exemplo de uso da ação de ativação do elemento em foco. Primeiramente é realizada uma ação de atribuir o foco para um elemento que contenha o texto "submit" (linha 1). Em seguida, esse elemento dispara um evento de pressionamento da tecla ENTER (linha 2). Caso esse elemento seja um link, por exemplo, o mesmo será ativado e o usuário deverá ser redirecionado para a página web para a qual esse link aponta. Vale destacar que essa ação não realiza nenhuma asserção, no entanto ela simula o comportamento de navegação de usuários que utilizem apenas o teclado para navegar na página web.

\section{I tab navigate to 'submit' button \\ 2. And I press enter}

A partir da elaboração dessas duas ações implementadas na ferramenta A-Pyccuracy, torna-se possível codificar casos de AT que avaliem requisitos de acessibilidade. Por exemplo, supondo

\footnotetext{
${ }^{2}$ http://www.apple.com/br/accessibility/osx/voiceover/
} 
que uma aplicação web tenha como requisito a navegação em um componente de interface do tipo menu, para obter informação sobre notícias de esportes, mais especificamente tenis, o seguinte caso de teste poderia ser elaborado, conforme o código a seguir.

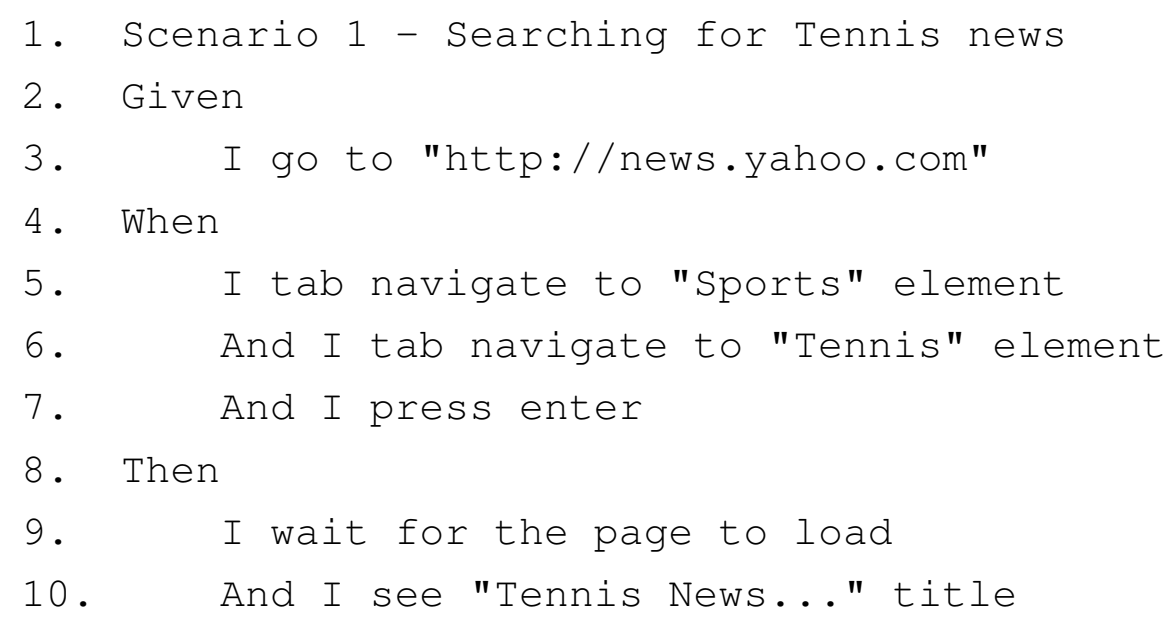

Esse caso de teste simula uma busca no portal de notícias do Yahoo! ${ }^{3}$ por um elemento interativo (dentro dos elementos da estrutura DOM da página que podem receber foco) que contenha o texto "Sports" (linha 5). Em seguida, é realizada a busca por um outro elemento interativo que contenha o texto "Tenis" (linha 6). O caso de teste deve ativar o elemento interativo com foco na página web (linha 7) e aguardar até que a nova página web seja carregada (linha 9). Por fim, o caso de teste deve checar se o título da nova página web corresponde a "Tennis News..." (linha 10). É importante observar, que, durante a execução da ação que procura pelo elemento interativo com o texto "Sports", o evento de foco nesse elemento interativo deve gerar uma atualização na estrutura DOM da página web que apresentaria o elemento interativo "Tenis", o que caracteriza um componente de interface rica e padrão de projeto de interação do tipo Fly-out Menu ${ }^{4}$.

Esse caso de teste, especificamente, ilustra um caso específico que permite a avaliação automática de atributos de RIA de uma aplicação web (considerando especificamente o requisito de WAI-ARIA para gerenciamento de foco nas aplicações web). A Figura 4.3 ilustra o funcionamento visual esperado do componente de interface Fly-out menu para o caso de teste apresentado.

Nesse caso de teste são executadas cada uma das ações especificadas na sua descrição. A ferramenta A-Pyccuracy determina se a ação pode ser realizada ou não (se houve uma falha de asserção). Se todas as ações forem executadas corretamente sem apresentar nenhuma falha de asserção, a funcionalidade representada pelo cenário de teste pode ser classificada como acessível para usuários que interajam com a aplicação web utilizando a mesma estratégia de interação (para o caso de teste descrito anteriormente, usuários que utilizem estratégias de navegação por teclado poderão interagir com a aplicação utilizando a estratégia de navegação com teclas TAB).

Se alguma das ações descritas no caso de teste falhar, então a aplicação web é considerada não acessível para usuários que utilizem a mesma estratégia de navegação que ela representa. Um

\footnotetext{
${ }^{3}$ http://news.yahoo.com

${ }^{4}$ http://www.welie.com/patterns/showPattern.php?patternID=fly-out-menu
} 


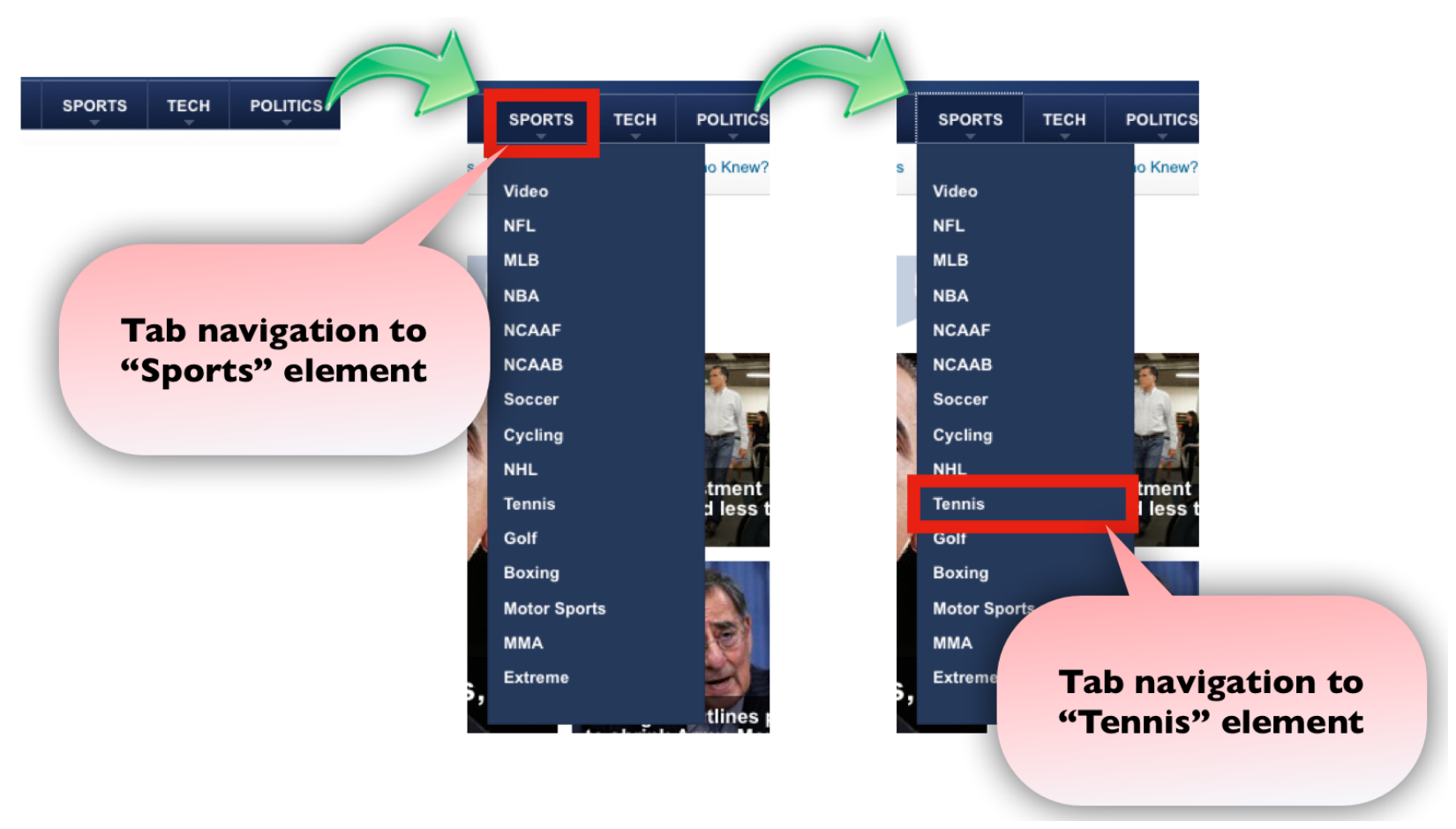

Figura 4.3: Esquema de navegação utilizando a tecla TAB no componente de interface Flyout menu, conforme avaliado no caso do AT escrito na ferramenta Pyccuracy.

exemplo de falha para esse cenário de uso, pode ser observado caso o protótipo não encontre um elemento interativo contendo a cadeia de caracteres "Tennis" (considerando a ação And I tab navigate to "Tennis"element) sendo apresentada após a atribuição de foco ao elemento contendo a cadeia de caracteres "Sports". Esse tipo de erro caracterizaria uma falha de implementação para casos em que o menu de tipo Fly-out foi implementado sem considerar a navegação por teclado, considerando apenas o evento HOVER (evento disparado quando o cursor do mouse encontra-se sobre um elemento da estrutura DOM de uma página web) para apresentar as opções de sub-menu.

Vale destacar que essa abordagem de avaliação de requisitos de acessibilidade utilizando AT nas aplicações web apresenta diferenças com relação às ferramentas de avaliação automática apresentadas no estado da arte. As abordagens tradicionais que consideram apenas a avaliação do conteúdo estático da marcação HTML ignoram os elementos gerados dinamicamente na estrutura DOM (Velasco et al., 2008). Por outro lado, a abordagem de uso de AT analisa a aplicação web pela perspectiva do usuário, simulando um cenário de uso orientado a tarefa e descrito em linguagem natural.

No exemplo de caso de teste apresentado anteriormente, a avaliação estática do conteúdo HTML, sem considerar o contexto da interação não seria capaz de analisar corretamente a apresentação do conteúdo interativo contendo o texto "Tennis" após a realização da operação de foco no elemento que contém o texto "Sports" da página web. A utilização de AT para avaliar esses requisitos também permite o teste sobre todas as camadas do software, desde o lado cliente da aplicação até as implementações do lado servidor que possam impactar na interface da aplicação com o usuário. 
Distinções na forma de apresentação dos problemas de acessibilidade entre as abordagens de avaliação também são encontradas. As ferramentas de avaliação automática que analisam apenas o conteúdo estático HTML apresentam um relatório contendo as linhas do código HTML que possuem erros de implementação, considerando as diretrizes da WCAG ou Section 508. Os AT, por outro lado, reportam os erros com uma lista dos cenários de uso que obtiveram falha de asserções na sua execução e, dessa forma, não seriam acessíveis aos usuários utilizando as mesmas estratégias e modelos de interação.

A utilização de AT para avaliar a acessibilidade auxilia na identificação dos cenários de uso que indivíduos com deficiência consideram durante sua interação. Mas essa característica também denota uma limitação da abordagem, se comparada às abordagens de avaliação automática atualmente utilizadas. Essa desvantagem está relacionada à necessidade de estabelecer previamente os casos de teste. Enquanto as abordagens de avaliação automática do código estático HTML geralmente atuam como ferramentas de validação de código, bastando o código estar pronto para utilização, os AT precisam que além do código da aplicação sejam preparados os casos de teste que serão executados pela ferramenta A-Pyccuracy. Os cenários, ou histórias do usuário, consideram detalhes específicos do domínio do conteúdo da aplicação (no exemplo apresentado anteriormente, é observada a busca por conteúdos textuais como as palavras "Sports" e "Tennis").

A definição prévia desses conteúdos textuais permite o estabelecimento de atributos de acessibilidade que não são considerados pelas ferramentas de avaliação automática de código estático HTML devido a subjetividade de análise. Borodin et al., por exemplo, reportam que, embora as ferramentas de avaliação automáticas possam avaliar se todas as imagens de um código HTML possuem alternativas textuais que as descrevam, essas ferramentas são incapazes de avaliar se o conteúdo dessa alternativa textual é de fato relevante para descrever a figura que elas mapeiam (Borodin et al., 2010). O estabelecimento prévio dos cenários de uso dos AT permite que essa avaliação subjetiva seja realizada durante a escrita do caso de teste, pelo desenvolvedor responsável pelo desenvolvimento do teste.

\subsection{Estudo de Caso}

Para avaliar o protótipo desenvolvido, foi realizado um estudo de caso utilizando AT e ferramentas de avaliação de acessibilidade em conteúdo estático HTML. Um estudo de caso é um estudo aprofundado em uma instância específica (ou em um número pequeno de instâncias) em um contexto específico da vida real. O exame das instâncias pode ser utilizado para construir entendimento, gerar teorias e hipóteses, apresentar evidências sobre a existência de um determinado comportamento ou para apresentar introspecções que seriam difíceis de serem adquiridas em experimentos (Lazar et al., 2010).

O estudo de caso apresentado neste capítulo teve como objetivo comparar os resultados de avaliações de acessibilidade realizadas com AT e os resultados obtidos utilizando as ferramentas 
de avaliação automática que estão disponíveis no mercado. A hipótese inicial desse estudo é a de que AT, por serem capazes de avaliar o conteúdo dinâmico de uma página web, dentro de um contexto de interação dos usuários, devem ser capazes de avaliar critérios de acessibilidade que a abordagem de avaliação automática estática de conteúdo HTML é incapaz de avaliar.

A ferramenta A-Pyccuracy implementa apenas interações de navegação por elementos interativos de uma página (utilizando a tecla TAB). Dessa forma, o estudo de caso utilizou como métricas apenas os resultados dos testes que estivessem relacionados com a navegação do usuário e a acessibilidade do teclado.

A seguir são apresentados os principais componentes do estudo de caso conduzido:

Questão : A análise da estrutura DOM renderizada no navegador web dentro de um contexto de utilização, considerando o uso de AT, possibilita a avaliação de requisitos de acessibilidade em RIA que não são avaliados por ferramentas de análise de código estático HTML?

Hipótese : A avaliação de acessibilidade utilizando AT permite a verificação de requisitos de acessibilidade que ferramentas de avaliação automática com base em código estático HTML não são capazes de avaliar em RIA.

Unidade de análise : Resultados obtidos da execução de avaliações automáticas de acessibilidade em RIA, utilizando ferramentas de análise de conteúdo estático HTML e AT. Foram desenvolvidas 13 widgets que continham diferentes componentes de interação de RIA, que implementavam requisitos de acessibilidade da WCAG 2.0.

Plano de análise de dados : Análise da compatibilidade dos resultados apresentados pelas avaliações automáticas com a implementação de requisitos de acessibilidade relacionados a critérios de sucesso da WCAG 2.0, nas 13 widgets.

As próximas seções apresentam detalhes a respeito da metodologia de pesquisa utilizada, os resultados obtidos e a discussão sobre os resultados.

\subsubsection{Metodologia}

Para comparar os resultados obtidos por testes de acessibilidade realizados com os AT e as ferramentas de avaliação automática de conteúdo estático HTML, considerando apenas problemas de acessibilidade associados à navegação de usuários, foi implementado um conjunto de páginas web para serem avaliadas por ambas abordagens.

Vale destacar que a hipótese deste trabalho está relacionada com a melhoria de processos de avaliação automática de aplicações web ricas (RIA). Assim, as páginas web implementadas continham widgets que realizavam a manipulação da sua estrutura DOM conforme interação do usuário. As widgets, utilizadas neste estudo, implementam quatro padrões de projeto de interação de 
Fly-out menu (ilustrado na Figura 4.4), Accordion menu (ilustrado na Figura 4.5), Overlay menu (ilustrdo na Figura 4.6) e Tabbed menu (ilustrado na Figura 4.7) definidos por Welie 5 .

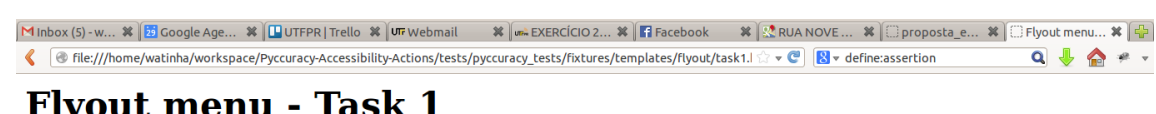

Flyout menu - Task 1

Select the North America item and then select the Canada link

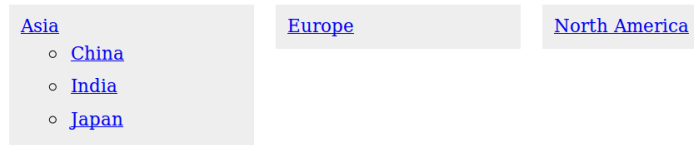

Give up this task

File:///home/watinha/workspace/Pyccuracy-Accessibility-Actions/tests/pyccuracy_tests/fixtures/templates/flyout/task1.htemlth

Figura 4.4: Exemplo de implementação da widget Fly-out utilizado no estudo de caso.

\section{Accordion - Task 2}

Click in the sports item and then click in the tenis link.

News
\[ \text { National } \]
Spornational
Sports

\section{Entertainment}

Figura 4.5: Exemplo de implementação da widget Accordion utilizado no estudo de caso.

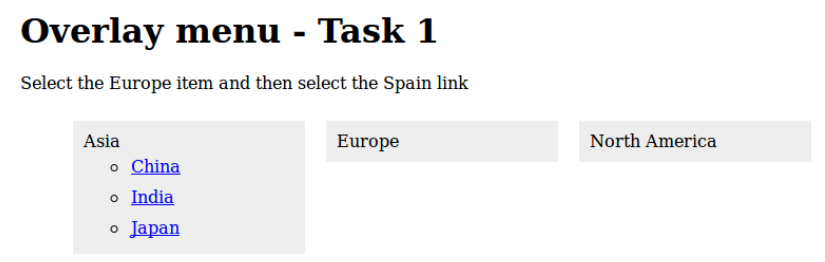

Figura 4.6: Exemplo de implementação da widget Overlay menu utilizado no estudo de caso.

A seguir, é descrito o funcionamento de cada um dos padrões de projeto implementados pelas widgets utilizadas no estudo de caso:

Fly-out : componente de interface de estilo menu, com múltiplos níveis de categorias. Subcategorias de um determinado nível podem ser acessadas posicionando o mouse sobre o elemento que representa a categoria de nível superior e contém essas sub-categorias. Ilustrado na Figura 4.4.

\footnotetext{
${ }^{5}$ http://www.welie.com/patterns
} 


\section{Tabbed Menu - Task 1}

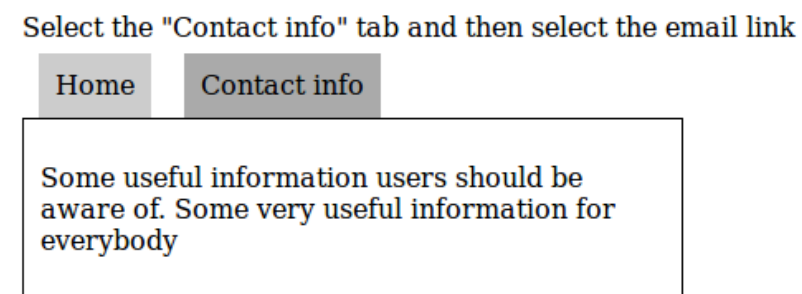

Figura 4.7: Exemplo de implementação da widget Tabbed menu utilizado no estudo de caso.

Accordion : componente de interface que guia a interação com múltiplos painéis. Apenas um painel é apresentado completamente e o usuário pode alterar qual painel é totalmente apresentado clicando em seções sempre visíveis associadas aos painéis. Ilutrado na Figura 4.5. As seções são freqüentemente posicionadas verticalmente no website e fazem parte do conteúdo de seu respectivo painel.

Overlay : componente de interface semelhante ao Fly-out, no entanto para acessar as sub-categorias é necessário que seja realizado um clique (em contraste à interação de posicionamento do mouse sobre o elemento do Fly-out) na categoria que as contém. Ilustrado na Figura 4.6.

Tabbed : componente de interface semelhante ao Accordion, no entanto a orientação das seções associadas aos painéis é freqüentemente apresentada horizontalmente e as seções não fazem parte do conteúdo de seu respectivo painel. Ilustrado na Figura 4.7.

Cada uma dessas widgets foi implementada em mais de uma página web, de modo que pudessem conter problemas de acessibilidade associados à navegação por teclado ou não. Os problemas de acessibilidade inseridos nas páginas web utilizadas nesse estudo estão associados à implementação de elementos que não podem receber foco ou que não respondem à ativação pelo teclado (pressionando a tecla ENTER). Esses problemas estão relacionados às diretrizes 6, 9, 12 e 13 da WCAG 1.0 e 1.3, 2.1, 2.4 e 3.2 da WCAG 2.0. Dessa forma, no estudo de caso, devem ser apenas considerados os problemas de acessibilidade reportados pelas ferramentas de avaliação de conformidade com as diretrizes da WCAG que estejam associados a essas diretrizes.

A distribuição das páginas web com suas respectivas implementações de widgets e problemas de acessibililidade nelas inseridos é apresentada a seguir:

1. Fly-out 1: Página web com uma widget Fly-out menu que não responde ao evento focus.

2. Fly-out 2: Página web com uma versão acessível da widget Fly-out menu.

3. Accordion 1: Página web com uma widget Accordion menu contendo elementos que não podem adquirir foco.

4. Accordion 2: Página web com uma widget Accordion menu contendo elementos que não respondem ao evento keypress da tecla ENTER. 
5. Accordion 3: Página web com uma versão acessível da widget Accordion menu implementada com elementos HEADINGS do HTML.

6. Accordion 4: Página web com uma versão acessível da widget Accordion menu implementada com elementos BUTTON do HTML.

7. Overlay 1: Página web com uma widget Overlay menu contendo elementos que não podem adquirir foco.

8. Overlay 2: Página web com uma widget Overlay menu contendo elementos que não respondem ao evento keypress da tecla ENTER.

9. Overlay 3: Página web com uma versão acessível da widget Overlay menu implementada com links.

10. Overlay 4: Página web com uma versão acessível da widget Overlay menu implementada utilizando elementos SPAN do HTML.

11. Tabbed 1: Página web com uma widget Tabbed menu contendo elementos que não podem adquirir foco.

12. Tabbed 2: Página web com uma widget Tabbed menu contendo elementos que não respondem ao evento keypress da tecla ENTER.

13. Tabbed 3: Página web com uma versão acessível da widget Tabbed menu.

Tabela 4.1: Widgets e problemas de acessibilidade utilizados no estudo de caso

\begin{tabular}{|c|c|c|c|}
\hline & Navegação por Foco & Interação por teclado & Estrutura de marcação \\
\hline (1.) Fly-out 1 & & & $<\mathrm{a}>$ \\
\hline (2.) Fly-out 2 & - & 匹 & $<\mathrm{a}>$ \\
\hline (3.) Accordion 1 & & & $<\mathrm{h} 2>$ \\
\hline (4.) Accordion 2 & I & & $<\mathrm{h} 2>$ \\
\hline (5.) Accordion 3 & - & 口 & $<\mathrm{h} 2>\mathrm{e}<\mathrm{a}>$ \\
\hline (6.) Accordion 4 & - & 口 & $<$ button $>$ \\
\hline (7.) Overlay 1 & & & $<\mathrm{li}>$ \\
\hline (8.) Overlay 2 & - & & $<\mathrm{li}>$ \\
\hline (9.) Overlay 3 & ! & 匹 & $<\mathrm{li}>\mathrm{e}<\mathrm{a}>$ \\
\hline (10.) Overlay 4 & 口 & 口 & $<\mathrm{li}>$ \\
\hline (11.) Tabbed 1 & & & $<\mathrm{li}>$ \\
\hline (12.) Tabbed 2 & " & & $<\mathrm{li}>$ \\
\hline (13.) Tabbed 3 & ! & प & $<\mathrm{li}>\mathrm{e}<\mathrm{a}>$ \\
\hline
\end{tabular}

Na Tabela 4.1, são apresentadas todas as widgets utilizadas no estudo de caso. Cada widget apresenta diferentes atributos em sua estrutura HTML que possibilita ou não a navegação por 
teclado, utilizando o evento de foco no navegador web. Os atributos apresentados na tabela estão relacionados aos seguite critérios:

- inserção dos elementos interativos na ordem de foco do navegador web (na coluna Navegação por Foco).

- presença de mecanismos que possibilitam a resposta a eventos gerados pelo teclado (na coluna Interação por teclado).

- estrutura de marcação HTML dos elementos interativos das widgets (na coluna Estrutura de marcação).

No estudo de caso, cada widget foi implementada como uma variação desses atributos (por exemplo, habilitando ou não a Navegação por Foco). E a combinação dos atributos de Navegação por Foco e Interação por teclado, garantem um interação acessível a usuários interagindo com a widget utilizando um leitor de tela e um teclado para navegar entre os elementos. Logo, esses atributos foram implementados de diferentes formas nas widgets do estudo de caso.

$\mathrm{O}$ atributo Estrutura de marcação foi inserido nas implementações de widgets para identificar se alterações realizadas na estrutura de marcação HTML da widget poderiam alterar os resultados das avaliações de acessibilidade das ferramentas.

Vale destacar, que todas as widgets sendo avaliadas consistem de componentes de interface que têm como objetivo fornecer mecanismos de navegação nas aplicações web. Assim, foi elaborado um cenário de navegação por teclado entre os elementos que compõem as widgets como caso de teste para a ferramenta que executa os AT. Os resultados obtidos pela execução desses casos de teste em cada uma das páginas web implementadas foram comparados com os resultados obtidos por ferramentas de avaliação automática de HTML estático disponíveis, atualmente.

Como métricas de avaliação entre as abordagens foram considerados os números de asserções corretas e erradas realizadas. As asserções tratam-se de afirmações que correspondem a critérios de sucesso da WCAG 2.0 e envolvem o resultado final do relatório de cada ferramenta, por exemplo:

- Se uma ferramenta identificar algum tipo de barreira de acessibilidade na página web e a página web realmente possui um problema na sua implementação, é contabilizada uma asserção correta para essa ferramenta.

- Se uma ferramenta identificar algum tipo de barreira de acessibilidade na página web e a página web não apresenta nenhum problema na sua implementação, é contabilizada uma asserção errada para essa ferramenta.

- Se uma ferramenta não identifica nenhuma barreira de acessibilidade na página web e a página web não apresenta nenhum problema na sua implementação, é contabilizada uma asserção correta para a ferramenta. 
- Se uma ferramenta não identifica nenhuma barreira de acessibilidade na página web e a página web possui um problema na sua implementação, é contabilizada uma asserção errada para a ferramenta.

Essa métrica de avaliação foi utilizada considerando o contexto de desenvolvimento web adotando práticas de Integração Contínua. Nesse processo de desenvolvimento, as ferramentas de avaliação automática definem a estabilidade de uma aplicação e podem interferir no processo de liberação de uma aplicação web se forem encontrados problemas que afetem a sua qualidade.

As ferramentas de avaliação automática de HTML estático utilizadas foram: (1.) DaSilva (disponível em http://dasilva.org.br/), (2.) EvalAccess (disponível em http://sipt07.si.ehu.es/evalaccess2/), (3.) WAVE (disponível em http://wave.webaim.org/) e (4.) fae - Functional Accessibility Evaluator (disponível em http://fae.cita.uiuc.edu/).

Essas ferramentas foram selecionadas de um conjunto de aplicações de avaliação automática apresentado pela $\mathrm{WAI}^{6}$. O critério de seleção considerou todas as ferramentas do conjunto estabelecido pela WAI que pudessem ser utilizadas pela plataforma web (sem a necessidade de instalação) e estivessem disponíveis para uso.

\subsubsection{Resultados}

No estudo de caso, as quatro ferramentas de avaliação de conteúdo estático HTML utilizadas (DaSilva, EvalAccess, WAVE e fae) reportaram problemas de acessibilidade associados às seguintes recomendações da WCAG, considerando apenas os problemas que estivessem associados à navegação nas widgets:

- Criar uma ordem lógica de navegação utilizando a tecla TAB pelos links, controle de formulários e objetos: checkpoint 9.4 da WCAG 1.0 e Critérios de Sucesso 2.4.3 e 1.3.1 da WCAG 2.0.

- Dividir blocos de informação: checkpoint 12.3 da WCAG 1.0 e Critério de Sucesso 2.4.1 da WCAG 2.0.

- Utilizar mecanismos de navegação de forma coerente: checkpoint 13.4 da WCAG 1.0 e Critérios de Sucesso 2.4.3 e 3.2.3 da WCAG 2.0.

- Agrupar links relacionados: checkpoint 13.6 da WCAG 1.0 e Critério de Sucesso 1.3.1 da WCAG 2.0.

Esses problemas de acessibilidade são reportados pelas ferramentas de avaliação de conteúdo estático HTML como erros de acessibilidade, indicando barreiras de acessibilidade da página web, e avisos (warnings) de acessibilidade, indicando possíveis barreiras de acessibilidade. Os

\footnotetext{
${ }^{6} \mathrm{http}: / / \mathrm{www} . w 3$. org/WAI/ER/tools/complete
} 
avisos de acessibilidade tratam-se de pontos de verificação (checkpoints) da WCAG 1.0 ou critérios de sucesso da WCAG 2.0 que não puderam ser verificados pelas ferramentas, mas devem ser analisados manualmente. Vale destacar que, neste estudo de caso, ambas as formas de relatório de problemas de acessibilidade (erros e avisos) foram contabilizadas como asserções na avaliação.

A partir do estudo de caso conduzido, as ferramentas de avaliação de conteúdo estático HTML e A-Pyccuracy, que utiliza AT, apresentaram os seguintes resultados em termos de números de asserções corretas e erradas para cada uma das ferramentas:

DaSilva : 5 asserções corretas e 8 asserções erradas.

EvalAccess : 7 asserções corretas e 6 asserções erradas.

WAVE : 6 asserções corretas e 7 asserções erradas.

fae report : 6 asserções corretas e 7 asserções erradas.

A-Pyccuracy (AT) : 12 asserções corretas e 1 asserção errada.

A Figura 4.8 ilustra em um gráfico de barras o conjunto geral dos números de asserções corretas e erradas de cada ferramenta.

\section{Asserções corretas e erradas}

15

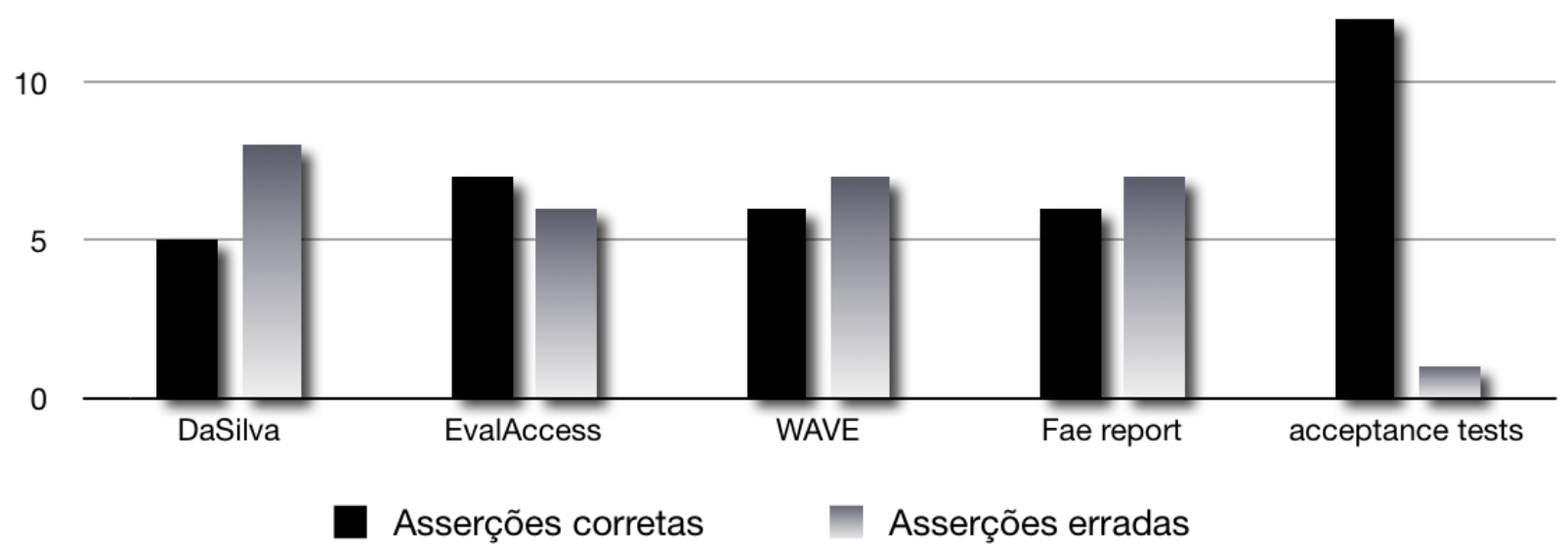

Figura 4.8: Número de asserções corretas e erradas para cada ferramenta de avaliação automática de acessibilidade utilizada no estudo de caso.

Para melhor analisar os resultados, as asserções erradas de cada ferramenta foram dividas em dois grupos: falso positivos, indicando que a ferramenta não identificou nenhuma barreira de acessibilidade enquanto a widget continha problemas na sua implementação; e falso negativos, indicando que a ferramenta identificou barreiras de acessibilidade quando a widget não possuía nenhum problema na sua implementação. Esses resultados são apresentados na Figura 4.9. 
Falso positivos e negativos

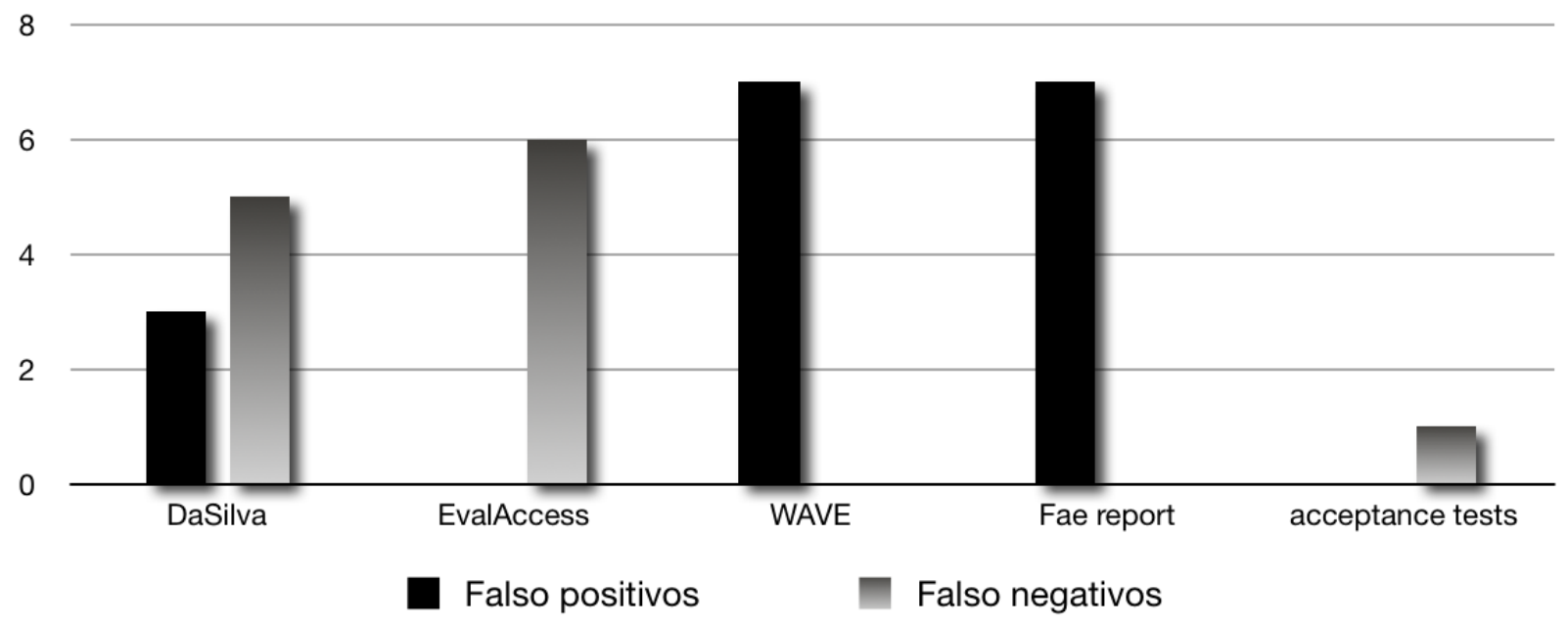

Figura 4.9: Esquema geral de avaliação de acessibilidade utilizando AT, em contraste ao método de avaliação de HTML estático

Vale destacar que as asserções incorretas (considerando ambos falso positivos e negativos) realizadas pelas ferramentas de avaliação de HTML estático foram causados pelo fato dessas ferramentas serem incapazes de identificar se um determinado elemento HTML é interativo ou não, utilizando JavaScript. Para definir se um elemento é interativo a usuários que navegam utilizando leitores de tela, são utilizados atributos TabIndex ou elementos de navegação como links, botões e formulários. As ferramentas de avaliação de conteúdo estático HTML são incapazes de analisar o estado do atributo TabIndex para elementos interativos, logo todos websites implementados com essas características foram classificados de forma errada na avaliação.

Essa mesma característica que levou as asserções incorretas nas ferramentas de avaliação de HTML estático não causou o mesmo impacto na utilizacão de AT. Os AT são capazes de avaliar a acessibilidade de navegação utilizando o atributo TabIndex e também são capazes de identificar os elementos HTML que são interativos em uma página web, simulando a interação do usuário e analisando se essa interação gerou alguma modificação na estrutura DOM.

\subsection{Discussão}

Considerando, inicialmente, o número de asserções corretas e erradas para cada ferramenta, pode ser observado que os AT apresentaram o menor número de asserções erradas nos testes, do estudo de caso (somente um). No entanto, é importante destacar que os AT também exigem um maior esforço para sua execução, uma vez que, diferente das outras ferramentas, essa abordagem tem como requisito a elaboração prévia dos casos de teste. Considerando o processo de desenvolvimento web que utiliza práticas de Integração Contínua, a elaboração de casos de AT é uma atividade inerente ao processo e a inclusão desses casos de teste específicos para o contexto de acessibilidade teriam baixo impacto nos custos gerais dessa atividade. 
Vale destacar também que a asserção correta ou errada para os AT é dependente da forma como os casos de teste foram elaborados. Para as widgets utilizadas no estudo de caso, foram elaborados casos de teste que aferiam o ponto exato da implementação que apresentava o problema de acessibilidade. Assim, a elaboração de um caso de teste para uma determinada widget não garante a validação de requisitos de acessibilidade para todas as suas funcionalidades. Os AT são realizados pela perspectiva do usuário, e validam um determinado cenário de uso, ou tarefa que deve ser realizada por ele. Nesse contexto, para garantir que a funcionalidade geral de uma aplicação web seja acessível aos usuários, é necessária a elaboração de múltiplos casos de teste e que esses casos de teste mapeiem todas as funcionalidades do sistema.

Tanto para o conjunto de widgets da amostra que apresentavam barreiras de acessibilidade quanto para o conjunto de widgets da amostra que não apresentavam barreiras de acessibilidade as ferramentas EvalAccess, WAVE e fae não identificaram nenhuma diferenciação. Ou seja, essas três ferramentas foram incapazes de avaliar requisitos de acessibilidade associados à navegação por teclado em RIA.

Enquanto as ferramentas WAVE e fae não reportaram nenhum tipo de erro ou aviso de acessibilidade para todas as páginas examinadas (fato que pode ser verificado pelo elevado número de falso positivos, que representam toda a amostra de páginas web que apresentavam problemas de implementação), a ferramenta EvalAccess apresentou avisos de acessibilidade para todas as versões de widgets utilizadas no estudo de caso (pode ser verificado pelo elevado número de falso negativos levantados pela ferramenta, que representam toda a amostra de páginas web que não apresentavam nenhum tipo de problema na sua implementação).

Considerando o contexto de desenvolvimento de aplicações Web 2.0, essas ferramentas gerariam um grande impacto no processo de liberação de sistemas para o ambiente de produção. As ferramentas WAVE e fae, devido ao elevado número de falso positivos reportados, não seriam capazes de identificar barreiras de acessibilidade similares aos utilizados nos casos de teste e, dessa forma, aumentariam os riscos de colocar um sistema contendo barreiras de acessibilidade em ambiente de produção. A ferramenta EvalAccess, por outro lado, impediria o processo de liberação do software em todos os casos de teste, mesmo para os casos em que o sistema não contém nenhum tipo de problema.

Por fim, é importante destacar que todos os problemas de acessibilidade identificados pelas ferramentas EvalAccess e DaSilva tratavam-se de avisos de acessibilidade, de forma que esses resultados precisariam ser validados por engenheiros e designers para identificar se eles realmente se tratavam de barreiras de acessibilidade. E, nesse contexto, essa forma de avaliação caracterizaria um método semi-automático, contrastando com a abordagem que utiliza AT, proposta deste trabalho, e que é totalmente automática após a elaboração do conjunto de casos de teste. 


\subsection{Considerações finais}

Este capítulo apresentou o desenvolvimento de uma abordagem que utiliza AT (ferramenta APyccuracy) para avaliar requisitos de acessibilidade em RIA. Foi descrita a implementação de uma ferramenta que executa os testes automaticamente e considera cenários de uso de indivíduos que interagem com as aplicações web por meio de Tecnologias Assistivas. A abordagem auxilia o desenvolvimento de soluções de design acessíveis com o uso de testes automáticos que verificam todas as camadas dos sistemas.

A solução adiciona custos relacionados à elaboração dos casos de teste que mapeiam o modelo de interação de usuários com deficiência. No entanto, esses custos possuem baixo impacto se incluídos em processos de desenvolvimento que utilizem práticas de Integração Contínua (uma vez que esses ambientes já elaboram os casos de teste para os requisitos funcionais do sistema).

A utilização de AT também permite avaliar a estrutura dinâmica do conteúdo HTML, inserida em um contexto de interação com o usuário, o que permite a validação de requisitos de acessibilidade em RIA. 



\section{ARIA-CHECK - Avaliando requisitos ARIA em widgets}

este capítulo, é descrita uma nova proposta de avaliação de requisitos de acessibilidade em RIA que estende a proposta apresentada no capítulo anterior (Capítulo 4). Esta proposta consiste da elaboração de um apoio à avaliação automática de ARIA, a ferramenta aria-check, que delimita o domínio de avaliação para widgets, em comparação com a avaliação da aplicação web como um todo. Essa delimitação do escopo de avaliação torna possível reutilizar casos de AT definidos para um conjunto de widgets, sem a necessidade de elaborar os casos de teste para cada aplicação sendo avaliada.

Considerando o contexto geral desta tese e o procedimento de pesquisa-ação, o desenvolvimento da ferramenta aria-check caracterizou a condução do segundo ciclo das atividades de planejar, agir, descrever e avaliar (Seção 1.4). A utilização de AT para avaliar a acessibilidade de RIA dentro das práticas de BDD tinha como principal desvantagem a necessidade de elaborar casos de AT para cada aplicação web sendo desenvolvida. Nesse contexto, essa etapa de desenvolvimento desta tese teve como objetivo melhorar a escalabilidade da avaliação de acessibilidade em RIA, para permitir o reuso de casos de teste entre diferentes aplicações web. Adicionalmente, nessa etapa, também foram desenvolvidos recursos que avaliam atributos da especificação ARIA, que não eram avaliados nas abordagens anteriormente descritas.

Os resultados apresentados neste capítulo foram também reportados em dois trabalhos submetidos para revista e conferência como resultados parciais desta tese, na linha de pesquisa de acessibilidade em RIA: 
Artigo Completo submetido para revista UAIS - Universal Access in the Information Society

: Using Acceptance Tests for Evaluating ARIA Requirements (em fase de revisão).

Artigo aceito para publicação no SAC 2014 - Symposium on Applied Computing : Keyboard Navigation Mechanisms in Tab Widgets: an investigation on ARIA's Conformance.

Este capítulo apresenta a seguinte estrutura: na próxima seção (Seção 5.1), é apresentada a motivação para o desenvolvimento do trabalho descrito neste capítulo; na Seção 5.2, é apresentada a abordagem de avaliação da especificação ARIA para widgets; na Seção 5.3, é apresentada uma comparação da ferramenta aria-check com trabalhos relacionados; e na Seção 5.4, são apresentadas as conclusões e considerações finais deste capítulo.

\subsection{Considerações Iniciais}

Como uma das principais referências em acessibilidade na Web, a WCAG (Kelly et al., 2005; Freire et al., 2007) estabelece um conjunto de diretrizes que descrevem potenciais barreiras de acessibilidade em aplicações web e provê soluções de design para elas (W3C, 1999, 2008b). A versão atual da WCAG (2.0) foi elaborada para ser tecnologicamente neutra, para ser aplicável no desenvolvimento de aplicações web que utilizam tecnologias atuais e do futuro (Kelly et al., 2007). As diretrizes também descrevem critérios que podem ser avaliados objetivamente com uma combinação de testes automáticos (utilizando ferramentas de avaliação automática, como Hera ${ }^{1} \mathrm{e}$ daSilva $^{2}$, e ferramentas de autoria como o Bluefish ${ }^{3}$ e Dreamweaver ${ }^{4}$ ) e inspeções humanas.

Avaliações manuais (inspeções por humanos) possuem um custo elevado de execução em ambientes de desenvolvimento nos quais o software é constantemente atualizado e liberado para produção. Nesses ambientes, a tarefa de avaliação de acessibilidade se utiliza apenas de práticas de testes automáticos. Nesse contexto, é importante destacar que, embora a utilização de testes automáticos apresente vantagens relacionadas a escalabilidade e ampla aplicação a uma variedade de páginas web, os testes automáticos utilizam-se de heurísticas para determinar violações das diretrizes de acessibilidade, não sendo capazes de detectar todo tipo de barreira de acessibilidade que possa ocorrer em uma aplicação web (Brajnik, 2008a). Segundo Velasco et al., os testes automáticos que analisam apenas o código HTML também não são capazes de avaliar todos requisitos da especificação ARIA impostos pelas aplicações "Web 2.0" e são incapazes de verificar conteúdos gerados dinamicamente na estrutura DOM, que são essenciais para RIA (Velasco et al., 2008).

Considerando a perspectiva do uso de diretrizes como base para uma avaliação de acessibilidade, alguns autores questionam a validade da WCAG com relação a sua clareza e objetividade.

\footnotetext{
${ }^{1}$ http://www.sidar.org/hera/index.php.en

${ }^{2}$ http://www.dasilva.org.br/

${ }^{3} \mathrm{http}: / /$ bluefish.openoffice.nl/

${ }^{4}$ http://www.adobe.com/products/dreamweaver/
} 
Brajnik et al., por exemplo, reportam um experimento em que avaliadores especialistas em acessibilidade relataram $20 \%$ falso positivos em uma avaliação de conformidade com as diretrizes e não conseguiram identificar 32\% problemas de acessibilidade de um website (Brajnik et al., 2010). Kelly et al. também destacaram o uso de linguagem genérica, termos e definicões vagas na documentação que podem atrapalhar o entendimento dos objetivos das diretrizes (Kelly et al., 2007). Nesse contexto, o processo de desenvolvimento deve considerar o uso de métodos empíricos para avaliar a acessibilidade como técnicas de screening e testes com usuário (Brajnik, 2008a). Porém, recrutar usuários reais para testar todos os aspectos de um design em evolução possui um custo elevado (Nielsen e Mack, 1994), agravando-se quando considerando o desenvolvimento de aplicações web que possuem elevada freqüência de atualizações e modificações sendo realizadas em curtos intervalo de tempo.

\subsection{AT para widget tabpanel}

O protótipo A-Pyccuracy descrito no Capítulo 4, se aplica no contexto de um método de avaliação de acessibilidade que tem como base a elaboração de casos de AT que sejam acessíveis. A ferramenta é capaz de analisar conteúdos gerados dinamicamente, utilizando a API DOM do JavaScript, realizando asserções na interface, dada a descrição de um cenário de uso (caso de AT). No entanto, essa abordagem requer que os AT sejam implementados utilizando a ferramenta Pyccuracy, antes que a avaliação seja de fato realizada. É importante destacar também que os casos de teste são fortemente acoplados ao domínio da página web para a qual eles foram escritos, e essa característica torna difícil o reuso desses casos de teste entre diferentes aplicações.

A ferramenta aria-check ${ }^{5}$ implementa a mesma abordagem utilizada no protótipo A-Pyccuracy descrita no Capítulo 4, utilizando Behaviour Based Acceptance Tests (Hsia et al., 1994) para avaliar a acessibilidade no comportamento dinâmico de uma RIA, mas sua abordagem inclui um conjunto de casos de testes que não são específicos de domínio e, portanto, podem ser reutilizados em diferentes aplicações web.

A abordagem definida na ferramenta aria-check também não exige que os desenvolvedores implementem os casos de teste, diferentemente do protótipo apresentado no Capítulo 4, uma vez que ela já inclui um conjunto de casos de teste que podem ser aplicados a qualquer aplicação web. No entanto, esse conjunto de casos de teste avaliam, até o momento, apenas o comportamento acessível de widgets RIA, como tabpanels ${ }^{6}$, $_{\text {tooltips }}{ }^{7}$, alert ${ }^{8}$, entre outras. Uma vez que as widgets RIA possuem um modelo pré-estabelecido de interação (definido na especificação ARIA (W3C, 2011)), torna-se possível gerar um único conjunto de casos de teste para cada widget, e esse conjunto de casos de teste pode ser aplicado a qualquer aplicação web que contenha essa widget.

\footnotetext{
${ }^{5}$ http://github.com/watinha/aria-check

${ }^{6}$ http://www.w3.org/TR/wai-aria/roles\#tab

${ }^{7}$ http://www.w3.org/TR/wai-aria/roles\#tooltip

${ }^{8}$ http://www.w3.org/TR/wai-aria/roles\#alert
} 
Os casos de AT da ferramenta aria-check foram elaborados seguindo uma implementação de referência de widgets desenvolvida em conformidade com a especificação ARIA (como por exemplo, utilizando as widgets disponíveis no website da iCITA - Illinois Center for Information Technology and Web Accessibility $^{9}$ ). Considerando essa implementação de referência, são realizados os seguinte passos:

1. Identificação dos cenários de uso acessíveis para uma determinada widget.

2. Elaboração dos casos de AT específicos de domínio para a mesma widget, seguindo uma abordagem semelhante à descrita no Capítulo 4.

3. Transformação do casos de AT específico de domínio para casos de Teste genéricos, removendo as asserções específicas de domínio da especificação dos testes.

Essa abordagem para gerar os casos de teste específicos de domínio a partir da implementação de referência e remover as asserções específicas de domínio dos casos de AT é ilustrada na Figura 5.1. Na figura, pode-se notar que, a partir da especificação da widget tab de ARIA, foi construída uma implementação acessível (que no caso deste trabalho, foi obtida da iCITA). A seguir, são construídos cenários de uso dessa widget, que servem como dados iniciais para o desenvolvimento de casos de teste a serem utilizados para simular os usuários interagindo com a widget. Todos os casos de teste gerados, que passam a ter situações mais genéricas de uso das interações, são então submetidos para a ferramenta aria-check executa-los automaticamente.

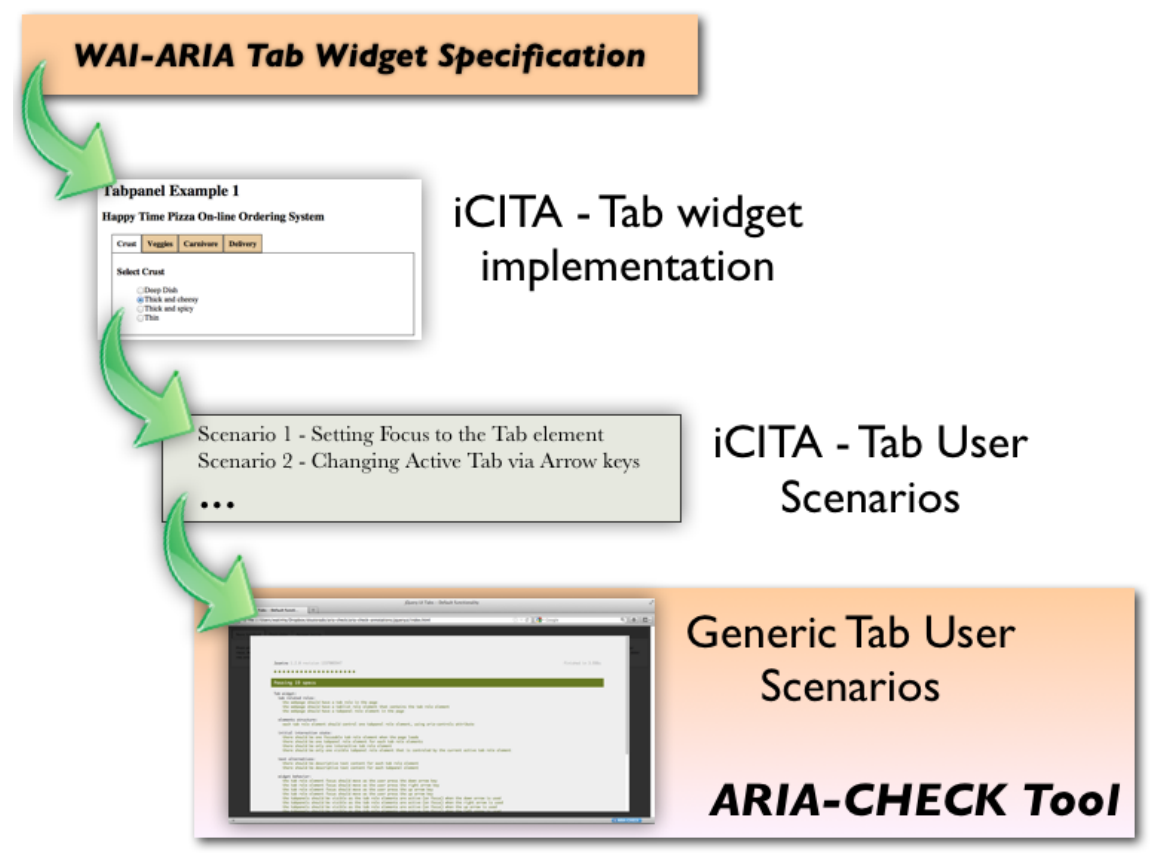

Figura 5.1: Geração dos casos de AT genéricos a partir de uma implementação de referência. Figura extraída do artigo submetido à UAIS - Universal Access in Information Society.

\footnotetext{
${ }^{9}$ http://test.cita.illinois.edu/aria/
} 
É importante destacar que, como a ferramenta aria-check não utiliza casos de teste específicos de domínio e pode ser assumido um modelo de interação pré-estabelecido dada uma implementação padrão da widget, torna-se possível reutilizar os casos de AT para diferentes aplicações web. No entanto, essa abordagem também torna impossível avaliar critérios subjetivos, que antes eram incluídos pelos desenvolvedores na fase de elaboração dos casos de teste. Esse processo de transformação dos casos de AT específicos de domínio em casos de teste genéricos é ilustrado na Figura 5.2 .

\section{iCITA - Tab User Scenarios}

\section{Generic Tab User Scenarios}

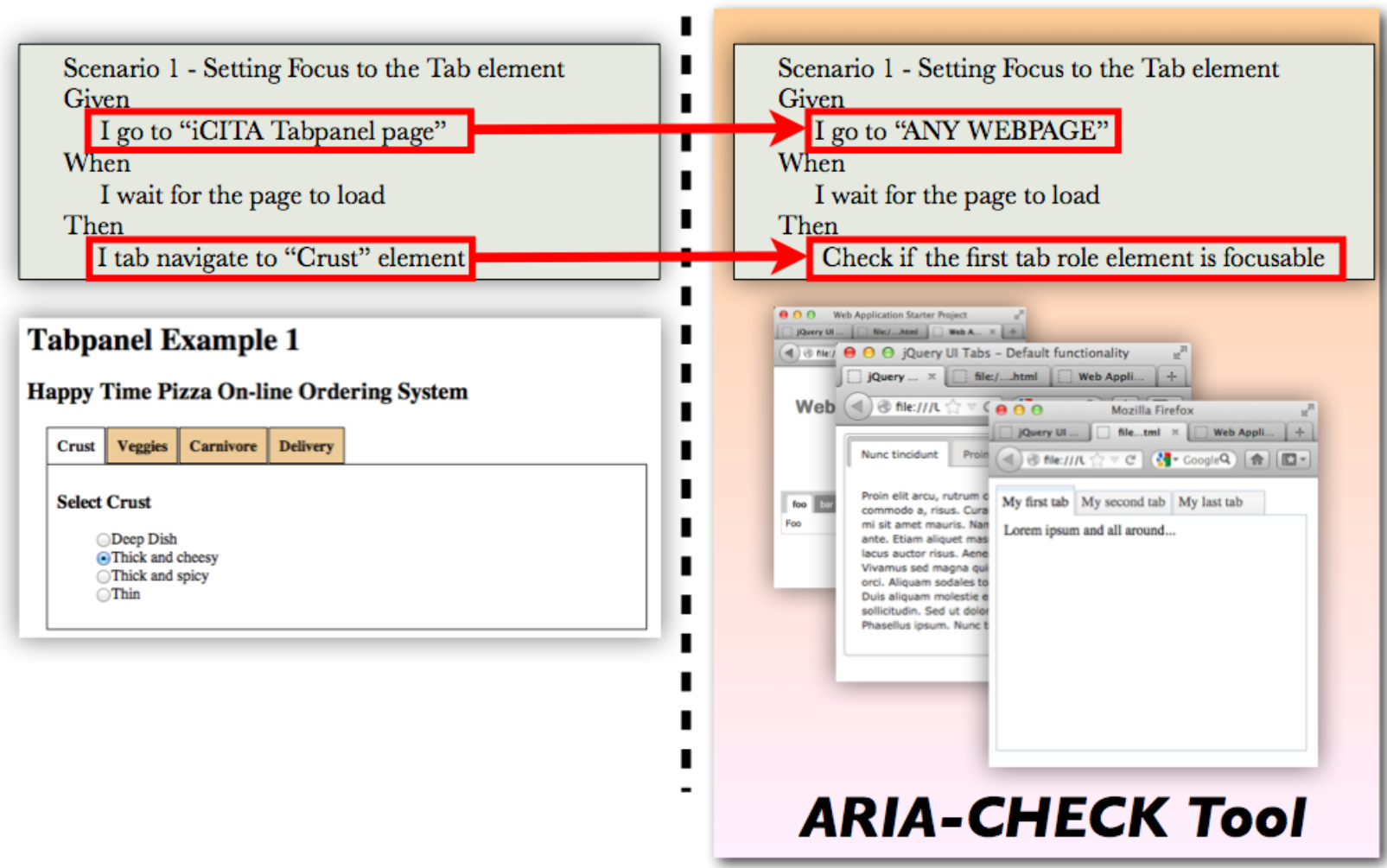

Figura 5.2: Geração dos casos de teste genéricos a partir dos casos de teste específicos de domínio. Figura extraída do artigo submetido à UAIS - Universal Access in Information Society.

A primeira versão da ferramenta aria-check implementa apenas a avaliação de requisitos ARIA para a widget tabpanel.

A ferramenta aria-check foi implementada utilizando o Mozilla Addon-SDK ${ }^{10}$, como um addon do navegador Mozilla Firefox para executar o conjunto de AT em qualquer página web que seja carregada no navegador. Foi também utilizado o framework Jasmine ${ }^{11}$ de Desenvolvimento Orientado a Comportamento (BDD - Behavior-Driven Development) para elaborar os casos de AT. O Addon-SDK da Mozilla permite a inserção dos casos de teste da ferramenta aria-check, escri-

\footnotetext{
${ }^{10}$ https://addons.mozilla.org/en-US/developers/docs/sdk/latest/

${ }^{11} \mathrm{http}: / /$ pivotal.github.com/jasmine/
} 
tos no framework Jasmine, em qualquer aplicação disponível na Web. Como implementação de referência da widget tabpanel foi utilizada a implementação exemplo disponível no website da iCITA $^{12}$.

Na Figura 5.3, o escopo da ferramenta aria-check é ilustrado. A figura, representa a ferramenta aria-check implementa um mecanismo de execução de um conjunto de verificações de atributos da especificação ARIA e casos de AT para a widget tabpanel. Assim, dada uma widget tabpanel, a ferramenta aria-check é executada e apresenta o relatório de verificações de atributos da especificação ARIA que foram corretamente inseridos ou não e os resultados da execução dos casos de AT para a widget tabpanel.

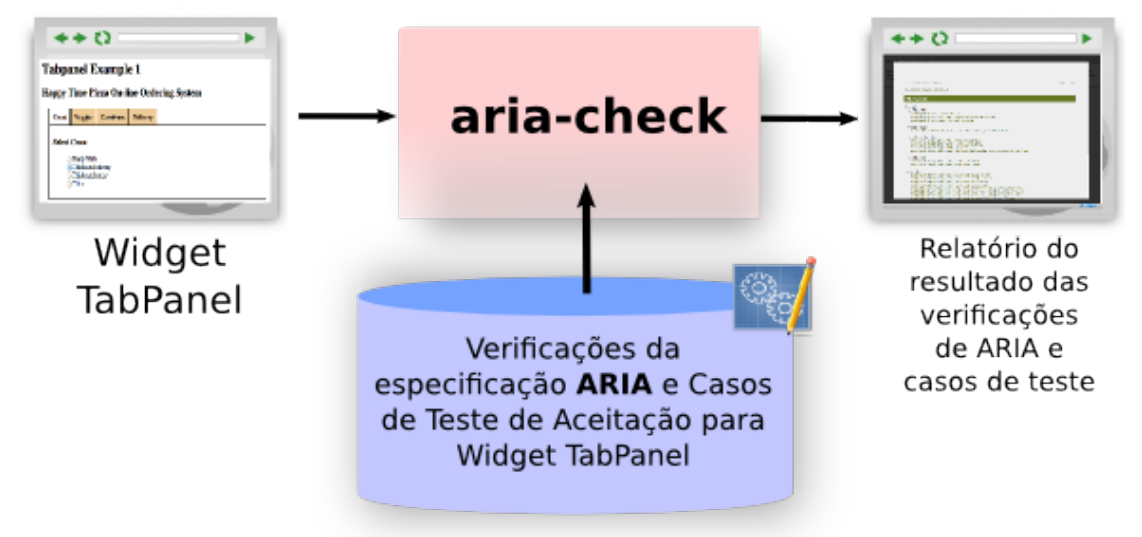

Figura 5.3: Esquema de funcionamento da ferramenta aria-check para avaliar a conformidade de tabpanel widgets com a especificação ARIA.

Quando uma página web é carregada no navegador Firefox com o addon aria-check instalado, um botão rotulado aria-check torna-se visível na barra de addons do Firefox (localizada na parte inferior do navegador). Quando esse botão é pressionado, o addon aria-check realiza um conjunto inicial de verificações nos elementos HTML de uma página web e executa casos de AT para avaliar se as widgets tabpanel apresentadas foram desenvolvidas em conformidade com os requisitos da especificação ARIA. Os resultados de todas as verificações e asserções são apresentados no navegador web, como ilustrado na Figura 5.4, para uma widget tabpanel que implementa todos os requisitos da especificação ARIA, e Figura 5.5 para uma widget tabpanel que não implementa todos os requisitos da especificação ARIA.

Na próxima seção (Seção 5.2.1), o modelo de interação da widget tabpanel é apresentado, utilizando a especificação ARIA. Esse modelo de interação foi utilizado como referência para a geração dos casos de teste genéricos da ferramenta aria-check. Na Seção 5.2.2, são descritas as verificações iniciais que são necessárias para executar os casos de AT para a widget tabpanel. Na Seção 5.2.3, são apresentados os casos de AT Comportamentais que avaliam a conformidade da widget tabpanel com a especificação ARIA. Na Seção 5.2.4, é descrito o processo de avaliação da ferramenta aria-check.

\footnotetext{
${ }^{12} \mathrm{http} / /$ test.cita.illinois.edu/aria/tabpanel/tabpanel1.php
} 


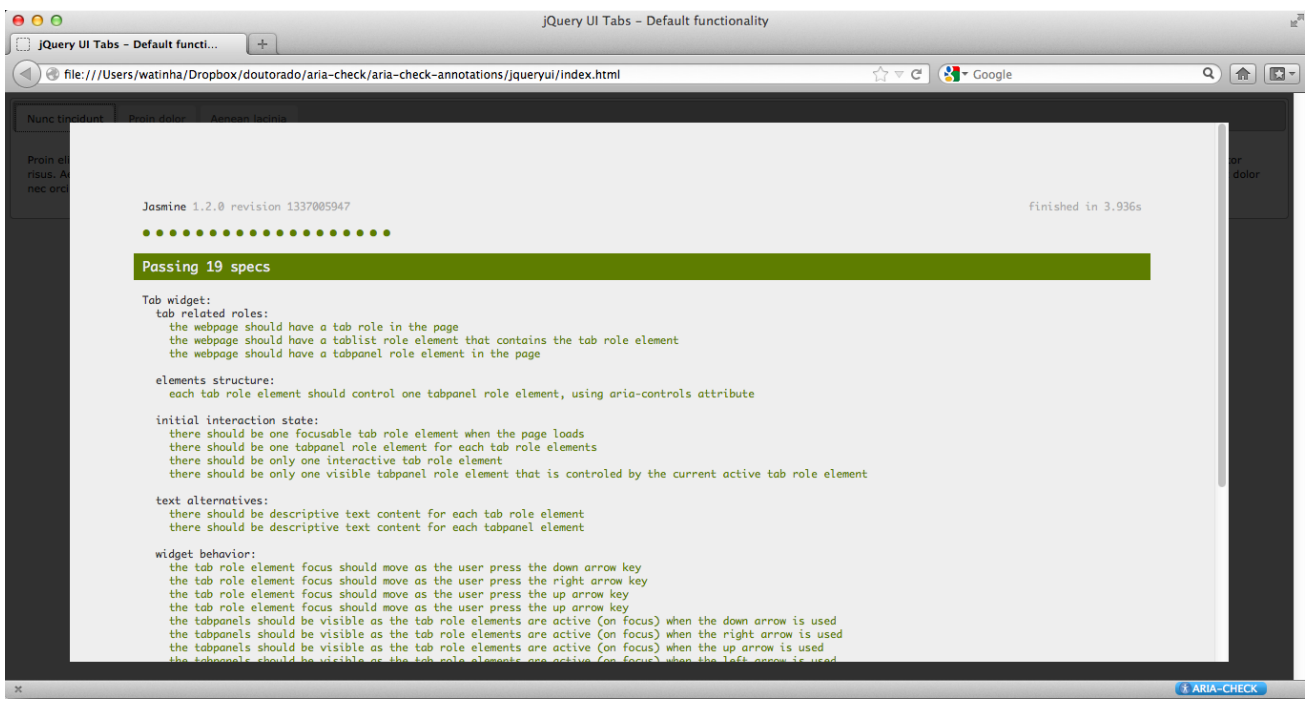

Figura 5.4: Tela da ferramenta aria-check que apresenta os resultados dos casos de teste para uma widget que implementa todas os requisitos da especificação ARIA.

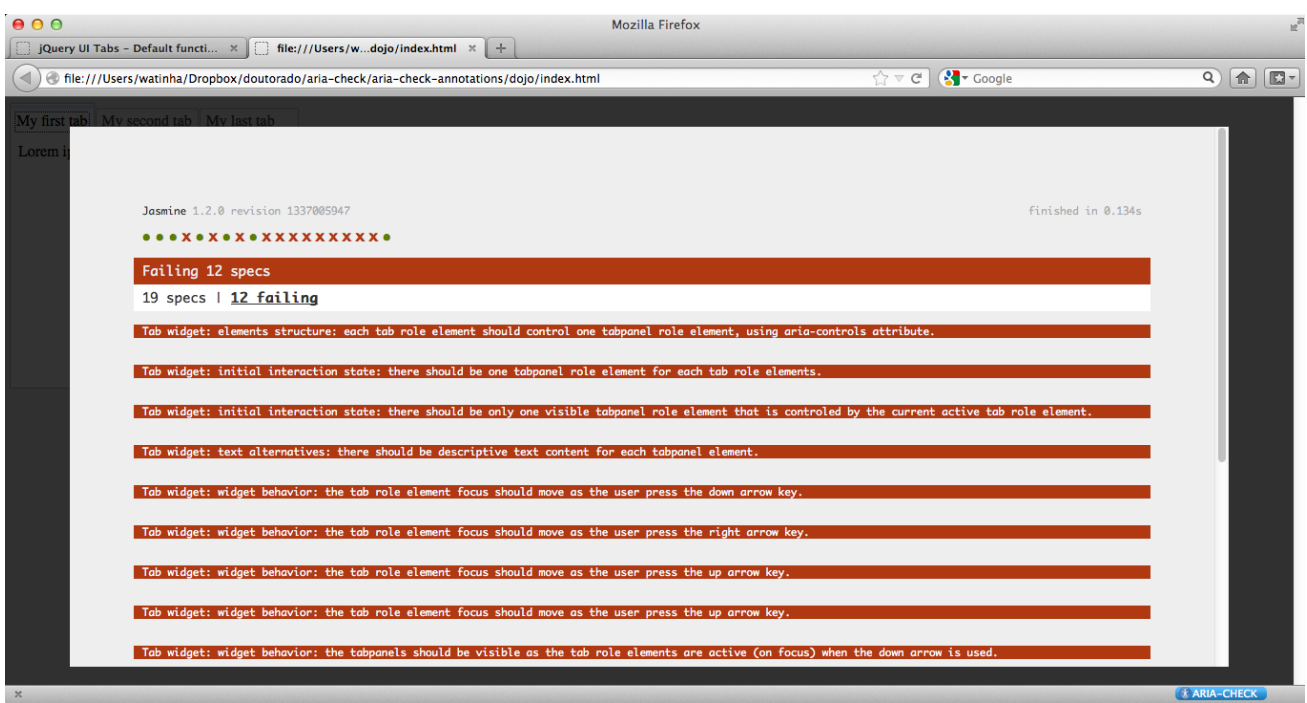

Figura 5.5: Tela da ferramenta aria-check que apresenta os resultados dos casos de teste para uma widget que não implementa todas os requisitos da especificação ARIA.

\subsubsection{Modelo de Interação Acessível para a widget tabpanel}

Widgets tabpanel são implementações em linguagem JavaScript do padrão de projeto de interação de "Abas", definido por Welie ${ }^{13}$. As Abas são freqüentemente utilizadas para navegação por diferentes seções de uma aplicação. O padrão de projeto considera o uso de uma linha horizontal de elementos que contém diferentes rótulos de seções, que representam as abas. Cada aba é associada a um painel que contém outros elementos que correspondem a uma determinada seção ou aba. Existe apenas uma aba ativa em um componente de interface de abas, e essa aba ativa é destacada e visualmente conectada com o painel que a representa. Apenas o painel associado com a aba ativa

\footnotetext{
${ }^{13} \mathrm{http}: / /$ www.welie.com/patterns/showPattern.php?patternID=tabbing
} 
é visível aos usuários. Todos os elementos de aba que não estão ativos podem ser ativados quando forem clicados.

$\mathrm{Na}$ ferramenta aria-check, foi utilizada como implementação de referência a widget tabpanel disponível no website da iCITA ${ }^{14}$, para gerar os casos de AT. Essa implementação de referência apresenta um modelo de interação que permite que os usuários naveguem pelas abas utilizando interações de teclado apenas. Além disso, a implementação de referência também apresenta marcações dos atributos role, state e property da especificação ARIA no código HTML, para disponibilizar informações semânticas necessárias para usuários com deficiência visual interagirem com a widget utilizando uma Tecnologia Assistiva.

A aba ativa da widget tabpanel é acessível por meio de navegação por foco (utilizando o atributo TabIndex do HTML). Quando a aba ativa recebe foco, o usuário pode escutar (por meio da Tecnologia Assistiva) que ele está interagindo com uma widget tabpanel e é informado de quantos elementos de aba estão disponíveis na widget. O usuário pode então mudar a aba que encontra-se ativa utilizando as teclas de seta para baixo e direita para mover o cursor de aba ativa para o próximo elemento de aba, ou utilizar as teclas de seta para cima e esquerda para mover o cursor de aba ativa para o elemento de aba anterior. Quando o usuário selecionar o elemento de aba que ele deseja interagir, o painel associado àquele elemento de aba é apresentado e o usuário pode interagir com o seu conteúdo.

Quando qualquer elemento de aba está ativo e tem o foco da aplicação web, o usuário pode pressionar as teclas control e home ao mesmo tempo $(C T R L+H O M E)$ para mover o cursor das abas e o foco do navegador web para o primeiro elemento de aba que é apresentado na widget, ou pressionar as teclas control e end ao mesmo tempo $(C T R L+E N D)$ para mover o cursor de abas e o foco do navegador para o último elemento de aba apresentado na widget.

Se o foco do navegador web estiver em qualquer painel, que seja associado a um elemento de aba específico, o usuário pode pressionar as teclas control e seta para cima ao mesmo tempo (CTRL + UP ARROW) para mover o foco do navegador de volta para o elemento de aba que é associado ao painel ativo no momento. Adicionalmente, se o foco do navegador web estiver dentro de um painel, o usuário pode mover o cursor de aba ativa e o foco do navegador para o próximo elemento de aba ou para a aba anterior, utilizando as teclas control e page up/down $(C T R L+P A G E U P$ para mover o cursor de aba ativa e o foco para a aba anterior e CTRL + PAGEDOWN para mover o foco para a próxima aba).

A ferramenta aria-check utiliza esse modelo de interação como implementação de referência para a widget tabpanel. O objetivo da ferramenta é avaliar se outras instâncias da widget tabpanel implementam o mesmo modelo de interação da widget tabpanel disponível no website da iCITA e que foi desenvolvido em conformidade com a especificação ARIA.

\footnotetext{
${ }^{14}$ http://test.cita.illinois.edu/aria/tabpanel/tabpanel1.php
} 


\subsubsection{Verificações Iniciais}

Antes de executar os casos de AT, a ferramenta aria-check precisa identificar os elementos que compõem a widget que será avaliada (Roles), a sua estrutura (Estrutura dos elementos), o Estado Inicial da Interação e o seu conteúdo (Alternativas Textuais). Na abordagem descrita no Capítulo 4, o desenvolvedor identificaria os elementos que compõem a widget, durante a elaboração dos casos de teste. Na abordagem utilizada pela ferramenta aria-check, por outro lado, esses elementos são identificados automaticamente, por meio de uma busca por elementos HTML que estejam marcados como sendo a widget que será avaliada, por meio do seu atributo role. Por exemplo: se a ferramenta está avaliando a acessibilidade de uma widget tabpanel, primeiramente é necessário identificar quais são os elementos HTML que compõem essa widget (como elementos que contenham a marcação do atributo role com o valor de tab, tabpanel e tablist), antes de executar os testes e simular a interação do usuário com esses elementos. Se essa verificação não for realizada, a ferramenta aria-check não teria conhecimento dos elementos que devem ser alvo dos passos de interação que seriam simulados durante os AT.

Essas verificações também são utilizadas para determinar se as propriedades e os estados da widget foram configurados corretamente e permitem que os casos de teste comportamentais sejam executados. Essas verificações foram divididas de acordo com os seguinte grupos:

\section{Roles :}

- Checar se existem elementos HTML com o atributo role com o valor $t^{2} b^{15}$.

- Checar se existe um elemento HTML com o atributo role com o valor tablist que contenha os outros elementos identificados como tabs ${ }^{16}$.

- Checar se existe um elemento HTML com o atributo role com o valor tabpanel para cada elemento HTML com atributo role com o valor $t a b^{17}$.

\section{Estrutura de Elementos :}

- Checar se todos os elementos HTML com atributo role com o valor tab são associados com um elemento HTML com o atributo role com o valor tabpanel utilizando o atributo aria-controls $^{18}$.

\section{Estado Inicial da Interação :}

- Checar se existe um elemento tab que possui o atributo TabIndex com um valor não negativo (W3C, 2013e).

- Checar se existe o mesmo número de elementos tabpanel e elementos tab.

\footnotetext{
${ }^{15} \mathrm{http} / / /$ www.w3.org/TR/wai-aria/roles\#tab

${ }^{16} \mathrm{http} / / /$ www.w3.org/TR/wai-aria/roles\#tablist

${ }^{17} \mathrm{http}: / /$ www.w3.org/TR/wai-aria/roles\#tabpanel

${ }^{18} \mathrm{http}$ ://www.w3.org/TR/wai-aria/states_and_properties\#aria-controls
} 
- Checar se existe apenas um elemento tab que pode receber foco (W3C, 2013e).

- Checar se existe um único elemento tabpanel que é visível quando a widget é carregada no navegador web: verificando os atributos CSS de visibilidade (visibility) ou display ou mesmo utilizando o atributo HTML aria-hidden ${ }^{19}$.

\section{Alternativas Textuais :}

- Checar se existe um conteúdo textual que descreve cada elemento tab: verificando os atributos HTML title, aria-labelledby, aria-describedby ou aria-labe $l^{20}$.

- Checar se existe algum conteúdo textual que descreve cada elemento tabpanel: verificando os atributos HTML title, aria-labelledby, aria-describedby ou aria-label ${ }^{21}$.

\subsubsection{AT para a widget TabPanel}

Após executar as verificações iniciais relacionadas a Roles, Estrutura de Elementos, Estado Inicial da Interação e Alternativas Textuais, a ferramenta aria-check executa os casos de AT. Considerando a implementação de referência da widget tabpanel disponível no website da iCITA $^{22}$, os casos de teste consistem de simulações de comandos de teclado e asserções de interface para verificar como a widget reage aos eventos disparados.

Existem nove atalhos de teclado que representam o modelo de interação da widget tabpanel disponível no website da iCITA (utilização de setas para cima/baixo/esquerda/direita, CONTROL + seta para cima, home, end, CONTROL+PAGEUP/PAGEDOWN). Para elaborar casos de AT que abordem cada um desses atalhos de teclado, foi implementado um caso de teste para cada possibilidade de interação descrita. Além disso, os atalhos de teclado referentes a navegação utilizando as setas (cima/baixo/esquerda/direita) possuem dois casos de teste possíveis: um para verificar a mudança de foco entre as abas e mudança de apresentação dos painéis associados a cada aba, totalizando treze casos de teste.

A lista completa de todos os casos de AT é apresentada a seguir:

1. Checar se o foco é alterado para o próximo elemento tab quando a tecla de seta para baixo é pressionada em todos os elementos tab:

(a) Posicionar o foco em um elemento tab.

(b) Disparar um evento de pressionamento da tecla de seta para baixo (utilizando os eventos JavaScript de keydown, keyup e keypress).

(c) Verificar se o foco foi alterado para o próximo elemento tab dentro da lista de abas.

\footnotetext{
${ }^{19}$ http://www.w3.org/TR/wai-aria/states_and_properties\#aria-hidden

${ }^{20} \mathrm{http}: / / \mathrm{www} . w 3$. org/TR/wai-aria/states_and_properties

${ }^{21} \mathrm{http}: / /$ www.w3.org/TR/wai-aria/states_and_properties

${ }^{22} \mathrm{http} / / /$ test.cita.illinois.edu/aria/tabpanel/tabpanel1.php
} 
2. Checar se o foco é alterado para o próximo elemento tab quando a tecla de seta para direita é pressionada em todos os elementos tab:

(a) Posicionar o foco em um elemento tab.

(b) Disparar um evento de pressionamento da tecla de seta para direita (utilizando os eventos JavaScript de keydown, keyup e keypress).

(c) Verificar se o foco foi alterado para o próximo elemento tab dentro da lista de abas.

3. Checar se o foco é alterado para o elemento tab anterior quando a tecla de seta para cima é pressionada em todos os elementos $t a b$ :

(a) Posicionar o foco em um elemento $t a b$.

(b) Disparar um evento de pressionamento da tecla de seta para cima (utilizando os eventos JavaScript de keydown, keyup e keypress).

(c) Verificar se o foco foi alterado para o elemento tab anterior dentro da lista de abas.

4. Checar se o foco é alterado para o elemento tab anterior quando a tecla de seta para esquerda é pressionada em todos os elementos tab:

(a) Posicionar o foco em um elemento tab.

(b) Disparar um evento de pressionamento da tecla de seta para esquerda (utilizando os eventos JavaScript de keydown, keyup e keypress).

(c) Verificar se o foco foi alterado para o elemento tab anterior dentro da lista de abas.

5. Checar se o foco é alterado para o primeiro elemento da lista de elementos tab, quando as teclas control e home (CONTROL + HOME) são pressionadas em todos os elementos tab:

(a) Posicionar o foco em um elemento tab.

(b) Disparar um evento de pressionamento das teclas control e home, simultaneamente (utilizando os eventos JavaScript de keydown, keyup e keypress).

(c) Verificar se o foco foi alterado para o primeiro elemento tab dentro da lista de abas.

(d) Verificar se o elemento tabpanel associado com o primeiro elemento tab é visível, enquanto todos os outros elementos tabpanel não são visíveis (utilizando os atributos CSS de display ou visibility ou o atributo HTML aria-hidden).

6. Checar se o foco é alterado para o último elemento da lista de elementos tab, quando as teclas control e end (CONTROL + END) são pressionadas em todos os elementos tab:

(a) Posicionar o foco em um elemento tab. 
(b) Disparar um evento de pressionamento das teclas control e end, simultaneamente (utilizando os eventos JavaScript de keydown, keyup e keypress).

(c) Verificar se o foco foi alterado para o último elemento tab dentro da lista de abas.

(d) Verificar se o elemento tabpanel associado com o último elemento tab é visível, enquanto todos os outros elementos tabpanel não são visíveis (utilizando os atributos CSS de display ou visibility ou o atributo HTML aria-hidden).

7. Checar se o elemento tabpanel associado com o elemento tab ativo é visível quando a tecla de seta para baixo é pressionada em todos os elementos tab:

(a) Posicionar o foco em um elemento tab.

(b) Disparar um evento de pressionamento da tecla de seta para baixo (utilizando os eventos JavaScript de keydown, keyup e keypress).

(c) Verificar se o elemento tabpanel associado com o elemento tab ativo é visível, enquanto todos os outros elementos tabpanel não são visíveis (utilizando os atributos CSS de display ou visibility ou o atributo HTML aria-hidden).

8. Checar se o elemento tabpanel associado com o elemento tab ativo é visível quando a tecla de seta para direita é pressionada em todos os elementos tab:

(a) Posicionar o foco em um elemento tab.

(b) Disparar um evento de pressionamento da tecla de seta para direita (utilizando os eventos JavaScript de keydown, keyup e keypress).

(c) Verificar se o elemento tabpanel associado com o elemento tab ativo é visível, enquanto todos os outros elementos tabpanel não são visíveis (utilizando os atributos CSS de display ou visibility ou o atributo HTML aria-hidden).

9. Checar se o elemento tabpanel associado com o elemento tab ativo é visível quando a tecla de seta para cima é pressionada em todos os elementos tab:

(a) Posicionar o foco em um elemento tab.

(b) Disparar um evento de pressionamento da tecla de seta para cima (utilizando os eventos JavaScript de keydown, keyup e keypress).

(c) Verificar se o elemento tabpanel associado com o elemento tab ativo é visível, enquanto todos os outros elementos tabpanel não são visíveis (utilizando os atributos CSS de display ou visibility ou o atributo HTML aria-hidden).

10. Checar se o elemento tabpanel associado com o elemento tab ativo é visível quando a tecla de seta para esquerda é pressionada em todos os elementos tab:

(a) Posicionar o foco em um elemento $t a b$. 
(b) Disparar um evento de pressionamento da tecla de seta para esquerda (utilizando os eventos JavaScript de keydown, keyup e keypress).

(c) Verificar se o elemento tabpanel associado com o elemento tab ativo é visível, enquanto todos os outros elementos tabpanel não são visíveis (utilizando os atributos CSS de display ou visibility ou o atributo HTML aria-hidden).

11. Checar se o foco é atribuído ao elemento tab ativo, quando o usuário está interagindo com o elemento tabpanel e pressiona as teclas control e seta para cima, simultaneamente:

(a) Posicionar o foco sobre o elemento tabpanel associado ao elemento tab ativo.

(b) Disparar um evento de pressionamento das teclas control e seta para cima (utilizando os eventos JavaScript de keydown, keyup e keypress).

(c) Verificar se o foco foi posicionado sobre o elemento tab ativo.

12. Checar se o foco é atribuído ao elemento tab anterior, quando o usuário está interagindo com o elemento tabpanel e pressiona as teclas control e pageup (CONTROL + PAGEUP), simultaneamente:

(a) Posicionar o foco sobre o elemento tabpanel associado ao elemento tab ativo.

(b) Disparar um evento de pressionamento das teclas control e pageup (utilizando os eventos JavaScript de keydown, keyup e keypress).

(c) Verificar se o foco foi alterado para o elemento tab anterior dentro da lista de abas.

13. Checar se o foco é atribuído ao próximo elemento tab, quando o usuário está interagindo com o elemento tabpanel e pressiona as teclas control e pagedown (CONTROL + PAGEDOWN), simultaneamente:

(a) Posicionar o foco sobre o elemento tabpanel associado ao elemento tab ativo.

(b) Disparar um evento de pressionamento das teclas control e pagedown (utilizando os eventos JavaScript de keydown, keyup e keypress).

(c) Verificar se o foco foi alterado para o próximo elemento tab dentro da lista de abas.

Após a ativação da ferramenta aria-check, dentro do navegador Firefox, todas as verificações iniciais (10 verificações também representadas como casos de teste na ferramenta) e todos os casos de AT (13 casos) podem ser executados sequencialmente. Assim, a ferramenta é encarregada de identificar quaisquer barreiras de acessibilidade inseridas em um tabpanel, sem a necessidade do desenvolvedor conhecer a especificação ARIA. 


\subsubsection{Estudo de caso}

Para avaliar a ferramenta aria-check, a abordagem foi executada em múltiplas implementações da widget tabpanel de diferentes conjuntos de bibliotecas JavaScript, para verificar quais problemas de conformidade com a especificação ARIA são reportados e como essas possíveis barreiras de acessibilidade se assemelham a avaliações manuais dos requisitos associados. Essa avaliação da ferramenta aria-check também foi realizada como um estudo de caso.

A seguir são apresentados os principais componentes do estudo de caso conduzido:

Questão : A abordagem de avaliação instanciada na ferramenta aria-check é capaz de identificar corretamente problemas na implementação de requisitos da especificação ARIA?

Hipótese : A ferramenta aria-check é capaz de apresentar relatórios contendo problemas de acessibilidade relacionados à especificação ARIA.

Unidade de análise : Relatórios de barreiras de acessibilidade relacionados à especificação ARIA em diferentes implementações de widgets tabpanel.

Plano de análise de dados : Comparar os relatórios de barreiras de acessibilidade relacionados à especificação ARIA que são gerados pela ferramenta aria-check e que são gerados por uma avaliação manual, com um especialista na especificação ARIA.

Na próxima seção, é descrita a metodologia utilizada na avaliação da ferramenta aria-check.

\section{Metodologia}

A hipótese deste trabalho é de que a abordagem implementada pela ferramenta aria-check é capaz de automaticamente avaliar requisitos da especificação ARIA em widgets tabpanel. Nesse contexto, a metodologia de avaliação foi conduzida com uma implementação da widget tabpanel de cada toolkit JavaScript mencionada na Seção 5.2.4. Cada implementação widget tabpanel foi avaliada utilizando a ferramenta aria-check e foi também avaliada manualmente por um especialista em acessibilidade. Em seguida, os relatórios de problemas de acessibilidade de ambas avaliações das widgets foram comparados. A hipótese desta pesquisa seria suportada por esse experimento se ambos resultados apresentassem similaridade em seus relatórios e a hipótese não seria suportada se ambos os resultados apresentassem relatórios com conclusões divergentes. $\mathrm{O}$ processo da metodologia de avaliação é ilustrado na Figura 5.6.

A etapa de avaliação manual de acessibilidade envolve um procedimento em que um especialista na tecnologia ARIA interage com cada uma das implementações da widget tabpanel, utilizando a técnica de screening (Henry e Grossnickle, 2004). A técnica de screening trata-se de um método empírico informal no qual o avaliador interage com a interface tendo algum dos seus sentidos artificialmente reduzidos. Na avaliação manual, o avaliador interagiu com as implementações utilizando um notebook com o monitor desligado, simulando a interação de um usuário com 
deficiência visual. O avaliador utilizou o sistema operacional MacOS (versão 10.8.2), o navegador web Safari (versão 6.0.2) e o utilitário VoiceOver como um software leitor de tela (versão 6.0). É importante observar que a configuração do estudo de caso descrito é compatível com a especificação ARIA e garante que o avaliador perceba todos os detalhes relacionados a uma experiência ARIA, durante a sessão. O especialista que realizou a etapa de avaliação manual foi um universitário doutorando e profissional de computação com mais de 5 anos de experiência na área de desenvolvimento web.

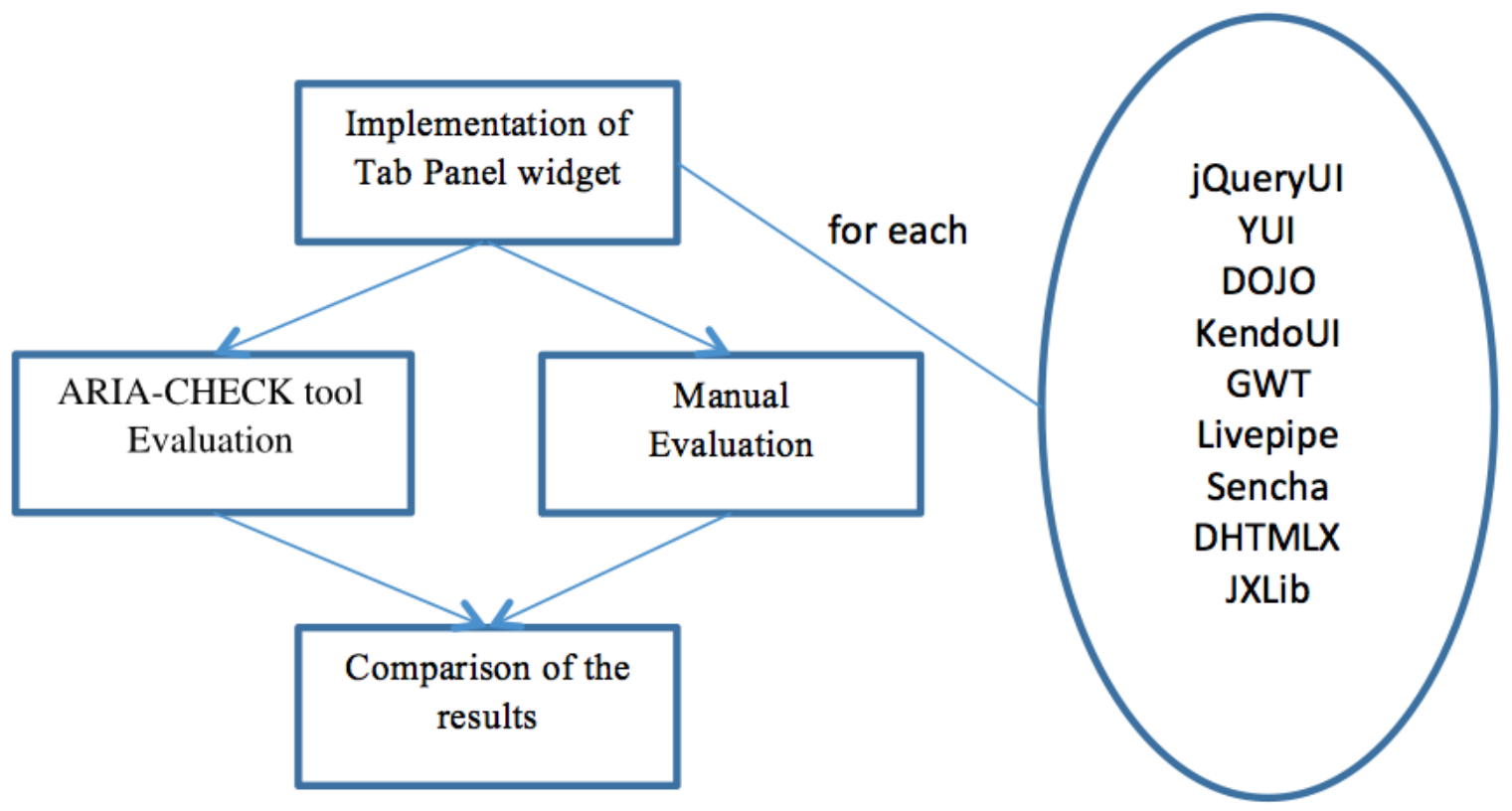

Figura 5.6: Processo de avaliação da ferramenta aria-check. Figura extraída do artigo submetido à UAIS - Universal Access in Information Society.

Também é importante destacar que os casos de teste apresentados na Seção 5.2.3 descrevem casos de uso que precisam ser implementados pelas widgets tabpanel. Nesse contexto, durante a sessão de avaliação manual, foi pedido que o avaliador realizasse os mesmos casos de uso de navegação utilizando o teclado que representam os treze casos de AT que foram definidos na ferramenta aria-check:

- Navegar pelos elementos tab utilizando as teclas de seta do teclado (teclas para baixo, cima, direita e esquerda): referentes aos casos de teste 1, 2, 3 e 4 .

- Navegar pelos elementos tab utilizando os atalhos de teclado CONTROL+HOME e CONTROL+END, para posicionar o foco na primeira e última aba, respectivamente: referentes aos casos de teste 5 e 6.

- Navegar pelos elementos tabpanel utilizando as teclas de seta do teclado (teclas para baixo, cima, direita e esquerda): referentes aos casos de teste 7, 8, 9, 10. 
- Retornar o foco para o elemento tab associado quando o atalho de teclado CONTROL+UP for pressionado no elemento tabpanel: referente ao caso de teste 11.

- Retornar o foco para o elemento tab anterior quando o atalho de teclado CONTROL+PAGEUP for pressionado no elemento tabpanel: referente ao caso de teste 12.

- Retornar o foco para o elemento tab posterior quando o atalho de teclado CONTROL+PAGEDOWN for pressionado no elemento tabpanel: referente ao caso de teste 13.

Depois que a sessão de avaliação utilizando a técnica de screening foi completada, os resultados foram analisados e foram identificadas as causas tecnológicas que geraram cada um dos problemas de acessibilidade identificados pelo avaliador. Ao final da avaliação, os relatórios completos gerados pelas avaliações manual e avaliação utilizando a ferramenta aria-check foram comparados. Ambos relatórios descrevem o número de casos de uso de um usuário com deficiência visual interagindo com a widget tabpanel que não foram desenvolvidos pelas implementações da widget.

É importante destacar que, na avaliação manual de acessibilidade, o especialista não analisou as implementações de widgets considerando a especificação ARIA, diretamente. O especialista investigou se a widget implementava corretamente o mesmo modelo de interação da widget tabpanel exemplo da iCITA. E uma vez que a widget tabpanel exemplo da iCITA está em conformidade com a especificação ARIA, qualquer widget tabpanel que implemente a mesma funcionalidade também está em conformidade com a especificação ARIA.

É importante observar que a ferramenta aria-check implementa apenas casos de AT para a widget tabpanel. E, nesse contexto, a avaliação foi realizada apenas com as bibliotecas JavaScript que disponibilizavam uma implementação da widget tabpanel.

Foram utilizadas nove bibliotecas JavaScript na avaliação, as quais são descritas a seguir:

jQueryUI : trata-se de uma biblioteca JavaScript livre de código aberto ${ }^{23}$. A biblioteca jQueryUI disponibiliza um conjunto de componentes de interface, efeitos, widgets e temas construídos utilizando a biblioteca jQuery ${ }^{24}$. Nesta avaliação, foi utilizada a versão 1.8 .3 da biblioteca jQuery e a versão 1.9.2 da biblioteca jQueryUI.

YUI : a biblioteca YUI - Yahoo! User Interface ${ }^{25}$ é mantida por um grupo de engenheiros de software da empresa Yahoo!. Essa biblioteca possui um sistema de consulta dos elementos DOM com base em seletores CSS, ênfase no uso de módulos granulares, um arquivo de inicialização de tamanho mínimo que carrega outros módulos sob-demanda e uma variedade de propriedades destinadas a facilitar o uso da biblioteca. Nesta avaliação, foi utilizada a versão 3.8.0 da biblioteca YUI.

\footnotetext{
${ }^{23} \mathrm{http}: / /$ jqueryui.com

${ }^{24}$ http://jquery.com

${ }^{25} \mathrm{http}: / /$ yuilibrary.com/
} 
DOJO : trata-se de uma biblioteca de software livre modular ${ }^{26}$. Essa biblioteca utiliza padrões web como plataforma de desenvolvimento e disponibiliza um sistema de carregamento de dependências de baixo custo para download que permite o carregamento de dependências assincronamente. A biblioteca também contém um conjunto de componentes de interface na forma de widgets, suporte a interfaces de dispositivos móveis e funcionalidades de visualização de dados e construção de gráficos. Nesta avaliação, foi utilizada a versão 1.8 .2 da biblioteca DOJO.

KendoUI : trata-se de uma coleção de ferramentas HTML5 e JavaScript para empresas ${ }^{27}$. Essa biblioteca também é implementada utilizando a biblioteca JavaScript jQuery e tem como foco o agrupamento de funcionalidades Ajax, como a implementação de widgets, APIs de Data-Sources, internacionalização, entre outras. Nesta avaliação, foi utilizada a versão 1.8.2 da biblioteca jQuery e a versão 2012.3.1114 da biblioteca KendoUI.

GWT : o GWT - Google Web Toolkit é uma biblioteca de código aberto proposta pela empresa Google. Essa biblioteca permite que desenvolvedores web implementem aplicações JavaScript complexas utilizando a linguagem Java ${ }^{28}$. O GWT possui um mecanismo que permite a implementação de widgets utilizando a linguagem de programação Java, realizando a transformação de códigos de widgets em linguagem Java para widgets escritas na linguagem JavaScript. Nesta avaliação, foi utilizada a versão 2.5.0 da biblioteca GWT.

Livepipe : trata-se de um conjunto de widgets e controles de alta qualidade para aplicações Web $2.0^{29}$. Essa biblioteca é implementada utilizando o framework Prototype ${ }^{30}$ e introduz um mecanismo de criação e observação de eventos em qualquer objeto, não apenas elementos DOM. Nesta avaliação, foi utilizada a versão 1.6.1 do framework Prototype e o código da biblioteca Livepipe foi gerado a partir da seguinte URL:

http://livepipe.net/javascripts/all.js?1256410438.

Sencha : o Sencha Ext JS trata-se de um framework JavaScript que implementa uma arquitetura seguindo o padrão de projeto de Model-View-Controller, funcionalidades para geração de gráficos, compatibilidade entre os diferentes navegadores web e componentes de interface na forma de widgets ${ }^{31}$. Nesta avaliação, foi utilizada a versão 4.0.0 do framework Sencha.

DHTMLX : trata-se de uma biblioteca JavaScript que disponibiliza componentes de interface com base em Ajax, de fácil utilização, alta-performance e promove uma interação rica aos

\footnotetext{
${ }^{26} \mathrm{http}: / /$ dojotoolkit.org

${ }^{27} \mathrm{http}: / /$ www.kendoui.com

${ }^{28} \mathrm{http}: / /$ developers.google.com/web-toolkit/

${ }^{29} \mathrm{http}: / /$ livepipe.net/

${ }^{30} \mathrm{http}: / /$ prototypejs.org

${ }^{31} \mathrm{http}: / /$ wwww.sencha.com/products/extjs
} 
usuários em diferentes navegadores web ${ }^{32}$. Nesta avaliação, foi utilizada a versão 3.5 da biblioteca DHTMLX.

JXLib : trata-se de um framework de componentes de interface JavaScript ${ }^{33}$, construído utilizando a biblioteca JavaScript MooTools ${ }^{34}$. JXLib tem como base a utilização de marcações HTML válidas e tem como objetivo ser estritamente compatível com a especificação W3C do CSS. Nesta avaliação, foi utilizada a versão 1.4.1 da biblioteca MooTools e a versão 3.1 do framework JXLib.

Na próxima seção, os resultados de ambas avaliações são apresentados.

\section{Resultados}

O relatório de quantidade de barreiras de acessibilidade identificadas pela ferramenta ariacheck, de acordo com o número de casos de teste que falharam em sua execução, é graficamente apresentado na Figura 5.7, incluindo o relatório individual para cada biblioteca/framework JavaScript em ordem crescente de quantidades de barreiras encontradas. A figura apresenta o número de casos de teste que falharam classificados de acordo com as verificações iniciais (Roles, Estrutura dos Elementos, Estado Inicial da Interação e Alternativas Textuais) e as verificações dos casos de AT.

Considerando o relatório da ferramenta aria-check, a implementação da widget tabpanel do biblioteca jQueryUI apresenta o menor número de casos de teste com falha durante a sua execução. Isso significa que a biblioteca jQueryUI implementa uma widget tabpanel que implementa o modelo de interação que mais se assemelha a widget tabpanel utilizada como implementação de referência da ferramenta aria-check. Por outro lado, as bibliotecas/frameworks Livepipe, Sencha, DHTMLX e JXLib apresentam o maior número de casos de teste com falha durante a sua execução, falhando em todas as verificações realizadas pela ferramenta aria-check ( 23 casos de teste: contendo 10 verificações iniciais e 13 casos de AT). Esse dado significa que que essas bibliotecas implementam um modelo de interação e possuem uma estrutura de marcação HTML que diverge da implementação da iCITA da widget tabpanel.

Os resumos dos relatórios das avaliações manuais de acessibilidade são apresentados a seguir, para cada implementação da widget tabpanel das bibliotecas/frameworks JavaScript do estudo:

jQueryUI : não implementa os atalhos das teclas control e homelend para mudar o foco para o primeiro e último elemento $t a b$, respectivamente. O jQueryUI implementa uma funcionalidade semelhante para as teclas homelend, mas não ativa o painel associado a essa aba, apenas posiciona o foco sobre a mesma. Também foi verificado que não são implementados os casos de uso associados aos atalhos das teclas control e pageup/pagedown, para mudar os

\footnotetext{
${ }^{32}$ http://dhtmlx.com

${ }^{33} \mathrm{http}: / /$ jxlib.org

${ }^{34} \mathrm{http}: / /$ mootools.net
} 


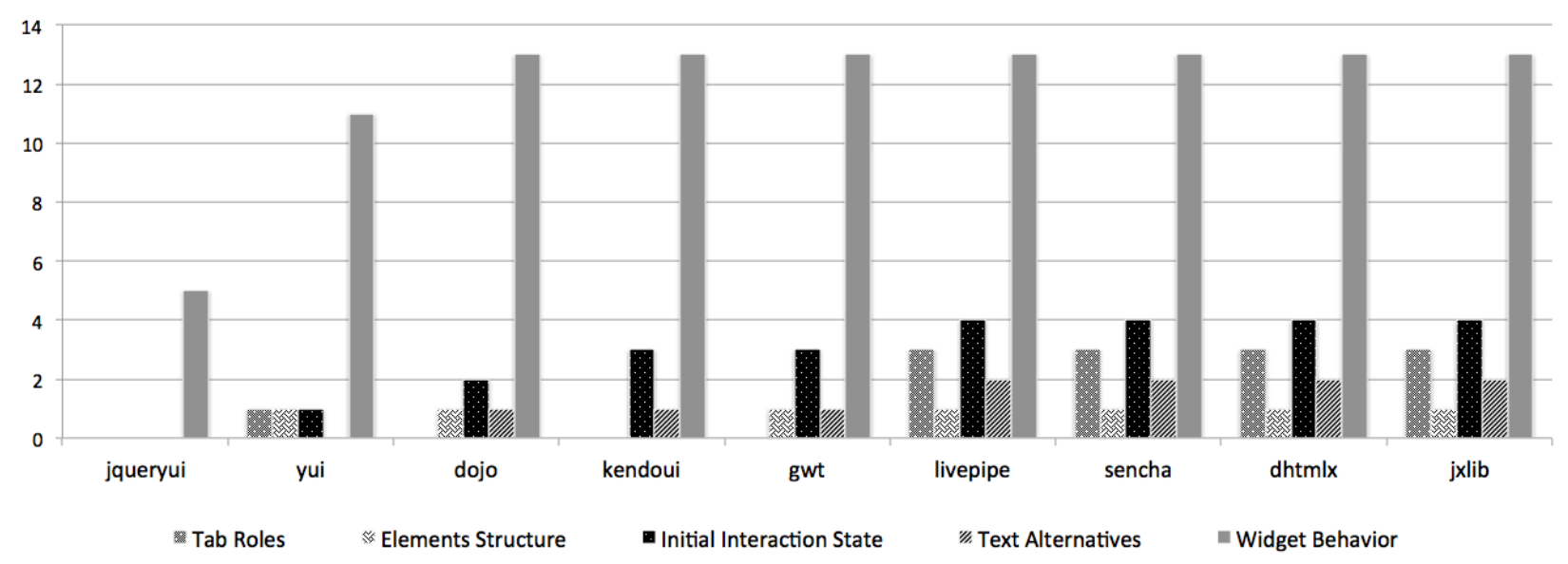

Figura 5.7: Número de casos de teste que falharam em cada implementação de widget, identificados de acordo com as verificações iniciais (Roles, Estrutura dos Elementos, Estados Inicial da Interação and Alternativas Textuais) and Casos de AT. Figura extraída do artigo submetido à UAIS - Universal Access in Information Society.

elementos tabpanel selecionados para a aba anterior e posterior, respectivamente. Todas as outras funcionalidades são implementadas corretamente.

- Portanto não implementa 4 casos de uso que estão disponíveis na implementação da widget tabpanel da iCITA.

YUI : implementa um modelo de interação diferente da widget tabpanel da iCITA. A widget tabpanel da biblioteca YUI apresenta a funcionalidade de gerência de foco sobre os elementos tab correta, quando utilizando as teclas de seta para esquerda e direita (não implementa a mesma funcionalidade para as teclas de seta para cima e para baixo). No entanto, os elementos tab não são ativados, dado o seu recebimento de foco. Para ativar as abas e painéis associados, é necessário que o usuário pressione a tecla enter sobre as abas que possuem foco.

- Portanto não implementa 11 casos de uso que estão disponíveis na implementação da widget tabpanel da iCITA.

DOJO : implementa corretamente a navegação entre os elementos $t a b$. No entanto, os elementos tabpanel não estão corretamente identificados. Existe um único elemento tabpanel que contém todos os elementos $t a b$. Essa implementação modifica significantemente o modelo de interação dos painéis. Quando o usuário seleciona uma aba, o usuário não é corretamente informado sobre a sua associação com o seu painel correspondente. Esse comportamento prejudica a identificação do elemento tabpanel com as informações que descrevem esse painel. Adicionalmente, como os paineis não são corretamente identificados na estrutura da widget, o leitor de telas não é capaz de ler os rótulos referentes a cada elemento tabpanel. 
- Portanto não implementa 7 casos de uso que estão disponíveis na implementação da widget tabpanel da iCITA.

KendoUI : apresenta os atalhos de teclado para navegação pelas abas, visualmente. No entanto, esses atalhos não estão acessíveis a usuário utilizando leitores de tela compatíveis com a especificação ARIA, devido a estrutura da widget tabpanel. A widget tabpanel dessa biblioteca é composta por um único elemento tablist que pode receber foco (ou seja, possui o atributo TabIndex do HTML com valor maior ou igual a 0). Todos os elementos $t a b$ e tabpanels estão inseridos dentro desse elemento tablist. Apesar da widget apresentar todos os elementos associados com os atributos role e properties marcados, a sua estrutura impede as Tecnologias Assistivas de identificar mudanças de seleção e ativação das abas.

- Portanto não implementa 13 casos de uso que estão disponíveis na implementação da widget tabpanel da iCITA.

GWT : também apresenta um modelo de interação diferente da implementação de referência da widget tabpanel deste estudo. Na widget do GWT, o usuário pode navegar entre os elementos $t a b$ apenas utilizando a navegação com foco (Estratégia de Navegação por Foco(W3C, 2013e)) e a tecla ENTER para ativar uma aba. A widget apresenta um único elemento tabpanel que tem seu conteúdo atualizado conforme uma aba é ativada. A widget também não apresenta alternativas textuais identificadas para o painel, logo o leitor de tela não é capaz de identificar o componente para o usuário.

- Portanto não implementa 13 casos de uso que estão disponíveis na implementação da widget tabpanel da iCITA.

Livepipe : não apresenta nenhum atributo da especificação ARIA definido ou modelo de interação acessível, utilizando o teclado, conforme descrito na Seção 5.2.1.

- Portanto não implementa 13 casos de uso que estão disponíveis na implementação da widget tabpanel da iCITA.

Sencha : não apresenta nenhum atributo da especificação ARIA definido ou modelo de interação acessível, utilizando o teclado, conforme descrito na Seção 5.2.1.

- Portanto não implementa 13 casos de uso que estão disponíveis na implementação da widget tabpanel da iCITA.

DHTMLX : não apresenta nenhum atributo da especificação ARIA definido ou modelo de interação acessível, utilizando o teclado, conforme descrito na Seção 5.2.1.

- Portanto não implementa 13 casos de uso que estão disponíveis na implementação da widget tabpanel da iCITA. 
JXLib : não apresenta nenhum atributo da especificação ARIA definido ou modelo de interação acessível, utilizando o teclado, conforme descrito na Seção 5.2.1.

- Portanto não implementa 13 casos de uso que estão disponíveis na implementação da widget tabpanel da iCITA.

Ambos, o número de casos de uso que foram identificados como faltantes pela avaliação manual e o número de asserções incorretas nos casos de AT que falharam, representam o número de funcionalidades que não foram implementadas em cada uma das implementações de widget, para que a widget apresente uma experiência de usuário seguindo o mesmo modelo de interação do exemplo de widget tabpanel da iCITA. Os dois valores obtidos podem ser utilizados como forma de comparação direta entre a abordagem de avaliação manual e automática, essa última proporcionada pela ferramenta aria-check. Os resultados quantitativos gerados pelas duas formas de avaliação são apresentados na Figura 5.8.

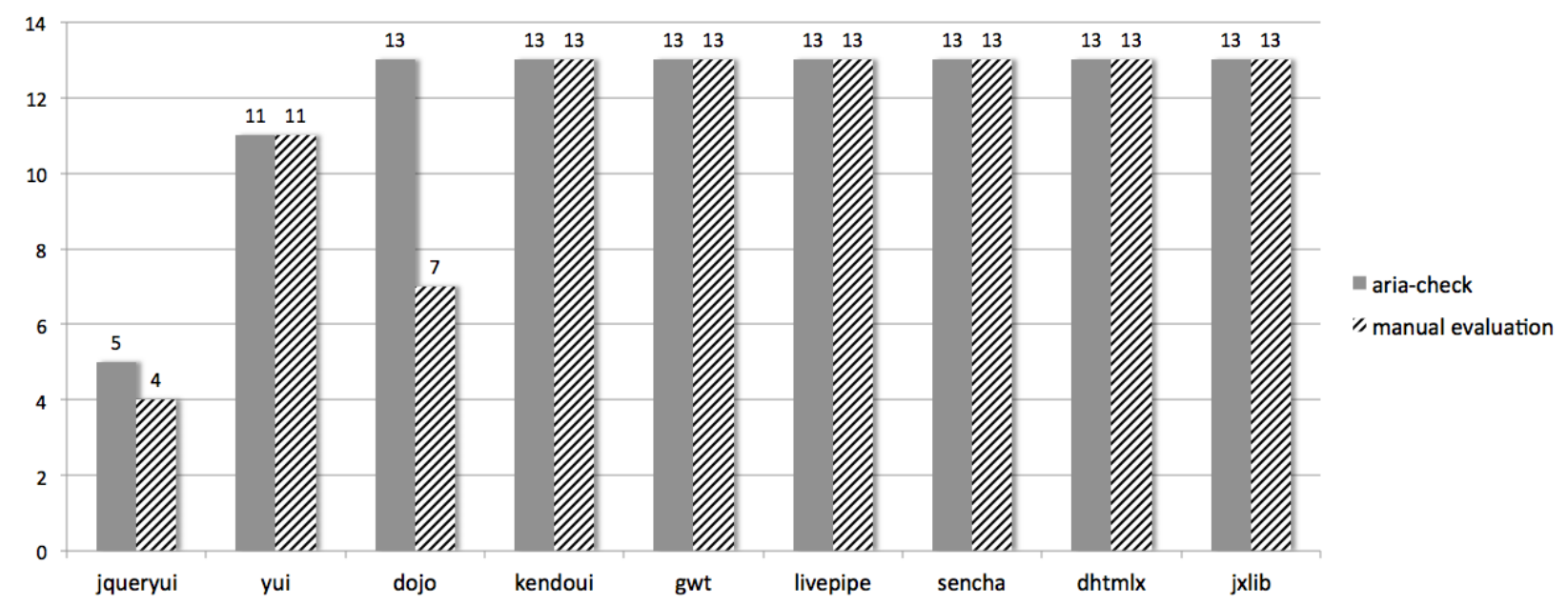

Figura 5.8: Número de problemas de implementação dos casos de uso de navegação por teclado pela avaliação manual e pela ferramenta aria-check. Figura extraída do artigo submetido à UAIS Universal Access in Information Society.

Na Figura 5.8, pode ser observado que todas bibliotecas/frameworks, com exceção das bibliotecas jQueryUI e DOJO, apresentam os mesmos números de identificação de falhas nas verificações dos casos de uso, considerando as quantidades obtidas pela avaliação manual e pela ferramenta aria-check.

É importante observar, considerando as bibliotecas que apresentaram diferença nos resultados entre a avaliação manual e a ferramenta aria-check, que a widget implementada pela biblioteca jQueryUI não responde imediatamente a eventos de teclado, quando os eventos são disparados. Essa widget possui um comportamento de aguardar 300 milisegundos antes de processar a interação realizada pelo teclado. Esse comportamento pode ter sido implementado para evitar a sobrecarga do navegador que precisa lidar com a re-apresentação de múltiplos painéis da widget, se o usuário pressionar a tecla de seta muitas vezes, em um curto período de tempo. No entanto, 
não é claro porque esse comportamento foi implementado para esse tipo de widget. Esse comportamento também dificulta a análise da widget por estratégias automáticas de avaliação e é a causa principal para a diferença de resultados entre a avaliação manual e a ferramenta aria-check.

Para a implementação da widget tabpanel da biblioteca DOJO, a ferramenta aria-check reportou que 13 casos de uso não foram implementados, enquanto a avaliação manual reportou que apenas 7 casos de uso não tinham sido implementados. Essa diferença é resultado da estratégia da biblioteca DOJO de previnir que a sua widget tabpanel responda a eventos sintéticos. A abordagem utilizada pela ferramenta aria-check exige que seja simulada a interação do usuário com as widgets para conseguir identificar problemas associados a especificação ARIA. Para simular a interação do usuário, a ferramenta gera eventos sintéticos que são disparados nos elementos HTML das widgets. Assim, uma vez que a implementação da widget pela biblioteca DOJO não responde a eventos sintéticos, a ferramenta aria-check foi incapaz de avaliar corretamente a widget tabpanel para essa biblioteca.

\subsection{Discussão}

A abordagem de avaliação automática de requisitos associados à especificação ARIA apresentada neste capítulo representa uma modificação do modelo de avaliação apresentado no capítulo anterior. A abordagem apresentada no capítulo anterior utiliza-se de uma extensão da ferramenta Pyccuracy de AT, que possibilita a elaboração de casos de teste que são capazes de analisar requisitos de acessibilidade no contexto de conteúdos gerados dinamicamente que caracterizam a Web 2.0 (Capítulo 4). A abordagem apresentada neste capítulo, por outro lado, foi implementada como uma extensão do navegador web Firefox (addon) que utiliza AT para avaliar requisitos da especificação ARIA em widgets.

A primeira abordagem (Pyccuracy) permite que os desenvolvedores web escrevam casos de teste que avaliam múltiplos requisitos de acessibilidade para qualquer parte da aplicação web que eles estejam desenvolvendo. No entanto, os desenvolvedores ou responsáveis pela elaboração dos testes devem codificar os casos de AT antes de realizar a avaliação, o que aumenta o custo do processo de desenvolvimento. A segunda abordagem (aria-check) restringe o número de cenários que podem ser avaliados, analisando apenas as widgets separadamente, para melhorar a escalabilidade da técnica. Uma vez que essa abordagem não exige a elaboração prévia dos casos de teste, a ferramenta aria-check pode ser utilizada para avaliar requisitos de acessibilidade em diferentes websites com um custo inferior à primeira abordagem.

Devem ser destacadas também diferenças tecnológicas entre as duas abordagens. A primeira abordagem utiliza a ferramenta Pyccuracy que utiliza a ferramenta Selenium para executar os casos de AT. A ferramenta Selenium permite que os testes sejam executados em uma camada superior ao navegador web e as interações do usuário que são simuladas nesses testes utilizam eventos reais. Logo, a biblioteca DOJO não impediria a sua widget tabpanel de responder a eventos gerados pela 
ferramenta Pyccuracy. A segunda abordagem (aria-check) utiliza a API DOM - Document Object Model para simular a interação do usuário com as widgets, o que caracteriza eventos sendo gerados dentro do navegador web. Como resultado, a segunda abordagem é incapaz de gerar eventos reais no navegador web, utilizando eventos sintéticos. Dessa forma, bibliotecas/frameworks JavaScript que implementam políticas de segurança que previnem suas widgets de responder a eventos sintéticos vão gerar falsos negativos nos resultados da ferramenta aria-check. Esse fato caracteriza uma limitação da segunda abordagem que deve ser considerada em trabalhos futuros.

É importante destacar que a ferramenta aria-check tem como objetivo avaliar se uma implementação de widget apresenta os mesmos casos de uso de uma implementação de referência dessa mesma widget. Nesse contexto, a ferramenta aria-check não avalia diretamente a conformância das widgets com a especificação ARIA. A verificação de conformância é realizada indiretamente por meio dessa implementação de referência da widget. Se a especificação for alterada, a ferramenta aria-check deve ser atualizada, alterando a implementação de referência que é utilizada pela ferramenta, repetindo todos os passos descritos na Seção 5.2, para que os casos de AT reflitam as mudanças feitas na especificação ARIA.

Os resultados apresentados pela avaliação utilizando a ferramenta aria-check (Seção 5.2.4) destacam como o modelo de interação da widget tabpanel diverge entre diferentes bibliotecas/frameworks JavaScript, apesar dos esforços da W3C em divulgar e padronizar um modelo de interação que deve ser implementado (W3C, 2013e).

É importante notar que os resultados de avaliação descritos neste capítulo caracterizam resultados preliminares de pesquisa, uma vez que os processos de avaliação foram conduzidos com um tamanho limitado de amostra. Dessa forma, por mais que os resultados suportem a hipótese inicial de que a abordagem implementada pela ferramenta aria-check é capaz de automaticamente avaliar requisitos da especificação ARIA em widgets tabpanel, os resultados não são conclusivos.

\subsection{Considerações Finais}

Neste capítulo, foi descrito o desenvolvimento da ferramenta aria-check, que utiliza AT para avaliar requisitos da especificação ARIA em implementações de widgets. Essa estratégia de avaliação estende o conceito da abordagem descrita no Capítulo 4, restringindo o domínio de avaliação para widgets. Essa estratégia pode ser utilizada para avaliar diferentes aplicações web sem a necessidade da elaboração prévia dos casos de teste.

A ferramenta aria-check foi implementada como uma extensão do navegador web Firefox e utiliza o framework de testes comportamentais para realizar asserções no estado da interface web de uma widget. A utilização desse conjunto de tecnologias implica na limitação de que a ferramenta não é capaz de gerar eventos reais para simular a interação do usuário.

O processo de avaliação também apresentou resultados que suportam a hipótese do trabalho, embora os resultados não sejam conclusivos devido ao tamanho da amostra do experimento. A ava- 
liação também revelou que o modelo de interação das widgets tabpanel diferem significantemente entre as diferentes bibliotecas/frameworks JavaScript, apesar dos esforços da W3C em padronizar esse comportamento para garantir a acessibilidade da Web 2.0. 
CAPÍTULO

6

\section{Fona - Métrica do requisito ARIA de Navegação por Foco}

$\mathrm{E}$ ste capítulo apresenta a definição de uma métrica quantitativa que calcula quanto dos elementos interativos de RIA que utilizam JavaScript podem implementar a Navegação por Foco. Essa métrica foi nomeada Fona - Focus Navigation Assessment. Como uma prova de conceito, foi desenvolvida uma ferramenta que calcula automaticamente o valor da métrica para uma aplicação web. Ao fim do capítulo, é descrita uma investigação sobre a implementação do requisito de acessibilidade de RIA de Navegação por Foco, utilizando a abordagem de avaliação com a métrica Fona, em um conjunto de websites mais populares na Internet segundo a empresa Alexa ${ }^{1}$.

A definição da métrica de avaliação do requisito de Navegação por Foco caracterizou a execução do terceiro ciclo do procedimento de pesquisa-ação desta tese (Seção 1.4). Nessa etapa, foram estabelecidos como objetivos, durante o planejamento do ciclo, que fossem avaliados critérios de navegação menos específicos de ARIA (como a Navegação por Foco, que pode ser avaliada em toda widget). Dessa forma, essa métrica pode ser aplicada de forma mais abrangente que a ferramenta aria-check descrita no capítulo anterior. A métrica Fona é capaz de analisar atributos de acessibilidade em todo elemento de uma aplicação web que possua interatividade implementada utilizando JavaScript, sem restringir a avaliação de acessibilidade apenas a widgets definidas na especificação ARIA.

Os resultados da investigação descrita neste capítulo foram reportados em um Artigo Completo para a revista ACM Transactions on the Web.

\footnotetext{
${ }^{1}$ http://www.alexa.com
} 
Este capítulo apresenta a seguinte estrutura: na próxima seção (Seção 6.1) são apresentadas as considerações iniciais deste capítulo; na Seção 6.2, é definida a métrica Fona; na Seção 6.3, é detalhado o desenvolvimento de uma ferramenta que calcula automaticamente a métrica Fona em uma página web; na Seção 6.4, é descrito o procedimento de avaliação da métrica Fona e uma investigação sobre como o requisito de Navegação por Foco tem sido implementado na Web; na Seção 6.5, é apresentada uma discussão acerca dos resultados da investigação realizada com a ferramenta Fona; e na Seção 6.6, são descritas as considerações finais deste Capítulo.

\subsection{Considerações Iniciais}

A WAI elaborou a especificação ARIA (W3C, 2011), que apresenta um framework de acessibilidade para RIA. A especificação ARIA descreve a codificação de propriedades de elementos HTML para atribuir semântica à marcação. Esses atributos informam às Tecnologias Assistivas sobre um comportamento pré-definido das widgets que deve ser informado aos usuários. A especificação também define a utilização de recursos para facilitar a navegação por teclado, atributos que definem relacionamento entre os elementos de uma página web, entre outros recursos (W3C, 2013e).

Um dos requisitos exigidos para garantir a navegação por teclado de widgets está diretamente associado à possibilidade de um elemento HTML receber o foco. A Navegação por Foco tratase de um requisito mandatório de acessibilidade em RIAs (W3C, 2011). Muitos usuários não são capazes de interagir com aplicações web utilizando o mouse. Para tornar a Web acessível para esses usuários, as páginas web têm que permitir que todas as suas funcionalidades estejam disponíveis por interações de teclado, de acordo com a diretriz 1.1 da WCAG 2.0 (W3C, 2008b).

A WCAG 2.0 especifica diretrizes neutras tecnologicamente para os desenvolvedores (Reid e Snow-Weaver, 2008) e essas diretrizes também se aplicam a RIAs. Os aspectos tecnológicos necessários para implementar a diretriz 2.1 da WCAG 2.0 são abordados na especificação ARIA (W3C, 2013e), que define que o suporte a interações por teclado é uma funcionalidade essencial a widgets da Web 2.0, e todas as funcionalidades de uma widget devem ser totalmente operáveis e funcionais por eventos gerados pelo teclado. No entanto, ao contrário de links, âncoras e elementos de formulários, que apresentam suporte a interação por teclado nativas por se tratarem de elementos HTML que proporcionam interações previsíveis, widgets são freqüentemente implementadas com marcação genérica. E, dessa forma, o suporte a interação por teclado deve ser elaborado pelo próprios desenvolvedores web.

Widgets que compõem uma aplicação Web 2.0 utilizam-se de recursos programáticos para possibilitar interações complexas com seus elementos. Se um dos elementos de uma widget gera um determinado comportamento quando recebe uma interação utilizando o mouse, é esperado que esse mesmo comportamento seja gerado utilizando-se uma interação por teclado. Para possibilitar essa interação por teclado, os elementos que respondem a interações por mouse devem ser inseridos 
na ordem de navegação por tab ${ }^{2}$ de uma página web, utilizando o atributo TabIndex (com um valor não-negativo) (W3C, 2013e).

Todo elemento HTML inserido na estrutura DOM de uma página web possui um atributo TabIndex contendo um valor numérico inteiro. Se um elemento HTML possui um atributo TabIndex de valor negativo, esse elemento não está inserido na ordem de navegação por tab. Elementos que não estão inseridos na ordem de navegação por tab não podem ser receber foco (recebendo o evento focus), logo não são capazes de receber eventos disparados pelo teclado. Assim, elementos que possuem um atributo TabIndex contendo um valor numérico negativo não são capazes de responder a interações por teclado, sendo inacessíveis a usuários que navegam em aplicações web utilizando apenas o teclado. Por outro lado, se um elemento HTML possui um atributo TabIndex de valor não negativo, esse elemento está inserido na ordem de navegação por tab e pode responder a eventos disparados pelo teclado.

Elementos interativos do HTML como links, INPUTs e BUTTONs possuem o atributo TabIndex contendo um valor não negativo, por padrão na estrutura DOM. Logo, esses elementos são capazes de responder a interações pelo teclado nativamente no navegador web. No entanto, elementos HTML como SPANs e DIVs, que são freqüentemente utlizados na construção de widgets em aplicações Web 2.0, possuem o atributo TabIndex contendo um valor negativo (-1), por padrão na estrutura DOM. Dessa forma, é de responsabilidade dos desenvolvedores web a implementação de mecanismos de navegação por teclado em widgets que utilizam esses elementos do HTML.

Para implementar mecanismos de navegação por teclado em widgets que utilizam elementos SPANs e DIVs, os desenvolvedores precisam inserir manualmente esses elementos na ordem de navegação por tab (utilizando o atributo TabIndex dos elementos) e implementar funções JavaScript que respondem a eventos de teclado conduzindo a navegação na estrutura DOM. Uma vez que esses elementos sejam corretamente inseridos na ordem de navegação por tab, os usuários podem navegar por esses elementos utilizando as teclas TAB e SHIFT+TAB para atribuir o foco a eles (Navegação por $\mathrm{Foco}^{3}$ ).

Adicionalmente, disponibilizar uma experiência de navegação efetiva é um fator crítico para usabilidade. E navegar por uma elevada quantidade de elementos interativos que compõem cada widget pode ser tedioso e caracteriza um comportamento inconsistente quando comparado com o cenário de navegação de componentes de interface de aplicações desktop (W3C, 2013e). Assim, a especificação ARIA descreve como desenvolvedores devem implementar navegação entre as widgets utilizando o atributo TabIndex de qualquer elemento HTML, controlando a ordem que cada widget recebe o foco (quando os usuários pressionam as teclas TAB e SHIFT+TAB), enquanto a navegação dentro de uma widget deve ser realizada com as teclas de setas do teclado.

Na próxima seção, é apresentada a métrica Fona.

\footnotetext{
${ }^{2}$ Tab Order

${ }^{3}$ Focus Navigation
} 


\subsection{Definição da Métrica}

A métrica Fona, determina um valor percentual que representa a quantidade de elementos que implementam recursos interativos por meio do uso de JavaScript e podem ser acessados por cenários de uso de navegação por teclado, segundo a especificação ARIA. Essa métrica foi elaborada com o objetivo de auxiliar a coleta de avaliações do requisito ARIA de Navegação por Foco em múltiplas aplicações web.

As implementações de Navegação por Foco são verificadas por meio da análise de todos os elementos HTML que possuem funções associadas que respondem a eventos de mouse (Mouse Events). Em seguida, é contabilizado o número desses elementos interativos que estão inseridos na ordem de navegação por tab de uma página web, checando se o atributo TabIndex possui um valor maior ou igual a zero. Se esses elementos interativos estão inseridos na ordem de navegação por tab de uma página web, esses elementos potencialmente podem implementar mecanismos de interação por teclado utilizando a linguagem JavaScript. Se esses elementos não estão inseridos na ordem de navegação por tab de uma página web, eles não implementam mecanismos de interação por teclado. Essa fase da verificação corresponde ao requisito da especificação ARIA que todos os elementos interativos devem poder receber foco (W3C, 2011).

É importante observar que algumas implementações de widgets ARIA não são constituídas por elementos interativos que estejam inseridos na ordem de navegação por tab, quando a página web é carregada. Por exemplo, a implementação da widget ARIA tabpanel ${ }^{4}$, apesar de todos os seus elementos marcados com o atributo role com o valor de tab responderem a eventos de clique para ativar cada aba, apenas uma das abas está inserida na ordem de navegação por tab (apenas um elemento possui o atributo TabIndex com valor igual ou maior a 0 ). No entanto, quando essa widget recebe o foco, e o usuário interage com a mesma utilizando eventos de teclado, o atributo TabIndex de todos os elementos que representam abas é alterado e outras abas podem receber o foco. Esses elementos que podem receber o foco, dada uma determinada interação do usuário, implementam um comportamento específico da widget, portanto devem ser marcados utilizando o atributo role para informar as Tecnologias Assistivas sobre essa possibilidade de interação. Assim, também é contabilizado o número de elementos HTML que respondem a eventos do mouse que apresentam o atributo role com um valor não nulo. Se um elemento HTML possui um atributo role não nulo, esse elemento pode receber foco dada uma interação específica do usuário, que corresponde ao tipo de atributo role definido. Se o elemento não contém um atributo role, esse elemento não implementa corretamente a especificação ARIA.

Considerando o número de elementos interativos que estão inseridos na ordem de navegação por tab de uma página web ou possuem um atributo role não nulo, foi definida a métrica que determina um valor quantitativo que representa a porcentagem de elementos com uma função de

\footnotetext{
${ }^{4}$ http://test.cita.illinois.edu/aria/tabpanel/tabpanel1.php
} 
resposta a eventos de mouse e estão inseridos na ordem de navegação por tab ou possuem um atributo role não nulo. A fórmula da métrica Fona é apresentada a seguir:

$$
\text { Fona }=\frac{\sum_{i=1}^{I} \min \left(T_{i}+R_{i}, 1\right)}{I}, \text { se } \mathrm{I}>0
$$

Onde $I$ é o número de funções JavaScript associadas a elementos HTML para responder a eventos de mouse, $T_{i}$ é um valor decimal que indica se o elemento HTML associado à $i$-ésima função que responde a eventos de mouse está inserido na ordem de navegação por tab (utilizando o valor 1 se esse elemento está inserido na ordem de navegação por tab e 0 se não) e $R_{i}$ é um valor decimal que indica se o elemento com função que responde a eventos de mouse $i$ possui um atributo role não nulo (utilizando o valor 1 se esse elemento possui um valor não nulo e 0 se esse elemento possui um valor nulo).

Se $I$ é igual a zero, a aplicação web sendo avaliada pela métrica não contém nenhuma funcionalidade JavaScript que responda a eventos do mouse e a métrica não é aplicável a essa aplicação web.

Assim, o cálculo da métrica gera um resultado numérico (com um valor de 0 a 1). Se o cálculo da métrica para uma aplicação web retornar o valor máximo 1 (100\%), todos elementos interativos da aplicação web, com funcionalidades JavaScript, que pode adquirir foco (o elemento não responde a interações por teclado) ou possui um atributo role (o elemento indica que implementa ARIA e pode receber foco dada interação com outros elementos). Se o cálculo da métrica para uma aplicação web retornar o valor 0 , todos os elementos interativos com funcionalidade JavaScript da aplicação web não podem adquirir foco (os elementos não respondem a interações por teclado) e não possuem o atributo role (os elementos não indicam que implementam ARIA e que podem receber foco dada interação com outros elementos).

Considerando o seguinte fragmento de código que implementa a estrutura HTML de uma widget tabpanel:

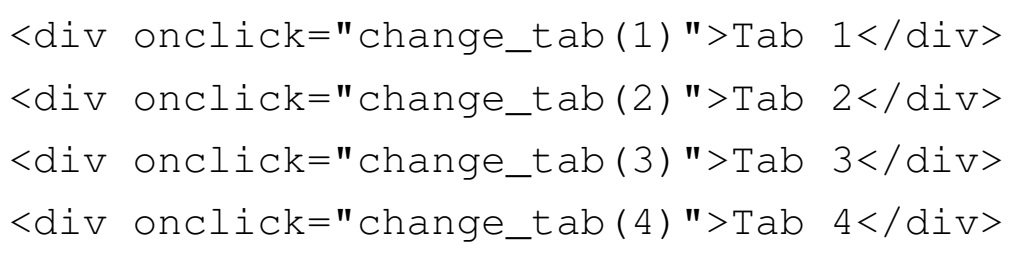

De acordo com o código apresentado, o cálculo da métrica Fona resulta no valor 0, uma vez que todos os elementos interativos com funcionalidade JavaScript (todos os quatro elementos DIV) do fragmento não podem receber foco e não apresentam o atributo role, indicando que eles implementam uma widget ARIA.

Por outro lado, se a métrica Fona for utilizada em uma página web contendo o seguinte fragmento de código HTML que também implementa uma widget tabpanel: 
Tab 1

$</$ div $>$

<iv role="tab" onclick="change_tab(2) ">Tab $2</$ div $>$

$<$ div role="tab" onclick="change_tab(3) " $>$ Tab $3</$ div $>$

<div role="tab" onclick="change_tab(4)" $>$ Tab $4</$ div $>$

A métrica retornaria o resultado de $100 \%$, uma vez que todos os elementos interativos com funcionalidade JavaScript do fragmento podem receber foco ou apresentam o atributo role, indicando que eles implementam uma widget ARIA. Vale destacar, que a atribuição de foco em um elemento HTML pode ser implementada sem a utilização explícita do atributo TabIndex. Elementos como links e botões (A e BUTTON do HTML) possuem o valor do atributo TabIndex igual a zero, por padrão. Nesse contexto, uma widget tabpanel poderia ser implementada com o seguinte fragmento de código:

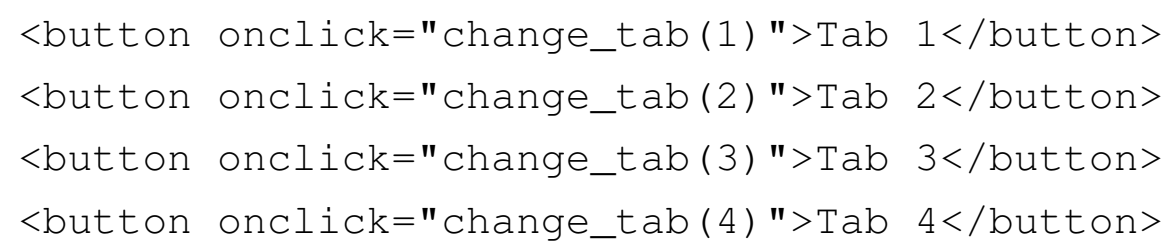

Apesar do fragmento de código apresentado não incluir os atributos role ou TabIndex, a utilização do elemento BUTTON do HTML garante que as abas da widget tabpanel possuam o atributo TabIndex igual a 0. Logo, os elementos que compõem essa widget podem receber foco e podem implementar navegação por teclado. A métrica reconhece esse comportamento e retorna o valor de $100 \%$ para esse fragmento.

É importante destacar que a métrica não verifica se a Navegação por Foco está corretamente implementada para os elementos que respondem a eventos de mouse. No entanto, a métrica identifica elementos que possuem funções JavaScript associadas que não implementam os requisitos da especificação ARIA. Mesmo que a métrica não considere muitos dos aspectos necessários para garantir que uma aplicação web corretamente implementa a Navegação por Foco em suas widgets, ela calcula um limite superior quantitativo que representa uma proporção do quanto o requisito de Navegaçõa por Foco é implementado. Uma vez que as variáveis necessárias para determinação do valor resultante da métrica (número de elementos HTML que possuem funções JavaScript associadas para responder a eventos de mouse, número de elementos que estão inseridos na ordem de navegação por tab e número de elementos que possuem atributo role não nulo) podem ser automaticamente calculados para qualquer página web, sem restrição de domínio (conforme observado no trabalho (Watanabe et al., 2012) que exige que os desenvolvedores manualmente elaborem e implementem os casos de teste para cada funcionalidade do seu sistema), a métrica pode ser utilizada para coletar dados quantitativos de um número elevado de páginas web a um custo reduzido.

Vale destacar que a métrica não apresenta um valor absoluto, mas a métrica determina um valor de porcentagem que representa uma fração entre o número de elementos que possuem funções de 
JavaScript associadas para responder a eventos de mouse e podem implementar um mecanismo de interação por teclado, e o número total de elementos que possuem funções JavaScript associadas para responder a eventos de mouse.

Na próxima seção, é descrita a ferramenta que calcula automaticamente o valor da métrica de Navegação por Foco para uma determinada aplicação web.

\subsection{Ferramenta de cálculo da métrica}

Foi implementada uma ferramenta ${ }^{5}$ para automaticamente coletar os valores da métrica para grupos de páginas web. A ferramenta utiliza o CasperJS ${ }^{6}$, um navegador web headless (que não requer o uso da interface gráfica) e permite a inserção de scripts nas páginas web para coletar dados e simular interação do usuário. Essa configuração tecnológica permite que sejam coletados os valores da métrica em um ambiente de avaliação dentro do navegador (Fernandes et al., 2011, 2012).

A ferramenta calcula separadamente a quantidade de elementos HTML que respondem a eventos de mouse utilizando funções JavaScript, a quantidade de elementos HTML que estão inseridos na ordem de navegação por tab da página web e a quantidade de elementos que apresentam um atributo role com valor não nulo. Depois de calcular cada um desses valores, a ferramenta combina todos eles para determinar o valor da métrica, conforme descrito na seção anterior.

Para calcular a quantidade de elementos HTML que respondem a eventos de mouse, a ferramenta contabiliza o número de chamadas realizadas ao método addEventListener de todas as instâncias da classe HTMLElement que passam como primeiro parâmetro valores que correspondem a eventos de mouse (click, mousedown, mousemove, mouseout, mouseover e mouseup). A ferramenta também contabiliza o número de elementos HTML que apresentem funções de callback atribuídas as propriedades onclick, onmousedown, onmousemove, onmouseout, onmouseover e onmouseup. A soma desses dois valores resulta no número de funções JavaScript que respondem a eventos de mouse nos elementos HTML de uma página web.

Como ilustrado na Figura 6.1, a ferramenta trata-se de um script em linha de comando que recebe uma URL como entrada. Essa URL é carregada em um navegador web headless (no ambiente do CasperJS) e o valor da métrica é calculado considerando todos os elementos interativos contidos na RIA indicada pela URL e as verificações relacionadas à especificação ARIA de Navegação por Foco. Ao final, a ferramenta imprime o valor numérico que representa o resultado da métrica.

Na próxima seção, é apresentada uma avaliação da métrica.

\footnotetext{
${ }^{5} \mathrm{http}: / /$ github.com/watinha/tabindex-counter

${ }^{6} \mathrm{http}: / /$ casperjs.org
} 


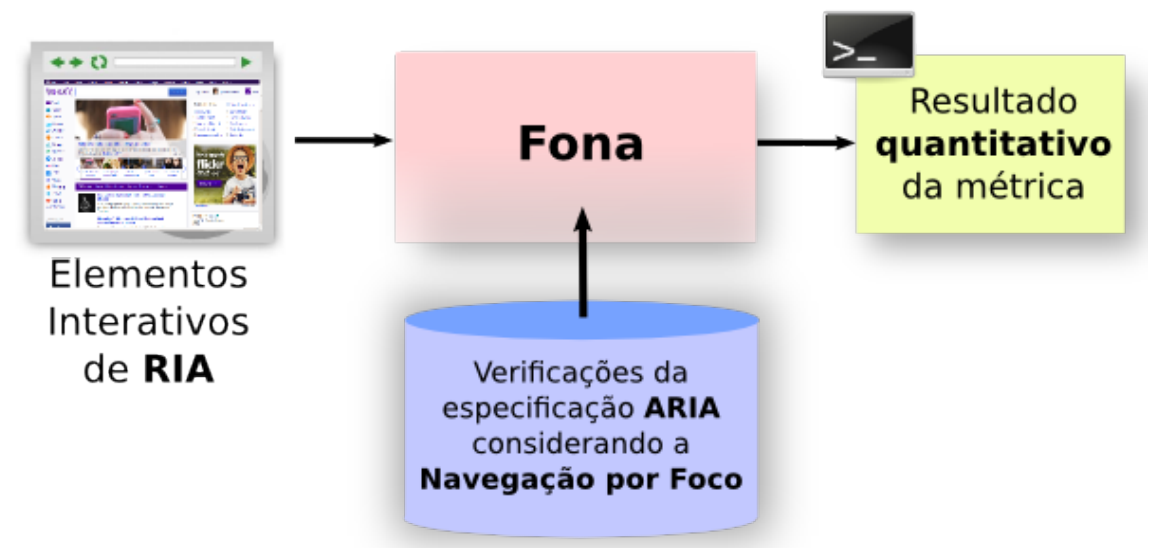

Figura 6.1: Esquema de funcionamento da ferramenta que calcula a métrica Fona em RIA.

\subsection{Avaliação}

Neste capítulo, é apresentada a métrica Fona que considera o número de elementos que podem receber foco (que apresentem a propriedade TabIndex com valor não negativo) e o número de elementos HTML que respondem a eventos de mouse, implementando widgets, para comparar os 349 websites mais populares de acordo com Alexa ${ }^{7}$ com os exemplos de implementação da especificação ARIA disponíveis pelo grupo iCITA ${ }^{8}$, de acordo com os seus recursos de Navegação por Foco.

Vale destacar que apesar de muitas iniciativas de desenvolvimento de RIA apoiarem e implementarem a especificação ARIA, como as bibliotecas jQueryUI ${ }^{9}, \mathrm{DOJO}^{10}$ e YUI ${ }^{11}$, não há garantias que essas soluções de design serão de fato utilizadas por desenvolvedores web (Watanabe et al., 2010c). Dessa forma, este capítulo também apresenta um relatório sobre como as soluções de design descritas na especificação ARIA têm sido implementadas em 349 websites mais populares, de acordo com a empresa Alexa. A investigação apresentada neste capítulo é direcionada ao requisito de Navegação por Foco, utilizando a métrica Fona.

Para analisar a adequação da métrica Fona, foi conduzida uma investigação sobre como a Navegação por Foco tem sido implementada nas mais populares páginas web. As Questões de Pesquisa que guiaram essa investigação são apresentadas a seguir:

1. A métrica proposta é capaz de identificar problemas na implementação do requisito de Navegação por Foco em aplicações web?

2. A métrica proposta é capaz de apontar diferenças entre aplicações web que implementam corretamente o requisito de Navegação por Foco e as aplicações web que não implementam esse requisito?

\footnotetext{
${ }^{7}$ https://gist.github.com/watinha/0f9b2679cb810f6c1a44

${ }^{8} \mathrm{http}: / /$ test.cita.illinois.edu/aria/

${ }^{9} \mathrm{http}: / /$ www.jqueryui.com

${ }^{10} \mathrm{http} / / /$ dojotoolkit.org/

${ }^{11} \mathrm{http} / / /$ yuilibrary.com/
} 
3. Os desenvolvedores web têm implementado o requisito de Navegação por Foco em suas páginas web?

Durante a investigação, foram comparados os valores da métrica Fona, descrita seção anterior (Seção 6.2) entre as 349 páginas mais populares segundo Alexa com exemplos de implementação de ARIA (Grupo de Controle).

A comparação entre os dois grupos permite que seja realizada uma análise experimental relacionada às Questões de Pesquisa 1 e 2. O conjunto dessas 349 páginas web mais populares segundo Alexa possibilita uma análise sobre a situação atual do Grupo Alvo, considerando a implementação do requisito de Navegação por Foco; esse conjunto indica respostas relacionadas à Questão de Pesquisa 3.

A próxima seção apresenta detalhes sobre os dois grupos utilizados nesta investigação: o grupo de 349 páginas web mais populares segundo Alexa e o grupo de exemplos de implementação de ARIA da iCITA.

\subsubsection{Grupos do experimento}

Esta investigação foi conduzida considerando dois grupos de páginas web: as 349 páginas web mais populares de acordo com Alexa (Grupo Alvo que representa uma amostra da população de websites que compõem a Web) e o grupo de 41 exemplos de implementação da especificação ARIA desenvolvidos pela iCITA - Illinois Center for Information Technology and Web Accessibility (Grupo Controle).

O Grupo Alvo consiste de 349 páginas web extraídas da lista da Alexa de websites que possuem o maior número de acessos. A Alexa é uma compania que provê métricas de acesso de websites globais gratuitamente. Essas 349 páginas web foram acessadas no dia 5 de maio de 2013, para coletar as métricas utilizadas nesta investigação. As requisições HTTP que carregaram essas páginas web foram todas realizadas por agentes do usuário (navegadores web) localizados no Brasil. Foram consideradas apenas os 349 websites da lista da Alexa, visto que muitos websites em posições superiores ao website de número 349 da lista da Alexa não puderam ser coletados, por terem acesso restrito (retornando uma resposta de status 403 na requisição HTTP) ou não estarem disponíveis (retornando uma resposta de status 404 na requisição HTTP).

As páginas web que representam o Grupo Alvo foram classificadas de acordo com os seguintes sub-grupos:

Portais : as páginas web desse sub-grupo apresentam conteúdo constantemente atualizado e múltiplos links para serviços. O objetivo dessas páginas web é disponibilizar informações relevantes sobre um determinado tópico em uma única página web. O acesso a essas páginas é público e não são necessárias credenciais/autenticação do usuário. Essas páginas web freqüentemente abordam tópicos relacionados a notícias, previsão do tempo, planos de 
ações, veículos, entre outros. Algumas dessas páginas web apresentam formulários de login e mecanismos de busca, mas esses mecanismos não encontram-se localizados nas partes centrais do layout.

Noventa e sete páginas web foram classificadas nesse sub-grupo (27,80\%).

Empresas/Produtos : as páginas web desse sub-grupo apresentam informações de apresentação/introdução de uma empresa ou produto. O objetivo dessas páginas web é divulgar o portfólio de uma determinada empresa ou um produto específico. Essas páginas freqüentemente disponibilizam widgets tipo slideshow, vídeos promocionais e informações de contato. As empresas e produtos desse sub-grupo são relacionados aos seguinte tópicos: informática, infra-estrutura em nuvem, segurança, entre outros.

Oitenta e seis páginas web foram classificadas nesse sub-grupo $(24,64 \%)$.

Busca : as páginas desse sub-grupo apresentam um campo de texto posicionado ao centro da tela. Essas páginas web têm como objetivo disponibilizar um serviço de busca na Web, utilizando como parâmetros palavras inseridas em um campo de texto. A maioria dessas páginas web apresentaram um único campo de texto com um sub-grupo de links para outros tipos de serviços, como: emails, mensagem instantânea, lojas online, portais de notícias, entre outros.

Sessenta e oito páginas web foram classificadas nesse sub-grupo (19,48\%).

E-commerce : as páginas desse sub-grupo apresentam uma loja online que informa preços de produtos e divulga promoções. Essas páginas têm o objetivo de guiar os usuários durante um processo de compra de produtos. As páginas freqüentemente apresentam componentes como Fly-out Menu para navegar entre diferentes categorias de produtos, widgets tipo slideshow divulgando produtos e informações de preço. Os produtos dessas lojas online estavam relacionados aos seguinte tópicos: informática, elétro-eletrônicos, livros, carros, entre outros tópicos.

Trinta e duas páginas web foram classificadas nesse sub-grupo $(9,16 \%)$.

Vídeo : as páginas desse sub-grupo apresentam múltiplos vídeos que podem ser assistidos no navegador web. O primeiro representante desse sub-grupo, de acordo com a lista da Alexa, é o Youtube ${ }^{12}$ e a maior parte das páginas web desse sub-grupo apresentam as mesmas características. O objetivo dessas páginas web é divulgar vídeos que podem ser assistidos na própria aplicação web. Essas páginas web apresentam múltiplos links com imagens que representam frames individuais e descrições textuais do vídeo. Os vídeos dessas páginas web estão freqüentemente relacionados aos seguinte tópicos: séries de TV, novelas, clips musicais e entretenimento em geral.

Vinte e oito páginas web foram classificadas nesse sub-grupo $(8,02 \%)$.

\footnotetext{
${ }^{12} \mathrm{http}: / /$ www.youtube.com
} 
Login : as páginas desse sub-grupo apresentam um único formulário de login e exigem a autenticação para que o usuário possa ter acesso às principais funcionalidades. Essas páginas freqüentemente implementam plataformas sociais, dessa forma, a autenticação se torna necessária para identificar o usuário e permitir a visualização de conteúdo e dados de outros usuários. Essas páginas disponibilizam o formulário de login e um texto/imagem que descreva as funcionalidades.

Vinte e cinco páginas web foram classificadas nesse sub-grupo $(7,16 \%)$.

403/404 : algumas páginas web da lista da Alexa tiveram seu acesso proibido ou estavam indisponíveis no momento da coleta (retornando respostas com status 403/404 para as requisições HTTP realizadas). Essas páginas web apresentavam um conteúdo textual que explica os motivos do conteúdo ser proibido ou indisponível, quando uma página de erro customizada era apresentada.

Nove páginas web foram classificadas nesse sub-grupo (2,60\%).

Forum : as páginas desse sub-grupo apresentam uma lista com questionamentos e comentários de usuários. O objetivo dessas páginas web é disponibilizar um serviço que permita que usuários comentem em tópicos publicados por outros usuários. Os conteúdos gerados por essa dinâmica são de acesso público e não exigem a autenticação dos usuários para realizar a leitura dos tópicos e comentários.

Quatro páginas web foram classificadas nesse sub-grupo $(1,14 \%)$.

Os números de páginas web por sub-grupo são apresentados na Figura 6.2.

O Grupo Controle consiste de 41 páginas web extraídas dos exemplos de implementação da especificação ARIA desenvolvidos pela iCITA. A iCITA disponibilizou esses exemplos para auxiliar desenvolvedores web na aprendizagem dos conceitos envolvidos e abordados na especificação ARIA. Essas páginas web foram acessadas no dia 4 de maio de 2013 com um agente de usuário localizado no Brasil, para coletar as métricas utilizadas nesta investigação. Essas páginas foram utilizadas como exemplos de implementação correta do requisito acessibilidade de navegação de foco da especificação ARIA.

Do grupo das 41 páginas web que constituem o Grupo de Controle, foram removidas 4 páginas, uma vez que essas páginas implementam rotinas de teste de Navegação por Foco e apresentam widgets que não seguem a especificação ARIA. As 4 páginas web que foram removidas dessa forma apresentam as seguintes funcionalidades: teste de foco para elementos de tipo botão ${ }^{13}$, teste de foco para elementos INPUT de tipo botão ${ }^{14}$, teste de foco para elementos de tipo âncora ${ }^{15}$ e teste de foco para elementos $D I V^{16}$.

\footnotetext{
${ }^{13} \mathrm{http}: / /$ test.cita.illinois.edu/aria/focus-test/button.php

${ }^{14} \mathrm{http}: / /$ test.cita.illinois.edu/aria/focus-tests/input-button.php

${ }^{15} \mathrm{http}$ ///test.cita/illinois.edu/aria/focus-test/href.php

${ }^{16}$ http://test.cita.illinois.edu/aria/focus-test/div.php
} 


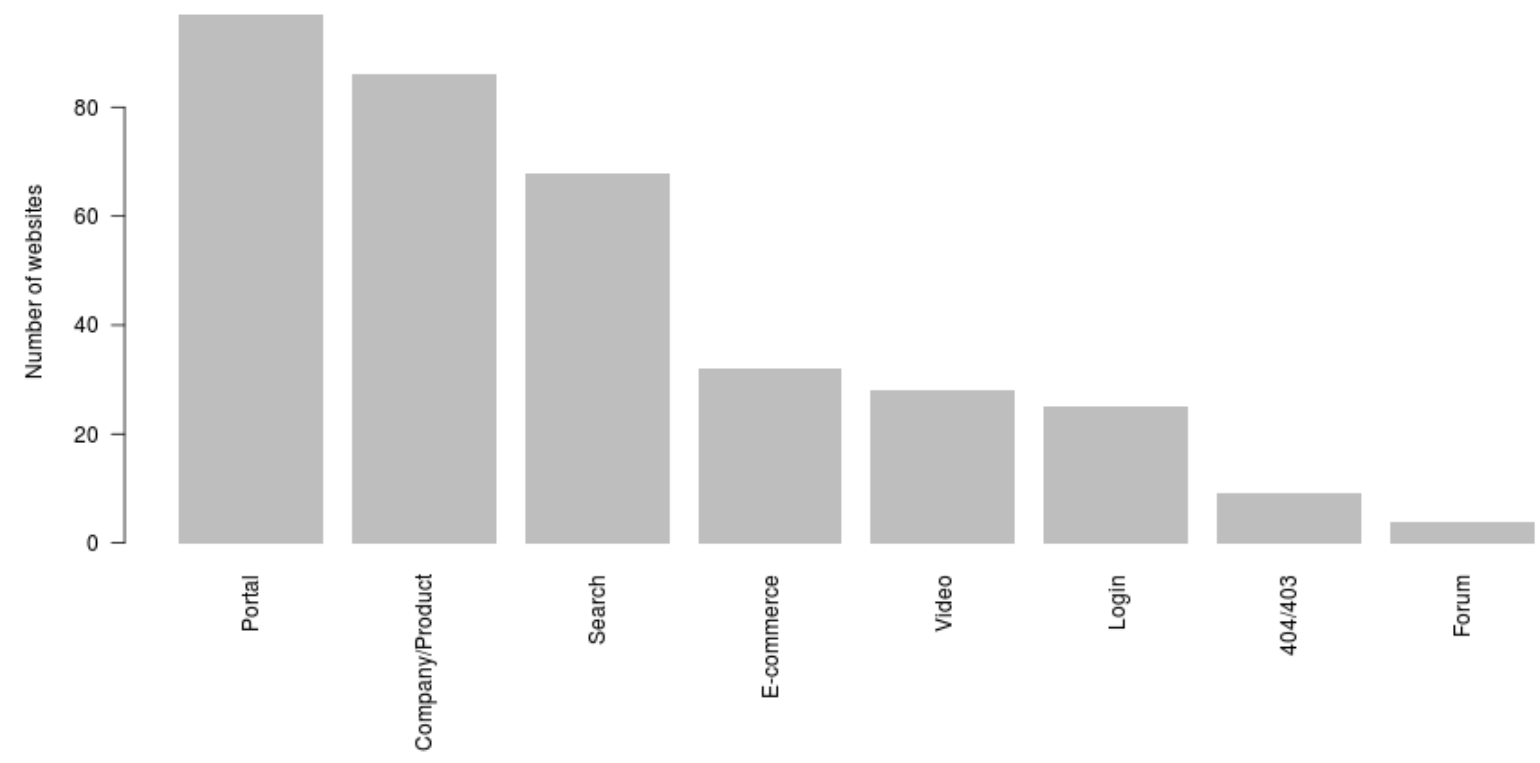

Figura 6.2: Números de páginas web por sub-grupo. Figura extraída do artigo submetido à revista ACM Transactions on the Web.

A próxima seção descreve a metodologia utilizada na avaliação da métrica Fona, utilizando a ferramenta desenvolvida.

\subsubsection{Metodologia}

Para avaliar a métrica Fona proposta, foram realizadas comparações entre os resultados da métrica para o Grupo Alvo, como uma amostra da população de todas as aplicações web da Internet, e o Grupo Controle, como uma amostra da população de todas as aplicações web que implementam a especificação ARIA. Considerando essas comparações que estão relacionadas às Questões de Pesquisa 1 e 2, foram estabelecidas as seguintes hipóteses a serem testadas:

H0: Fona não diferencia um grupo de páginas web que implementam os requisitos de Navegação por Foco da especificação ARIA de um grupo que não implementa a especificação.

H1: Fona é capaz de diferenciar um grupo de páginas web que implementam os requisitos de Navegação por Foco da especificação ARIA de um grupo que não implementa a especificação.

Se a média do valor da métrica Fona for significantemente maior ou igual no Grupo Alvo quando comparada com o Grupo Controle, a hipótese H0 é confirmada e H1 é rejeitada pela investigação. E, portanto, pelos resultados da investigação, a Fona não é capaz de diferenciar 
grupos de páginas web que implementam requisitos de Navegação por Foco da especificação ARIA de grupos de páginas web que não implementam esses requisitos.

Por outro lado, se a média do valor da métrica for significantemente menor no Grupo Alvo quando comparada com o Grupo Controle, a hipótese H1 é confirmada pela investigação e H0 é rejeitada pela investigação. E, portanto, pelos resultados da investigação, a métrica é capaz de diferenciar grupos de páginas web que implementam requisitos de Navegação por Foco.

Adicionalmente, se a hipótese $\mathbf{H 1}$ for aceita pela investigação, os resultados da coleta da métrica no Grupo Alvo devem apresentar o estado da implementação do requisito de Navegação por Foco na Web. E esses resultados fornecem contribuições relacionadas à Questão de Pesquisa 3.

Para calcular a métrica, torna-se necessário identificar para cada página web o número de elementos HTML que possuem funcionalidade em JavaScript que responde a eventos do mouse e o número de elementos HTML que possuem o atributo role com valor não nulo. Ambos valores também foram coletados separadamente para melhor caracterizar o Grupo Alvo e o Grupo Controle.

A próxima seção apresenta os resultados da investigação.

\subsubsection{Resultados}

Os resultados foram agrupados de acordo com as seguintes avaliações coletadas:

- Número de funções JavaScript que respondem a eventos de mouse.

- Número de elementos HTML que possuem o atributo role com um valor não nulo.

- Valor da métrica de Navegação por Foco.

\section{Número de Funções JavaScript que respondem a eventos de mouse}

O Grupo Alvo apresentou um valor médio de 126,7 funções JavaScript que respondem a eventos de mouse. Aproximadamente $75 \%$ das páginas web que compõem esse grupo apresentam 14 ou mais funções JavaScript associadas a elementos HTML da estrutura DOM para responder a eventos de mouse. A Figura 6.3 ilustra um histrograma do número de elementos HTML que possuem funções JavaScript que respondem a eventos de mouse no Grupo Alvo.

Dentre os sub-grupos que compõem o Grupo Alvo, os sub-grupos Portal e Vídeo apresentaram as maiores médias de números de elementos HTML com funcionalidades JavaScript que respondem a eventos de mouse (254,2 para o sub-grupo das páginas web de tipo Portal e 245,2 para o sub-grupo, Vídeo). As menores médias foram registradas para os sub-grupos de páginas web 403/404 (todas as páginas desse grupo não possuiam elementos HTML com funcionalidade JavaScript) e Login (17,08 na média). 


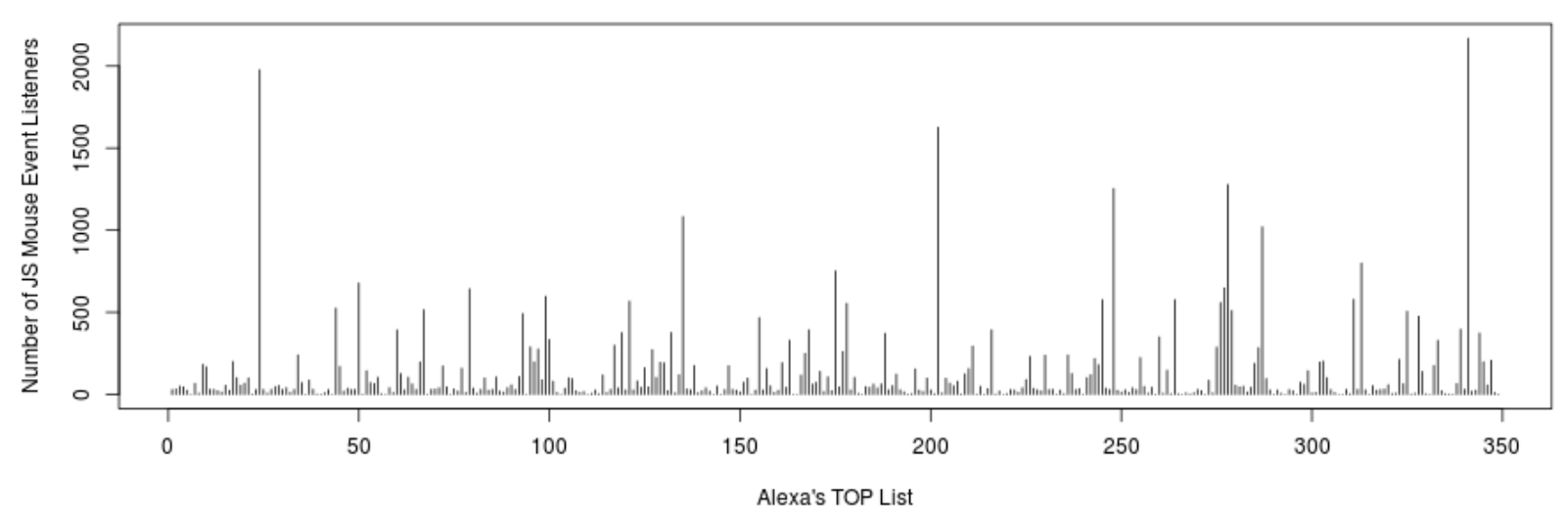

Figura 6.3: Número de funções JavaScript que respondem a interação por mouse no Grupo Alvo. Figura extraída do artigo submetido à revista ACM Transactions on the Web

No Grupo Alvo, 29 páginas web não apresentaram nenhuma função JavaScript para responder a eventos de mouse (aproximadamente 8,5\%). É importante observar que o fato de 29 websites não apresentarem funções JavaScript para responder a eventos de mouse não implica que esses 29 websites não tinham nenhuma funcionalidade JavaScript em seus códigos. A ferramenta não analiza todo o conteúdo das páginas web, a ferramenta apenas contabiliza funções JavaScript que estejam associadas a algum elemento HTML da estrutura DOM e que respondam a eventos de mouse.

As 29 páginas web que não apresentaram nenhuma função JavaScript para responder a eventos de mouse consistiam de:

- Páginas web de acesso proibido ou indisponíveis: 7 páginas web não puderam ser acessadas ou não foram encontradas quando a investigação foi realizada (receberam uma resposta HTTP de status 403 ou 404, quando a ferramenta realizou a requisição pela página). Alguns nomes de domínio não se encontram disponíveis dependendo da origem da requisição HTTP. Essa política é aplicada a websites que bloqueiam o acesso a usuários dependendo da região que originou a requisição HTTP. Não foi realizada uma investigação aprofundada para determinar qual a razão para esses 7 websites terem seu acesso restrito ou não terem sido encontrados, no entanto essa política poderia ser a causa para esse comportamento.

- Páginas web de entrada e busca: 3 páginas web apresentaram um simples conteúdo HTML contendo apenas um formulário para efetuar a entrada na aplicação web (login) ou para realizar uma busca no seu conteúdo, e não apresentaram nenhuma função JavaScript para responder a eventos por mouse.

- Página Inicial de portais de Notícias ou Propaganda: 19 páginas web apresentaram um código HTML com um conteúdo em Flash ou uma lista de links que representavam a página inicial de um portal de notícias ou de propaganda. 
Essas 29 páginas web sem nenhuma função JavaScript que responde a eventos de mouse foram removidas da etapa de análise de dados, uma vez que esses websites não implementavam qualquer tipo de comportamento de interação por mouse que caracteriza uma RIA. Como resultado, o Grupo Alvo foi reduzido para 320 páginas web nessa etapa de análise dos resultados.

O Grupo Controle apresentou uma média de 16,68 funções JavaScript para responder a eventos de mouse e $75 \%$ dos seus websites apresentavam 6 ou mais funções JavaScript associadas a elementos HTML para responder a eventos de mouse.

Uma página web do Grupo Controle não apresentou nenhuma funcionalidade JavaScript que responda a eventos de mouse. Essa página web implementa um exemplo de utilização de Landmarks. Os Landmarks são utilizados para incrementar a navegação para leitores de tela e outras Tecnologias Assistivas. Como os Landmarks não requerem a utilização de funcionalidade JavaScript, esse exemplo não se enquadra no escopo desta investigação, e portanto esse exemplo foi removido do Grupo Controle.

Todos os valores de mínimo, mediana, média e máximo para o número de elementos com funcionalidade JavaScript que respondem a eventos de mouse para cada sub-grupo e grupo do estudo são apresentados na Tabela 6.1 e a distribuição desses valores é ilustrada na Figura 6.4.

Tabela 6.1: Valores mínimo, mediana, média e máximo do número de elementos HTML com funcionalidade JavaScript que respondem a eventos de mouse nos grupos e sub-grupos da investigação.

\begin{tabular}{|l||r|r|r|r|}
\hline Sub-grupo & Minímo & Mediana & Média & Máximo \\
\hline Portais & 0,00 & 118,00 & 254,20 & 2169,00 \\
\hline Empresas/Produtos & 0,00 & 19,50 & 71,33 & 678,00 \\
\hline Busca & 0,00 & 28,50 & 34,26 & 232,00 \\
\hline E-commerce & 0,00 & 64,50 & 104,47 & 643,00 \\
\hline Vídeo & 0,00 & 132,50 & 245,20 & 1627,00 \\
\hline Login & 0,00 & 11,00 & 17,08 & 56,00 \\
\hline $403 / 404$ & 0,00 & 0,00 & 0,00 & 0,00 \\
\hline Forum & 21,00 & 71,50 & 115,80 & 299,00 \\
\hline \hline Grupo & Minímo & Mediana & Média & Máximo \\
\hline Grupo Alvo & 0,00 & 35,00 & 126,70 & 2169,00 \\
\hline Grupo Controle & 0,00 & 13,00 & 16,68 & 64,00 \\
\hline
\end{tabular}

Na Figura 6.5, são ilustrustradas as distribuições do número de funções JavaScript que respondem a eventos do mouse do Grupo Alvo e do Grupo Controle.

Na próxima seção, são apresentados os resultados da investigação considerando o número de elementos HTML com atributos role.

\section{Número de elementos HTML com atributo role}

Considerando o número de atributos role não nulos, o Grupo Alvo, apesar de apresentar uma média de 126,7 funções JavaScript que respondem a eventos de mouse, apresentou uma média 


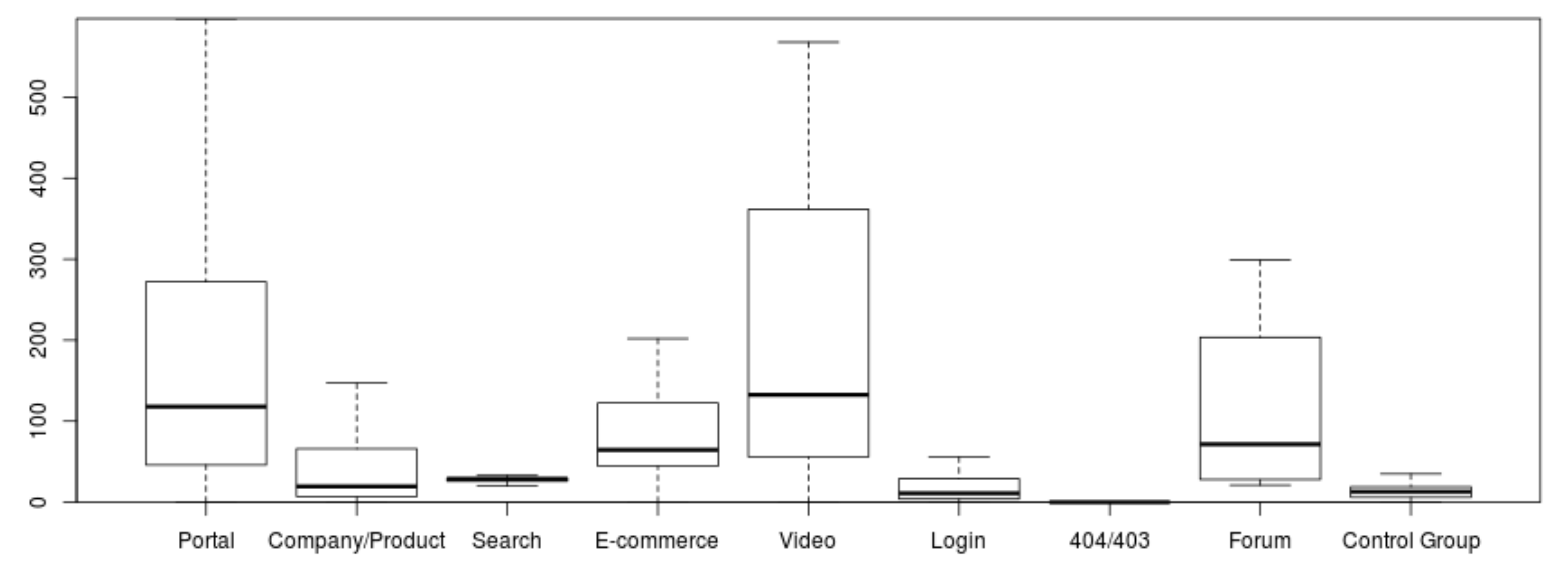

Figura 6.4: Representação em Boxplot que apresenta o número de funções JavaScript do Grupo Alvo. Figura extraída do artigo submetido à revista ACM Transactions on the Web.

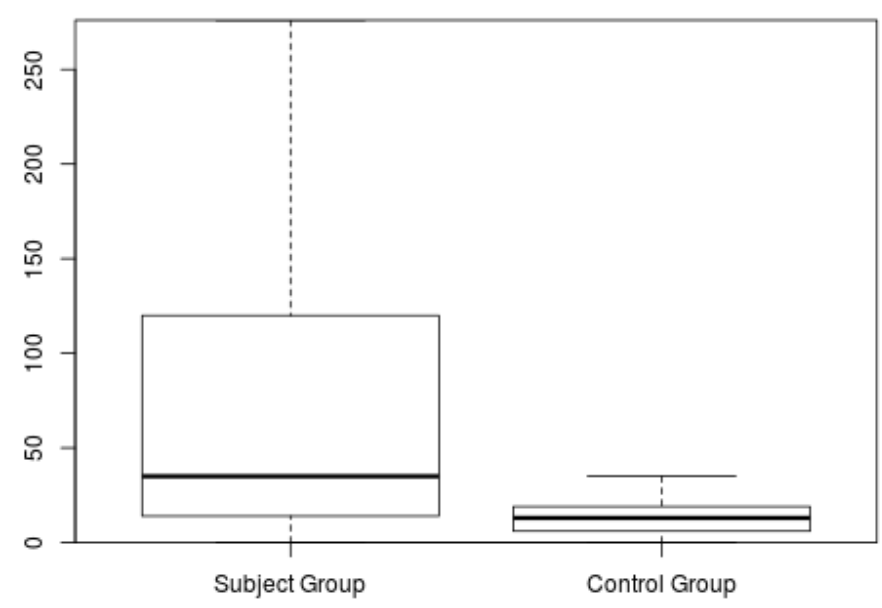

Figura 6.5: Representação em Boxplot que apresenta o número de funções JavaScript do Grupo Alvo em comparação com o Grupo Controle. Figura extraída do artigo submetido à revista $A C M$ Transactions on the Web.

de 3,134 elementos HTML com um atributo role não nulo. Além disso, aproximadamente $80 \%$ das páginas web não apresentavam nenhum elemento HTML com atributo role. Na Figura 6.6, é ilustrado um histograma que apresenta o número de elementos HTML com atributo role por página web.

Dentre os sub-grupos, os grupos de websites tipo Forum e E-commerce apresentaram as maiores médias de número de atributos role não nulo por página: 24,25 para o grupo Forum e 10,68 para o grupo E-commerce. 


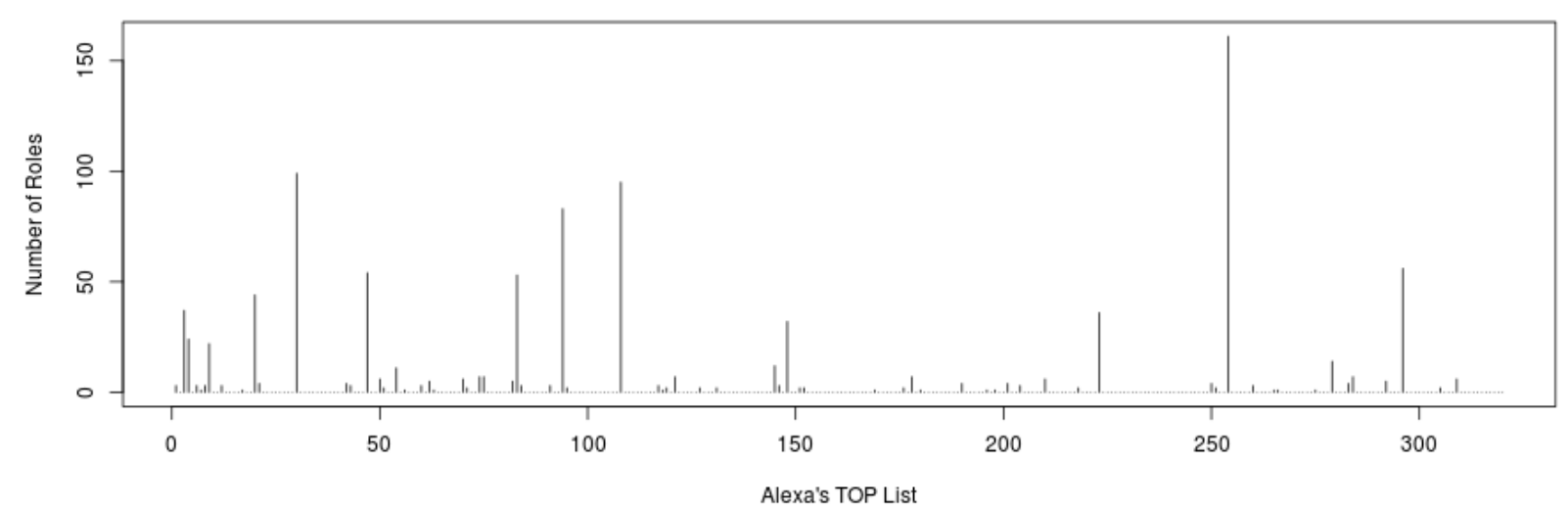

Figura 6.6: Número de elementos HTML que foram marcados com um atributo role não nulo no Grupo Alvo. Figura extraída do artigo submetido à revista ACM Transactions on the Web.

Por outro lado, o Grupo Controle, que consiste dos exemplos de implementações da especificação ARIA, apresentou uma média de 23 elementos HTML com atributo role não nulo, com $75 \%$ dos websites com mais de 7 elementos HTML com o atributo. Ambos grupos (Grupo Alvo e Grupo Controle) apresentaram uma diferença estatisticamente significante nessa métrica, considerando um teste-t de duas amostras de Welch (Welch Two Sample t-test), com um valor de $\mathrm{p}$ (p-value) igual a 1,405 × $10^{-6}$ em um intervalo de confiança de $95 \%$.

Todos os valores de mínimo, mediana, média e máximo para o número de elementos com atributo role não nulo para cada sub-grupo e grupo do estudo são apresentados na Tabela 6.2 e a distribuição desses valores é ilustrada na Figura 6.7.

Tabela 6.2: Valores mínimo, mediana, média e máximo do número de elementos HTML com atributo role não nulo nos grupos e sub-grupos da investigação.

\begin{tabular}{|l||r|r|r|r|}
\hline Sub-Grupo & Minímo & Mediana & Média & Máximo \\
\hline Portais & 0 & 0,00 & 0,9787 & 24 \\
\hline Empresas/Produtos & 0 & 0,00 & 5,2310 & 161 \\
\hline Busca & 0 & 0,00 & 0,0769 & 4 \\
\hline E-commerce & 0 & 3,00 & 10,6800 & 83 \\
\hline Vídeo & 0 & 0,00 & 1,9620 & 37 \\
\hline Login & 0 & 0,00 & 0,8636 & 56 \\
\hline Forum & 0 & 1,00 & 24,2500 & 95 \\
\hline \hline Grupo & Minímo & Mediana & Média & Máximo \\
\hline Grupo Alvo & 0 & 0,00 & 3,1340 & 161 \\
\hline Grupo Controle & 0 & 12,50 & 23,0000 & 93 \\
\hline
\end{tabular}

Na Figura 6.8, são ilustrustradas as distribuições do número de elementos HTML com o atributo role do Grupo Alvo e do Grupo Controle.

No Grupo Alvo, 13 páginas web apresentaram mais de 20 elementos HTML com atributo role. Os atributos role identificados nesse grupo possuiam valores de landmarks, botões, menu, tab e 


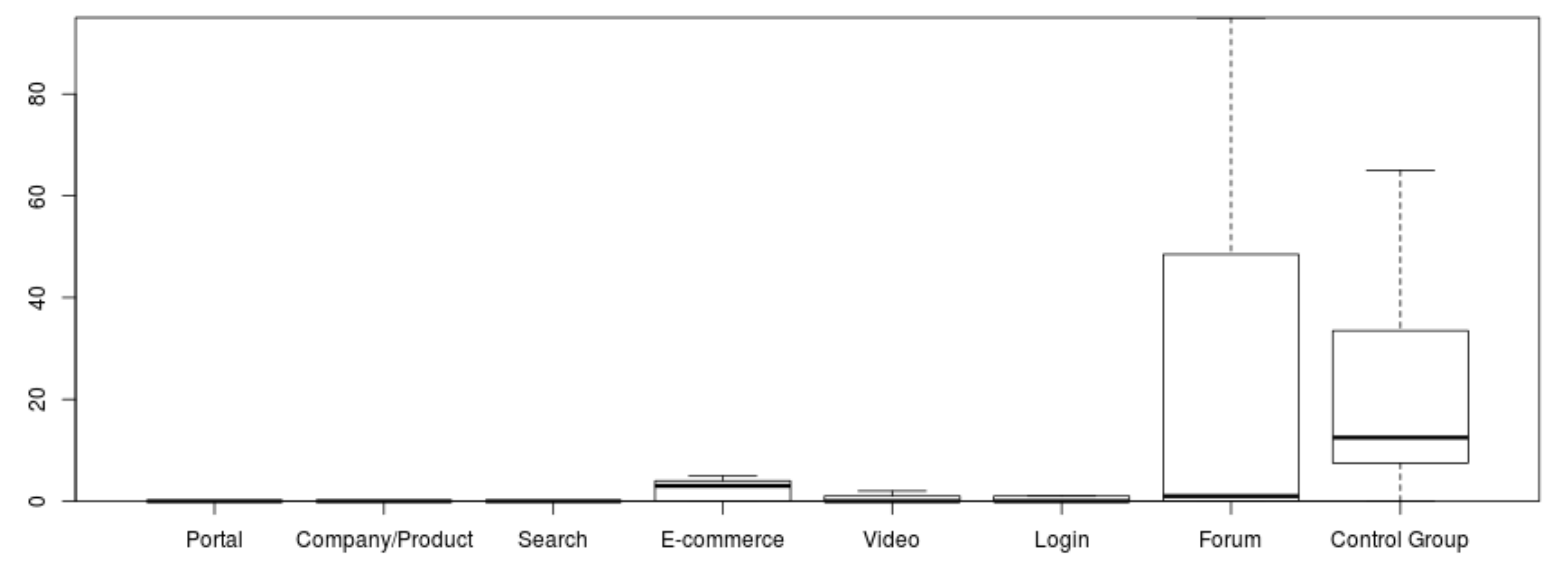

Figura 6.7: Representação em Boxplot que apresenta o número de elementos HTML com atributo role não nulo nos grupos e sub-grupos da investigação. Figura extraída do artigo submetido à revista ACM Transactions on the Web.

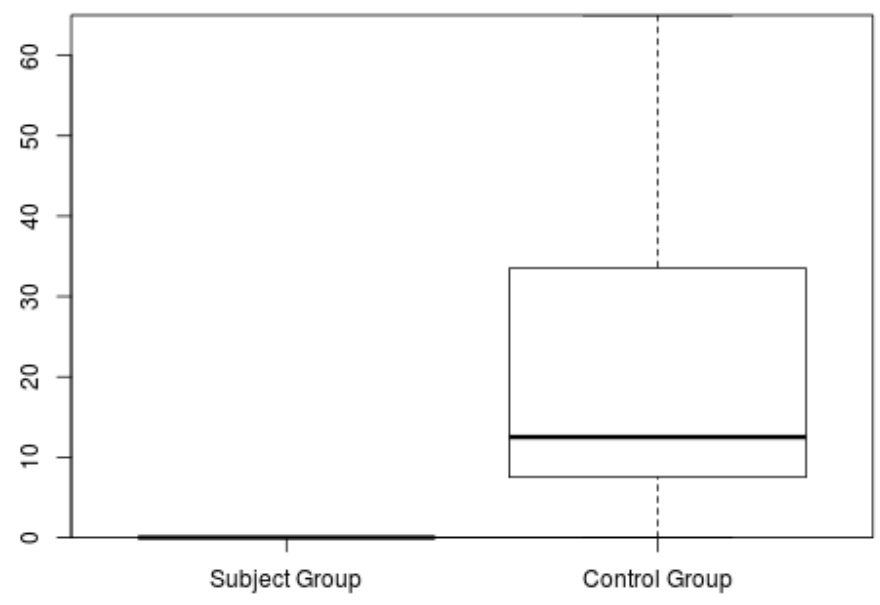

Figura 6.8: Representação em Boxplot que apresenta o número elementos HTML com atributo role do Grupo Alvo em comparação com o Grupo Controle. Figura extraída do artigo submetido à revista ACM Transactions on the Web.

caixas de diálogo. Quatro desses websites utilizaram a biblioteca jQuery, mas apenas um deles utilizou uma biblioteca de componentes de interface (YUI - Yahoo! User Interface) para construir suas widgets. Todos os outros 9 websites implementaram suas próprias soluções na construção de widgets. 


\section{Resultados da métrica de Navegação por Foco}

O Grupo Alvo apresentou uma média de valor para a métrica de $61,15 \%$ e aproximadamente 75\% das páginas web desse grupo apresentaram uma pontuação superior a 33,33\%.

Dentre os sub-grupos do Grupo Alvo, os websites de Busca apresentou o maior valor médio para a métrica: $89,51 \%$. O valor médio dos outros sub-grupos variou entre 37,85\% (Grupo de websites Forum) e 56,82\% (Grupo de websites de Empresas/Produtos).

O Grupo Controle, por outro lado, apresentou uma média de pontuação de 96,07\%, e apenas 1 website apresentou uma pontuação inferior a $75 \%$.

Todos os valores de mínimo, mediana, média e máximo do valor da métrica para cada subgrupo e grupo do estudo são apresentados na Tabela 6.3 e a distribuição desses valores é ilustrada na Figura 6.9.

Tabela 6.3: Valores mínimo, mediana, média e máximo da métrica Fona nos grupos e sub-grupos da investigação.

\begin{tabular}{|l||r|r|r|r|}
\hline Sub-Grupo & Minímo & Mediana & Média & Máximo \\
\hline Portais & $0,0000 \%$ & $54,69 \%$ & $55,93 \%$ & $100,00 \%$ \\
\hline Empresas/Produtos & $0,0000 \%$ & $65,15 \%$ & $56,82 \%$ & $100,00 \%$ \\
\hline Busca & $25,0000 \%$ & $96,43 \%$ & $89,51 \%$ & $100,00 \%$ \\
\hline E-commerce & $0,7246 \%$ & $36,20 \%$ & $41,13 \%$ & $100,00 \%$ \\
\hline Vídeo & $0,0000 \%$ & $46,37 \%$ & $54,21 \%$ & $100,00 \%$ \\
\hline Login & $0,0000 \%$ & $60,61 \%$ & $55,59 \%$ & $100,00 \%$ \\
\hline Forum & $4,6300 \%$ & $34,76 \%$ & $37,85 \%$ & $77,26 \%$ \\
\hline \hline Grupo & Minímo & Mediana & Média & Máximo \\
\hline Grupo Alvo & $0,0000 \%$ & $66,03 \%$ & $61,15 \%$ & $100,00 \%$ \\
\hline Grupo Controle & $13,04 \%$ & $100,00 \%$ & $96,07 \%$ & $100,00 \%$ \\
\hline
\end{tabular}

Na Figura 6.10, são ilustrustradas as distribuições do valor da métrica Fona do Grupo Alvo e do Grupo Controle.

Todos os sub-grupos e o Grupo Alvo apresentaram diferenças estatisticamente significativas com o Grupo Controle para os valores da métrica Fona em comparações de teste-t de duas amostras de Welch (Welch Two Sample t-test), considerando um intervalo de confiança de 0,95. Logo, os resultados destas comparações suportam a hipótese $\mathbf{H 1}$ da investigação. Todos os valores de $\mathrm{p}$ ( $p$-value) de todas as comparações entre os sub-grupos e o Grupo Controle são apresentados a seguir:

Portais: $2,2 \times 10^{-16}$

Empresas/Produtos: $3,21 \times 10^{-14}$

Busca: $2,452 \times 10^{-2}$

E-commerce: $8,077 \times 10^{-15}$

Vídeo: $3,166 \times 10^{-7}$ 


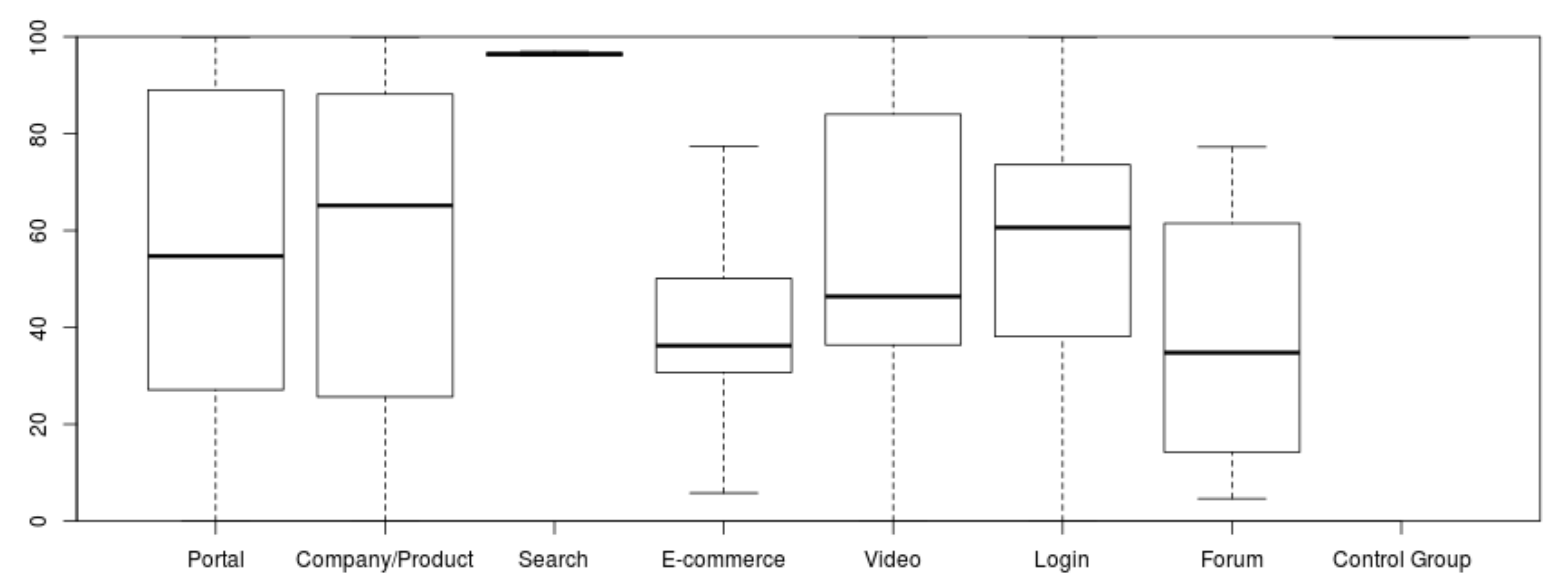

Figura 6.9: Representação em Boxplot que apresenta o valor da métrica Fona nos grupos e sub-grupos da investigação. Figura extraída do artigo submetido à revista ACM Transactions on the Web.

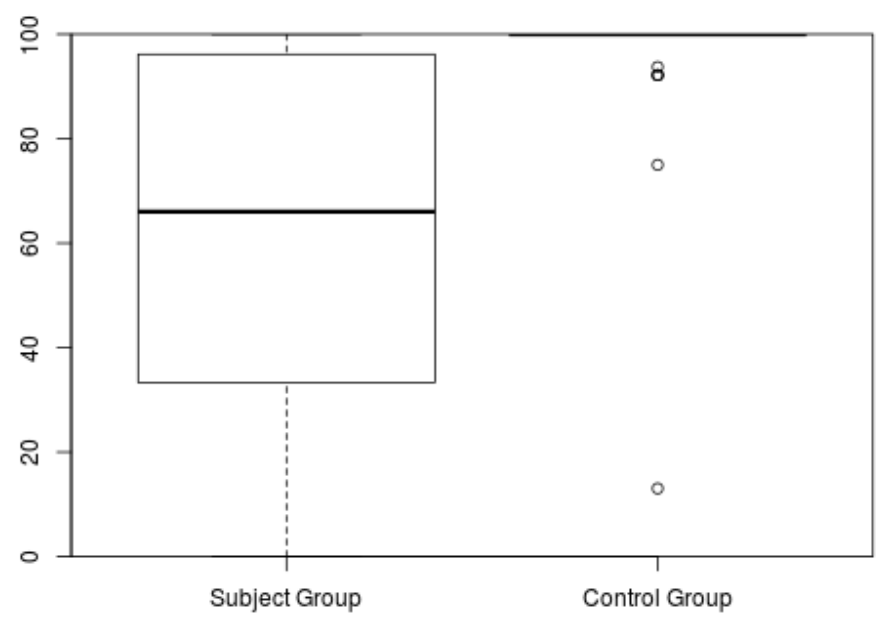

Figura 6.10: Representação em Boxplot que apresenta a distribuição do valor da métrica Fona do Grupo Alvo em comparação com o Grupo Controle. Figura extraída do artigo submetido à revista ACM Transactions on the Web.

Login: $1,528 \times 10^{-6}$

Forum: 0,015 87

Grupo Alvo: $2,2 \times 10^{-16}$

A próxima seção apresenta uma discussão sobre os resultados obtidos nessa investigação. 


\subsection{Discussão}

O conceito de aplicações ricas de Internet (RIA) existe desde 2005, quando surgiu o movimento Ajax (Garrett, 2005). Esse movimento introduziu o uso de tecnologias abertas que compõem a Web, em especial o JavaScript, para implementar mecanismos de interação rica em aplicações web. Os resultados da investigação realizada para avaliar a métrica Fona, recentemente conduzida, indicam que as páginas web mais populares, segundo Alexa, apresentam em média 126,7 funções de JavaScript para responder a eventos de mouse em sua estrutura DOM. Esses resultados revelam a importância que a tecnologia JavaScript adquiriu ao longo dos anos e enfatizam a necessidade de tornar essa tecnologia acessível a usuários com deficiência. Apenas 29 páginas web do Grupo Alvo (ou seja, 8,30\% do total) não apresentam qualquer funcionalidade JavaScript que respondesse a eventos de mouse (Figura 6.3), no entanto, isso não significa que essas páginas não implementam algum tipo de funcionalidade JavaScript, conforme descrito anteriormente. Desse modo, pode ser observado que a grande maioria $(91,70 \%)$ das páginas mais populares implementam funções em linguagem JavaScript que respondem a eventos de mouse, o qual é o objeto de interesse desta pesquisa.

O número de elementos HTML que apresentam atributos role não apresentou as mesmas taxas elevadas que o número de funções JavaScript que respondem a eventos de mouse no Grupo Alvo (Figura 6.6 e Figura 6.7). Apesar da especificação ARIA ter atingido o estado de Candidata a Recomendação da W3C (W3C Candidate Recommendation) em 8 de janeiro de 2011, uma elevada proporção de páginas web do Grupo Alvo não apresentaram nenhum elemento HTML contendo um atributo role (278 das 349 páginas web não apresentaram nenhum atributo role em seus elementos HTML, aproximadamente 80\%). Nesse contexto, nota-se que muitos projetos de aplicações web ainda não consideram os requisitos descritos na especificação ARIA, apesar do elevado número médio de funcionalidade JavaScript que existe na Web, atualmente.

É importante observar que, apesar do Grupo Controle ser composto por páginas web com um número reduzido de funcionalidades JavaScript (Figura 6.4 e Figura 6.5), esse grupo ainda apresenta uma quantidade de atributos role dos elementos HTML das páginas web significantemente superior ao Grupo Alvo (levando em consideração um teste-t de análise de diferenças e a distribuição de elementos representada na Figura 6.7 e 6.8). Se considerada a especificação ARIA, conforme o número de funcionalidades JavaScript aumenta, o número de elementos HTML contendo o atributo role não nulo também deve aumentar. Portanto, destaca-se a diferença de implementação dos requisitos da especificação ARIA entre os dois grupos, o Grupo Controle implementa a especificação ARIA, uma vez que apresenta valores absolutos maiores no uso do atributo role que o Grupo Alvo, apesar do Grupo Alvo conter um maior número de funcionalidades JavaScript.

Treze páginas web do Grupo Alvo apresentaram mais do que 20 elementos HTML contendo um atributo role não nulo (Figura 6.6). Assim, essas páginas web potencialmente representam no Grupo Alvo as melhores implementações da especificação ARIA. No entanto, considerando esses treze websites, apenas um deles utilizou uma biblioteca de componentes de interface JavaScript 
que implementa a especificação ARIA. Isso pode ser resultado do fato que as 349 páginas web da Alexa são compostas por páginas iniciais de aplicações web, e muitas delas têm como objetivo reduzir ao máximo o número de requisições HTTP para carregar suas bibliotecas JavaScript, para também reduzir o tempo geral de carregamento da sua aplicação no navegador web. A utilização de bibliotecas JavaScript que implementam componentes de interface pode aumentar o número de dependências de código JavaScript que precisa ser carregado pelo navegador web, embora reduzam o esforço necessário para desenvolver widgets que estejam em conformidade com a especificação ARIA.

A avaliação realizada em separado, para obtenção do número de funcionalidades JavaScript e da quantidade de elementos HTML com o atributo role possibilitou uma análise com base em valores absolutos sobre como a especificação ARIA tem sido considerada nos projetos web (Figura 6.7). Já sob a perspectiva da métrica de Navegação por Foco, definida neste trabalho, o objetivo foi determinar um valor proporcional que indicasse o número de funcionalidade JavaScript que responde a eventos de mouse e que podem ter implementado uma alternativa de interação por teclado para o seu comportamento. Uma vez que a Fona provê um valor proporcional, ele pode ser utilizado para estimar a quantidade de cenários de uso dos mecanismos implementados com JavaScript que não implementam um recurso alternativo de interação por teclado (Figura 6.9).

A métrica de Navegação por Foco utiliza-se dos atributos TabIndex dos elementos HTML para verificar se um elemento que possui uma função JavaScript que escuta eventos de mouse pode ser alvo de eventos de teclado, para então implementar uma funcionalidade acessível por teclado. Avaliar o número de elementos com o atributo TabIndex maior ou igual que 0 não caracteriza um indicador de acessibilidade, uma vez que links e elementos de formulários que não tenham nenhuma funcionalidade JavaScript associada também apresentam o atributo TabIndex com um valor igual ou superior a 0 . Logo, a verificação do atributo TabIndex foi utilizada em conjunto com o número de elementos HTML que responde a eventos de mouse e o número de elementos com o atributo role para compor a métrica de Navegação por Foco.

Considerando as Questões de Pesquisa (Seção 6.4), a métrica foi capaz de diferenciar o grupo de páginas web mais populares segundo Alexa, que não necessariamente implementam widgets ARIA, e o grupo de exemplos de implementação de widgets ARIA (revelando diferenças estatiscamente significantes entre o Grupo Alvo e o Grupo Controle), suportando a hipótese H1. Apesar de Fona definir um valor que representa o limite superior da acessibilidade, segundo o requisito de Navegação por Foco, a determinação desse valor foi suficiente para apresentar diferenças entre os dois grupos.

Para contabilizar o valor da métrica, é preciso identificar as funções JavaScript que respondem a eventos de mouse que não implementam uma alternativa por teclado desse mecanismo de interação. O resultado obtido por meio desta investigação revelou que muitos projetos web não implementam a Navegação por Foco em suas widgets. Além disso, muitas dessas widgets não são capazes de receber foco em seus elementos, dessa forma não implementam os cenários de interação por teclado que representam requisitos mandatórios da especificação ARIA. 
A métrica proposta nesta Tese também destacou diferenças de comportamento quando comparando o Grupo Alvo e o Grupo Controle. O Grupo Controle apresentou um valor médio aproximado de $100 \%$ para a métrica, enquanto o Grupo Alvo apresentou um valor médio de $61,23 \%$, com uma diferença estatisticamente relevante. Essa diferença mostra que a Web (representada com a amostra de 349 websites mais populares segundo a empresa Alexa) não implementa as mesmas estratégias de navegação que aplicações web que implementam a especificação ARIA. Dessa forma, a Web apresenta severas barreiras de acessibilidade para funcionalidades desenvolvidas em widgets e outros componentes interativos que caracterizam a Web 2.0. Além disso, a avaliação de acessibilidade utilizando Fona mostra que 48,77\% de toda funcionalidade JavaScript que responde a eventos de mouse do Grupo Alvo não são acessíveis por teclado, ou seja, não utilizam estratégias de Navegação por Foco ou interações sofisticadas definidas na especificação ARIA. A métrica, porém, não é capaz de determinar se uma estratégia de navegação por teclado foi corretamente implementada em um website, ela fornece um limite superior de acessibilidade que representa a quantidade de elementos que possuem funcionalidade JavaScript para responder a eventos do mouse que potencialmente podem implementar uma interação acessível.

A partir da análise separada dos valores da métrica obtidos nos sub-grupos, revelou-se que o sub-grupo de websites de Busca apresentou o maior valor médio para a métrica (Figura 6.7). No entanto, vale destacar que esse sub-grupo contém uma distribuição inferior de funcionalidades JavaScript que respondem a eventos de mouse que os outros sub-grupos. Muitos websites do sub-grupo de Busca também representavam aplicações web semelhantes para diferentes idiomas, como: http://www.google.com (aplicação de busca do Google em língua inglesa), http://www.google.co.id (aplicação de busca do Google em língua indonésia), http://www.google.com.tw (aplicação de busca do Google em língua chinesa), entre outros exemplos. Essas diferentes instâncias da mesma aplicação web, apesar das muitas semelhanças entre elas, não foram unificadas na análise dos dados, uma vez que muitas delas apresentavam valores diferentes para a métrica. Como por exemplo, o website da Amazon, que apresentou o valor de 32,8358\% quando renderizado em língua inglesa (no domínio amazon.com) e 100\% quando renderizado em língua japonesa (no domínio amazon.com.jp).

\section{Ameaças à validade}

Todas as páginas web do Grupo Alvo constituem a primeira página de uma aplicação web (frontpage). As frontpages podem ser acessadas por uma ampla variedade de usuários e implementam cenários de interação simplificados (que requerem menos funcionalidades de tecnologias como o JavaScript para implementar mecanismos de interação sofisticados), uma vez que essas páginas freqüentemente orientam os usuários na busca por outros conteúdos e outras páginas web mais complexas. Dessa forma, as análises apresentadas nesta investigação devem apresentar resultados de acessibilidade melhores que uma análise realizada em profundidade nas páginas web (analisando outras páginas além das páginas iniciais). 
É importante destacar que a métrica não é capaz de avaliar widgets construídas apenas com CSS, uma vez que a métrica precisa verificar as funções JavaScript associadas a elementos HTML para calcular o seu valor.

A métrica também contabiliza negativamente elementos HTML que possuem funcionalidade JavaScript para gerar efeitos decorativos. Por exemplo, se um elemento HTML possui uma função JavaScript que altera a sua cor de fundo em resposta a um evento hover e esse elemento não possuir um atributo role ou não estiver acessível a Navegação por Foco, a métrica contabilizaria esse elemento como inacessível, apesar do efeito não impactar negativamente a acessibilidade da aplicação web. No entanto, efeitos decorativos são freqüentemente utilizados para destacar elementos interativos com uma determinada funcionalidade de uma aplicação web. Uma vez que existe funcionalidade associada a esses elementos, eles devem ser acessíveis por navegação de teclado aos usuários e devem ser analisados por estratégias de avaliação de conformidade com a especificação ARIA. Além disso, a implementação de efeitos meramente decorativos em elementos é freqüentemente implementada utilizando apenas CSS.

\subsection{Considerações Finais}

Neste capítulo, foram apresentadas a definição de uma métrica, entitulada Fona, que calcula um valor quantitativo que representa o quanto uma RIA implementa o requisito de Navegação por Foco e os resultados de uma investigação sobre como a funcionalidade de Navegação por Foco tem sido implementada na Web. A implementação de mecanismos de Navegação por Foco tratase de um requisito mandatório de acessibilidade da especificação ARIA que permite que widgets suportem cenários de interação por teclado.

A investigação foi realizada com base na métrica quantitativa Fona que utiliza o número de funções JavaScript que respondem a eventos de mouse, número de elementos HTML com um atributo role não nulo e número de elementos que estão inseridos na ordem de navegação por tab de uma página web. Essa métrica permite estimar a quantidade de casos de uso relacionados à interação por mouse que não possuem cenários de uso alternativos por interações utilizando apenas o teclado.

Os resultados desta invetigação comprovaram que muitas páginas web ainda não implementam os requisitos da especificação ARIA, apesar do número elevado de funcionalidades JavaScript que existem na Web e a especificação ARIA ter atingido o estado de Candidata a Recomandação da W3C há mais de 1 ano. 
Acessibilidade corresponde a um requisito não funcional de sistemas computacionais, 1 que destaca a importância de promover a inclusão digital de indivíduos com deficiên1 cia. Com o estabelecimento da Web 2.0, as aplicações web passaram a utilizar um novo conjunto de tecnologias que melhoram a interação do usuário e potencializam a utilidade desse ambiente para as pessoas. No entanto, o novo conjunto de tecnologias sendo utilizadas demandam novos esforços para promover o acesso universal da Web para usuários com deficiência. A comodidade e simplicidade que determinados serviços web promovem aos usuários não deve ser restrita a um grupo específico de pessoas, mas ser acessível por toda a população.

Por outro lado, a implementação dos requisitos associados à acessibilidade na web requer o conhecimento das técnicas, padrões e metodologias de desenvolvimento acessível de aplicações web. No entanto, as tecnologias que constituem a plataforma da Web estão em constante evolução e torna-se difícil garantir que todos os envolvidos no processo de engenharia web tenham conhecimento de tudo que é necessário para entregar uma aplicação web acessível.

Nesse contexto, esta tese teve o objetivo de investigar estratégias que apoiem o processo de desenvolvimento de aplicações web em conformidade com a especificação ARIA.

Assim, a seguinte questão de pesquisa que norteou os trabalhos científicos conduzidos nesta tese foi: É possível projetar estratégias de avaliação automática de critérios de acessibilidade em RIA, para apoiar o desenvolvimento de widgets acessíveis a usuários que interajam com aplicações web utilizando leitores de tela?

Para responder a essa questão de pesquisa foram realizados ciclos do procedimento de pesquisaação, conforme apresentados na Figura 7.1. A Figura 7.1 representa em três eixos (tempo, escopo 
da análise de acessibilidade e escala dos processos de validação) os ciclos realizados. Na Figura 7.1, cada ciclo corresponde ao desenvolvimento de uma estratégia automática de avaliação de acessibilidade em RIA (nos passos de planejar e agir) e sua respectiva validação (nos passos de descrever e avaliar). Nessa figura, é ilustrado que com a passagem dos ciclos, o escopo da análise de acessibilidade e a escala dos processos de validação das ferramentas são incrementados, gradativamente. Por fim, na figura, também são apresentadas as execuções dos ciclos seguindo a ordem cronológica (eixo de tempo) na condução dos trabalhos que compõem esta tese.

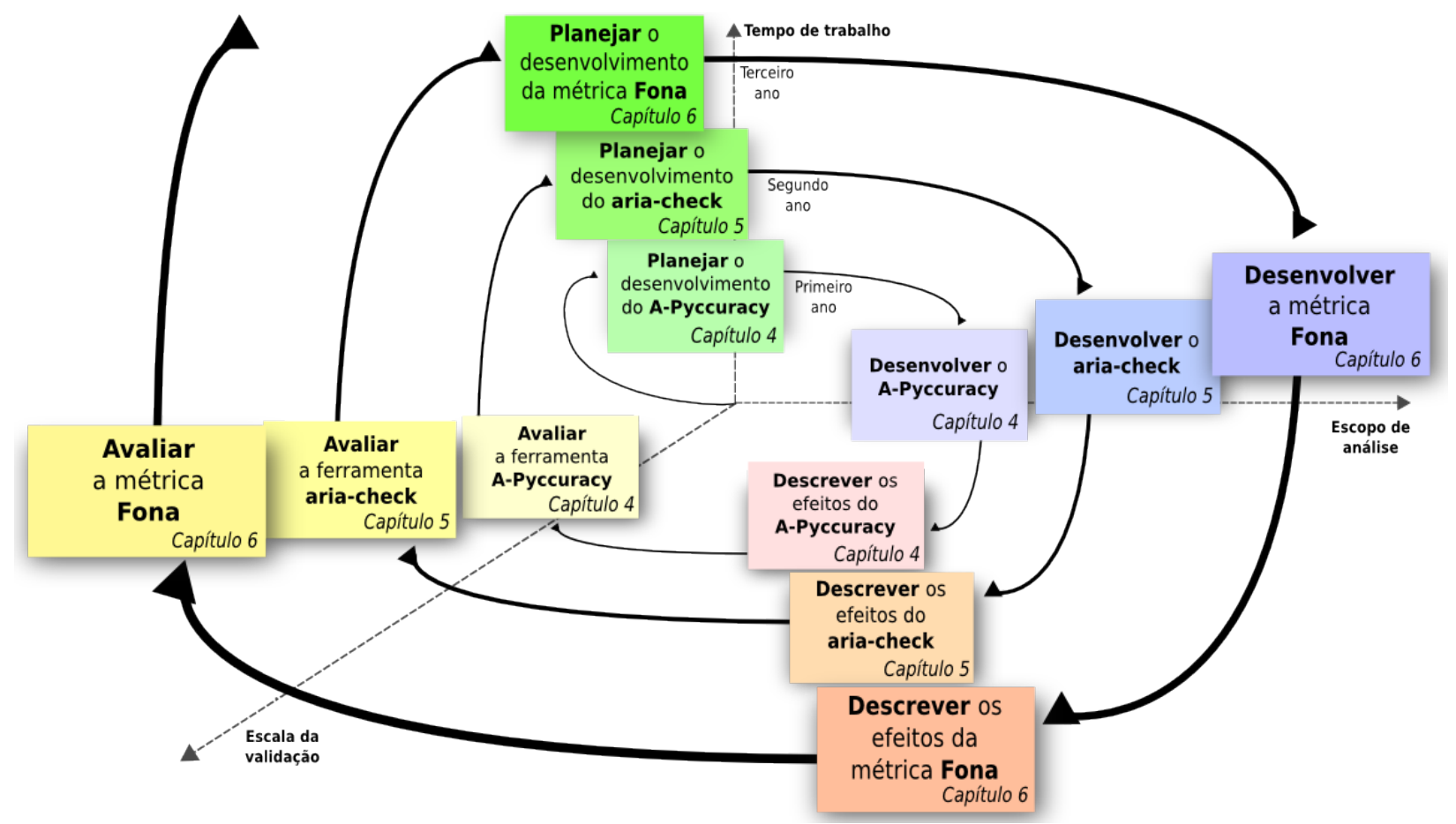

Figura 7.1: Representação das atividades conduzidas nesta tese, considerando os três ciclos do procedimento de pesquisa-ação.

Foram desenvolvidas, inicialmente, duas ferramentas de avaliação com base no conceito de AT. As duas ferramentas atuam de forma diferente no processo de desenvolvimento de software. A primeira (descrita no Capítulo 4) trata-se de uma extensão da ferramenta Pyccuracy de elaboração de AT (A-Pyccuracy), e exige que os desenvolvedores elaborem casos de teste, manualmente. A elaboração manual dos casos de teste permite que todos os aspectos da aplicação web sejam testados automaticamente dentro de um processo de engenharia web. A segunda ferramenta (descrita no Capítulo 5) caracteriza-se pela sua restrição de aplicação na interface, uma vez que avalia widgets e componentes de interface (aria-check). No entanto, os casos de teste são reutilizáveis para diferentes implementações da mesma widget.

Por fim, foi realizada uma investigação na Web, com o objetivo de identificar como mecanismos que permitem a Navegação por Foco nas aplicações web têm sido implementados. Esse trabalho definiu uma métrica (Fona), calculada automaticamente, que identifica a proporção de elementos que possuem mecanismos de interação de widgets que não contemplam um caso de uso de interações utilizando o teclado (descrita no Capítulo 6). 
Os estudos de caso e experimentos desenvolvidos durante esta tese apresentaram tendências de que os requisitos de acessibilidade da especificação ARIA podem ser avaliados automaticamente. A implementação das ferramentas contribuiu para a diminuição do custo do processo de Engenharia Web de aplicações Web 2.0 acessíveis.

Ao longo do trabalho, foram utilizadas abordagens com base em AT e análise da estrutura DOM de uma página web renderizada no navegador, para validar requisitos de acessibilidade de aplicações Web 2.0. Essas abordagens utilizavam como estratégia a análise da interface do software, considerando o comportamento do usuário e os casos de uso de indivíduos com deficiência visual. Essa estratégia, com base no comportamento do usuário, se mostrou essencial para validar os requisitos de acessibilidade estabelecidos pela especificação ARIA, que estão associados com a dinamicidade apresentada pela interface de aplicações Web 2.0.

Durante o desenvolvimento de software, podem ser utilizados diferentes tipos de testes para verificar a conformidade dos atributos de qualidade da aplicação (Leung e Wong, 1997). No entanto, uma vez que o usuário final é responsável pela determinação sobre a qualidade de um sistema, torna-se necessária uma estratégia de teste que considere a perspectiva do usuário. Nesse contexto, os AT são realizados considerando a perspectiva do usuário final (Araújo et al., 2007; Melnik e Maurer, 2005) e constituem o último estágio de teste de uma aplicação (Leung e Wong, 1997).

Os AT foram utilizados para determinar as estratégias de uso das aplicaçães web por usuários com deficiência e avaliar se a interface do software permite a realização dessa estratégia de uso. Dessa forma, a implementação concreta e posterior execução de casos de AT que considerem o comportamento de usuários que utilizem Tecnologias Assistivas mostrou-se capaz de identificar problemas de acessibilidade previstos na especificação ARIA na interface sendo desenvolvida.

Os métodos de avaliação automática utilizados atualmente determinam a conformidade dos websites considerando apenas as tecnologias sendo utilizadas no seu desenvolvimento (Velasco et al., 2008). A utilização de AT para avaliar acessibilidade, por outro lado, permite que sejam realizadas análises do conteúdo dinâmico do DOM, considerando inclusive as possíveis alterações e mudanças que possam ocorrer em sua estrutura durante a interação com o usuário. Uma vez que os AT são previamente estabelecidos e mapeiam uma estratégia específica de uso das aplicações web, torna-se possível, também, avaliar a acessibilidade com uma perspectiva centrada no usuário.

A avaliação utilizando a estrutura DOM renderizada no navegador web também destaca a necessidade de se considerar todos os componentes tecnológicos que compõem uma aplicação web. Em contraste aos métodos de avaliação que analisam apenas o código HTML, mostrou-se necessário elaborar um método de avaliação que realize a verificação e validação de todas as tecnologias utilizadas em RIA de uma perspectiva mais próxima a observada pelo usuário.

Ambas as ferramentas desenvolvidas com AT (A-Pyccuracy e aria-check) também introduzem aspectos de avaliação que exigem a execução de múltiplas etapas de simulação de interação e verificação da estrutura DOM (interface web com o usuário). Anteriormente, os métodos de avaliação automática realizavam a validação dos requisitos de acessibilidade de acordo apenas com análises 
no estado inicial de uma aplicação web. No entanto, para avaliar a acessibilidade em RIA foi necessária a realização de múltiplos passos (simulações de interação e verificações intermediárias) em uma determinada ordem para validar um único requisito.

Nos trabalhos descritos nos Capítulos 5 e 6, foram realizados processos de validação das propostas em um conjunto de ferramentas (bibliotecas JavaScript testadas pela ferramenta aria-check no Capítulo 5) e websites (conjunto de websites mais populares segundo Alexa), que constituem tecnolologias web utilizadas em ambientes reais de desenvolvimento. Nesse contexto, os resultados apresentados em ambos capítulos também representam o estado atual de implementação da especificação ARIA na Web. Ambos os resultados demonstram que, apesar dos esforços da W3C em divulgar especificações de acessibilidade na web, muitas RIAs ainda são desenvolvidas sem considerar os requisitos de acessibilidade.

Na Tabela 7.1, são apresentadas todas as ferramentas de avaliação automática de acessibilidade em RIA desenvolvidas nesta tese, e apresenta uma comparação com os trabalhos relacionados (Capítulo 3). Nessa tabela, os trabalhos são classificados de acordo com o Método de avaliação utilizado pelas estratégias de avaliação automática, Especificação avaliada, Componentes avaliados e Requisitos para que a avaliação seja realizada.

De acordo com a classificação por Método de avaliação utilizado, o trabalho de Tateishi et al. 2007 realiza a avaliação estática do código JavaScript de RIA, enquanto todos os outros trabalhos realizam a avaliação na estrutura DOM renderizada no navegador web.

Considerando o critério relacionado a qual à Especificação de Acessibilidade utilizada como base na avaliação, os trabalhos de Tateishi et al. 2007, Doush et al. 2013, a ferramenta ariacheck e a métrica Fona utilizam a especificação ARIA, enquanto a abordagem de Fernandes et al. 2011/2012 utiliza a especificação WCAG 2.0; a ferramenta A-Pyccuracy utiliza ambas especificações WCAG 2.0 e ARIA.

Levando em conta o critério de quais Componentes são o alvo da avaliação, os trabalhos de Fernandes et al. 2011/2012, Doush et al. 2013 e a ferramenta A-Pyccuracy avaliam todos os elementos de uma RIA, enquanto Tateishi et al. 2007 analisa apenas o código JavaScript (verificando os elementos impactados por chamadas a métodos da API DOM), a ferramenta aria-check analisa apenas os elementos relacionados a uma widget específica mapeada pela ferramenta (widget tabpanel) e a métrica Fona analisa apenas os elementos interativos de RIA.

Por fim, de acordo com o critério de Requisito de execução das ferramentas, as ferramentas de Tateishi et al. 2007, Fernandes 2011/2012, aria-check e Fona não possuem nenhum requisito, enquanto a ferramenta A-Pyccuracy requer que sejam elaborados casos de AT específicos para cada aplicação e o trabalho de Doush et al. não implementa um suporte automático, mas apresenta apenas um framework que pode ser utilizado na avaliação de ARIA.

Na próxima seção, são enumeradas as principais contribuições desta tese. 


\begin{tabular}{|c|c|c|c|c|}
\hline Trabalho & $\begin{array}{l}\text { Método de } \\
\text { avaliação }\end{array}$ & $\begin{array}{l}\text { Especificação } \\
\text { avaliada }\end{array}$ & $\begin{array}{l}\text { Componentes } \\
\text { avaliados }\end{array}$ & $\begin{array}{l}\text { Requisitos de exe- } \\
\text { cução }\end{array}$ \\
\hline $\begin{array}{l}\text { Tateishi et al. } \\
2007\end{array}$ & $\begin{array}{l}\text { Análise } \\
\text { de código } \\
\text { estático } \\
\text { JavaScript }\end{array}$ & ARIA & $\begin{array}{l}\text { Código JavaS- } \\
\text { cript }\end{array}$ & Nenhum \\
\hline $\begin{array}{l}\text { Fernandes et al. } \\
2011 \text { e } 2012\end{array}$ & $\begin{array}{l}\text { Análise da } \\
\text { Estrutura } \\
\text { DOM }\end{array}$ & WCAG 2.0 & Todos elementos & Nenhum \\
\hline Doush et al. 2013 & $\begin{array}{l}\text { Análise da } \\
\text { Estrutura } \\
\text { DOM }\end{array}$ & ARIA & Todos elementos & $\begin{array}{l}\text { Não se aplica (ne- } \\
\text { nhuma ferramenta } \\
\text { foi implementada) }\end{array}$ \\
\hline $\begin{array}{l}\text { Capítulo } 4 \text { - } \\
\text { A-Pyccuracy }\end{array}$ & $\begin{array}{l}\text { Análise da } \\
\text { Estrutura } \\
\text { DOM }\end{array}$ & $\begin{array}{l}\text { WCAG } 2.0 \mathrm{e} \\
\text { ARIA }\end{array}$ & Todos elementos & $\begin{array}{l}\text { Elaboração prévia } \\
\text { dos casos de AT }\end{array}$ \\
\hline $\begin{array}{l}\text { Capítulo } 5 \text { - } \\
\text { aria-check }\end{array}$ & $\begin{array}{l}\text { Análise da } \\
\text { Estrutura } \\
\text { DOM }\end{array}$ & ARIA & $\begin{array}{l}\text { Elementos que } \\
\text { compõem uma } \\
\text { tabpanel widget }\end{array}$ & Nenhum \\
\hline $\begin{array}{l}\text { Capítulo } 6 \text { - } \\
\text { Fona }\end{array}$ & $\begin{array}{l}\text { Análise da } \\
\text { Estrutura } \\
\text { DOM }\end{array}$ & ARIA & $\begin{array}{l}\text { Elementos } \\
\text { interativos de } \\
\text { RIA }\end{array}$ & Nenhum \\
\hline
\end{tabular}

Tabela 7.1: Quadro comparativo das diferentes estratégias de avaliação automática de acessibilidade em RIA.

\subsection{Principais Contribuições}

Este trabalho de doutorado apresentou as seguintes contribuições para o tópico de acessibilidade em RIA:

- Elaboração de uma estratégia de avaliação automática de acessibilidade para RIA: componentes de interface dinâmicos que constituem RIA são difíceis de ser avaliados, dada a mudança e atualização da estrutura DOM das páginas web, durante a interação com o usuário. A elaboração de uma estratégia de avaliação automática considerando esses atributos de uma aplicação web contribui para o processo de Engenharia Web de RIA, diminuindo o esforço de desenvolvimento dessas aplicações, em conformidade com os requisitos de acessibilidade.

- Desenvolvimento de algoritmos de avaliação automática de acessibilidade que consideram o comportamento do usuário: os métodos de avaliação automática de acessibilidade disponíveis, atualmente, realizam análise na estrutura de disponibilização do conteúdo, considerando apenas o aspecto tecnológico para apresentar os resultados. Nesta tese, foram descritos algoritmos que têm como foco o comportamento do usuário e suas estratégias de 
uso das aplicações web para avaliar os requisitos de acessibilidade. Como resultado, foram levantados aspectos positivos e negativos da estratégia elaborada neste trabalho, em comparação aos outros métodos previamente estabelecidos na literatura. Todos os códigos das ferramentas desenvolvidas nesta tese foram disponibilizados com licensa de software livre e encontram-se disponíveis em repositórios online.

- Elaboração de uma estratégia de avaliação automática considerando o modelo de interação de widgets: componentes de interface de aplicações desktop beneficiam-se do fato de que os seus modelos de interação são conhecidos pelas Tecnologias Assistivas. Assim, foi elaborada uma abordagem de avaliação dos requisitos da especificação ARIA, realizando a avaliação de acessibilidade separadamente para cada widget. Essa abordagem utiliza-se do modelo de comportamento pré-estabelecido que cada widget deve implementar de acordo com a especificação ARIA. Esse resultado está descrito no Capítulo 5.

\section{- Desenvolvimento de ferramentas de avaliação dos requisitos da especificação ARIA} com base em AT: até o momento da elaboração deste trabalho, haviam poucas ferramentas que tinham como proposta a avaliação automática de requisitos de acessibilidade da especificação ARIA. Neste trabalho, são apresentadas estratégias de avaliação automática desses requisitos, utilizando AT. Esses resultados estão descritos nos Capítulos 4 e 5.

- Definição de uma métrica quantitativa que identifica cenários de uso não acessíveis por interações de teclado: a WCAG apresenta entre suas diretrizes e critérios de sucesso o requisito que determina que toda funcionalidade de uma aplicação web deve ser alcançável por meio de interações geradas pelo teclado apenas. Nesse contexto, foi proposta uma métrica quantitativa que identifica a quantidade de elementos interativos de uma página web que não implementam um mecanismo de interação por teclado, apenas por mouse. Esse resultado está descrito no Capítulo 6.

\section{- Levantamento de implementações do requisito de acessibilidade de Navegação por}

Foco: foi realizado um levantamento das implementações de widgets seguindo um requisito da especificação ARIA, considerando métricas quantitativas como número de elementos que possuem o atributo role que é abordado na especificação ARIA. O levantamento foi realizado em 349 aplicações web reais e os resultados mostram que muitas páginas web ainda não implementam os requisitos da especificação ARIA. Esse resultado está descrito no Capítulo 6.

\section{- Levantamento de implementações de resquisitos da especificação ARIA em bibliote-} cas JavaScript: foram avaliadas nove widgets de diferentes bibliotecas de componentes de interface JavaScript (Capítulo 5). Essa avaliação apresentou múltiplos problemas de implementação em cada componente de interface e detalhou possíveis soluções para os problemas encontrados. Esses resultados também denotaram que a especificação ARIA, apesar de ter 
atingido o estado de recomendação da W3C e da elevada popularidade de RIA, ainda não é considerada em muitos projetos de aplicações web.

\subsection{Artigos Resultantes da Tese}

Durante o desenvolvimento da Tese, os resultados foram reportados nos seguintes trabalhos:

1. Artigo publicado no SIGDOC 2010 - International Conference on Design of Communication: WATANABE, W. M.; NETO, D. F.; BITTAR, T. J.; FORTES, R. P. M. WCAG conformance approach based on Model-Driven Development and WebML. In: Proceedings of the 28th ACM International Conference on Design of Communication, SIGDOC '10, New York, NY, USA: ACM, 2010c, p. 167-174 (SIGDOC'10).

2. Artigo publicado no SIGDOC 2010 - International Conference on Design of Communication: LARA, S. M.; WATANABE, W. M.; SANTOS, E. P. B.; FORTES, R. P. M. Improving WCAG for elderly web accessibility. In: Proceedings of the 28th ACM International Conference on Design of Communication, SIGDOC '10, New York, NY, USA: ACM, 2010c, p. 175-182 (SIGDOC'10).

3. Artigo Completo no W4A 2012 - International Cross-Disciplinary Conference on Web Accessibility: WATANABE, W. M.; FORTES, R. P. M.; DIAS, A. L. Using acceptance tests to validate accessibility requirements in RIA. In: Proceedings of the International CrossDisciplinary Conference on Web Accessibility, W4A '12, New York, NY, USA: ACM, 2012, p. 15:1-15:10 (W4A'12).

4. Artigo submetido para a revista UAIS - Universal Access in the Information Society: WATANABE, W. M.; FORTES, R. P. M.; DIAS, A. L. Using Acceptance Tests for Evaluating ARIA Requirements. Universal Access in the Information Society.

5. Artigo submetido para a revista ACM Transactions on the Web: WATANABE, W. M.; DIAS, A. L.; FORTES R. P. M. Investigating Focus Navigation on Rich Internet Applications. ACM Transactions on the Web.

6. Artigo aceito para publicação no SAC 2014 - Symposium on Applied Computing]: WATANABE, W. M.; GERALDO, R. J.; FORTES R. P. M. Keyboard Navigation Mechanisms in Tab Widgets: an investigation on ARIA's Conformance.

Durante este doutorado, também foram reportados resultados relacionados ao tema desta tese:

1. WATANABE, W. M.; FORTES, R. P. M.; PIMENTEL, M. G. C. The Link-Offset-Scale Mechanism for Improving the Usability of Touch Screen Displays on the Web. Lecture Notes in Computer Science, v. 6948, p. 356-372, 2011. 
2. SANTOS E.; LARA, S. M. A.; WATANABE, W. M. ; CASTRO, M.; FORTES, R. P. M. Usability evaluation of horizontal navigation bar with drop-down menus by middle aged adults. In: 29th ACM international conference on Design of communication. SIGDOC '11. New York, NY, US: ACM - Association for Computing Machinery, 2011. v. 1. p. 145150 (SIGDOC '11).

3. WATANABE, W. M.; CANDIDO, A.; AMANCIO, M. A.; DE OLIVEIRA, M.; PARDO, T. A. S.; FORTES, R. P. M. ; ALUISIO, S. M. Adapting Web content for low-literacy readers by using lexical elaboration and named entities labeling. New Review of Hypermedia and Multimedia, v. 15, p. 303-327, 2010.

4. NAFTALI, M.; WATANABE, W. M.; SLOAN, D. W4A 2010: a web accessibility conference report from the Google W4A student award winners. ACM SIGWEB Newsletter, v. 1 , p. $1,2010$.

\subsection{Limitações dos estudos realizados}

Foram identificadas as seguintes limitações considerando as tecnologias utilizadas:

- Os AT requerem que sejam elaborados casos de teste que correspondam ao comportamento do usuário durante uma interação com a interface de uma aplicação web. No entanto, ainda é difícil mapear cada possibilidade de interação do usuário com a interface. Logo, as abordagens relacionadas ao uso de AT garantem que cenários específicos de uso sejam verificados, mas não garante que todos os cenários acessíveis sejam contemplados pelas aplicações web.

- A simulação de interação do usuário, que é requisito das ferramentas que utilizam AT, exige que o comportamento exato do usuário seja mapeado em um caso de teste. Dessa forma, torna-se difícil reaproveitar os casos de teste entre diferentes aplicações. A restrição do domínio de aplicação dessa abordagem para widgets, em contraste com a aplicação como um todo, utilizada no desenvolvimento da ferramenta aria-check, permite um determinado grau de reuso dessa abordagem. Mas essa estratégia não poderia ser aplicada para todos os tipos de widgets. Como por exemplo, determinadas widgets são apresentadas apenas quando um componente é ativado, mas o AT precisaria estar previamente instrumentado para identicar qual é o componente que precisa ser ativado para poder avaliar essa widget. No entanto, não existe um padrão de identificação desse tipo de comportamento.

- As tecnologias envolvidas na execução dos AT também apresentaram limitações, considerando a simulação de interação do usuário com a aplicação web. Durante o desenvolvimento da ferramenta aria-check, foram utilizados eventos sintéticos de JavaScript para simular a interação do usuário, mas determinadas bibliotecas e frameworks JavaScript previnem seus 
componentes de interface de responder a esses eventos. Dessa forma, a ferramenta ariacheck foi incapaz de avaliar corretamente algumas bibliotecas e frameworks.

- A utilização de AT apresenta como relatório de erro o cenário de uso que falhou durante a verificação de um determinado caso de teste. Nesse contexto, ferramentas de avaliação com base nesse tipo de teste não fornecem mensagens informativas sobre a exata linha do código fonte que gerou o problema. Essa característica pode dificultar a interpretação da falha de verificação do caso de teste pelo desenvolvedor e posterior ratreamento da causa do problema.

- Métricas quantitativas de acessibilidade freqüentemente são determinadas com base em verificações simples e não são capazes de validar se todos os critérios de acessibilidade foram implementados em uma aplicação web. A métrica elaborada neste trabalho (Fona) apresenta essa mesma limitação e se concentra na verificação de um único critério de acessibilidade em RIA. Essa métrica também é apenas capaz de identificar um tipo de falha de implementação desse critério de acessibilidade, mas é incapaz de identificar se a aplicação implementou corretamente esse critério.

\subsection{Trabalhos Futuros}

Como trabalhos futuros identificados a partir do trabalho desenvolvido, podem ser destacadas diversas alternativas.

Os estudos conduzidos nesta tese foram direcionados a usuários que apresentam deficiências visuais. É importante realizar também os mesmos tipos de avaliação considerando um modelo de interação de usuários, com outras deficiências, para cenários de uso que contemplem o comportamento de uma variedade maior de usuários.

A ferramenta aria-check apresentada nesta tese implementa casos de teste para a widget tabpanel. Um trabalho futuro que contribuiria para a consolidação da estratégia proposta seria estender a ferramenta aria-check para avaliar todas as demais widgets da especificação ARIA.

Foi descrita uma investigação realizada em 349 páginas web, identificando problemas de acessibilidade relacionadas a mecanismos de Navegação por Foco. Os resultados desse estudo demonstraram que muitos dos requisitos mais básicos da especificação ARIA não são implementados, mesmo em websites de grande popularidade. Essa metodologia de investigação pode ser estendida considerando outros requisitos da especificação, no intuito de identificar os problemas de acessibilidade em RIA e suas possíveis causas na ambiente de desenvolvimento.

A especificação ARIA é implementada por diferentes bibliotecas e frameworks de componentes de interface JavaScript. No entanto, conforme observado na investigação de mecanismos de Navegação por Foco em páginas web populares, muitas dessas páginas não utilizam nenhuma 
biblioteca JavaScript de widgets, apesar dessas bibliotecas implementarem corretamente os requisitos da especificação ARIA. A razão para essa baixa popularidade das bibliotecas entre as aplicações web mais populares segundo Alexa deve ser investigada para identificar possíveis soluções que melhorem a implementação da especificação ARIA na Web.

A partir dos estudos conduzidos nesta tese, todas as três ferramentas têm como requisito identificar um padrão de comportamento do usuário que possa ser automatizável em uma verificação de interface. A ferramenta A-Pyccuracy permite que esse comportamento seja manualmente modelado antes de executar a sua avaliação. A ferramenta aria-check e a métrica Fona restringem o processo de avaliação para partes de uma aplicação web que possuam um modelo de interação padrão (widgets e seus elementos interativos). Um trabalho futuro relacionado a essas características seria a generalização desses modelos de interação para desenvolver um agente inteligente capaz de simular todas as estratégias de interação para uma avaliação automática de acessibilidade em RIA.

A estratégia de avaliação de acessibilidade da ferramenta A-Pyccuracy utiliza uma DSL Domain-Specific Language, uma linguagem/modelo específico de domínio, para elaborar casos de ATs. Um outro trabalho futuro seria a possibilidade de geração automática desses casos de AT acessíveis a partir de casos de AT convencionais de aplicações web. Na linha de pesquisa de MDD - Model-Driven Development, modelos são transformados com o objetivo de melhorar a reusabilidade, portabilidade e produtividade no processo de desenvolvimento de software. Assim, a transformação de modelos também poderia ser utilizada para transformar casos de AT convencionais em casos de AT acessíveis, minimizando os custos associados a elaboração de casos de AT acessíveis da estratégia empregada pelo uso da ferramenta A-Pyccuracy.

\subsection{Considerações Finais}

Os trabalhos desenvolvidos nesta tese caracterizaram estudos exploratórios com o objetivo de elaborar abordagens de avaliação automática de acessibilidade em RIA. Apesar da elevada popularidade no uso de tecnologias Ajax na implementação de RIA, ainda existem poucas abordagens de auxílio ao desenvolvimento da especificação ARIA. Assim, esta tese apresentou diferentes abordagens de avaliação automática da especificação ARIA, com enfoque na avaliação do conteúdo dinâmico de RIA e sua respectiva apresentação a usuários que utilizam leitores de tela.

Há um elevado número de diretrizes e recomendações de acessibilidade para aplicações web e, muitas vezes, os desenvolvedores não estão cientes de todos os detalhes técnicos necessários para implementar essas recomendações. Neste contexto, este trabalho utilizou a metodologia de pesquisa-ação como uma etapa inicial na elaboração de diferentes estratégias que contribuem com o processo de Engenharia Web de aplicações “Web 2.0” acessíveis.

Ao longo da condução dos trabalhos descritos nesta tese, foram realizados o desenvolvimento de ferramentas e sua respectiva validação. Cada processo de validação também apresentou dados significativos que demonstram que muitos projetos web ainda não consideram as especificações de 
acessibilidade, destacando a importância de trabalhos que auxiliem o processo de desenvolvimento como o conduzido nesta tese. A validação das estratégias desenvolvidas com aplicações reais e de ambientes empresariais contribuiu significantemente com os resultados apresentando a ampla heterogeneidade de formas de implementação de aplicações web que precisam ser consideradas pelas ferramentas de avaliação. 
Acerbis, R.; Bongio, A.; Brambilla, M.; Butti, S.; Ceri, S.; Fraternali, P. Web applications design and development with WebML and WebRatio 5.0. In: Objects, Components, Models and Patterns, Springer Berlin Heidelberg, 2008, p. 392-411 (Lecture Notes in Business Information Processing, v.11).

AdAms, J. Test-driven data structures: revitalizing CS2. In: Proceedings of the 40th ACM technical symposium on Computer science education, New York, NY, USA: ACM, 2009, p. 143-147 (SIGCSE'09, v.1).

Altarawneh, H.; ShieKh, A. E. A theoretical agile process framework for web applications development in small software firms. In: Proceedings of the 2008 Sixth International Conference on Software Engineering Research, Management and Applications, Washington, DC, USA: IEEE Computer Society, 2008, p. 125-132 (SERA ’08, v.1).

Araújo, B. C.; Rocha, A. C.; Xavier, A.; Muniz, A. I.; Garcia, F. P. Web-based tool for automatic acceptance test execution and scripting for programmers and customers. In: Proceedings of the 2007 Euro American conference on Telematics and information systems, New York, NY, USA: ACM, 2007, p. 56:1-56:4 (EATIS ’07, v.1).

BECK, K. Test-driven development : by example. Boston: Addison-Wesley, 2003.

BECK, K.; ANDRES, C. Extreme programming explained: Embrace change (2nd edition). Addison-Wesley Professional, 2004.

Beck, K.; Beedle, M.; Bennekum, A.; Cockburn, A.; Cunningham, W.; Fowler, M.; Grenning, J.; Highsmith, J.; Hunt, A.; JefFries, R.; Kern, J.; MARICK, B.; Martin, R. C.; Mellor, S.; Schwaber, K.; Sutherland, J.; Thomas, D. Manifesto for agile software development. 2001.

Disponível em: http://www.agilemanifesto.org/ (Acessado em 16 de janeiro de 2014) 
BERNERS-LEE, T. Information management: A proposal. W3C archive, 1990.

Disponível em: http://www.nic.funet.fi/index/FUNET/history/ internet/w3c/proposal.html (Acessado em 16 de janeiro de 2014)

BeydedA, S.; GRUhn, V. Model-driven software development. Secaucus, NJ, USA: SpringerVerlag New York, Inc., 2005.

Bittar, T. J.; Fortes, R. P.; Lobato, L. L.; Watanabe, W. M. Web communication and interaction modeling using model-driven development. In: Proceedings of the 27th ACM international conference on Design of communication, New York, NY, USA: ACM, 2009, p. 193-198 (SIGDOC '09, v.1).

Boenm, B. A view of 20th and 21st century software engineering. In: Proceedings of the 28th international conference on Software engineering, New York, NY, USA: ACM, 2006, p. 12-29 (ICSE' O6, v.1).

BoldyrefF, C. Determination and evaluation of web accessibility. In: WETICE '02: Proceedings of the 11th IEEE International Workshops on Enabling Technologies, Washington, DC, USA: IEEE Computer Society, 2002, p. 35-42.

Borodin, Y.; Bigham, J. P.; Dausch, G.; Ramakrishnan, I. V. More than meets the eye: a survey of screen-reader browsing strategies. In: Proceedings of the 2010 International Cross Disciplinary Conference on Web Accessibility (W4A), New York, NY, USA: ACM, 2010, p. 13:1-13:10 (W4A' '10, v.1).

BRAJNIK, G. Web accessibility testing: When the method is the culprit. In: Computers Helping People with Special Needs, Springer Berlin / Heidelberg, 2006, p. 156-163 (Lecture Notes in Computer Science, v.4061).

BRAJNIK, G. Beyond conformance: The role of accessibility evaluation methods. In: Web Information Systems Engineering - WISE 2008 Workshops, Springer Berlin / Heidelberg, 2008a, p. 63-80 (Lecture Notes in Computer Science, v.5176).

BrajniK, G. A comparative test of web accessibility evaluation methods. In: Assets '08: Proceedings of the 10th international ACM SIGACCESS conference on Computers and accessibility, New York, NY, USA: ACM, 2008b, p. 113-120.

BRAJNIK, G.; YesILADA, Y.; HARPER, S. Testability and validity of WCAG 2.0: the expertise effect. In: Proceedings of the 12th international ACM SIGACCESS conference on Computers and accessibility, New York, NY, USA: ACM, 2010, p. 43-50 (ASSETS '10, v.1).

BRATT, S. Breaking barriers to a read/write web that empowers all. In: Proceedings of the 2010 International Cross Disciplinary Conference on Web Accessibility (W4A), New York, NY, USA: ACM, 2010, p. 1:1-1:1 (W4A '10, v.1). 
Bühler, C.; Heck, H.; Perlick, O.; Nietzio, A.; Ulltveit-Moe, N. Interpreting results from large scale automatic evaluation of web accessibility. In: Proceedings of the 10th international conference on Computers Helping People with Special Needs, Berlin, Heidelberg: Springer-Verlag, 2006, p. 184-191 (ICCHP'O6, v.1).

Canfora, G.; Cimitile, A.; Garcia, F.; Piattini, M.; Visaggio, C. A. Evaluating advantages of test driven development: a controlled experiment with professionals. In: Proceedings of the 2006 ACM/IEEE international symposium on Empirical software engineering, New York, NY, USA: ACM, 2006, p. 364-371 (ISESE '06, v.1).

Cannizzo, F.; Clutton, R.; Ramesh, R. Pushing the boundaries of testing and continuous integration. In: Proceedings of the Agile 2008, Washington, DC, USA: IEEE Computer Society, 2008, p. 501-505.

Centeno, V. L.; Kloos, C. D.; Gaedke, M.; Nussbaumer, M. WCAG formalization with W3C standards. In: WWW '05: Special interest tracks and posters of the 14th international conference on World Wide Web, New York, NY, USA: ACM, 2005, p. 1146-1147.

Ceri, S.; Fraternali, P.; Bongio, A. Web modeling language (WebML): a modeling language for designing web sites. Comput. Netw., v. 33, n. 1-6, p. 137-157, 2000.

Clarke, L. A.; Rosenblum, D. S. A historical perspective on runtime assertion checking in software development. SIGSOFT Softw. Eng. Notes, v. 31, n. 3, p. 25-37, 2006.

Cluster, W. W. A. B. Unified web evaluation methodology (UWEM 1.0). 2006.

Disponível em: http: //www.wabcluster.org/uwem/ (Acessado em 16 de janeiro de 2014)

Cook, A. M.; Hussey, S. M. Assistive technologies: Principles and practice, v. 2a ed. Mosby - Year Book, 523 p., 2001.

COOPER, M. Accessibility of emerging rich web technologies: web 2.0 and the semantic web. In: Proceedings of the 2007 international cross-disciplinary conference on Web accessibility (W4A), New York, NY, USA: ACM, 2007, p. 93-98 (W4A '07, v.1).

Costabile, M. F.; Matera, M. Guidelines for hypermedia usability inspection. IEEE MultiMedia, v. 8, n. 1, p. 66-69, 2001.

Doush, I. A.; Alkhateeb, F.; Maghayreh, E. A.; Al-Betar, M. A. The design of RiA accessibility evaluation tool. Advances in Engineering Software, v. 57, n. 0, p. 1 - 7, 2013.

Erdogmus, H.; Morisio, M.; Torchiano, M. On the effectiveness of the test-first approach to programming. IEEE Trans. Softw. Eng., v. 31, n. 3, p. 226-237, 2005. 
escalona, M. J.; Gutiérrez, J.; Morero, F.; Parra, C.; Nieto, J.; Pérez, F.; MarTÍN, F.; Llergo, A. A practical environment to apply model-driven web engineering. In: Information Systems Development, Springer US, 2009, p. 249-258.

Fernandes, N.; Batista, A. S.; Costa, D.; Duarte, C.; Carriço, L. Three web accessibility evaluation perspectives for RIA. In: Proceedings of the 10th International CrossDisciplinary Conference on Web Accessibility, New York, NY, USA: ACM, 2013, p. 12:1-12:9 (W4A'13, v.1).

Fernandes, N.; Costa, D.; Neves, S.; Duarte, C.; CARriço, L. Evaluating the accessibility of rich internet applications. In: Proceedings of the International Cross-Disciplinary Conference on Web Accessibility, New York, NY, USA: ACM, 2012, p. 13:1-13:4 (W4A '12, v.1).

Fernandes, N.; Lopes, R.; CARRiçO, L. On web accessibility evaluation environments. In: Proceedings of the International Cross-Disciplinary Conference on Web Accessibility, New York, NY, USA: ACM, 2011, p. 4:1-4:10 (W4A '11, v.1).

Fons, J.; Valderas, P.; Ruiz, M.; Rojas, G.; Pastor, O. OOWS: A method to develop web applications from web-oriented conceptual models. In: In: International Workshop on Web Oriented Software Technology (IWWOST). (2003) 65-70, 2003, p. 65-70.

Fortes, R. P. M.; Pansanato, L. T. E.; Lara, S. M. A.; Pimenta, A. P. Minicursos do webmedia 2005, v. 1. Belo Horizonte-MG: FuMARC Editora, 197-226 p., 2005.

Fowler, M.; FoEMmel, M. Continuous integration, http://www.martinfowler.com/articles/continuousIntegration.html. 2005.

Fraternali, P.; Comai, S.; Bozzon, A.; Carughi, G. T. Engineering rich internet applications with a model-driven approach. ACM Trans. Web, v. 4, n. 2, p. 1-47, 2010.

Fraternali, P.; Paolini, P. Model-driven development of web applications: the AutoWeb systems. ACM Trans. Inf. Syst., v. 18, n. 4, p. 323-382, 2000.

Freeman, S.; Pryce, N. Growing object-oriented software, guided by tests. 1st ed. AddisonWesley Professional, 2009.

Freire, A. P.; Bittar, T. J.; Fortes, R. P. M. An approach based on metrics for monitoring web accessibility in brazilian municipalities web sites. In: SAC '08: Proceedings of the 2008 ACM symposium on Applied computing, New York, NY, USA: ACM, 2008a, p. 2421-2425.

Freire, A. P.; Fortes, R. P. M.; Turine, M. A. S.; Paiva, D. M. B. An evaluation of web accessibility metrics based on their attributes. In: SIGDOC'08: Proceedings of the 26th annual ACM international conference on Design of communication, New York, NY, USA: ACM, 2008b, p. 73-80. 
Freire, A. P.; Goularte, R.; Fortes, R. P. M. Techniques for developing more accessible web applications: a survey towards a process classification. In: SIGDOC '07: Proceedings of the 25th annual ACM international conference on Design of communication, New York, NY, USA: ACM, 2007, p. 162-169.

Freire, A. P.; Power, C.; Petrie, H.; Tanaka, E. H.; Rocha, H. V.; Fortes, R. P. Web accessibility metrics: Effects of different computational approaches. In: Proceedings of the 5th International Conference on Universal Access in Human-Computer Interaction. Part III: Applications and Services, Berlin, Heidelberg: Springer-Verlag, 2009, p. 664-673 (UAHCI '09, v.1).

Freire, A. P.; Russo, C. M.; Fortes, R. P. M. A survey on the accessibility awareness of people involved in web development projects in brazil. In: W4A '08: Proceedings of the 2008 international cross-disciplinary conference on Web accessibility (W4A), New York, NY, USA: ACM, 2008c, p. 87-96.

Freire, A. P.; Russo, C. M.; Mattos Fortes, R. P. The perception of accessibility in web development by academy, industry and government: a survey of the brazilian scenario. New Review of Hypermedia and Multimedia, v. 14, n. 2, p. 149-175, $2008 \mathrm{~d}$.

Garrett, J. J. Ajax: A new approach to web applications. 2005.

Disponível em: http://www.adaptivepath.com/ideas/ ajax-new-approach-web-applications / (Acessado em 16 de janeiro de 2014)

Ge, X.; Paige, R. F.; Polack, F. A.; Chivers, H.; Brooke, P. J. Agile development of secure web applications. In: Proceedings of the 6th international conference on Web engineering, New York, NY, USA: ACM, 2006, p. 305-312 (ICWE '06, v.1).

Gehtland, J.; Almaer, D.; Galbraith, B. Pragmatic ajax: A web 2.0 primer. Pragmatic Bookshelf, 2006.

GIBSON, B. Enabling an accessible web 2.0. In: Proceedings of the 2007 international crossdisciplinary conference on Web accessibility (W4A), New York, NY, USA: ACM, 2007, p. 1-6 (W4A '07, v.1).

GIBSON, B.; SCHWERDTFEGER, R. DHTML accessibility: solving the javascript accessibility problem. In: Proceedings of the 7th international ACM SIGACCESS conference on Computers and accessibility, New York, NY, USA: ACM, 2005, p. 202-203 (Assets '05, v.1).

Ginige, A.; Murugesan, S. Web engineering an introduction. IEEE MultiMedia, v. 8, n. 1, p. $14-18,2001$.

Gitzel, R.; Korthaus, A.; Schader, M. Using established web engineering knowledge in model-driven approaches. Sci. Comput. Program., v. 66, n. 2, p. 105-124, 2007. 
Goette, T.; Collier, C.; White, J. D. An exploratory study of the accessibility of state government web sites. Univers. Access Inf. Soc., v. 5, n. 1, p. 41-50, 2006.

GRÄTNER, M.; GRÄTNER, M. ATDD by example: A practical guide to acceptance test-driven development. 1st ed. Addison-Wesley Professional, 2012.

Hammond, S.; Umphress, D. Test driven development: the state of the practice. In: Proceedings of the 50th Annual Southeast Regional Conference, New York, NY, USA: ACM, 2012, p. 158-163 (ACM-SE' 12, v.1).

Hanson, V. L.; Richards, J. T. Progress on website accessibility? ACM Trans. Web, v. 7, n. 1, p. 2:1-2:30, 2013.

Henry, S. L.; Grossnickle, M. Just ask: Accessibility. In: in the User-Centered Design Process. Georgia Tech Research Corporation, 2004.

Hsia, P.; Gao, J.; Samuel, J.; Kung, D.; Toyoshima, Y.; Chen, C. Behavior-based acceptance testing of software systems: a formal scenario approach. In: Computer Software and Applications Conference, 1994. COMPSAC 94. Proceedings., Eighteenth Annual International, 1994, p. $293-298$.

IBGE Mais um registro da maior operação censitária do país. 2000.

Disponível em: http: / /www.ibge.gov.br/censo/revista9.pdf (Acessado em 16 de junho de 2013)

IBGE Síntese dos indicadores sociais - uma análise das condições de vida da população brasileira. 2008.

Disponível em: http://biblioteca.ibge.gov.br/visualizacao/ monografias/GEBIS20-\%20RJ/sintese_indic/indic_sociais2008.pdf

(Acessado em 16 de junho de 2013)

IBGE, I. B. D. G. E. E. Censo demográfico 2010 - caracterísiticas gerais da população, religião e pessoas com deficiência. 2010.

Disponível em: ftp://ftp.ibge.gov.br/Censos/Censo_Demografico_2010/ Caracteristicas_Gerais_Religiao_Deficiencia/caracteristicas_ religiao_deficiencia.pdf (Acessado em 16 de junho de 2013)

IEEE, I. O. E. A. E. E. Ieee standard for software verification and validation plans. IEEE Std 1012-1986, p. I-, 1986.

Kelly, B.; Sloan, D.; Brown, S.; Seale, J.; Petrie, H.; Lauke, P.; Ball, S. Accessibility 2.0: people, policies and processes. In: W4A '07: Proceedings of the 2007 international cross-disciplinary conference on Web accessibility (W4A), New York, NY, USA: ACM, 2007, p. $138-147$. 
Kelly, B.; SloAn, D.; PhipPs, L.; Petrie, H.; Hamilton, F. Forcing standardization or accommodating diversity?: a framework for applying the wcag in the real world. In: W4A '05: Proceedings of the 2005 International Cross-Disciplinary Workshop on Web Accessibility (W4A), New York, NY, USA: ACM, 2005, p. 46-54.

KIM, E. H.; NA, J. C.; RYOo, S. M. Test automation framework for implementing continuous integration. In: Proceedings of the 2009 Sixth International Conference on Information Technology: New Generations, Washington, DC, USA: IEEE Computer Society, 2009, p. 784-789.

KIM, S.; PARK, S.; YUN, J.; LEE, Y. Automated continuous integration of component-based software: An industrial experience. In: Proceedings of the 2008 23rd IEEE/ACM International Conference on Automated Software Engineering, Washington, DC, USA: IEEE Computer Society, 2008, p. 423-426 (ASE' '08, v.1).

Kluge, J.; KARgL, F.; Weber, M. The effects of the ajax technology on web application usability. In: 3rd International Conference on Web Information Systems and Technologies (WebIST 2007), Barcelona, Spain, 2007.

Lara, S. M.; Watanabe, W. M.; Santos, E. P. B.; Fortes, R. P. M. Improving WCAG for elderly web accessibility. In: Proceedings of the 28th ACM International Conference on Design of Communication, New York, NY, USA: ACM, 2010, p. 175-182 (SIGDOC '10, v.1).

LAZAR, J.; Feng, J. H.; HochHeISER, H. Research methods in human-computer interaction. Wiley Publishing, 2010.

Leung, H. K. N.; Wong, P. W. L. A study of user acceptance tests. Software Quality Control, v. 6, p. 137-149, 1997.

LEwIS, C. H. Using the "Thinking Aloud"Method In Cognitive Interface Design. Relatório Técnico RC-9265, IBM, 1982.

Linaje, M.; Preciado, J. C.; SAnchez-Figueroa, F. Domain-specific model for designing rich internet application user interfaces. In: Computer-Aided Design of User Interfaces VI, Springer London, 2009, p. 295-306.

Lucca, G. A. D.; Fasolino, A. R.; Tramontana, P. Web site accessibility: Identifying and fixing accessibility problems in client page code. In: WSE '05: Proceedings of the Seventh IEEE International Symposium on Web Site Evolution, Washington, DC, USA: IEEE Computer Society, 2005, p. 71-78.

Mahemoff, M. Ajax design patterns. O'Reilly Media, Inc., 2006.

Mahemoff, M.; Johnston, L. Reusing knowledge about users. In: 4th Australian Conference on Requirements Engineering, 1999, p. 59-69. 
Matheson, F. Designing for a moving target. In: Proceedings of the 4th Nordic conference on Human-computer interaction: changing roles, New York, NY, USA: ACM, 2006, p. 495-496 (NordiCHI'06, v.1).

McDonald, A. G. The agile web engineering (AWE) process. PhD Thesis, 2004.

Melnik, G.; MAURER, F. The practice of specifying requirements using executable acceptance tests in computer science courses. In: Companion to the 20th annual ACM SIGPLAN conference on Object-oriented programming, systems, languages, and applications, New York, NY, USA: ACM, 2005, p. 365-370 (OOPSLA '05, v.1).

MolinA, F.; TOVAL, A. Integrating usability requirements that can be evaluated in design time into model driven engineering of web information systems. Adv. Eng. Softw., v. 40, n. 12, p. 1306-1317, 2009.

Munson, E. V.; Pimentel, M. D. G. Specialized documents. In: Web Accessibility, Springer London, 2008, p. 274-285 (Human-Computer Interaction Series, v.4).

Naftali, M.; Watanabe, W.; Sloan, D. W4A 2010: a web accessibility conference report from the google W4A student award winners. SIGWEB Newsl., p. 1:1-1:5, 2010.

Navarro, A.; Fernández-Valmayor, A.; FernándeZ-Manjón, B.; Sierra, J. L. Characterizing navigation maps for web applications with the NMM approach. Sci. Comput. Program., v. 71, n. 1, p. 1-16, 2008.

NiELSEN, J.; MACK, R. L., eds. Usability inspection methods. New York, NY, USA: John Wiley \& Sons, Inc., 1994.

NoRTH, D. Introducing BDD. 2006.

Disponível em: http://dannorth. net/introducing-bdd/ (Acessado em 16 de junho de 2013)

Ostroff, J.; Makalsky, D.; Paige, R. Agile specification-driven development. In: ECKSTEIn, J.; BAUMEISTER, H., eds. Extreme Programming and Agile Processes in Software Engineering, v. 3092 de Lecture Notes in Computer Science, Springer Berlin Heidelberg, p. 104-112, 2004.

Parmanto, B.; Zeng, X. Metric for web accessibility evaluation. J. Am. Soc. Inf. Sci. Technol., v. 56, n. 13, p. 1394-1404, 2005.

Pereira Moreira, G. D.; Mellado, R. P.; Montini, D. Á.; Dias, L. A. V.; Cunha, A. Software product measurement and analysis in a continuous integration environment. In: Proceedings of the 2010 Seventh International Conference on Information Technology: New Generations, Washington, DC, USA: IEEE Computer Society, 2010, p. 1177-1182 (ITNG '10, v.1). 
Polson, P. G.; Lewis, C.; Rieman, J.; Wharton, C. Cognitive walkthroughs: A method for theory-based evaluation of user interfaces. Int. J. Man-Mach. Stud., v. 36, n. 5, p. 741-773, 1992.

Preciado, J. C.; Linaje, M.; SAnchez, F.; Comai, S. Necessity of methodologies to model rich internet applications. In: WSE '05: Proceedings of the Seventh IEEE International Symposium on Web Site Evolution, Washington, DC, USA: IEEE Computer Society, 2005, p. 7-13.

Pressman, R. Software engineering: A practitioner's approach. 7 ed. New York, NY, USA: McGraw-Hill, Inc., 2010.

Pressman, R.; LOWE, D. Web engineering: A practitioner's approach. 1 ed. New York, NY, USA: McGraw-Hill, Inc., 2009.

REID, L. G.; SNOW-WEAVER, A. WCAG 2.0: a web accessibility standard for the evolving web. In: W4A '08: Proceedings of the 2008 international cross-disciplinary conference on Web accessibility (W4A), New York, NY, USA: ACM, 2008, p. 109-115.

Romen, D.; Svanaes, D. Evaluating web site accessibility: validating the WAI guidelines through usability testing with disabled users. In: NordiCHI '08: Proceedings of the 5th Nordic conference on Human-computer interaction, New York, NY, USA: ACM, 2008, p. 535-538.

Santos, E. P.; Lara, S. M.; Watanabe, W. M.; Filho, M. C.; Fortes, R. P. Usability evaluation of horizontal navigation bar with drop-down menus by middle aged adults. In: Proceedings of the 29th ACM international conference on Design of communication, New York, NY, USA: ACM, 2011, p. 145-150 (SIGDOC'11, v.1).

Schmidt, K.-U.; Dörflinger, J.; Rahmani, T.; SAhbi, M.; Stojanovic, L.; Thomas, S. M. An user interface adaptation architecture for rich internet applications. In: ESWC'08: Proceedings of the 5th European semantic web conference on The semantic web, Berlin, Heidelberg: Springer-Verlag, 2008, p. 736-750.

Schwabe, D.; Almeida Pontes, R.; Moura, I. OOHDM-Web: an environment for implementation of hypermedia applications in the WWW. SIGWEB Newsl., v. 8, n. 2, p. 18-34, 1999.

Sommerville, I. Software engineering (8th ed.). Redwood City, CA, USA: Addison Wesley Longman Publishing Co., Inc., 2007.

Stolberg, S. Enabling agile testing through continuous integration. In: Proceedings of the 2009 Agile Conference, Washington, DC, USA: IEEE Computer Society, 2009, p. 369-374 (AGILE'09, v.1). 
Sullivan, T.; Matson, R. Barriers to use: usability and content accessibility on the web's most popular sites. In: Proceedings on the 2000 conference on Universal Usability, New York, NY, USA: ACM, 2000, p. 139-144 (CUU '00, v.1).

TAteishi, T.; Miyashita, H.; NAOshi, T.; SAito, S.; OnO, K. DHTML accessibility checking based on static javascript analysis. In: STEPHANIDIS, C., ed. Universal Access in HumanComputer Interaction. Applications and Services, v. 4556 de Lecture Notes in Computer Science, Springer Berlin Heidelberg, p. 167-176, 2007.

ThIESSEn, P. WAI-ARIA live regions and HTML5. In: Proceedings of the International CrossDisciplinary Conference on Web Accessibility, New York, NY, USA: ACM, 2011, p. 27:1-27:4 (W4A'11, v.1).

Thiessen, P.; Hockema, S. WAI-ARIA live regions: eBuddy IM as a case example. In: Proceedings of the 2010 International Cross Disciplinary Conference on Web Accessibility (W4A), New York, NY, USA: ACM, 2010, p. 33:1-33:9 (W4A '10, v.1).

TRIPP, D. Pesquisa-ação: uma introdução metodológica. Educ. Pesqui., v. 31, n. 3, p. 443-466, 2005.

UmbACH, J. M. Web 2.0 - the new commons. Feliciter. Canadian Library Association. HighBeam Research., 2006.

Disponível em: http://www.highbeam.com/doc/1P3-1156039661.html (Acessado em 16 de janeiro de 2014)

Velasco, C. A.; Denev, D.; Stegemann, D.; Mohamad, Y. A web compliance engineering framework to support the development of accessible rich internet applications. In: W4A '08: Proceedings of the 2008 international cross-disciplinary conference on Web accessibility (W4A), New York, NY, USA: ACM, 2008, p. 45-49.

Vigo, M.; Arrue, M.; Brajnik, G.; Lomuscio, R.; Abascal, J. Quantitative metrics for measuring web accessibility. In: W4A '07: Proceedings of the 2007 international crossdisciplinary conference on Web accessibility (W4A), New York, NY, USA: ACM, 2007, p. 99107.

W3C Web content accessibility guidelines 1.0. W3C Recommendation, 1999.

Disponível em: http: / / www.w3.org/TR/WCAG10/ (Acessado em 16 de janeiro de 2014)

W3C Authoring tool accessibility guidelines 1.0. W3C Recommendation, 2000a.

Disponível em: http: / / www .w3.org/TR/ATAG10/ (Acessado em 16 de janeiro de 2014)

W3C Techniques for web content accessibility guidelines 1.0. W3C Note, 2000b.

Disponível em: http: //Www.w3.org/TR/WAI-WEBCONTENT-TECHS/ (Acessado em 16 de janeiro de 2014) 
W3C User agent accessibility guidelines 1.0. W3C Recommendation, 2002.

Disponível em: http: / /wWw.w3 .org/TR/UAAG10/ (Acessado em 16 de janeiro de 2014)

W3C Conformance evaluation of web sites for accessibility. 2008a.

Disponível em: http: / /WwW.w3.org/WAI/eval/conformance.html (Acessado em 16 de janeiro de 2014)

W3C Web content accessibility guidelines 2.0. W3C Recommendation, 2008b.

Disponível em: http: / /www.w3 .org/TR/WCAG20 / (Acessado em 16 de janeiro de 2014)

W3C Involving users in web accessibility evaluation. 2010a.

Disponível em: http: / /www.w3 .org/WAI/eval/users.html (Acessado em 16 de janeiro de 2014)

W3C WAI-ARIA 1.0 primer - an introduction to rich internet application accessibility challenges and solutions. W3C Working Draft, 2010b.

Disponível em: http: / /www.w3 .org/TR/wai-aria-primer/ (Acessado em 16 de janeiro de 2014)

W3C Accessible rich internet applications - version 1.0. W3C Candidate Recommendation, 2011.

Disponível em: http://www.w3.org/TR/wai-aria/ (Acessado em 16 de janeiro de 2014)

W3C Packaged web apps (widgets) - packaging and xml configuration (second edition). W3C Recommendation, 2012a.

Disponível em: http://www.w3.org/TR/widgets/ (Acessado em 16 de janeiro de 2014)

W3C XMLHttpRequest. W3C Working Draft, 2012b.

Disponível em: http://www.w3.org/TR/XMLHttpRequest/ (Acessado em 16 de janeiro de 2014)

W3C A guide to understanding and implementing web content accessibility guidelines 2.0. W3C Working Group Note, 2013a.

Disponível em: http://www.w3.org/TR/UNDERSTANDING-WCAG20/Overview . html (Acessado em 16 de janeiro de 2014)

W3C HTML5 - a vocabulary and associated APIs from HTML and XHTML. W3C Candidate Recommendation, 2013b.

Disponível em: http://www.w3.org/TR/htm15/ (Acessado em 16 de janeiro de 2014) 
W3C Preliminary review of web sites for accessibility. 2013c.

Disponível em: http://www.w3.org/WAI/eval/preliminary.html (Acessado em 16 de janeiro de 2014)

W3C Techniques and failures for web content accessibility guidelines 2.0. W3C Working Group Note, 2013d.

Disponível em: http: / / www .w3 . org/TR/WCAG20-TECHS / (Acessado em 16 de janeiro de 2014)

W3C WAI-ARIA 1.0 authoring practices - an author's guide to understanding and implementing accessible rich internet applications. W3C Working Draft, 2013e.

Disponível em: http://www.w3.org/TR/wai-aria-practices/ (Acessado em 16 de janeiro de 2014)

Wamelen, J.; Kool, D. Web 2.0: a basis for the second society? In: Proceedings of the 2nd international conference on Theory and practice of electronic governance, New York, NY, USA: ACM, 2008, p. 349-354 (ICEGOV'08, v.1).

WANG, Y. D.; Zahadat, N. Teaching web development in the web 2.0 era. In: Proceedings of the 10th ACM conference on SIG-information technology education, New York, NY, USA: ACM, 2009, p. 80-86 (SIGITE '09, v.1).

Watanabe, T. Experimental evaluation of usability and accessibility of heading elements. In: W4A '07: Proceedings of the 2007 international cross-disciplinary conference on Web accessibility (W4A), New York, NY, USA: ACM, 2007, p. 157-164.

Watanabe, W. M.; Candido, A.; Amâncio, M. A.; De Oliveira, M.; Pardo, T. A. S.; Fortes, R. P. M.; Aluísio, S. M. Adapting web content for low-literacy readers by using lexical elaboration and named entities labeling. New Review of Hypermedia and Multimedia, v. 16, n. 3, p. 303-327, 2010a.

Watanabe, W. M.; Fortes, R. P. M. Revisão sistemática sobre princípios de design de aplicações web acessíveis para analfabetos funcionais. In: SEMISH - XXXVI Seminário Integrado de Software e Hardware, 2009, CSBC - XXIX Congresso da Sociedade Brasileira da Computação, 2009, p. 403-417.

Watanabe, W. M.; Fortes, R. P. M.; Dias, A. L. Using acceptance tests to validate accessibility requirements in RIA. In: Proceedings of the International Cross-Disciplinary Conference on Web Accessibility, New York, NY, USA: ACM, 2012, p. 15:1-15:10 (W4A '12, v.1).

Watanabe, W. M.; Jr., A. C.; AmÂncio, M. A.; Oliveira, M.; Fortes, R. P. M.; Pardo, T. A. S.; Aluísio, S. M. Adapting web content for low-literacy readers by using lexical elaboration and named entities labeling. In: Proceedings of W4A 2010 - 7th International Cross-Disciplinary Conference on Web Accessibility, Raleigh, NC, USA: ACM, 2010b, p. 1-9. 
Watanabe, W. M.; Jr., A. C.; Uzeda, V. R.; Fortes, R. P. M.; Pardo, T. A. S.; AluíSIO, S. M. Facilita: Reading assistance for low-literacy readers. In: ACM SIGDOC 2009, Bloomington, IN, USA: ACM, 2009a, p. 29-36.

Watanabe, W. M.; Mattos Fortes, R. P.; Sandra Maria Aluísio, T. A. S. P. Facilita: Auxílio a leitura de textos disponíveis na web. In: Webmedia 2009, Fortaleza, CE, Brazil, 2009b, p. 1-4.

Watanabe, W. M.; Neto, D. F.; Bittar, T. J.; Fortes, R. P. M. WCAG conformance approach based on model-driven development and WebML. In: Proceedings of the 28th ACM International Conference on Design of Communication, New York, NY, USA: ACM, 2010c, p. 167-174 (SIGDOC'10, v.1).

Williams, L.; Maximilien, E. M.; Vouk, M. Test-driven development as a defect-reduction practice. In: Proceedings of the 14th International Symposium on Software Reliability Engineering, Washington, DC, USA: IEEE Computer Society, 2003, p. 34- (ISSRE '03, v.1). 